\title{
Processamento de imagens de holografia digital para o estudo de organismos planctônicos
}

\author{
Jefferson Serafim Ascaneo
}

\author{
DISSERTAÇÃO APRESENTADA \\ $\mathrm{AO}$ \\ Instituto DE MATEMÁticA E EstatísticA \\ DA \\ UNIVERSIDADE DE SÃO PAULO \\ PARA \\ OBTENÇÃO DO TÍTULO \\ $\mathrm{DE}$ \\ MESTRE EM CiÊNCIAS
}

Programa: Ciência da Computação

Orientador: Prof. Dr. Roberto Hirata Jr.

Durante o desenvolvimento deste trabalho o autor recebeu auxílio financeiro da CAPES

São Paulo, março de 2017 


\title{
Processamento de imagens de holografia digital para o estudo de organismos planctônicos
}

\begin{abstract}
Esta versão da dissertação contém as correções e alterações sugeridas pela Comissão Julgadora durante a defesa da versão original do trabalho, realizada em 15/03/2017. Uma cópia da versão original está disponível no Instituto de Matemática e Estatística da Universidade de São Paulo.
\end{abstract}

Comissão Julgadora:

- Prof. Dr. Roberto Hirata Junior (orientador) - IME-USP

- Prof. Dr. Rubens Mendes Lopes - IO-USP

- Prof. Dr. João Eduardo Kogler Junior - EP-USP 


\section{Resumo}

ASCANEO, J. S. Processamento de imagens de holografia digital para o estudo de organismos planctônicos. 2017. 110 pp. Dissertação (Mestrado) - Instituto de Matemática e Estatística, Universidade de São Paulo, São Paulo, 2017.

O estudo de plâncton é importante para estimar a biodiversidade em ambientes marinhos, auxiliando na compreensão de sua dinâmica e do impacto da atividade humana. Neste trabalho, estudamos as etapas necessárias para a observação de organismos planctônicos utilizando um sistema holográfico digital em linha. A holografia digital permite que as imagens sejam numericamente focalizadas após sua aquisição através de algoritmos de reconstrução holográfica, o que remove a limitação da baixa profundidade de foco presente em métodos mais tradicionais, e permite a observação de um volume maior de água. É feita uma análise das limitações teóricas deste sistema holográfico em termos das frequências presentes no holograma e na sua reconstrução, observando-se as consequências para a escolha e implementação dos algoritmos de reconstrução. Também são considerados alguns detalhes de implementação que decorrem da natureza finita e discreta dos algoritmos. No processamento dos hologramas, os organismos são automaticamente localizados segmentando-se regiões de interesse por meio de uma reconstrução volumétrica. Estas regiões são reconstruídas a diversas distâncias e é feita a escolha de um plano focal utilizando uma medida de foco. Diversas medidas são comparadas em imagens obtidas experimentalmente para determinar a mais adequada na focalização de organismos planctônicos. Por fim, descrevemos a aplicação web desenvolvida para o processamento distribuído de imagens holográficas digitais de plâncton.

Palavras-chave: processamento de imagens, holografia, plâncton, visão computacional, processamento digital de sinais. 


\section{Abstract}

\section{ASCANEO, J. S. Processing of digital holography images for the study of planktonic or-}

ganisms. 2017. 110 pp. Masters dissertation - Instituto de Matemática e Estatística, Universidade de São Paulo, São Paulo, 2017.

The study of plankton is important for estimating biodiversity in marine environments, helping in the understanding of its dynamics and the impact of human activity. In this work, we study the necessary steps for the observation of planktonic organisms using an inline digital holographic system. Digital holography allows images to be numerically focused after its acquisition through holographic reconstruction algorithms, which removes the limitation of low depth of focus present in more traditional methods, and allows the observation of a bigger volume of water. We present an analysis of the theoretical limitations of this holographic system concerning the frequencies present in the hologram and its reconstruction, noting the consequences for the choice and implementation of reconstruction algorithms. Also considered are some implementation details that stem from the finite and discrete nature of the algorithms. In the processing of holograms, organisms are automatically located by segmenting regions of interest in a volumetric reconstruction. These regions are reconstructed at numerous distances and the choice of a focal plane is made using the values of a focus measure. Various measures are compared in experimentally obtained images to determine the most adequate for focusing planktonic organisms. Finally, we describe a web application developed for distributed processing of digital holographic images of plankton.

Keywords: image processing, holography, plankton, computer vision, digital signal processing. 


\section{Sumário}

Lista de Abreviaturas vii

$\begin{array}{ll}\text { Lista de Símbolos } & \text { ix }\end{array}$

Lista de Figuras $\quad$ xi

Lista de Tabelas $\quad$ xiii

1 Introdução $\quad 1$

1.1 Considerações Preliminares . . . . . . . . . . . . . . . . . . 1

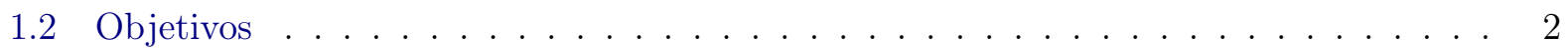

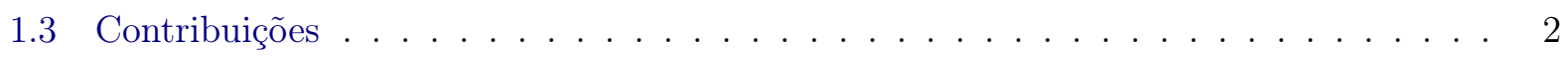

1.4 Organização do Trabalho . . . . . . . . . . . . . . . . . . . . . . 3

2 Conceitos $\quad 5$

2.1 Fundamentos de Processamento Digital de Sinais . . . . . . . . . . . . . . . 5

2.2 Fundamentos de Óptica de Fourier . . . . . . . . . . . . . . . . . . . . . 6

2.2.1 Equações de Maxwell e de Helmholtz . . . . . . . . . . . . . . . . . . . . . . 7

2.2.2 Método do espectro angular . . . . . . . . . . . . . . . . . 8

2.2 .3 Aproximação de Fresnel . . . . . . . . . . . . . . . . . . . . . . . . . . . . . 9

3 Processamento de hologramas de plâncton $\quad 11$

3.1 Holografia . . . . . . . . . . . . . . . . . . . . . . . . 11

3.1 .1 Remoção de fundo . . . . . . . . . . . . . . . . . . . . . . . . 13

3.1 .2 Algoritmos de reconstrução . . . . . . . . . . . . . . . . . . . . . . . . . . 14

3.1.3 Captura e propagação das frequências em holografia digital . . . . . . . . . 18

3.2 Detalhes de implementação . . . . . . . . . . . . . . . . . . . . . . 22

3.2 .1 FFT real e funções de transferência . . . . . . . . . . . . . . . . . . . 22

3.2 .2 Sobreposição espacial . . . . . . . . . . . . . . . . . . . . . . . . 23

3.2 .3 Efeito de borda . . . . . . . . . . . . . . . . . . 25

3.2 .4 Amostragem . . . . . . . . . . . . . . . . . . . . . 25

3.3 Segmentação de região de interesse . . . . . . . . . . . . . . . . . 28

3.3 .1 Reconstrução volumétrica . . . . . . . . . . . . . . . . . . . . . . . 28

3.3 .2 Focalização . . . . . . . . . . . . . . . . . . . . . . . . . . . . . 29

3.4 Segmentação Final . . . . . . . . . . . . . . . . . . . . . . . . . . . . . . . 29

3.5 Outras considerações . . . . . . . . . . . . . . . . . . . . 30 
3.5.1 Custo computacional . . . . . . . . . . . . . . . . . 30

3.5 .2 Processamentos adicionais . . . . . . . . . . . . . . . 30

4 Efeito de borda $\quad 33$

4.1 Introdução . . . . . . . . . . . . . . . . . . . . . . . . . . . 33

4.2 Métodos . . . . . . . . . . . . . . . . . . . 35

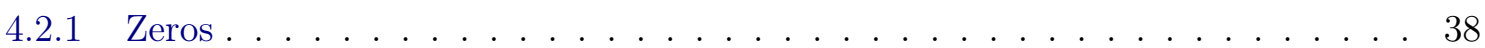

4.2 .2 Média . . . . . . . . . . . . . . . . . . . . . 38

4.2 .3 Cópia da borda . . . . . . . . . . . . . . . . . . . . . . . . . 38

4.2 .4 Mediana da borda . . . . . . . . . . . . . . . . . . . 38

4.2 .5 Reflexão . . . . . . . . . . . . . . . . . . . . . . 38

4.2 .6 Rampa linear . . . . . . . . . . . . . . . . . . . . . . 38

4.2 .7 Rampa linear circular . . . . . . . . . . . . . . . . . . . . . . 38

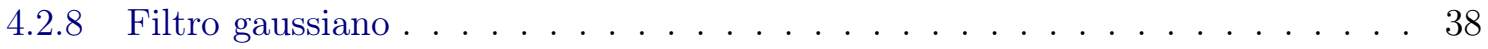

4.2 .9 Filtro gaussiano iterativo . . . . . . . . . . . . . . . . . . . . 38

4.2 .10 Rampa linear com janela de Tukey . . . . . . . . . . . . . . . . . . 39

4.2.11 Cópia da borda com janela Spline . . . . . . . . . . . . . . . . . . . . . . . . . 39

4.2 .12 Mediana com janela de cosseno . . . . . . . . . . . . . . . . . . 40

4.2 .13 Minimização de frequências altas . . . . . . . . . . . . . . . . . . . . . . 40

4.2 .14 Minimização do Laplaciano . . . . . . . . . . . . . . . . . . . . . . . . . . 41

4.3 Complexidade computacional . . . . . . . . . . . . . . . . . . . . . 45

4.4 Resultados experimentais . . . . . . . . . . . . . . . . . 47

4.4 .1 Resultados . . . . . . . . . . . . . . . . . . . . . . 49

5 Focalização $\quad 55$

5.1 Medidas de foco . . . . . . . . . . . . . . . . . . . 57

5.1 .1 Medidas estatísticas . . . . . . . . . . . . . . . . 57

5.1 .2 Medidas com filtro espacial . . . . . . . . . . . . . . . . . 58

5.1 .3 Medidas com janelas . . . . . . . . . . . . . . . . . . . 63

5.2 Complexidade computacional . . . . . . . . . . . . . . . . . . 64

5.3 Resultados experimentais . . . . . . . . . . . . . . . . . 64 64

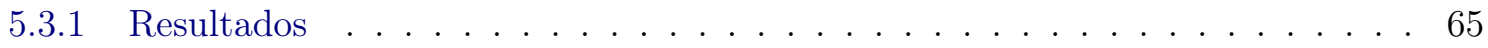

$\begin{array}{lll}6 & \text { Sistema } w e b & \mathbf{7 7}\end{array}$

6.1 Arquitetura . . . . . . . . . . . . . . . . . . . 77

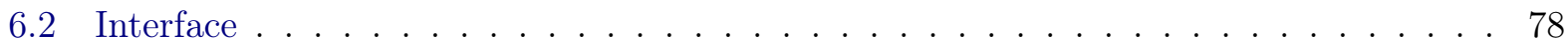

7 Conclusão $\quad 85$

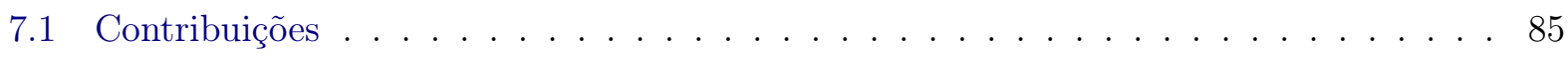

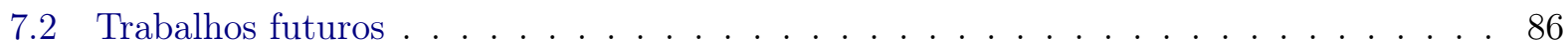

A Imagens utilizadas no experimento de extensões de borda $\quad 89$

B Imagens utilizadas no experimento de focalização 95

$\begin{array}{ll}\text { Referências Bibliográficas } & 105\end{array}$ 


\section{Lista de Abreviaturas}

FFT Transformada Rápida de Fourier

IFFT Transformada Rápida de Fourier Inversa

FFT $_{\text {real }} \quad$ Transformada Rápida de Fourier de uma sequência de números reais

IFFT $_{\text {real }}$ Transformada Rápida de Fourier Inversa de uma sequência de números reais

RMSE Raiz do Erro Quadrático Médio

ACM Momento Central Absoluto (Image Absolute Central Moment)

HPACM Momento Central Absoluto com Filtro Passa-altas (High-pass filter image absolute central moment)

TV Variação Total (Total Variation)

GGMSUM Somatório da Magnitude do Gradiente Gaussiano

GGMVAR Variância da Magnitude do Gradiente Gaussiano

SIM Somatório do Máximo Orientado da Intensidade (Steerable Intensity Maximum)

SIMVAR Variância do Máximo Orientado da Intensidade

SDC Correlação do Desvio Padrão

SML Soma do Laplaciano Modificado

XSML Soma Cruzada do Laplaciano Modificado

PK Medida de Pieper e Korpel

EOL Energia do Laplaciano

EOGS Energia Quadrática do Gradiente

SOBVAR Variância de Sobel

LAPVAR Variância do Laplaciano

GBLVAR Variância Global

GBLVAR $_{\mathrm{GG}}$ Variância Global do Gradiente Gaussiano

TOTVAR Variância Total do Gradiente Gaussiano

GBLVAR $_{\text {LoG }}$ Variância Global do Laplaciano do Gaussiano 


\title{
Lista de Símbolos
}

\author{
$\operatorname{circ}(r) \quad$ Função circular \\ $\operatorname{sinc}(x) \quad$ Função seno cardinal \\ $\operatorname{rect}(x) \quad$ Função retangular \\ $\mathcal{F}\{f\} \quad$ Transformada Contínua de Fourier da função $f$ \\ $\mathcal{F}^{-1}\{F\} \quad$ Transformada Contínua de Fourier Inversa da função $F$ \\ FFT Algoritmo que calcula a Transformada Discreta de Fourier \\ IFFT Algoritmo que calcula a Transformada Discreta de Fourier Inversa \\ FFT $_{\text {real }}$ Algoritmo que calcula a Transformada Discreta de Fourier de números reais \\ IFFT $_{\text {real }}$ Algoritmo que calcula a Transformada Discreta de Fourier Inversa de números reais \\ Re Parte real de um número complexo \\ Im Parte imaginária de um número complexo \\ $\mathrm{E}(I) \quad$ Esperança de $I$ \\ $\operatorname{Var}(I) \quad$ Variância de $I$ \\ c Velocidade da luz no vácuo \\ $\lambda$ Comprimento de onda \\ $k \quad$ Número de onda \\ $\nu \quad$ Frequência óptica
}




\section{Lista de Figuras}

3.1 Gravação e reconstrução de holograma . . . . . . . . . . . . . . . . . . . . . . . 11

3.2 Sistema holográfico . . . . . . . . . . . . . . . . . . . . . . . . . 12

3.3 Exemplo de remoção de fundo de um holograma . . . . . . . . . . . . . . . . . . . 14

3.4 Reconstrução de um organismo de amplitude . . . . . . . . . . . . . . . . . . . 15

3.5 Reconstrução de um organismo de fase . . . . . . . . . . . . . . . . . . . . . . 15

3.6 Reconstrução holográfica pelo algoritmo da Integração de Fresnel . . . . . . . . . . . 17

3.7 Exemplo numérico da propagação das frequências . . . . . . . . . . . . . . . . . . . 19

3.8 Exemplo numérico da propagação de uma frequência . . . . . . . . . . . . . . . . 20

3.9 Exemplo numérico da propagação de uma frequência . . . . . . . . . . . . . . . . . 21

3.10 Exemplo numérico das frequências presentes em um holograma . . . . . . . . . . . 23

3.11 Reconstrução holográfica com sobreposição espacial . . . . . . . . . . . . . . . . . 24

3.12 Exemplo numérico da propagação e supressão de frequências em um holograma . . . 25

3.13 Efeito da borda na reconstrução holográfica . . . . . . . . . . . . . . . . . . 26

3.14 Segmentação de um holograma em regiões de interesse . . . . . . . . . . . . . . . . . 29

3.15 Focalização de um holograma segundo a medida de entropia . . . . . . . . . . . . . . 29

3.16 Segmentação final de uma região de interesse focalizada. . . . . . . . . . . . . . . 30

3.17 Ilustração do efeito da imagem gêmea . . . . . . . . . . . . . . . . . . . . . 31

4.1 Efeito da borda na reconstrução holográfica . . . . . . . . . . . . . . . . . . . . 34

4.2 Apodização do holograma para evitar efeito da borda . . . . . . . . . . . . . . . . 34

4.3 Extensão de holograma para evitar efeito da borda . . . . . . . . . . . . . . . . 35

4.4 Métodos de extensão de borda . . . . . . . . . . . . . . . . . 36

4.5 Métodos de extensão de borda . . . . . . . . . . . . . . . . . . . . . . 37

4.6 Janela de Tukey . . . . . . . . . . . . . . . . . . . . . . . . . . . . . . . . . 39

4.7 Janela de spline cúbica . . . . . . . . . . . . . . . . . . . . . . . . . . 39

4.8 Janela de cosseno . . . . . . . . . . . . . . . . . . . . . . . . . . . . 40

4.9 Minimização do Laplaciano . . . . . . . . . . . . . . . . . . . . . . . . . . . 41

4.10 Tempo de execução dos algoritmos de extensão de borda . . . . . . . . . . . . . . . 46

4.11 Tempo de execução dos algoritmos de extensão de borda (detalhe) . . . . . . . . . . 47

4.12 Cálculo do erro dos métodos de extensão de borda . . . . . . . . . . . . . . . 48

4.13 Holograma utilizado nos gráficos de erro por distância e erro por tamanho da reconstrução . . . . . . . . . . . . . . . . . . . . . . . . . 49

4.14 Comparação entre extensões de borda para diferentes distâncias de reconstrução . . . 50 
4.15 Comparação entre extensões de borda para diferentes distâncias de reconstrução (detalhe) . . . . . . . . . . . . . . . . . . . . 50

4.16 Comparação entre extensões de borda para diferentes distâncias de reconstrução

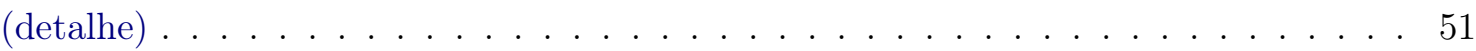

4.17 Comparação entre extensões de borda para diferentes tamanhos de imagem . . . . . 51

4.18 Comparação entre extensões de borda para diferentes tamanhos de imagem (detalhe) 52

4.19 Comparação entre extensões de borda para diferentes tamanhos de imagem (detalhe

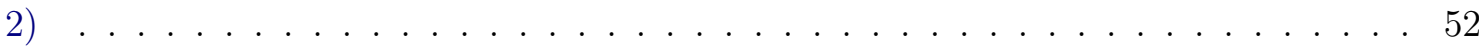

5.1 Focalização de um holograma segundo a medida de entropia . . . . . . . . . . . . 55

5.2 Exemplo de organismo sendo focalizado . . . . . . . . . . . . . . . . 66

5.3 Valores de medidas de foco para um organismo . . . . . . . . . . . . . . . 67

5.4 Exemplo de organismo sendo focalizado . . . . . . . . . . . . . . . . 68

5.5 Valores de medidas de foco para um organismo . . . . . . . . . . . . . . . 69

5.6 Distribuição dos erros de focalização . . . . . . . . . . . . . . . . . . . 70

5.7 Exemplo de execução do algoritmo de autofoco . . . . . . . . . . . . . . . . 72

5.8 Exemplo de execução do algoritmo de autofoco . . . . . . . . . . . . . . . . . 73

6.1 Arquitetura do sistema . . . . . . . . . . . . . . . . . . . 77

6.2 Tela inicial . . . . . . . . . . . . . . . . . . . . . . . . 79

6.3 Parâmetros de um experimento . . . . . . . . . . . . . . . . . . . . . . . . 79

6.4 Tela para upload de hologramas . . . . . . . . . . . . . . . . . . 80

6.5 Visualização dos hologramas enviados . . . . . . . . . . . . . . . 80

6.6 Visualização de um holograma . . . . . . . . . . . . . . . . . . . . . . 81

6.7 Visualização dos organismos segmentados . . . . . . . . . . . . . . . . . . 82

6.8 Focalização manual de um organismo . . . . . . . . . . . . . . . . . . . . 83

A.1 Hologramas utilizados no experimento de extensão de borda . . . . . . . . . . . . . . 89

A.2 Hologramas utilizados no experimento de extensão de borda . . . . . . . . . . . . . 90

A.3 Hologramas utilizados no experimento de extensão de borda . . . . . . . . . . . . . . 91

A.4 Hologramas utilizados no experimento de extensão de borda . . . . . . . . . . . . . . 92

A.5 Reconstruções dos hologramas utilizados no experimento de extensão de borda . . 92

A.6 Reconstruções dos hologramas utilizados no experimento de extensão de borda . . 93

A.7 Reconstruções dos hologramas utilizados no experimento de extensão de borda . . . 94

B.1 Reconstruções do conjunto A utilizadas no experimento de focalização . . . . . . . . 96

B.2 Reconstruções do conjunto A utilizadas no experimento de focalização . . . . . . . . 97

B.3 Reconstruções do conjunto B utilizadas no experimento de focalização . . . . . . . . 98

B.4 Reconstruções do conjunto B utilizadas no experimento de focalização ....... 99

B.5 Reconstruções do conjunto C utilizadas no experimento de focalização . . . . . . . . 100

B.6 Reconstruções do conjunto C utilizadas no experimento de focalização . . . . . . . . 101

B.7 Reconstruções do conjunto C utilizadas no experimento de focalização . . . . . . . . 102

B.8 Reconstruções do conjunto C utilizadas no experimento de focalização . . . . . . . . 103 


\section{Lista de Tabelas}

4.1 Erros das extensões . . . . . . . . . . . . . . . . . . . . . . . . 53

4.2 Erros das extensões . . . . . . . . . . . . . . . . . . . . . . . 53

5.1 Erros de focalização - Conjunto A . . . . . . . . . . . . . 66

5.2 Erros de focalização - Conjunto B . . . . . . . . . . . . . . . . . . . . 67

5.3 Erros de focalização - Conjunto C . . . . . . . . . . . . . . . . . . . . . 69

5.4 Erros de focalização - Total . . . . . . . . . . . . . . . . . . . . . 71

5.5 Erros de focalização - Mediana . . . . . . . . . . . . . . . . . . . 72

5.6 Erros de autofoco - Conjunto A . . . . . . . . . . . . . . . . . 74

5.7 Erros de autofoco - Conjunto B . . . . . . . . . . . . . . . 74

5.8 Erros de autofoco - Conjunto C . . . . . . . . . . . . . . . . 75 


\section{Capítulo 1}

\section{Introdução}

Faremos algumas considerações preliminares sobre o estudo de plâncton e o uso de sistemas holográficos para sua observação e monitoramento. A seguir, apresentaremos os objetivos deste trabalho, suas contribuições e a organização dos capítulos.

\subsection{Considerações Preliminares}

A maior parte da superfície terrestre é coberta pelos oceanos, que contêm um sistema ecológico complexo onde diversos organismos interagem entre si e com o ambiente em que vivem. Dentre estes organismos, o plâncton forma a base da cadeia alimentar, sendo responsável por grande parte da fotossíntese que ocorre no planeta. O plâncton é composto por uma grande variedade de seres vivos, como por exemplo as algas, crustáceos pequenos, larvas de peixes e bactérias. Seu estudo é, portanto, essencial para melhor compreender a dinâmica dos ecossistemas marinhos, além de permitir estudar o impacto da atividade humana nestes ambientes aquáticos.

Normalmente, o estudo de plâncton é realizado com amostras coletadas através de redes e outros mecanismos que, embora permitam identificar as espécies presentes, possuem uma resolução espacial e temporal extremamente limitadas, além de poderem danificar organismos mais frágeis. Estas amostras requerem a análise manual, em microscópios, por pessoas treinadas, o que gasta muito tempo e limita a quantidade de dados que podem ser analisados. Estes dados são, portanto, insuficientes para compreender a variabilidade manifesta em escalas mais refinadas e realizar previsões com grande acurácia.

Mais recentemente, o avanço em tecnologias que permitem capturar imagens digitais, analisá-las e classificá-las de forma automática ou semi-automática permitiu o surgimento de novos equipamentos, com os quais pode-se estudar a distribuição de plâncton de forma mais eficiente. Entre eles, destacam-se o ZooScan [GPWG04, GOP ${ }^{+}$10] e o FlowCAMß[SSY98]. Além de realizarem a classificação de organismos e detritos, alguns destes sistemas possuem acurácia comparável à de um especialista [CWR ${ }^{+}$03]. Porém, muitos destes equipamentos não permitem a análise in situ de grandes volumes de água, o que ainda é um fator limitante para estudos mais detalhados. Os sistemas ópticos utilizados possuem uma profundidade de campo limitada, deixando apenas duas opções: ou capturar imagens de um pequeno volume, como uma região laminar [GPWG04] ou uma câmara micro-fluídica [SSY98], ou detectar e descartar imagens fora de foco [TSV $\left.{ }^{+} 98\right]$.

Para observar o plâncton em seu habitat natural, e coletar imagens de grandes volumes, sistemas holográficos digitais em linha têm se mostrado promissores [SHPW07, THM+13, MAK99]. Por não utilizar lentes, a focalização é feita numericamente após a aquisição da imagem e, assim, a holografia digital permite superar a limitação da profundidade de campo e coletar imagens de volumes maiores. O uso de holografia em linha simplifica o sistema holográfico, facilitando o seu alinhamento, estabilização e miniaturização, características estas que são desejáveis no desenvolvimento de um sistema para observação in situ.

Entretanto, a classificação automática destas imagens ainda se mostra desafiadora, e artigos recentes $\left[\mathrm{THM}^{+} 13\right]$ realizam a classificação de organismos, como copépodes e diatomáceas, de forma 
visual. Existem várias dificuldades devido à alta variabilidade dos organismos. Além disso, estes podem ser observados de qualquer ângulo, com algumas observações fornecendo pouquíssima informação que ajude em uma identificação correta. Em alguns equipamentos, como o ZooScan, é possível ajustar o posicionamento e orientação dos organismos para obter a melhor imagem possível, mas esta estruturação não pode ser feita no sistema holográfico utilizado neste trabalho.

Dentre os aspectos mais suscetíveis de serem controlados e com grande influência na qualidade da classificação está a correta segmentação e focalização do organismo, um problema que está longe de ser completamente solucionado, embora tenham sido feitos vários esforços neste sentido [Loo11]. Sem algoritmos confiáveis para se obter imagens bem focalizadas dos organismos, a holografia digital perde sua vantagem mais essencial no estudo de plâncton. É necessário, portanto, desenvolver e comparar algoritmos e métodos de focalização para que se possa aproveitar a riqueza de detalhes proporcionada pela holografia digital. Também é preciso levar em conta a teoria de processamento digital de sinais, para obter boas reconstruções holográficas sem artefatos provenientes de um processamento numérico mal planejado, e entender melhor alguns algoritmos de focalização e segmentação.

\subsection{Objetivos}

Este trabalho tem como objetivo o estudo das diferentes etapas necessárias para a observação de plâncton por meio de imagens de holografia digital em linha, incluindo a reconstrução holográfica, focalização e segmentação, e com ênfase nos diversos algoritmos de processamento de imagens utilizados, realizando este estudo a partir das teorias da Óptica de Fourier e do Processamento Digital de Sinais. Também visa realizar análises e comparações dos algoritmos estudados em exemplos simulados e reais, objetivando melhorar a qualidade das imagens resultantes. Esta melhoria na qualidade é feita através da eliminação ou supressão de artefatos que são provenientes do sistema óptico holográfico e dos algoritmos de processamento de imagens, e que não representam adequadamente a morfologia dos organismos, e através da recuperação de uma maior quantidade de detalhes destes organismos sem que isso incorra em um custo computacional demasiadamente elevado. Com isso, espera-se obter imagens de alta qualidade dos organismos presentes nos hologramas digitais, viabilizando trabalhos futuros de classificação automática de plâncton, cuja correta identificação e categorização em classes mais específicas (fine-grained categorization [KSDFF13, KJYFF15]) depende do reconhecimento de estruturas e detalhes finos.

\subsection{Contribuições}

As principais contribuições deste trabalho são as seguintes:

- Um estudo aprofundado de algoritmos de reconstrução holográfica, com a análise das frequências presentes nas imagens e sua propagação, e de detalhes de implementação que afetam a qualidade da imagem reconstruída, decorrentes da natureza finita e discreta dos algoritmos.

- Vasta comparação experimental de diferentes algoritmos de extensão de borda, necessários para diminuir artefatos presentes na imagem final. É proposto um novo algoritmo, a Minimização do Laplaciano, que é baseado em um algoritmo presente na literatura e que obtém resultados superiores a todos os outros algoritmos considerados no experimento.

- Extensa comparação experimental de diferentes medidas de foco, utilizadas para determinar a distância da reconstrução holográfica e obter uma imagem bem focalizada. São propostas algumas novas medidas, incluindo a Variância Total do Gradiente Gaussiano e a Variância do Máximo Orientado da Intensidade, que obtiveram excelentes resultados na focalização de imagens holográficas de organismos planctônicos, com erros médios extremamente pequenos e inferiores aos de todas as outras medidas consideradas no experimento. 
- Desenvolvimento de um sistema web para o processamento distribuído de imagens holográficas de organismos planctônicos, facilitando a aplicação dos resultados deste trabalho por outros pesquisadores e contribuindo para tornar o uso de sistemas holográficos uma alternativa prática no estudo de plâncton.

\subsection{Organização do Trabalho}

No Capítulo 2, apresentamos algumas definições da área de Processamento Digital de Sinais, além de uma breve introdução a alguns conceitos de Óptica de Fourier que serão utilizados ao longo do texto. No Capítulo 3, fazemos uma análise da propagação das frequências na formação do holograma e na sua reconstrução, discutimos os diferentes algoritmos de reconstrução, além de todas as outras etapas do processamento destas imagens, como a localização de regiões de interesse, focalização dos organismos e segmentação. No Capítulo 4, comparamos diversos algoritmos para diminuir o efeito de difração da borda do holograma na reconstrução. No Capítulo 5, comparamos algumas medidas de foco utilizadas para determinar a melhor distância de reconstrução dos hologramas. No Capítulo 6, apresentamos o sistema desenvolvido para o processamento distribuído de imagens holográficas de plâncton. Finalmente, no Capítulo 7 apresentamos as conclusões e indicamos futuras linhas de pesquisa.

As imagens utilizadas em um dos experimentos realizados no Capítulo 4 estão disponíveis no Apêndice A. O Apêndice B apresenta algumas das imagens utilizadas no experimento do Capítulo 5. 


\section{Capítulo 2}

\section{Conceitos}

Faremos uma pequena revisão de alguns conceitos de Processamento Digital de Sinais e de Óptica de Fourier. Estes serão utilizados ao longo do texto, principalmente no estudo dos algoritmos de reconstrução holográfica e dos processamentos digitais de imagens realizados. O foco será um pouco maior na Óptica de Fourier, com a qual leitores provavelmente terão menor familiaridade.

\subsection{Fundamentos de Processamento Digital de Sinais}

A seguir estão algumas definições da área de Processamento Digital de Sinais que serão utilizadas ao longo do texto. É esperada alguma familiaridade com estes conceitos, e maiores detalhes podem ser encontrados em diversos livros da área [OSB ${ }^{+}$89, PV08].

A transformada de Fourier (espectro de Fourier ou espectro de frequências) de uma função $g$ de duas variáveis independentes $x, y \in \mathbb{C}$ é definida como

$$
G\left(f_{X}, f_{Y}\right)=\mathcal{F}\{g\}=\int_{-\infty}^{+\infty} \int_{\infty} g(x, y) \exp \left[-j 2 \pi\left(f_{X} x+f_{Y} y\right)\right] d x d y
$$

onde $j=\sqrt{-1}$. As variáveis $f_{X}$ e $f_{Y}$ normalmente serão chamadas de frequências.

A transformada de Fourier inversa de uma função $G$ de duas variáveis independentes $f_{X}, f_{Y} \in \mathbb{C}$ é definida como

$$
g(x, y)=\mathcal{F}^{-1}\{G\}=\int_{-\infty}^{+\infty} \int_{\infty} G\left(f_{X}, f_{Y}\right) \exp \left[j 2 \pi\left(f_{X} x+f_{Y} y\right)\right] d f_{X} d f_{Y} .
$$

Os algoritmos para calcular a transformada de Fourier discreta e sua inversa serão denotados por FFT e IFFT, respectivamente.

Teorema do Deslocamento. Se $\mathcal{F}\{g(x, y)\}=G\left(f_{X}, f_{Y}\right)$, então

$$
\mathcal{F}\{g(x-a, y-b)\}=G\left(f_{X}, f_{Y}\right) \exp \left[-j 2 \pi\left(f_{X} a+f_{Y} b\right)\right] .
$$

Teorema da Convolução. Se $\mathcal{F}\{g(x, y)\}=G\left(f_{X}, f_{Y}\right)$ e $\mathcal{F}\{h(x, y)\}=H\left(f_{X}, f_{Y}\right)$, então

$$
\mathcal{F}\{g * h\}=\mathcal{F}\left\{\int_{-\infty}^{+\infty} \int_{-\infty} g(\xi, \eta) h(x-\xi, y-\eta) d \xi d \eta\right\}=G\left(f_{X}, f_{Y}\right) H\left(f_{X}, f_{Y}\right),
$$

onde * denota a operação de convolução.

Uma função $g$ é separável nas coordenadas retangulares $(x, y)$ se

$$
g(x, y)=g_{X}(x) g_{Y}(y)
$$


onde $g_{X}(x)$ e $g_{Y}(y)$ são funções de uma variável, e $x$ e $y$ são variáveis independentes.

Se $g$ é separável nas coordenadas retangulares $(x, y)$, então

$$
\mathcal{F}\{g(x, y)\}=\mathcal{F}_{X}\left\{g_{X}\right\} \mathcal{F}_{Y}\left\{g_{Y}\right\},
$$

onde $\mathcal{F}_{X}$ e $\mathcal{F}_{Y}$ são as transformadas de Fourier unidimensionais nas variáveis $x$ e $y$, respectivamente.

A função círculo é definida como

$$
\operatorname{circ}\left(\sqrt{x^{2}+y^{2}}\right)= \begin{cases}1 & \text { se } \sqrt{x^{2}+y^{2}}<1 \\ \frac{1}{2} & \text { se } \sqrt{x^{2}+y^{2}}=1 \\ 0 & \text { caso contrário. }\end{cases}
$$

A função retângulo é definida como

$$
\operatorname{rect}(x)= \begin{cases}1 & \text { se }|x|<\frac{1}{2} \\ \frac{1}{2} & \text { se }|x|=\frac{1}{2} \\ 0 & \text { caso contrário. }\end{cases}
$$

A função sinc é definida como

$$
\operatorname{sinc}(x)=\frac{\sin (\pi x)}{\pi x} .
$$

Um filtro passa-baixa atenua frequências acima de uma frequência de corte. A multiplicação no espectro de Fourier pela função sinc pode ser interpretada como a aplicação de um filtro passa-baixa, e corresponde à convolução pela função rect.

Qualquer função complexa $g$ pode ser representada na forma

$$
g(x, y)=a(x, y) \exp [j \phi(x, y)]
$$

onde $a(x, y)$ é uma distribuição real e não negativa de amplitude, e $\phi(x, y)$ é uma distribuição real de fase.

A frequência espacial local da função $g$ é o par de frequências

$$
f_{l X}=\frac{1}{2 \pi} \frac{\partial}{\partial x} \phi(x, y) \quad f_{l Y}=\frac{1}{2 \pi} \frac{\partial}{\partial y} \phi(x, y)
$$

Além disso, ambas as frequências locais $f_{l X}$ e $f_{l Y}$ são zero por definição em regiões onde a função $g$ torna-se zero. Enquanto que o espectro de Fourier permite analisar a presença de frequências em toda a imagem, de forma global, as frequências locais permitem associar uma região limitada da função a uma frequência específica. Isto dá uma ideia aproximada de onde frequências do espectro de Fourier ocorrem na função, desde que as variações em $\phi(x, y)$ sejam suficientemente "lentas".

\subsection{Fundamentos de Óptica de Fourier}

O texto a seguir é uma breve introdução à teoria escalar de difração de ondas ópticas, que é a base dos algoritmos de reconstrução holográfica. Maiores detalhes podem ser encontrados em textos como o de Goodman [Goo96], ou o de Born e Wolf [BW99]. 


\subsubsection{Equações de Maxwell e de Helmholtz}

Sendo uma onda eletromagnética, a luz obedece às equações de Maxwell. Em unidades MKS e na ausência de carga livre, as equações são

$$
\begin{aligned}
\nabla \times \mathbf{E} & =-\mu \frac{\partial \mathbf{H}}{\partial t} \\
\nabla \times \mathbf{H} & =\varepsilon \frac{\partial \mathbf{E}}{\partial t} \\
\nabla \cdot \varepsilon \mathbf{E} & =0 \\
\nabla \cdot \mu \mathbf{H} & =0
\end{aligned}
$$

onde $\mathbf{E}$ é o campo elétrico, $\mathbf{H}$ é o campo magnético, $\mu$ e $\varepsilon$ são, respectivamente, a permeabilidade e permissividade do meio no qual a onda se propaga.

Note que estas equações definem campos vetoriais. Para poder desenvolver uma teoria escalar, iremos supor que algumas propriedades são válidas no meio de propagação da luz. Faremos as suposições de que o meio é dielétrico, não magnético (permeabilidade igual ao vácuo), homogêneo (permissividade constante), não dispersivo (permissividade independente dos comprimentos de onda sendo propagados), linear (conforme a teoria de sistemas lineares, também conhecido como princípio de superposição), e isotrópico (propriedades não dependem da direção de polarização). Com isso, é possível mostrar que todos os componentes dos campos magnético e elétrico se comportam da mesma forma, podendo ser descritos pela equação de onda escalar

$$
\nabla^{2} u-\frac{n^{2}}{c^{2}} \frac{\partial^{2} u}{\partial t^{2}}=0
$$

onde $\nabla^{2}$ é o operador Laplaciano, $c$ é a velocidade de propagação da luz no vácuo e $n$ é o índice de refração do meio. Os valores de $c$ e $n$ são

$$
\begin{aligned}
c & =\frac{1}{\sqrt{\mu_{0} \varepsilon_{0}}} \\
n & =\left(\frac{\varepsilon}{\varepsilon_{0}}\right)^{\frac{1}{2}}
\end{aligned}
$$

onde $\mu_{0}$ e $\varepsilon_{0}$ são a permeabilidade e permissividade do vácuo.

Uma onda monocromática que obedece à equação de onda pode ser escrita, utilizando notação complexa, por

$$
u(P, t)=\operatorname{Re}\{U(P) \exp (-j 2 \pi \nu t)\}
$$

onde $\operatorname{Re}\{\}$ é a parte real, $\nu$ é a frequência óptica, e $U(P)$ é uma função complexa de posição,

$$
U(P)=A(P) \exp (-j \phi(P))
$$

onde $A(P)$ e $\phi(P)$ são a amplitude e a fase na posição $P$, respectivamente. Definiremos o formato da onda como sendo o formato de uma superfície de fase constante.

A função complexa $U(P)$ será utilizada para descrever as ondas estudadas, já que a oscilação $\exp (-j 2 \pi \nu t)$ é rápida demais para ser detectada pelos instrumentos. Substituindo a equação 2.2 na equação 2.1, chegamos na equação de Helmholtz

$$
\nabla^{2} U+k^{2} U=0 .
$$

O valor $k$ é o número de onda definido por

$$
k=2 \pi n \frac{\nu}{c}=\frac{2 \pi}{\lambda},
$$


onde $\lambda$ é o comprimento de onda no meio dielétrico e $\lambda=c / n \nu$.

\subsubsection{Método do espectro angular}

O nome desta abordagem deve-se à interpretação da decomposição de Fourier de um campo $U$ como uma soma de ondas planas propagando-se em diferentes direções, e maiores detalhes deste ponto de vista podem ser encontrados em Goodman [Goo96]. Suponha que uma onda monocromática incidente no plano $(x, y)$ propaga-se na direção $z$. Seja $U(x, y, 0)$ o campo complexo no plano $z=0$; queremos encontrar o campo $U(x, y, z)$ que está a uma distância $z$ do primeiro plano. Podemos escrever este segundo plano como a transformada inversa de Fourier de seu espectro $A(x, y ; z)$, ou seja,

$$
U(x, y, z)=\int_{-\infty}^{+\infty} \int_{\infty} A\left(f_{X}, f_{Y} ; z\right) \exp \left[j 2 \pi\left(f_{X} x+f_{Y} y\right)\right] d f_{X} d f_{Y} .
$$

Além disso, em todos os pontos que não são fonte, $U$ precisa satisfazer a equação de Helmholtz 2.3 , ou seja,

$$
\begin{aligned}
& \nabla^{2} \int_{-\infty}^{+\infty} \int_{-} A\left(f_{X}, f_{Y} ; z\right) \exp \left[j 2 \pi\left(f_{X} x+f_{Y} y\right)\right] d f_{X} d f_{Y} \\
& \quad+k^{2} \int_{-\infty}^{+\infty} A\left(f_{X}, f_{Y} ; z\right) \exp \left[j 2 \pi\left(f_{X} x+f_{Y} y\right)\right] d f_{X} d f_{Y}=0
\end{aligned}
$$

Usando as equações

$$
\begin{aligned}
& \frac{d^{2}}{d z^{2}}\left(A\left(f_{X}, f_{Y} ; z\right) \exp \left[j 2 \pi\left(f_{X} x+f_{Y} y\right)\right]\right)=\exp \left[j 2 \pi\left(f_{X} x+f_{Y} y\right)\right] \frac{d^{2}}{d z^{2}} A\left(f_{X}, f_{Y} ; z\right) \\
& \frac{d^{2}}{d x^{2}}\left(A\left(f_{X}, f_{Y} ; z\right) \exp \left[j 2 \pi\left(f_{X} x+f_{Y} y\right)\right]\right)=-\left(2 \pi f_{X}\right)^{2} A\left(f_{X}, f_{Y} ; z\right) \exp \left[j 2 \pi\left(f_{X} x+f_{Y} y\right)\right] \\
& \frac{d^{2}}{d y^{2}}\left(A\left(f_{X}, f_{Y} ; z\right) \exp \left[j 2 \pi\left(f_{X} x+f_{Y} y\right)\right]\right)=-\left(2 \pi f_{Y}\right)^{2} A\left(f_{X}, f_{Y} ; z\right) \exp \left[j 2 \pi\left(f_{X} x+f_{Y} y\right)\right]
\end{aligned}
$$

temos

$$
\begin{aligned}
& \int_{-\infty}^{+\infty}\left(\frac{d^{2}}{d z^{2}} A\left(f_{X}, f_{Y} ; z\right)\right. \\
& \left.\quad+\left[(2 \pi)^{2}\left[-\left(f_{X}\right)^{2}-\left(f_{Y}\right)^{2}\right]+k^{2}\right] A\left(f_{X}, f_{Y} ; z\right)\right) \exp \left[j 2 \pi\left(f_{X} x+f_{Y} y\right)\right] d f_{X} d f_{Y}=0 \\
& \quad \int_{-\infty}^{+\infty}\left(\frac{d^{2}}{d z^{2}} A\left(f_{X}, f_{Y} ; z\right)\right. \\
& \left.\quad+\left(\frac{2 \pi}{\lambda}\right)^{2}\left[1-\left(\lambda f_{X}\right)^{2}-\left(\lambda f_{Y}\right)^{2}\right] A\left(f_{X}, f_{Y} ; z\right)\right) \exp \left[j 2 \pi\left(f_{X} x+f_{Y} y\right)\right] d f_{X} d f_{Y}=0 .
\end{aligned}
$$

Note que, como a equação está no formato da transformada inversa de Fourier, podemos calcular a transformada de Fourier para chegar na equação diferencial

$$
\frac{d^{2}}{d z^{2}} A\left(f_{X}, f_{Y} ; z\right)+\left(\frac{2 \pi}{\lambda}\right)^{2}\left[1-\left(\lambda f_{X}\right)^{2}-\left(\lambda f_{Y}\right)^{2}\right] A\left(f_{X}, f_{Y} ; z\right)=0 .
$$


Uma solução elementar é

$$
A\left(f_{X}, f_{Y} ; z\right)=A\left(f_{X}, f_{Y} ; 0\right) \exp \left(j \frac{2 \pi}{\lambda} \sqrt{1-\left(\lambda f_{X}\right)^{2}-\left(\lambda f_{Y}\right)^{2}} z\right) .
$$

Note que, quando $\left(\lambda f_{X}\right)^{2}+\left(\lambda f_{Y}\right)^{2}>1$, podemos reescrever a solução como

$$
A\left(f_{X}, f_{Y} ; z\right)=A\left(f_{X}, f_{Y} ; 0\right) \exp (-\mu z)
$$

onde

$$
\mu=\frac{2 \pi}{\lambda} \sqrt{\left(\lambda f_{X}\right)^{2}+\left(\lambda f_{Y}\right)^{2}-1}
$$

Como $\mu$ é um número real positivo, estes componentes são rapidamente atenuados devido ao termo $\exp (-\mu z)$. Eles são conhecidos como ondas evanescentes e podem ser desconsiderados caso a distância de propagação $z$ seja superior a alguns comprimentos de onda. Portanto, limitaremos a região do espectro de Fourier com a função circ para eliminar estes componentes.

Chegamos então na equação

$$
A\left(f_{X}, f_{Y} ; z\right)=A\left(f_{X}, f_{Y} ; 0\right) \operatorname{circ}\left(\sqrt{\left(\lambda f_{X}\right)^{2}+\left(\lambda f_{Y}\right)^{2}}\right) \exp \left[j \frac{2 \pi}{\lambda} z \sqrt{1-\left(\lambda f_{X}\right)^{2}-\left(\lambda f_{Y}\right)^{2}}\right]
$$

da qual podemos obter a função

$$
H\left(f_{X}, f_{Y}\right)= \begin{cases}\exp \left[j \frac{2 \pi}{\lambda} z \sqrt{1-\left(\lambda f_{X}\right)^{2}-\left(\lambda f_{Y}\right)^{2}}\right] & \text { se } \sqrt{f_{X}^{2}+f_{Y}^{2}} \leq \frac{1}{\lambda} \\ 0 & \text { caso contrário }\end{cases}
$$

A função $H$ é chamada função de transferência, e relaciona a "entrada" $U(x, y, 0)$ à "saída" $U(x, y, z)$ em termos das frequências espaciais $A\left(f_{X}, f_{Y} ; z\right)$.

Note que nenhuma frequência superior a $\lambda^{-1}$ é preservada, e portanto não é possível identificar estruturas com um período menor do que o comprimento de onda usado.

\subsubsection{Aproximação de Fresnel}

Suponha que uma abertura, ou seja, algo que bloqueia a luz fora de uma determinada região, está localizada no plano $(\xi, \eta)$ e é iluminada na direção positiva $z$. Queremos calcular o campo no plano $(x, y)$, que é paralelo ao plano $(\xi, \eta)$ e está à distância $z$ deste. O eixo $z$ passa pela origem de ambos os planos. Segundo o princípio de Huygens-Fresnel e a fórmula de difração de Rayleigh-Sommerfeld,

$$
U(x, y)=\frac{z}{j \lambda} \int_{-\infty}^{+\infty} U(\xi, \eta) \frac{\exp \left(j k r_{01}\right)}{r_{01}^{2}} d \xi d \eta
$$

onde $r_{01}$ é a distância

$$
r_{01}=\sqrt{z^{2}+(x-\xi)^{2}+(y-\eta)^{2}} .
$$

Até agora supusemos as condições da teoria escalar e que $r_{01} \gg \lambda$. Podemos aproximar $r_{01}$ movendo $z$ para fora da raiz, e usar a expansão binomial para obter

$$
r_{01} \approx z\left[1+\frac{1}{2}\left(\frac{x-\xi}{z}\right)^{2}+\frac{1}{2}\left(\frac{y-\eta}{z}\right)^{2}\right]
$$


No denominador, aproximamos $r_{01}$ por $z$ apenas. Com isso, a equação para o campo em $(x, y)$ é

$$
U(x, y)=\frac{e^{j k z}}{j \lambda z} \iint_{-\infty}^{+\infty} U(\xi, \eta) \exp \left(j \frac{k}{2 z}\left[(x-\xi)^{2}+(y-\eta)^{2}\right]\right) d \xi d \eta \text {. }
$$

Esta equação pode ser interpretada como a convolução de $U(\xi, \eta)$ por

$$
h(x, y)=\frac{e^{j k z}}{j \lambda z} \exp \left[j \frac{k}{2 z}\left(x^{2}+y^{2}\right)\right] .
$$

Calculando analiticamente a transformada de Fourier de $h(x, y)$,

$$
\begin{aligned}
H\left(f_{X}, f_{Y}\right) & =\mathcal{F}\left\{\frac{e^{j k z}}{j \lambda z} \exp \left[j \frac{\pi}{\lambda z}\left(x^{2}+y^{2}\right)\right]\right\} \\
& =e^{j k z} \exp \left[-j \pi \lambda z\left(f_{X}^{2}+f_{Y}^{2}\right)\right] .
\end{aligned}
$$

Esta função de transferência é uma aproximação da função 2.5, utilizando a expansão binomial

$$
\sqrt{1-\left(\lambda f_{X}\right)^{2}-\left(\lambda f_{Y}\right)^{2}} \approx 1-\frac{\left(\lambda f_{X}\right)^{2}}{2}-\frac{\left(\lambda f_{Y}\right)^{2}}{2},
$$

que é válida quando $\left|\lambda f_{X}\right| \ll 1$ e $\left|\lambda f_{Y}\right| \ll 1$. Isto ocorre com pequenos ângulos de difração, ou seja, quando $x, y, \xi, \eta \ll z$. Esta aproximação é conhecida como aproximação de Fresnel ou aproximação paraxial.

Reescrevendo a equação 2.6, obtemos

$$
U(x, y)=\underbrace{\frac{e^{j k z}}{j \lambda z}}_{1} \underbrace{e^{j \frac{k}{2 z}\left(x^{2}+y^{2}\right)}}_{2} \underbrace{\int_{-\infty}^{\infty} \int_{\infty} U(\xi, \eta) \overbrace{e^{j \frac{k}{2 z}\left(\xi^{2}+\eta^{2}\right)}}^{4} e^{-j \frac{2 \pi}{\lambda z}(x \xi+y \eta)} d \xi d \eta}_{3} .
$$

O termo (1) apenas altera a amplitude e fase globalmente, enquanto que o (2) altera somente a fase, e normalmente podem ser desconsiderados. Já o termo (3) pode ser interpretado como uma transformada de Fourier, e o (4) é uma exponencial de fase quadrática (função chirp). 


\section{Capítulo 3}

\section{Processamento de hologramas de plâncton}

Neste capítulo iremos fazer uma breve análise da formação e reconstrução de imagens holográficas, e estudar as diversas etapas de processamento que são necessárias para obter imagens individuais dos organismos planctônicos, permitindo sua identificação. Serão analisados alguns algoritmos de reconstrução holográfica, a localização e focalização de organismos em um holograma, e sua posterior segmentação.

\subsection{Holografia}

Holografia é a técnica de gravar e reconstruir a amplitude e a fase de um objeto, utilizando iluminação coerente. Denotaremos por reconstrução ou propagação o processo de obter a amplitude e fase de uma onda em outro(s) plano(s), o que pode ser feito numericamente ou com instrumentos ópticos, como ilustrado na figura 3.1. Meios de gravação, incluindo filmes fotográficos e sensores digitais, respondem apenas à intensidade da luz, que é proporcional a $|U(P)|^{2}$, onde $U(P)$ é a representação complexa utilizada anteriormente na discussão sobre a difração de ondas. Portanto, a informação da fase precisa ser gravada como intensidade, caso contrário ela será completamente perdida. Para isso, grava-se a interferência entre a onda do objeto e uma segunda onda, coerente com a primeira e com amplitude e fase conhecidas.

Neste trabalho utilizamos imagens digitais de hologramas de Gabor, criadas com o sistema holográfico em linha que pode ser visto na figura 3.2. A vantagem da holografia digital está na facilidade de criação, armazenamento, reconstrução e processamento, não sendo preciso realizar tarefas como processar quimicamente os filmes ou fazer reconstruções ópticas manualmente. Um dos motivos para utilizar hologramas de Gabor na observação de plâncton é a baixa resolução espacial em hologramas digitais, se comparada à de filmes holográficos. Isto não permite a utilização de outras técnicas que envolvem o uso de um feixe de referência em um ângulo com o holograma, o que criaria franjas de interferência com frequências espaciais mais altas do que seria possível gravar

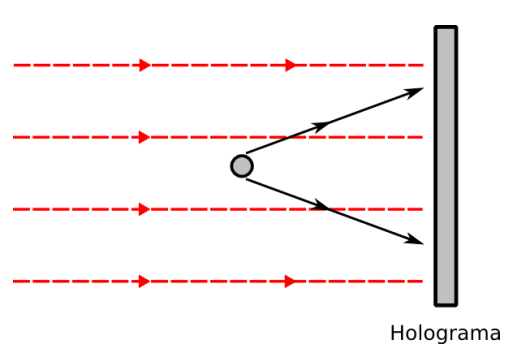

(a) Gravação do holograma

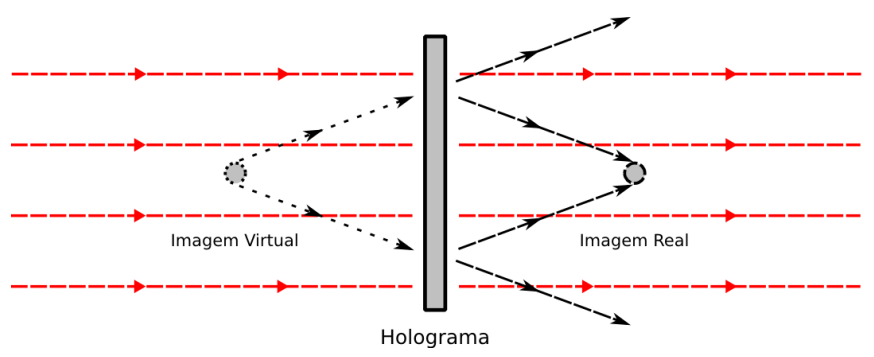

(b) Reconstrução óptica

Figura 3.1: Gravação e reconstrução de holograma. 

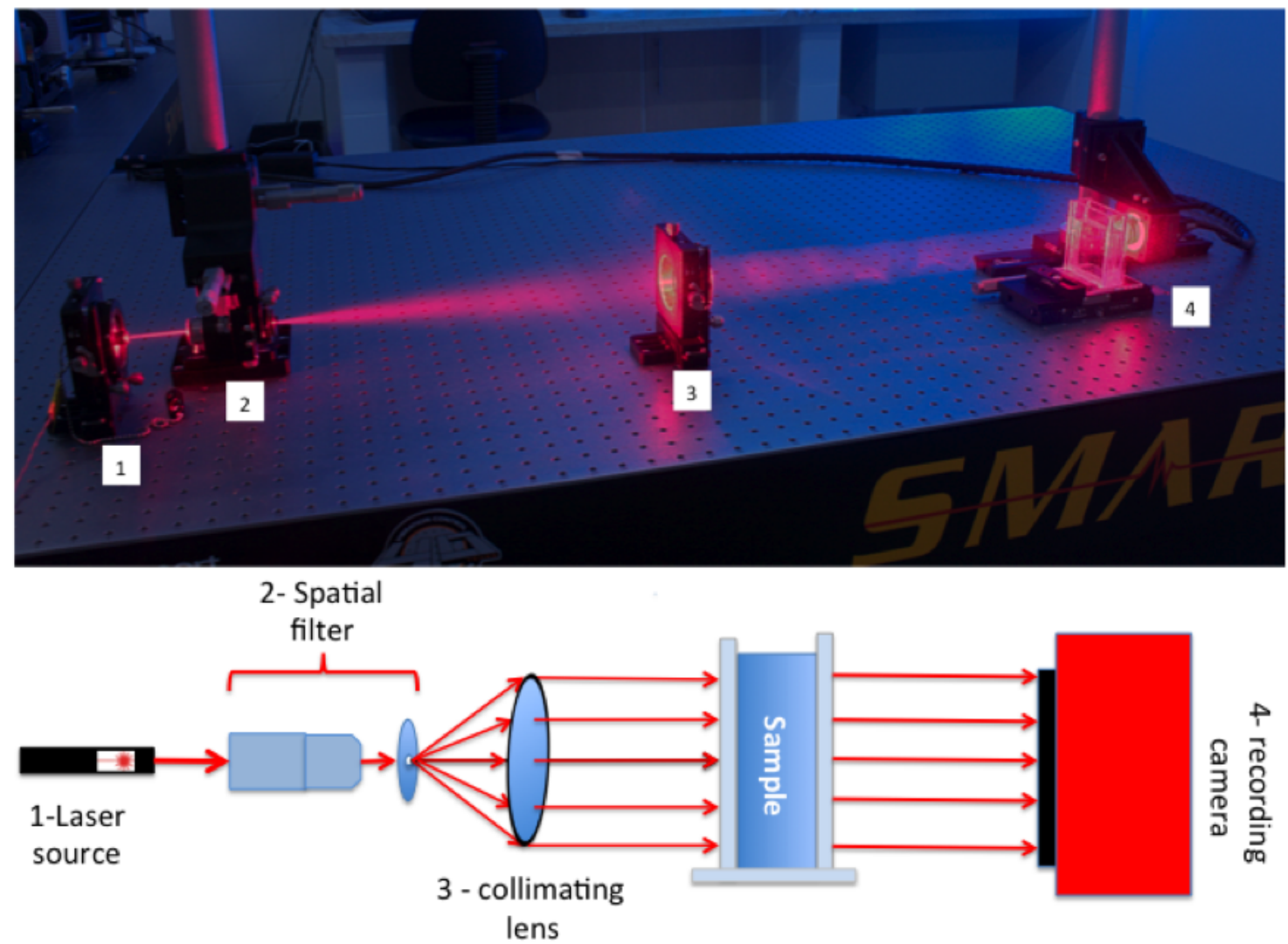

Figura 3.2: Sistema holográfico utilizado nos experimentos. A iluminação proveniente de um laser é filtrada espacialmente, para remover frequências indesejadas, e depois é expandida e colimada, formando uma onda aproximadamente plana que atravessa a amostra e é registrada por uma câmera. (Imagem fornecida pelo $L A P S-I O-U S P)$

com um sensor digital.

Um holograma de Gabor é obtido quando um objeto altamente transparente é iluminado por uma onda colimada coerente. Suponha que o objeto possua transmissão de amplitude

$$
t\left(x_{o}, y_{o}\right)=t_{o}+\Delta t\left(x_{o}, y_{o}\right),
$$

onde $t_{o}$ é a média de transmissão e $\Delta t$ são as variações desta média, e

$$
|\Delta t| \ll\left|t_{o}\right|
$$

Ao ser iluminado pela onda colimada coerente, a luz transmitida será composta por uma onda plana forte, devido ao termo $t_{o}$, e uma onda dispersa fraca devido ao termo $\Delta t\left(x_{o}, y_{o}\right)$. A intensidade gravada à distância $z_{o}$ do objeto é

$$
\begin{aligned}
\mathcal{I}(x, y) & =|A+a(x, y)|^{2} \\
& =|A|^{2}+|a(x, y)|^{2}+A^{*} a(x, y)+A a^{*}(x, y),
\end{aligned}
$$

onde $A$ é a amplitude da onda plana e $a(x, y)$ é a amplitude da onda dispersa no plano de gravação.

Supondo que o meio de gravação responde linearmente à intensidade, a amplitude gravada é

$$
t_{A}(x, y)=t_{b}+\beta^{\prime}\left(|a(x, y)|^{2}+A^{*} a(x, y)+A a^{*}(x, y)\right),
$$

onde $t_{b}$ e $\beta^{\prime}$ são constantes. Iluminando o holograma por uma onda plana com amplitude uniforme 
$B$, o campo transmitido é

$$
B t_{A}(x, y)=\underbrace{B t_{b}}_{U_{1}}+\underbrace{\beta^{\prime} B|a(x, y)|^{2}}_{U_{2}}+\underbrace{\beta^{\prime} A^{*} B a(x, y)}_{U_{3}}+\underbrace{\beta^{\prime} A B a^{*}(x, y)}_{U_{4}} .
$$

O primeiro termo $U_{1}$ é uma onda plana com amplitude uniforme. O segundo termo $U_{2}$ pode ser ignorado usando a hipótese da fórmula 3.1, que implica em $|a(x, y)| \ll A$. O terceiro termo $U_{3}$ é uma duplicação exata da frente de onda $a(x, y)$, a menos de um fator constante, e aparenta originar de uma imagem virtual a uma distância $z_{o}$ do holograma. Similarmente, o termo $U_{4}$ é proporcional a $a^{*}(x, y)$, e leva à formação de uma imagem real à distância $z_{o}$ no lado oposto do holograma. Com isso, vemos que o holograma de Gabor gera duas imagens da variação de transmissão $\Delta t$, separadas por uma distância axial $2 z_{o}$, e acompanhadas de um fundo coerente $U_{1}$ e um halo $U_{2}$.

$\mathrm{Na}$ holografia de plâncton, podemos supor a hipótese da fórmula 3.1, pois quase a totalidade do volume sendo imageado estará vazio, preenchido apenas com água, e somente alguns poucos organismos pequenos irão difratar a onda de luz sendo transmitida. Um estudo sobre o efeito de grandes quantidades de partículas na qualidade da reconstrução pode ser encontrado na tese de doutorado de Loomis [Loo11]. Além disso, normalmente as imagens gêmeas $U_{3}$ e $U_{4}$ poderiam ser problemáticas, pois a reconstrução de uma delas é acompanhada pela outra imagem desfocada. Porém, como os organismos observados são muito pequenos em relação à distância da câmera, a imagem gêmea aparece extremamente desfocada e normalmente não interfere na correta visualização da imagem reconstruída. Esta imagem gêmea só começa a causar problemas quando a quantidade de plâncton é muito elevada, ou os organismos são grandes.

\subsubsection{Remoção de fundo}

Podemos calcular o fundo $t_{b}$ da equação 3.2 e subtraí-lo do holograma gravado, melhorando a reconstrução ao eliminar o termo $U_{1}$ da equação 3.3. Isto pode ser feito de várias formas, como por exemplo modelando o feixe transmitido, ou subtraindo uma média global ou local da imagem.

Uma vantagem de remover o fundo é que, embora tenhamos suposto que a onda de referência possui intensidade constante no plano do holograma, na prática ela pode variar de acordo com a posição, e nos experimentos feitos ela segue uma distribuição de intensidade aproximadamente gaussiana, com centro próximo ao da imagem, devido ao laser e configuração óptica utilizados. Sem o fundo, a iluminação torna-se praticamente uniforme, facilitando processamentos posteriores. Removê-lo também acaba melhorando a qualidade da imagem ao subtrair padrões de interferência indesejados, provenientes de imperfeições no sistema óptico, como partículas de poeira. Após remover o fundo, a imagem é linearmente normalizada para que ocupe todo o intervalo [0,255]. Isso acaba adicionando um termo constante em toda a imagem, o que facilita sua visualização, mas pode trazer problemas se não for feito um tratamento adequado da borda, conforme será discutido em uma seção posterior e com mais detalhes no Capítulo 4 .

Durante os experimentos que foram realizados, foram testadas duas maneiras de se obter a imagem de fundo. A primeira consistiu na obtenção de uma sequência curta de imagens antes da colocação da amostra a ser observada. Com isto, é possível calcular uma imagem média de fundo, que é subtraída das imagens obtidas após a colocação da amostra. A maior dificuldade desta técnica consiste na fixação dos componentes. Na prática, ao capturar estas imagens em laboratório, é preciso colocar uma amostra de água do mar filtrada, e só depois substituí-la pela amostra de interesse. Nesta substituição, muitas vezes o recipiente acaba sendo levemente movido, o que é suficiente para mudar completamente o fundo do holograma. Embora ainda não tenha sido testada em um equipamento in situ, é possível que outras dificuldades apareçam. Alguns detritos podem grudar nos vidros externos, prejudicando a qualidade da imagem. Caso o fundo seja calculado previamente, eles não serão parcialmente removidos junto com o fundo. $O$ fundo também pode ser influenciado pela profundidade sendo amostrada, alterando a proporção da iluminação laser que é absorvida pela água e a intensidade da iluminação solar que pode chegar na câmera.

A outra técnica testada consiste no cálculo do fundo a partir dos hologramas obtidos das amos- 


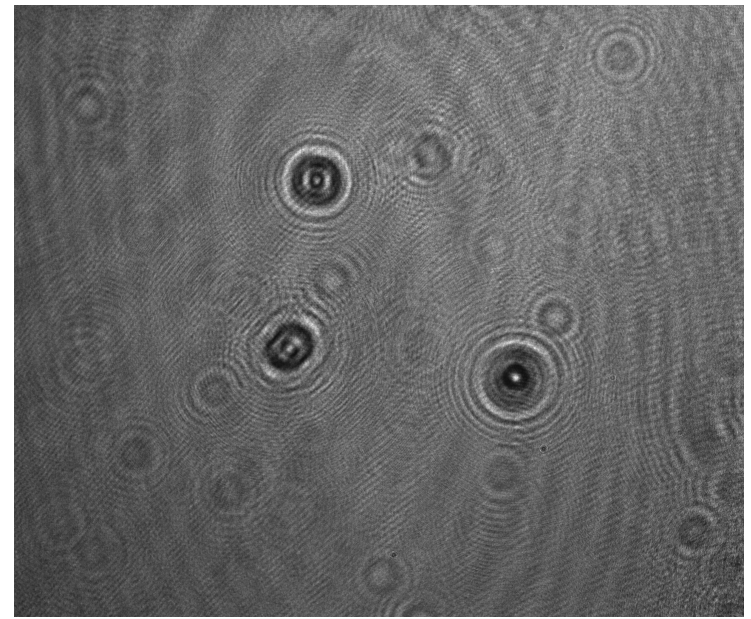

(a) Holograma original

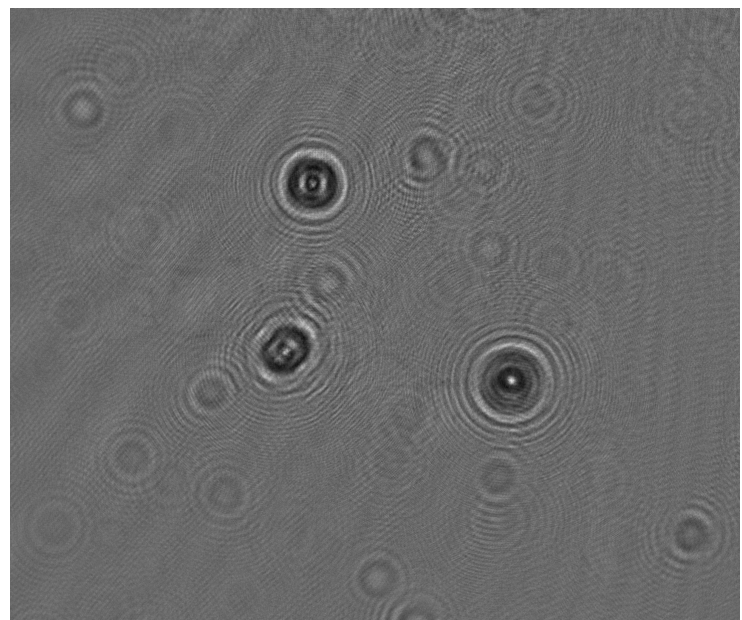

(b) Holograma sem fundo

Figura 3.3: Exemplo de remoção de fundo de um holograma utilizando a média de vários hologramas.

tras. Caso existam hologramas suficientes, é possível calcular uma simples média a partir de uma seleção grande (maior do que 50, por exemplo) dos hologramas, preferencialmente com organismos ocupando posições diferentes da imagem, e utilizá-la como fundo. Um exemplo do resultado desta técnica pode ser visto na figura 3.3. Caso a quantidade de hologramas disponíveis para o cálculo seja pequena (como 30 imagens no total, por exemplo), a média de intensidade de cada pixel pode ser feita desconsiderando uma certa porcentagem (obtida experimentalmente) dos valores mais extremos, com o objetivo de ignorar grande parte dos pixels que representam a interferência de algum organismo em movimento. Isto supõe que, embora existam poucas imagens, elas são suficientemente diferentes umas das outras, não havendo nenhuma região que é ocupada por organismos na maior parte dos hologramas.

Um exemplo de subtração da média local em blocos, para uniformizar a iluminação do holograma, pode ser encontrado na dissertação de mestrado de Domínguez-Caballero [DC06]. A desvantagem é que os padrões de interferência indesejados não são minimizados, e a iluminação realiza pequenos saltos de um bloco para outro. Isto fez com que, na dissertação citada, esta imagem sem fundo tenha sido utilizada apenas para realizar uma segmentação inicial, não sendo utilizada nas reconstruções dos segmentos.

\subsubsection{Algoritmos de reconstrução}

Tradicionalmente, a reconstrução holográfica é feita iluminando o holograma por uma onda igual ao feixe de referência utilizado, embora alguns tipos de holograma permitam outras formas de iluminação, como luz branca. Em holografia digital, a iluminação do holograma e sua observação é feita numericamente, calculando-se o efeito de difração que a onda sofreria ao passar pelo holograma.

Após a remoção do fundo, e supondo que o termo $U_{2}$ pode ser ignorado, conforme discutido anteriormente, ao iluminar o holograma por uma onda plana $B$ o campo resultante é

$$
\begin{aligned}
E_{B} & =\beta^{\prime} A^{*} B a(x, y)+\beta^{\prime} A B a^{*}(x, y) . \\
& =U_{3}+U_{4} .
\end{aligned}
$$

Como estamos iluminando por uma onda plana $B$ qualquer, podemos escolher os parâmetros desta onda da forma que for mais conveniente, com a única restrição de que a amplitude deve ser estritamente maior do que zero. Ou seja, podemos supor que, em todo o plano $(x, y)$, ela possui amplitude igual a 1 e fase igual a 0 , o que significa que iluminar o holograma por $B$ consiste em multiplicá-lo por 1. Portanto, esta operação pode ser ignorada, e utilizamos os valores originais do holograma como sendo o holograma iluminado por uma onda plana. Caso estivéssemos utilizando uma onda esférica, por exemplo, isto não seria possível, pois a fase da onda seria diferente dependendo da 


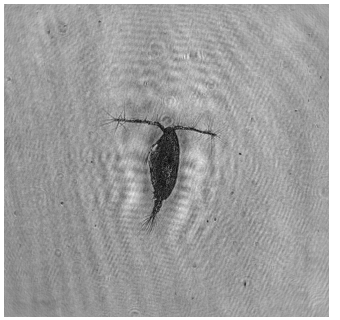

(a) Magnitude

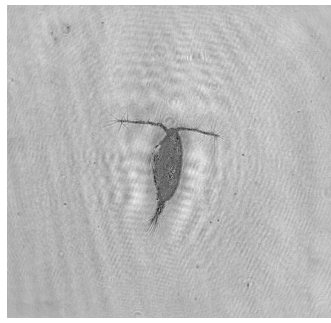

(b) Parte Real

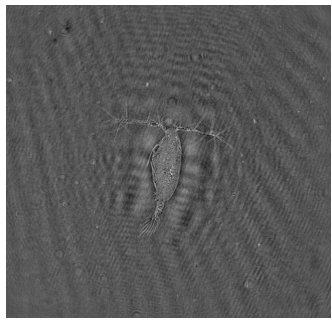

(c) Parte Imaginária

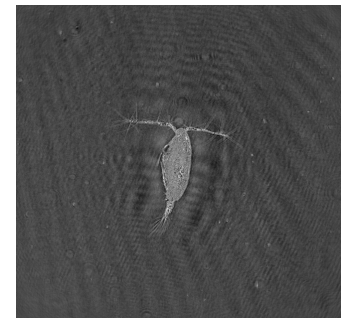

(d) Fase

Figura 3.4: Reconstrução de um organismo de amplitude.

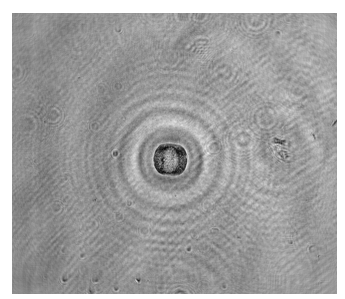

(a) Magnitude

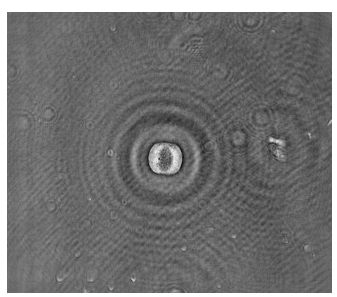

(b) Parte Real

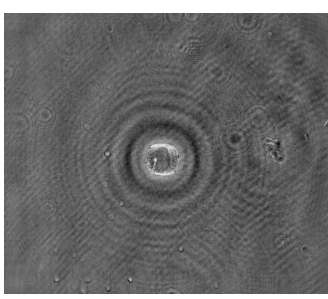

(c) Parte Imaginária

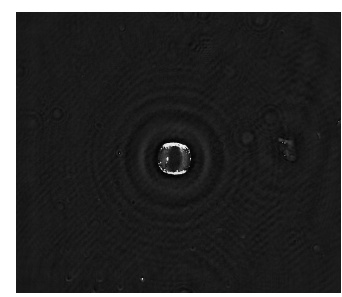

(d) Fase

Figura 3.5: Reconstrução de um organismo de fase.

posição no holograma.

Para obter a onda $a(x, y)$ do objeto focalizada, ainda precisamos propagar a onda à distância $z_{o}$, pois estamos no plano do holograma e queremos a onda no plano do objeto. Esta propagação é feita numericamente utilizando as fórmulas de difração presentes na seção 2.2 , como será detalhado abaixo. Após realizar esta propagação, obtemos a soma da imagem do objeto com sua imagem desfocada a uma distância $2 z_{o}$, cada uma correspondendo a um dos termos $U_{3}$ e $U_{4}$.

O resultado da propagação é uma matriz de números complexos $E\left(x, y ; z_{o}\right)$, a partir da qual podemos calcular a magnitude

$$
I=|E|,
$$

a intensidade que seria observada opticamente

$$
\mathcal{I}=|E|^{2}
$$

e a fase $\Phi$ a partir de

$$
\tan [\Phi]=\frac{\operatorname{Im}[E]}{\operatorname{Re}[E]}
$$

Nas figuras 3.4 e 3.5 podem ser vistos exemplos do resultado desta propagação.

A seguir apresentamos a Reconstrução pela Integração de Fresnel e a Reconstrução por Convolução, que são formas diferentes de utilizar as fórmulas da seção 2.2 para calcular a propagação da onda a uma distância $z$.

\section{Reconstrução pela Integração de Fresnel}

Fazendo as substituições

$$
\nu=\frac{x}{\lambda z} \quad \mu=\frac{y}{\lambda z}
$$


na equação 2.9 , temos

$$
U(\nu, \mu)=\frac{-j}{\lambda z} e^{j \pi \lambda z\left(\nu^{2}+\mu^{2}\right)} \underbrace{\iint_{-\infty}^{+\infty} \overbrace{U(\xi, \eta) e^{j \frac{\pi}{\lambda z}\left(\xi^{2}+\eta^{2}\right)}}^{1} e^{-j 2 \pi(\nu \xi+\mu \eta)} d \xi d \eta}_{2}
$$

onde omitimos o fator $e^{j k z}$, pois só altera a fase globalmente. O termo (2) é a transformada de Fourier do termo (1), ou seja,

$$
U(\nu, \mu)=\frac{-j}{\lambda z} e^{j \pi \lambda z\left(\nu^{2}+\mu^{2}\right)} \mathcal{F}\left\{U(\xi, \eta) e^{j \frac{\pi}{\lambda z}\left(\xi^{2}+\eta^{2}\right)}\right\} .
$$

Portanto, podemos reconstruir o holograma a uma distância $z$ calculando [SJ02]

$$
I_{\text {rec }}=d \cdot \operatorname{FFT}\left(I_{\text {holo }} \cdot c\right) \text {, }
$$

onde $\cdot$ representa a multiplicação ponto a ponto, $I_{\text {holo }}$ é a imagem do holograma, e

$$
c(\xi, \eta)=e^{j \frac{\pi}{\lambda z}\left(\xi^{2}+\eta^{2}\right)} \quad d(\nu, \mu)=\frac{-j}{\lambda z} e^{j \pi \lambda z\left(\nu^{2}+\mu^{2}\right)} .
$$

Podemos ignorar o termo $d$ se não estivermos interessados na fase.

As seguintes relações são válidas na transformada de Fourier para as dimensões dos pixels $\Delta \xi \mathrm{e}$ $\Delta \eta$ no holograma original:

$$
\Delta \nu=\frac{1}{M \Delta \xi} \quad \Delta \mu=\frac{1}{N \Delta \eta},
$$

onde $M$ e $N$ são o número de pixels em cada eixo. Após refazermos a substituição da equação 3.4,

$$
\Delta x=\frac{\lambda z}{M \Delta \xi} \quad \Delta y=\frac{\lambda z}{N \Delta \eta}
$$

Podemos ver que o tamanho $\Delta x$ do pixel na reconstrução não é necessariamente igual ao tamanho $\Delta \xi$ do pixel no holograma, podendo ser maior ou menor dependendo da distância da reconstrução. Por causa disto, este algoritmo não é utilizado para calcular propagações a distâncias muito pequenas.

Para manter o tamanho do pixel aproximadamente constante, pode-se aumentar a imagem com zeros, alterando com isso os valores de $M$ e $N$ e as dimensões de $\Delta x$ e $\Delta y$. Porém, isso aumenta o custo computacional consideravelmente, não sendo prático a distâncias um pouco maiores. Como exemplo, se estivermos calculando uma reconstrução com $\lambda=660 \mathrm{~nm}, \Delta x=3,45 \mu \mathrm{m}$ e $z=15 \mathrm{~cm}$, precisaríamos ter $M \approx 8317$ pixels.

Uma outra maneira de manter as dimensões dos pixels é através do cálculo do espectro apenas das frequências mais baixas, utilizando o algoritmo conhecido como Chirp Z-Transform [RSR69], cujo resultado é ilustrado na figura 3.6. Porém, isto envolve o cálculo de uma convolução entre matrizes de números complexos, eliminando assim a principal vantagem deste algoritmo de reconstrução holográfica, que é a eficiência obtida com o cálculo de uma única FFT.

\section{Reconstrução por Convolução}

É possível reconstruir o holograma realizando a convolução pela função $h(x, y)$, obtida na discussão sobre difração escalar, e que depende dos parâmetros do experimento e a distância de propagação escolhida. Como é possível calcular a transformada de Fourier de $h(x, y)$ analiticamente, iremos utilizar a matriz $H(x, y)$ resultante, o que evita computações desnecessárias. O cálculo da reconstrução 


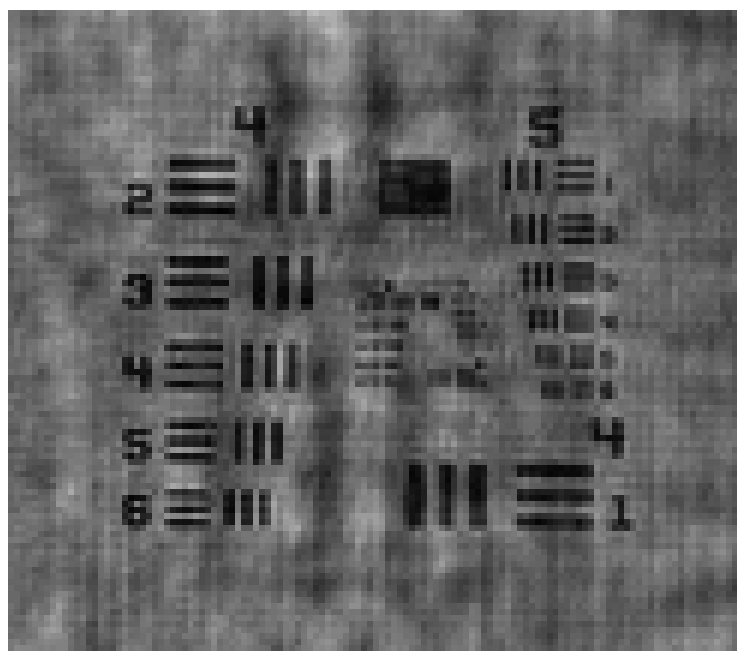

(a) Reconstrução padrão

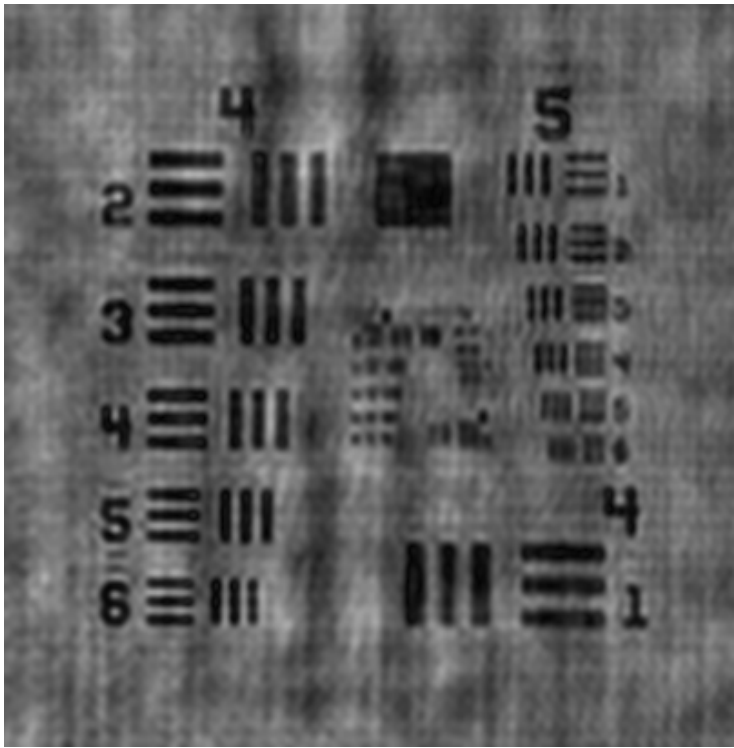

(b) Reconstrução com Chirp Z-Transform

Figura 3.6: Reconstrução holográfica pelo algoritmo da Integração de Fresnel. Como o holograma original possuía diferentes números de pixels nos dois eixos, isto resulta em diferentes dimensões dos pixels na reconstrução padrão. Estas imagens exibem apenas a região central da reconstrução de um padrão de teste de resolução 1951 USAF, a cerca de 15,6 cm de distância.

$I_{r e c}$ à distância $z$, utilizando o holograma $I_{\text {holo }}$ e a função de transferência $H$, é

$$
I_{\text {rec }}=\operatorname{IFFT}\left(\operatorname{FFT}\left(I_{\text {holo }}\right) \cdot H\right)
$$

onde $\cdot$ representa a multiplicação ponto a ponto. Embora pareça simples, existem alguns detalhes de implementação importantes que serão mencionados na seção 3.2. Se desejarmos calcular diversas distâncias de propagação do mesmo holograma, podemos guardar o resultado de $\mathrm{FFT}\left(I_{\text {holo }}\right)$ e executar apenas os cálculos restantes. Desta forma calculamos a transformada de Fourier do holograma uma única vez, e cada reconstrução posterior necessita apenas do cálculo da função $H$ e de uma transformada inversa de Fourier.

A partir das fórmulas da seção 2.2 , temos as funções de transferência

$$
\begin{aligned}
& H_{e}\left(f_{X}, f_{Y}\right)= \begin{cases}\exp \left[j k z \sqrt{1-\left(\lambda f_{X}\right)^{2}-\left(\lambda f_{Y}\right)^{2}}\right] & \text { se } \sqrt{f_{X}^{2}+f_{Y}^{2}} \leq \frac{1}{\lambda} \\
0 & \text { caso contrário }\end{cases} \\
& H_{f}\left(f_{X}, f_{Y}\right)=e^{j k z} \exp \left[-j \pi \lambda z\left(f_{X}^{2}+f_{Y}^{2}\right)\right]
\end{aligned}
$$

onde $H_{e}$ é a função de transferência "exata" obtida no método do espectro angular, e $H_{f}$ é a aproximação de Fresnel. Não existe diferença significativa entre o resultado obtido a partir das duas funções, exceto em distâncias extremamente pequenas ou em casos em que as distâncias laterais não são pequenas em relação à distância axial, conforme já foi estudado em diversos artigos [Sou81, SR89, MH03]. A aproximação de Fresnel pode resultar em uma computação mais rápida, por não exigir o cálculo de uma raiz quadrada, e o termo $e^{j k z}$ pode ser ignorado, pois podemos supor que estamos iluminando o holograma com uma onda plana da forma $e^{-j k z}$, o que cancelaria este termo. 


\subsubsection{Captura e propagação das frequências em holografia digital}

Para visualizar os efeitos da propagação numérica do holograma, iremos analisar separadamente frequências da forma

$$
u_{f_{x}}=\operatorname{rect}\left(\frac{x}{L}\right) \exp \left(j 2 \pi x f_{x}\right),
$$

onde $L$ é a largura do holograma e $f_{x}$ é a frequência sendo estudada. No caso de hologramas digitais, $L$ é a largura do sensor da câmera referente à região do holograma sendo reconstruída. Limitarnos-emos ao caso unidimensional, já que as duas dimensões podem ser facilmente separadas na aproximação de Fresnel.

A propagação da frequência $f_{x}=0$ reduz-se à difração por uma abertura retangular, que pode ser calculada numericamente através das integrais de Fresnel [Goo96]. Supondo que a distância de propagação não é extremamente grande, condição que é satisfeita na holografia de plâncton, quase toda a intensidade continuará no intervalo original de largura $L$.

Seja $U_{0}=\mathcal{F}\left\{u_{0}\right\}$, ou seja, $U_{0}$ é a transformada de Fourier quando $f_{x}=0$. A propagação de uma frequência $f_{x} \neq 0$ a uma distância $z$ é

$$
\begin{aligned}
u_{f_{x}}(x ; z) & =\mathcal{F}^{-1}\left\{\mathcal{F}\left\{\operatorname{rect}\left(\frac{x}{L}\right) \exp \left(j 2 \pi x f_{x}\right)\right\}(\xi) \cdot H_{z}(\xi)\right\}(x) & & \\
& =\mathcal{F}^{-1}\left\{\mathcal{F}\left\{\operatorname{rect}\left(\frac{x}{L}\right)\right\}\left(\xi-f_{x}\right) \cdot H_{z}(\xi)\right\}(x) & & \text { (Propriedade de deslocamento) } \\
& =\mathcal{F}^{-1}\left\{\left[U_{0}(\xi) \cdot H_{z}\left(\xi+f_{x}\right)\right]\left(\xi-f_{x}\right)\right\}(x) & & \text { (Reorganizando deslocamentos) } \\
& =\mathcal{F}^{-1}\left\{U_{0}(\xi) \cdot H_{z}\left(\xi+f_{x}\right)\right\}(x) \cdot \exp \left(j 2 \pi x f_{x}\right) & &
\end{aligned}
$$

Utilizando a aproximação de Fresnel, e ignorando o termo global de fase que não depende da frequência, temos

$$
\begin{aligned}
H_{z}\left(\xi+f_{x}\right) & =\exp \left[-j \pi \lambda z\left(\xi+f_{x}\right)^{2}\right] \\
& =\exp \left[-j \pi \lambda z(\xi)^{2}\right] \exp \left[-j \pi \lambda z\left(2 \xi f_{x}\right)\right] \exp \left[-j \pi \lambda z\left(f_{x}\right)^{2}\right] \\
& =H_{z}(\xi) \exp \left(-j 2 \pi \xi f_{x} \lambda z\right) \exp \left(-j \pi \lambda z f_{x}^{2}\right)
\end{aligned}
$$

Portanto,

$$
\begin{aligned}
u_{f_{x}}(x ; z) & =\mathcal{F}^{-1}\left\{U_{0}(\xi) \cdot H_{z}(\xi) \cdot \exp \left(-j 2 \pi \xi f_{x} \lambda z\right) \exp \left(-j \pi \lambda z f_{x}^{2}\right)\right\}(x) \cdot \exp \left(j 2 \pi x f_{x}\right) \\
& =\mathcal{F}^{-1}\left\{U_{0}(\xi) \cdot H_{z}(\xi) \cdot \exp \left(-j 2 \pi \xi f_{x} \lambda z\right)\right\}(x) \cdot \exp \left(-j \pi \lambda z f_{x}^{2}\right) \exp \left(j 2 \pi x f_{x}\right) \\
& =\mathcal{F}^{-1}\left\{U_{0}(\xi) \cdot H_{z}(\xi)\right\}\left(x-f_{x} \lambda z\right) \cdot \exp \left(-j \pi \lambda z f_{x}^{2}\right) \exp \left(j 2 \pi x f_{x}\right) \\
& =u_{0}\left(x-f_{x} \lambda z ; z\right) \exp \left(-j \pi \lambda z f_{x}^{2}\right) \exp \left(j 2 \pi x f_{x}\right) .
\end{aligned}
$$

Podemos tirar algumas conclusões a partir desta fórmula, que é uma aplicação direta da propriedade de deslocamento da Transformada Canônica Linear (Linear Canonical Transform) [HS05]. A primeira é a de que todas as frequências são preservadas, o que pode ser visto no último termo, sofrendo apenas uma mudança de fase, representada pelo segundo termo. Isto já era esperado pela forma da função de transferência na aproximação de Fresnel, que possui amplitude unitária em toda sua extensão e apenas altera as fases. A segunda é a de que todas as frequências sofrem o mesmo efeito de difração pela borda do holograma, o que pode ser visto no primeiro termo $u_{0}(\circ ; z)$. É importante notar que isto é uma consequência da aproximação de Fresnel, que remove a raiz quadrada da função de transferência, fazendo com que todas as frequências sejam tratadas de forma linear. Por último, cada frequência desloca-se uma distância $f_{x} \lambda z$ com a propagação.

Nas figuras 3.7, 3.8 e 3.9 é possível visualizar os deslocamentos que ocorrem com diferentes frequências nas reconstruções holográficas. Outro fenômeno que pode ser observado é o que ocorre na figura 3.9, onde o holograma possui apenas valores reais, ou seja, seus valores imaginários são nulos, sendo portanto mais representativo dos hologramas deste trabalho, já que não utilizamos nenhuma técnica de recuperação de fase. Sem a informação da fase, a frequência divide-se em duas, 


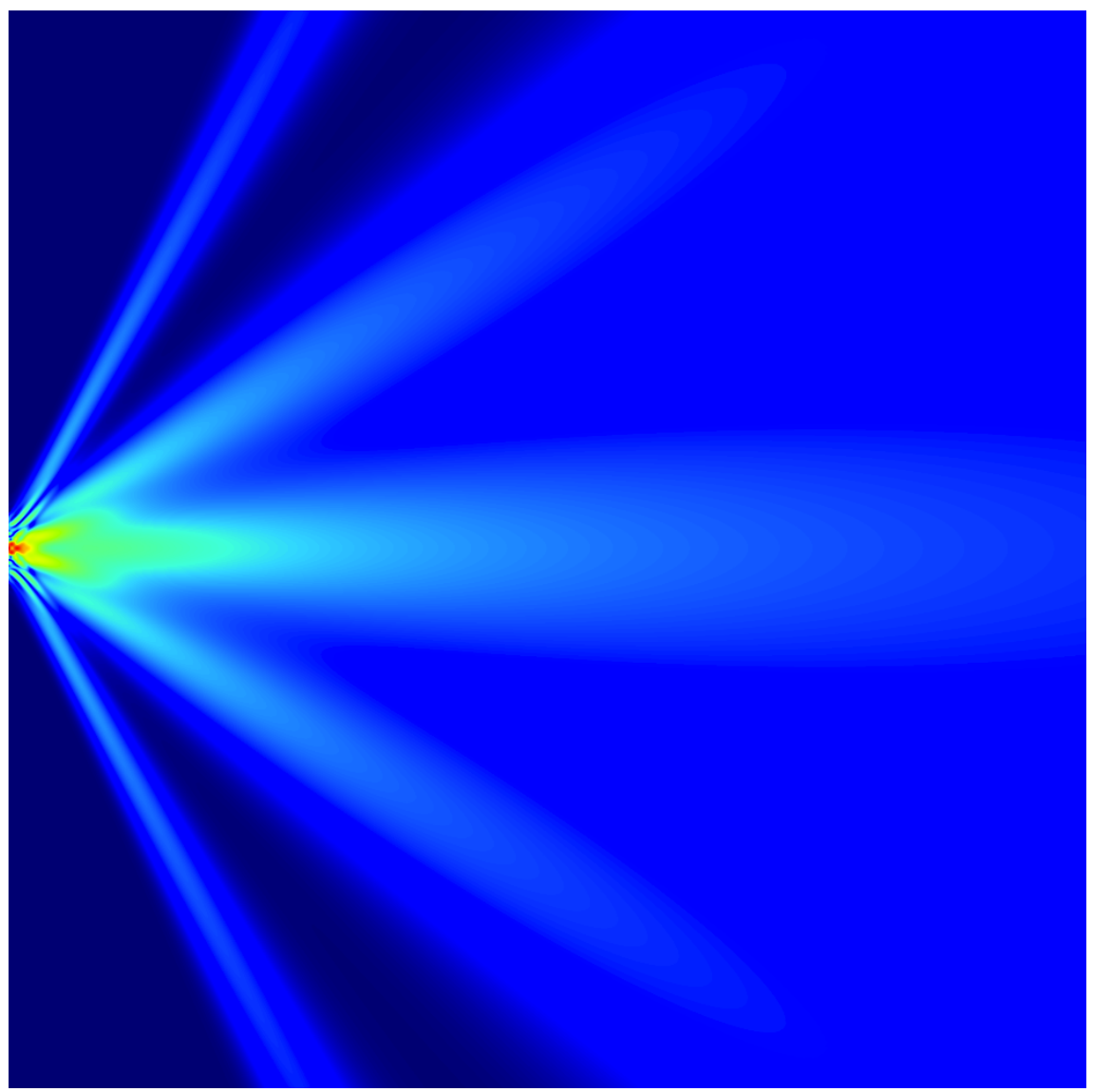

Figura 3.7: Exemplo numérico da propagação das frequências de um holograma, que está na região central à esquerda, sendo iluminado por uma onda plana que se propaga para a direita. Cada coluna da imagem é calculada a partir da reconstrução numérica do holograma até a distância apropriada, sendo exibida a amplitude resultante. A onda plana é bloqueada nas duas regiões à esquerda que não fazem parte da região central com o holograma. O holograma é formado pela adição de três funções cosseno, com frequência linear, e tem sua intensidade modulada por uma função gaussiana para evitar os efeitos de difração da borda. Uma destas frequências é nula, formando a região central do feixe, e as outras duas frequências formam os outros quatro feixes. Como o holograma possui apenas valores reais, sem a parte imaginária, cada frequência não nula presente no holograma provoca o surgimento de dois feixes, que correspondem àquela frequência em sentido horário e anti-horário. A maior frequência forma os feixes externos, pois se desloca mais com a propagação. 


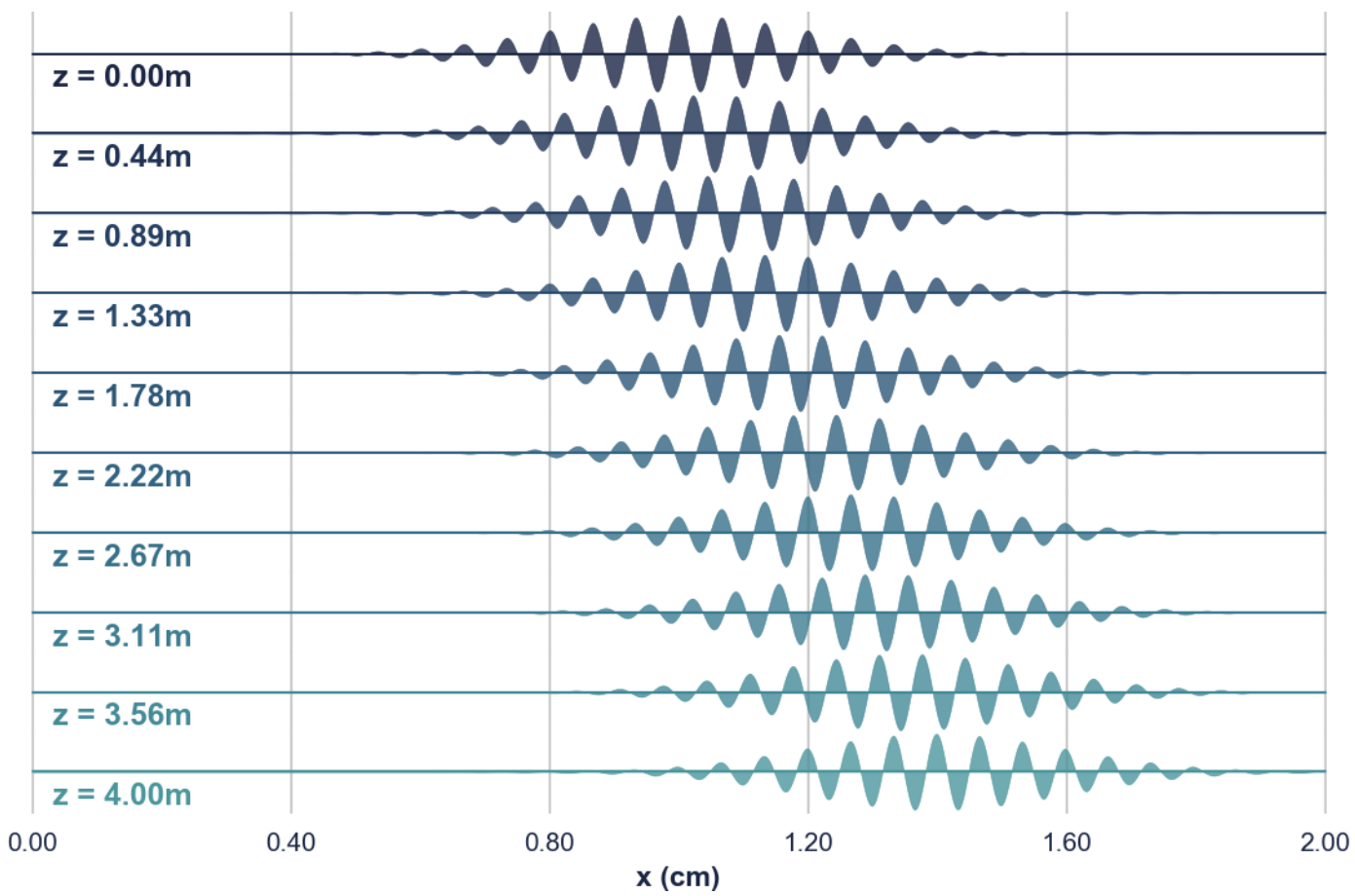

(a) Propagação de frequência de 15 ciclos/centímetro

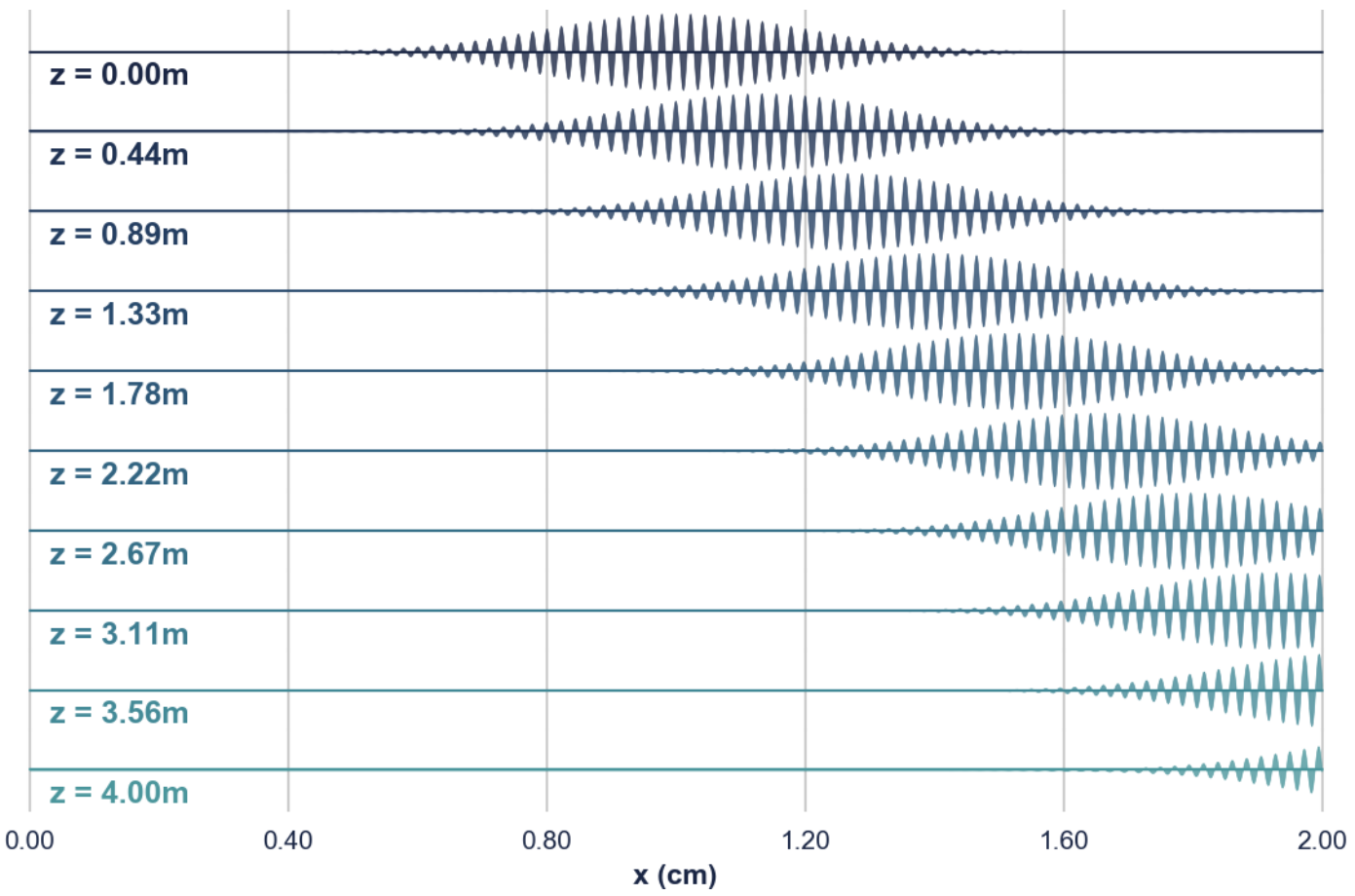

(b) Propagação de frequência de 45 ciclos/centímetro

Figura 3.8: Exemplo numérico da propagação de uma frequência baixa. O holograma unidimensional é exibido no topo de cada imagem, sendo calculada sua reconstrução a diferentes distâncias, até $4 \mathrm{~m}$. Apenas a parte real é exibida, pois a parte imaginária é bem similar, e a intensidade do holograma foi modulada por uma função gaussiana, para que não ocorram efeitos de difração da borda. Cada pixel possui $4 \mu \mathrm{m}$ de largura, e foi simulada a iluminação por um laser com comprimento de onda igual a $660 \mathrm{~nm}$. Cada frequência desloca-se uma distância $f_{x} \lambda z$ com a propagação, ou seja, após $4 \mathrm{~m}$ a frequência de 15 ciclos/centímetro sofre um deslocamento de $15 \times 10^{2} \times 660 \times 10^{-9} \times 4=3.96 \times 10^{-3} \mathrm{~m}$, e a frequência de 45 ciclos/centímetro sofre um deslocamento de $45 \times 10^{2} \times 660 \times 10^{-9} \times 4=1.188 \times 10^{-2} \mathrm{~m}$, conforme pode ser observado na parte inferior de cada figura. 


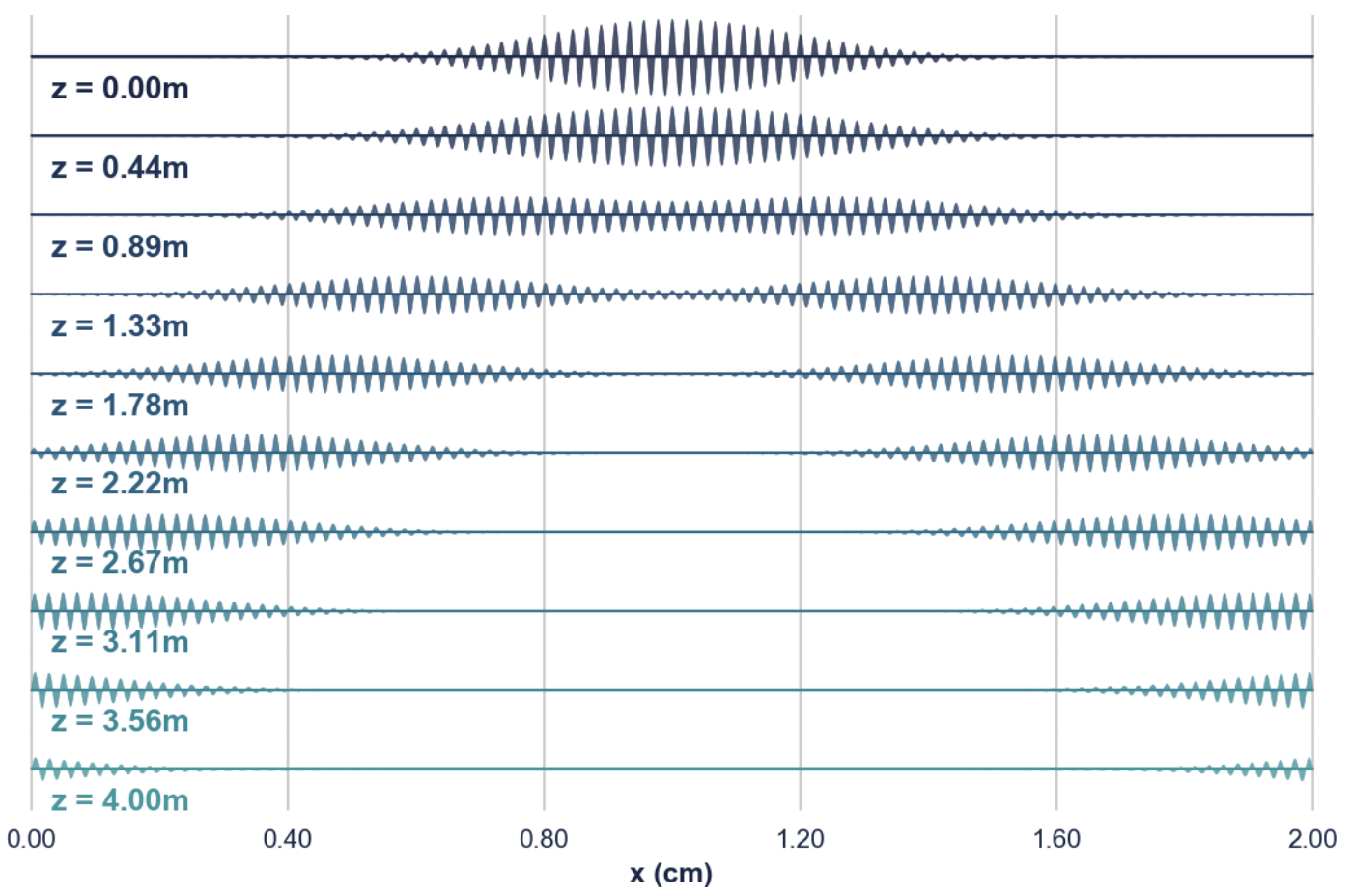

Figura 3.9: Exemplo numérico da propagação de uma frequência baixa, de 45 ciclos/centímetro. O holograma unidimensional é exibido no topo da imagem, sendo calculada sua reconstrução a diferentes distâncias, até $4 \mathrm{~m}$. A parte imaginária do holograma é nula, pois este é formado por uma função cosseno, e sua intensidade foi modulada por uma função gaussiana, para que não ocorram efeitos de difração da borda. Cada pixel possui $4 \mathrm{\mu m}$ de largura, e foi simulada a iluminação por um laser com comprimento de onda igual a $660 \mathrm{~nm}$. Como cada frequência desloca-se uma distância $f_{x} \lambda z$ com a propagação, após $4 \mathrm{~m}$ a frequência de 45 ciclos/centímetro sofre um deslocamento de $45 \times 10^{2} \times 660 \times 10^{-9} \times 4=1.188 \times 10^{-2} \mathrm{~m}$, conforme pode ser observado na parte inferior da figura. O holograma não possui parte imaginária, portanto é equivalente à soma de duas frequências idênticas, mas em sentidos opostos, o que faz com que suas partes imaginárias se anulem, pois $\cos x=\left(e^{i x}+e^{-i x}\right) / 2$. Com a propagação, estas duas frequências sofrem deslocamentos em sentidos opostos, separando-se uma da outra. 
cada uma sofrendo um deslocamento em uma direção. Visualmente, isto corresponde à formação da imagem real e da imagem virtual (ou imagem gêmea).

Caso estejamos interessados em obter a propagação do holograma para uma região paralela de mesma largura $L$, que está à distância $z$ do holograma e diretamente à sua frente, podemos supor que as frequências que tenham se deslocado mais do que $L$ podem ser ignoradas. Ou seja, as frequências $f_{x}$ presentes na reconstrução são

$$
\left|f_{x}\right| \leq \frac{L}{\lambda z}
$$

Historicamente, este resultado relaciona-se à teoria da formação da imagem de E. Abbe [Abb73], que estudou a difração da luz em microscópios e observou que frequências mais altas afastam-se mais do eixo ótico, levando a uma perda da qualidade da imagem obtida quando parte das frequências não é capturada ou sofre distorções devido às lentes. A fórmula 3.7 obtida acima é similar às fórmulas (17) e (20) apresentadas no artigo de Kelly et al. [KHHS11], que considera a formação do holograma, não sua reconstrução. Um artigo mais recente de Kelly [Kel14] considera esta análise do ponto de vista da reconstrução numérica.

Também precisamos considerar o efeito de amostragem e integração realizado pelos pixels da câmera. A integração pelos pixels resulta na aplicação de um filtro passa-baixa no holograma, e a amostragem impede que frequências acima de $\frac{1}{2 \Delta x}$ sejam representadas no espectro, onde $\Delta x$ é a largura de um pixel no eixo $x$, resultando em aliasing.

Pode-se dividir a propagação em três regiões [KNR $\left.{ }^{+} 09\right]$, uma na qual a abertura da câmera limita a resolução, outra na qual tanto a abertura quanto o tamanho do pixel limitam a resolução, e uma última na qual apenas o tamanho do pixel limita a resolução. Supondo que a região a ser reconstruída e o holograma possuem largura $L$, a integração do pixel pode ser ignorada quando

$$
\Delta x \leq \frac{3}{10}\left[\frac{\lambda z}{L}\right]
$$

E a abertura da câmera pode ser ignorada quando

$$
\Delta x \geq 6\left[\frac{\lambda z}{L}\right]
$$

Kelly et al. [KHHS11] fazem uma análise mais geral, considerando diversos tipos de sistemas holográficos, e uma das conclusões é a de que uma iluminação esférica altera a distribuição das frequências, o que pode permitir uma reconstrução mais exata em comparação à iluminação plana.

Na figura 3.10 podemos ver um exemplo numérico destas equações quando $\lambda=660 \mathrm{~nm}, L=$ $7.0725 \mathrm{~mm}$ e $\Delta x=3.45 \mu \mathrm{m}$. Até cerca de $7.5 \mathrm{~cm}$, o tamanho dos pixels impede que todas as frequências que poderiam estar na reconstrução sejam corretamente amostradas. Na região em vermelho, a partir de pouco mais de $12 \mathrm{~cm}$, uma parte considerável das frequências presentes na imagem não fará parte de uma reconstrução com a mesma largura do holograma, e diminuir o tamanho dos pixels não traria grandes benefícios, pois a resolução está limitada pelo tamanho do sensor da câmera. A região em que a abertura da câmera pode ser ignorada não é exibida por ser extremamente pequena, extendendo-se a pouco mais de $6 \mathrm{~mm}$ de distância do holograma.

\subsection{Detalhes de implementação}

\subsubsection{FFT real e funções de transferência}

Para calcular a transformada de Fourier do holograma, é altamente recomendável utilizar a versão da FFT para matrizes reais, que aproveita a simetria existente no espectro para diminuir consideravelmente o tempo de processamento e o uso de memória. Com isso, não é possível utilizar a versão original da função de transferência, pois ela é a transformada de Fourier de uma matriz de 


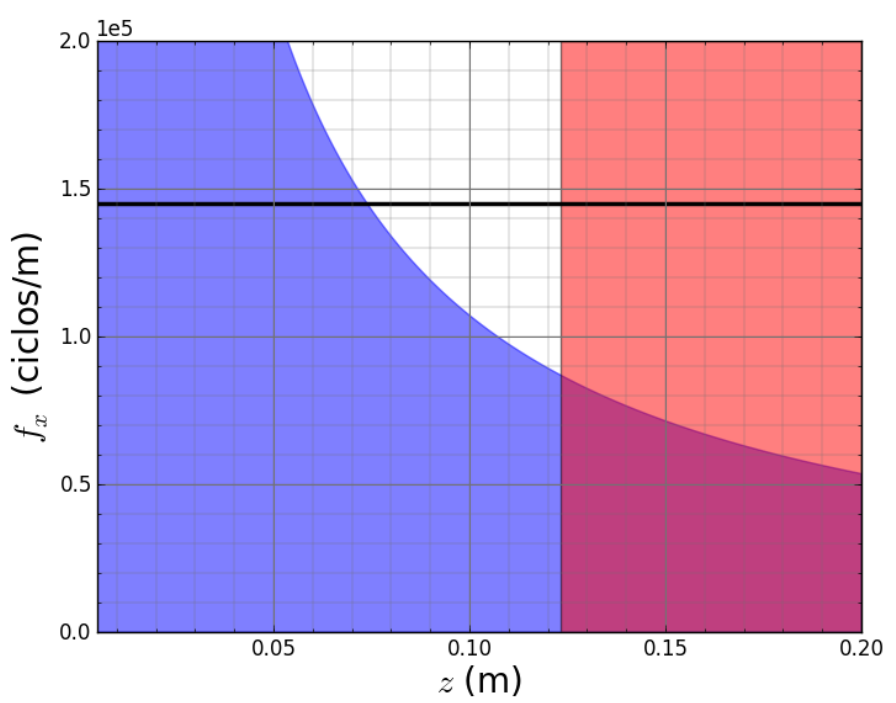

Figura 3.10: Exemplo numérico das frequências presentes em um holograma com $\lambda=660 \mathrm{~nm}$, L= $7,0725 \mathrm{~mm}$ e $\Delta x=3,45 \mu \mathrm{m}$. A linha horizontal preta é a frequência de Nyquist, a região azul representa as frequências que satisfazem a equação 3.7 e fazem parte da reconstrução, e a região vermelha é a área em que a integração do pixel pode ser ignorada segundo a equação 3.8.

números complexos. Portanto, para obter os mesmos resultados é necessário separá-la em termos de seno e cosseno, e realizar as convoluções separadamente, somando os resultados no final. Ou seja, para obter a reconstrução $I_{r e c}$ a partir do holograma $I_{\text {holo }}$, calculamos

$$
I_{\text {rec }}=\operatorname{IFFT}_{\text {real }}\left(I_{\mathrm{FFT}} \cdot H_{\mathrm{cos}}\right)+1 j \cdot \operatorname{IFFT}_{\text {real }}\left(I_{\mathrm{FFT}} \cdot H_{\mathrm{sin}}\right)
$$

onde $I_{\mathrm{FFT}}=\mathrm{FFT}_{\text {real }}\left(I_{\text {holo }}\right), H_{\mathrm{cos}}=\operatorname{Re}\left[H_{f}\right]$ e $H_{\sin }=\operatorname{Im}\left[H_{f}\right]$. Note que, por se tratar da transformada de Fourier de uma matriz real, uma das dimensões terá metade do tamanho da imagem original, e os índices da função de transferência devem percorrer apenas os valores não negativos nesta dimensão.

Se supusermos que o objeto de interesse possui apenas absorção da luz, não afetando a fase da onda, podemos aproximar a magnitude calculando apenas a parte real da convolução, ou seja, utilizamos apenas a função de transferência $H_{\text {cos }}$.

\subsubsection{Sobreposição espacial}

Ao realizar a convolução através da FFT, estamos calculando uma convolução circular, o que pode ter resultados indesejados se não forem tomados certos cuidados. Como a iluminação do feixe de laser normalmente é bem maior do que a área do sensor, padrões de interferência de objetos que não estão diretamente à frente da câmera acabam criando padrões na área do sensor. Uma situação similar pode ocorrer se estivermos reconstruindo apenas uma região do holograma, que pode conter a interferência de objetos próximos desta região. O resultado é que, ao reconstruir o holograma utilizando uma convolução circular, objetos que estão logo à direita da área à frente da câmera acabam sendo parcialmente reconstruídos na região esquerda do holograma, aparecendo como "imagens fantasmas". Algo análogo ocorre nas outras bordas, e objetos que são cortados pela borda continuam na borda oposta, de forma mais fraca e menos detalhada. Os efeitos da convolução circular podem ser vistos nas imagens de algumas publicações $\left[\mathrm{CVM}^{+} 11, \mathrm{SBB}^{+} 08\right]$ e na figura 3.11 .

A FFT supõe que estamos calculando a transformada de Fourier de uma função periódica, e o efeito disso é que, ao calcularmos a difração como uma convolução, de um ponto de vista físico estamos calculando a difração de uma parede formada por infinitas cópias do holograma lado a lado. Lembrando da análise apresentada na seção 3.1.3, vemos que as frequências mais altas destas cópias acabam sobrepostas na reconstrução, causando a perda da qualidade da imagem descrita 


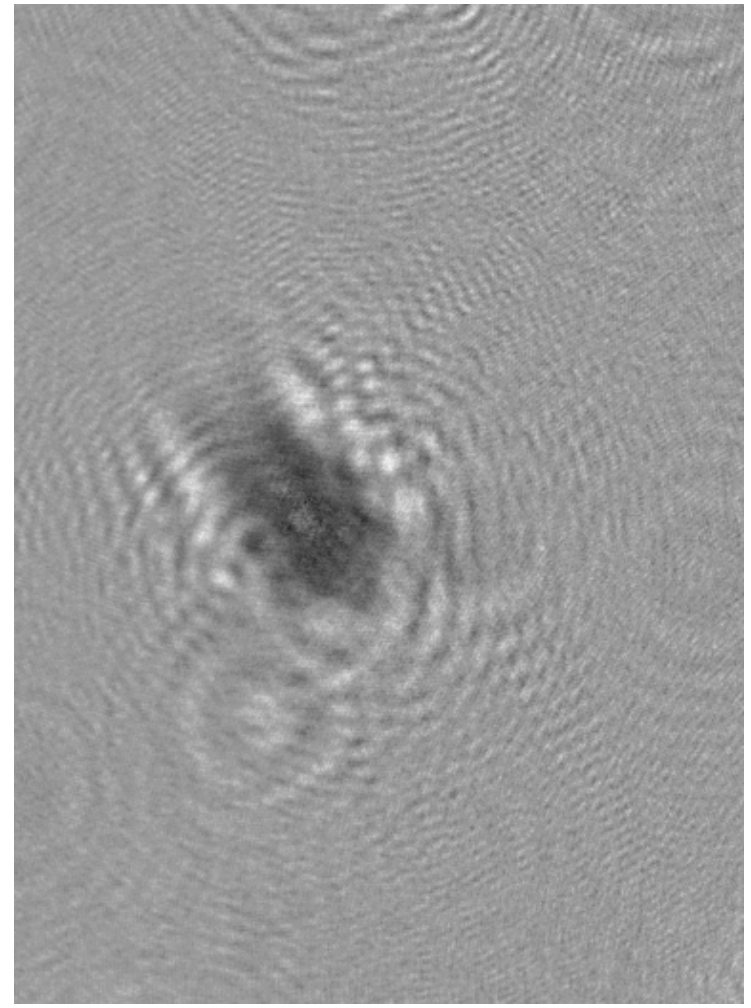

(a) Holograma

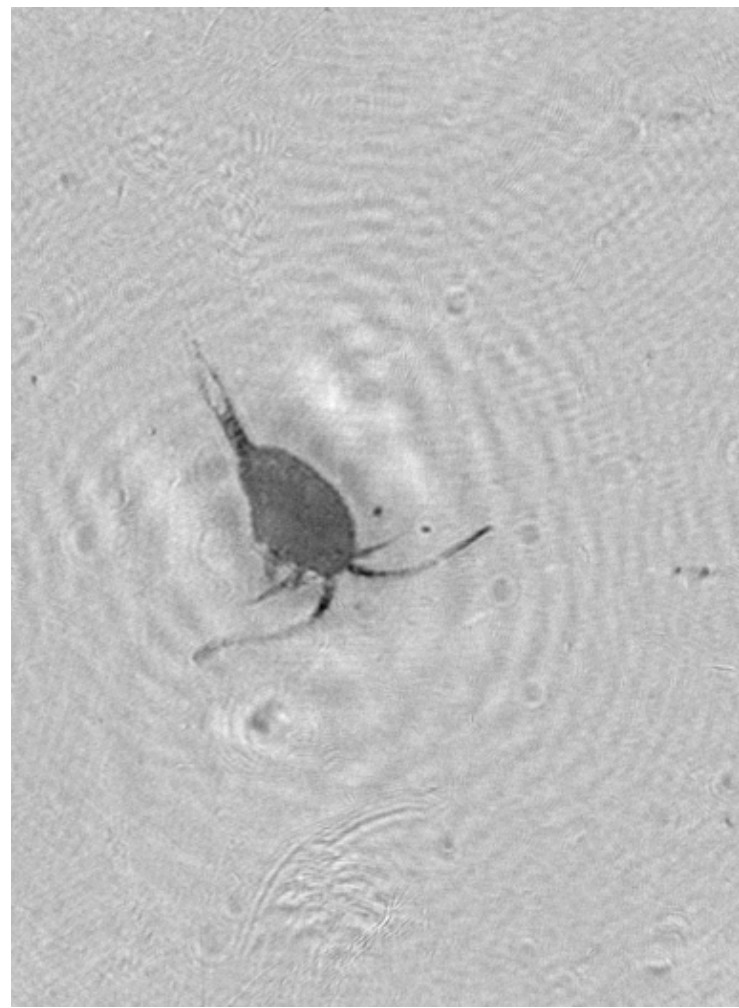

(b) Reconstrução com "imagem fantasma"

Figura 3.11: Reconstrução holográfica com sobreposição espacial. No holograma existem ondas de difração de outro organismo na parte superior da imagem, que provocam o surgimento de uma "imagem fantasma" deste organismo na parte inferior da reconstrução.

acima. Note que na reconstrução pela integração de Fresnel, como o tamanho dos pixels diminui de forma inversamente proporcional à propagação da frequência de Nyquist, esta sobreposição não ocorre neste algoritmo.

Para diminuir o efeito destas sobreposições, uma abordagem é aumentar o holograma com zeros, deixando-o com tamanho suficiente para que nenhuma frequência se afaste a ponto de causar problemas [Kel14, KFK12]. Porém, com o aumento da distância isso provoca um aumento computacional considerável, e uma abordagem mais razoável é a combinação da adição de zeros com um filtro passa-baixa.

Para calcular a convolução linear, podemos fazer com que o holograma fique com o triplo do tamanho adicionando zeros, e calculamos a função de transferência como sendo a transformada de Fourier de

$$
h_{R}(x, y)=\frac{e^{j k z}}{j \lambda z} \exp \left[j \frac{k}{2 z}\left(x^{2}+y^{2}\right)\right] \operatorname{rect}\left(\frac{x}{2 L_{X}}\right) \operatorname{rect}\left(\frac{y}{2 L_{Y}}\right),
$$

com $L_{X}$ e $L_{Y}$ sendo iguais ao tamanho original do holograma nos dois eixos. Note que estamos usando a aproximação de Fresnel.

Podemos evitar o cálculo da transformada de Fourier de $h_{R}(x, y)$ fazendo algumas aproximações. As frequências locais de $h_{R}(x, y)$ são

$$
f_{l X}=\frac{x}{\lambda z} \operatorname{rect}\left(\frac{x}{2 L_{X}}\right), \quad \quad f_{l Y}=\frac{y}{\lambda z} \operatorname{rect}\left(\frac{y}{2 L_{Y}}\right) .
$$

Portanto, podemos aproximar o espectro de Fourier de $h_{R}(x, y)$ calculando $H_{f}(x, y)$, como definida na equação 3.5, e aplicando um filtro para suprimir frequências maiores do que

$$
f_{l X}^{\mathrm{MAX}}=\frac{L_{X}}{\lambda z}, \quad \quad f_{l Y}^{\mathrm{MAX}}=\frac{L_{Y}}{\lambda z} .
$$




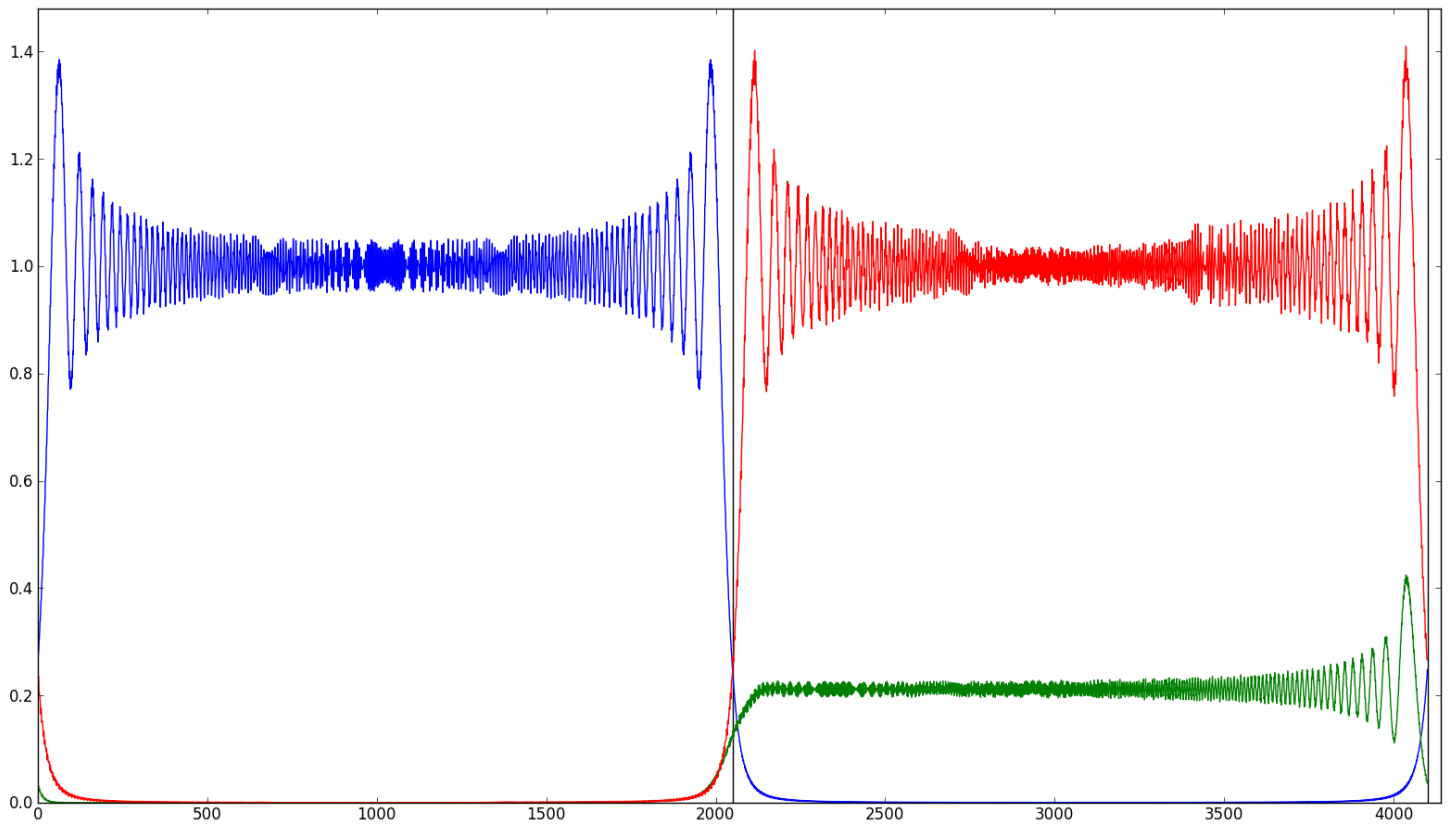

Figura 3.12: Exemplo numérico da propagação das frequências de um holograma, utilizando um filtro para suprimir frequências acima de $f_{c}=\frac{L}{\lambda z}$. Os parâmetros utilizados foram $\lambda=660 \mathrm{~nm}, L=7,0725 \mathrm{~mm}$, $z=10 \mathrm{~cm}$ e $\Delta x=3,45 \mu \mathrm{m}$. Foram propagados dois hologramas: o de uma onda plana (constante igual a 1), e o de uma onda com frequência igual a $f_{c}$. Adicionou-se zeros para duplicar o tamanho do holograma, e esta região adicional, demarcada com linhas verticais pretas, é exibida no lado direito da figura. A curva azul mostra a intensidade da difração da onda plana, e a curva verde mostra a intensidade da difração da onda de frequência $f_{c}$. Em vermelho, é possível ver a intensidade da difração da onda de frequência $f_{c}$, sem a utilização de nenhum filtro passa-baixa.

Esta condição é igual à da equação 3.7, e devido à análise da propagação das frequências, podemos adicionar zeros no holograma para que tenha apenas o dobro do tamanho, e não o triplo, sem que isso cause muita degradação na reconstrução.

Na figura 3.12 é possível ver o efeito de aplicar um filtro passa-baixa, no caso uma janela de Tukey, para suprimir frequências acima de $f_{c}=L /(\lambda z)$. No lado esquerdo da figura aparecem os efeitos da convolução circular. Embora a onda propagada sem o filtro, em vermelho, tenha uma intensidade considerável na borda esquerda, a onda filtrada, em verde, possui uma intensidade extremamente baixa. Na borda direita da região sendo propagada, que aparece demarcada por uma linha vertical no centro da figura, é possível ver que as ondas em verde e vermelho possuem intensidades muito próximas, exceto nos cerca de 25 pixels finais, em que a onda em verde acaba tendo uma intensidade menor devido ao filtro. Todas as difrações foram calculadas com a aproximação de Fresnel, e a falta de simetria na onda em vermelho provavelmente se deve à baixa taxa de amostragem da função de transferência, assunto que será tratado em uma seção posterior.

\subsubsection{Efeito de borda}

Ao reconstruir o holograma, o resultado é não apenas a difração da imagem formada no sensor da câmera, mas também a difração da abertura retangular que limita esta região. Isto gera artefatos indesejáveis, como ilustrado na figura 3.13. Trataremos deste assunto com detalhes no Capítulo 4.

\subsubsection{Amostragem}

A função de transferência $H_{f}\left(f_{X}, f_{Y}\right)$ apresenta frequências que aumentam conforme a distância ao centro, e pode sofrer problemas de amostragem caso estas frequências ultrapassem a frequência de Nyquist. Como na aproximação de Fresnel os dois eixos são separáveis, faremos a análise do caso unidimensional, e as mesmas fórmulas serão válidas no caso bidimensional para os dois eixos. A 


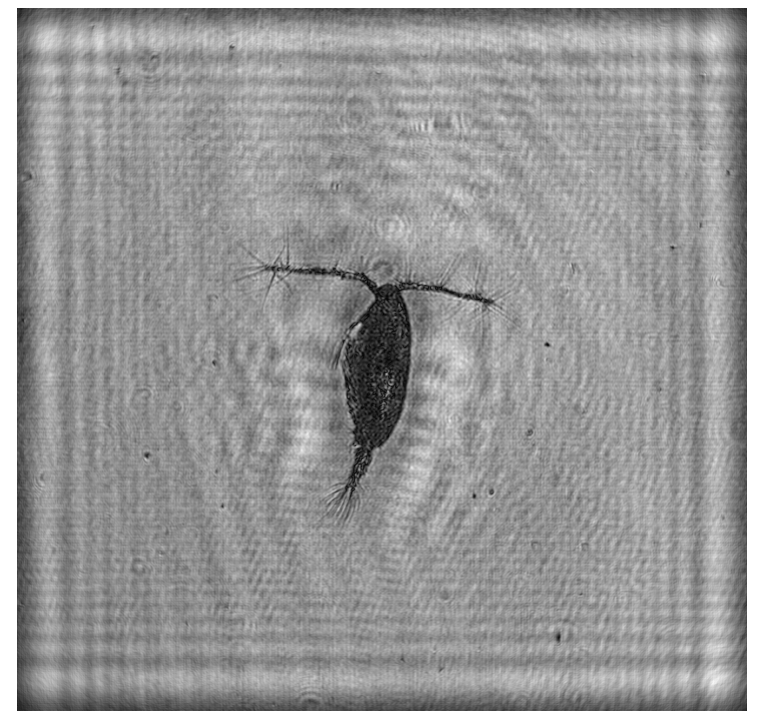

(a) Reconstrução de holograma estendido com zeros

Figura 3.13: Efeito da borda na reconstrução holográfica. A reconstrução exibe os efeitos da difração da borda, pois no cálculo da convolução o holograma foi estendido com zeros.

frequência local de $H_{f}\left(f_{X}\right)$ é

$$
f_{l X}=-\lambda z f_{X} .
$$

Note que $f_{l X}$ refere-se à frequência local de $H_{f}$, enquanto que $f_{X}$ refere-se à frequência do espectro de $h_{f}$.

Para satisfazer o critério de amostragem, é preciso que [VR09]

$$
\left|\lambda z f_{X}\right|<\frac{1}{2 \Delta f_{X}}
$$

Supondo que o tamanho do holograma foi duplicado com zeros, e sua largura original é $L$, temos

$$
\Delta f_{X}=\frac{1}{2 L} .
$$

Logo, precisamos satisfazer

$$
\left|\lambda z f_{X}\right|<L
$$

Supondo que $z, \lambda \geq 0$,

$$
\left|f_{X}\right|<\frac{L}{\lambda z}
$$

Ou seja, temos novamente a equação 3.7 .

Para satisfazer esta equação, podemos suprimir as frequências mais altas, o que foi sugerido no método conhecido como "Band-Limited Angular Spectrum" [MS09], que trata do algoritmo do Espectro Angular, não da Aproximação de Fresnel. Alguns artigos posteriores sugerem melhorias adicionais $\left[\mathrm{YXY}^{+} 12, \mathrm{YXH}^{+} 12\right]$.

Observando a amostragem de $H_{f}$, poderíamos argumentar que, caso uma distância $z$ viole a condição acima, é possível calcular várias propagações a distâncias menores, que separadamente não violam esta condição, e que somadas resultam na distância $z$ desejada. Observando a fórmula da função de transferência $H_{f}$, fica óbvio que isto não iria alterar em nada o resultado, exceto possivelmente por alguns pequenos erros numéricos. A propagação por distâncias menores múltiplas vezes já foi sugerida na literatura [Kre02, Syp95], embora outros artigos digam que esta abordagem apresenta os mesmos problemas [VR09], ou os troca por novos tipos de erros [MS09], dependendo dos detalhes de implementação. 
Também é interessante observar o caso em que

$$
f_{\mathrm{NYQ}}<\frac{L}{\lambda z}
$$

o que ocorre a pequenas distâncias de propagação, ou seja, quando

$$
z<\frac{L 2 \Delta x}{\lambda}
$$

Se observarmos a função $h_{f}$, vemos que sua frequência local é

$$
f_{l X}=\frac{x}{\lambda z},
$$

e para satifazer o critério de amostragem é necessário que

$$
\frac{x}{\lambda z}<\frac{1}{2 \Delta x} .
$$

Como estamos calculando $h_{f}$ em uma região de largura $2 L$, o valor máximo de $x$ é $L$, e portanto a distância $z$ precisa satisfazer

$$
z>\frac{L 2 \Delta x}{\lambda}
$$

Ou seja, quando temos uma superamostragem de $H_{f}$, a função $h_{f}$ está subamostrada, e vice-versa [VR09].

A função $H_{f}$ pode ser interpretada como uma função chirp [Goo96] multiplicada por uma janela retangular, limitando sua extensão ao domínio em que a frequência de Nyquist não é ultrapassada. A Transformada Inversa de Fourier de $H_{f}$ é, aproximadamente, uma função chirp em que a magnitude é próxima de 1 em uma região finita, e próxima de 0 nas demais regiões [Goo96, VR09]. Conforme a distância $z$ diminui, a Transformada Inversa de Fourier de $H_{f}$ corresponde aproximadamente a um chirp de duração finita cada vez menor, não violando a condição de amostragem de $h_{f}$. Do ponto de vista da convolução, ao calcularmos a propagação utilizando $H_{f}$, o tamanho finito da função $h_{f}$ correspondente limita os ângulos de difração sendo calculados. Utilizando a discussão anterior sobre a propagação das frequências, podemos calcular o ângulo máximo de difração na aproximação de Fresnel como sendo [DC06]

$$
\theta_{\mathrm{MAX}}=\arctan \left(\frac{f_{\mathrm{NYQ}} \lambda z}{z}\right)=\arctan \left(\frac{\lambda}{2 \Delta x}\right) .
$$

Como exemplo, quando temos $\lambda=660 \mathrm{~nm}$ e $\Delta x=3.45 \mu \mathrm{m}$, o ângulo máximo de difração é $\theta_{\text {MAX }} \approx 0.095$ radianos, ou cerca de $5.45^{\circ}$. Isso significa que os ângulos de difração sendo calculados são pequenos o suficiente para que a aproximação de Fresnel seja válida, obtendo resultados muito próximos aos do método do Espectro Angular, mesmo a pequenas distâncias. O método do Espectro Angular só apresentaria diferenças significativas em relação à Aproximação de Fresnel caso $\lambda$ seja maior ou aproximadamente igual a $\Delta x$, o que não ocorre com o comprimento de onda usado em holografia de plâncton e a tecnologia atual de sensores CCD (não estamos considerando o caso de microscopia holográfica).

A tese de Domínguez-Caballero [DC06] considera que este ângulo determina uma distância mínima para que um objeto possa ser observado, de forma que não ocorra aliasing. Porém, a distâncias menores do que a recomendada na tese, este aliasing apenas causaria a perda de detalhes mais finos, que também não seriam gravados a uma distância maior, e possivelmente uma pequena degradação na imagem. A distâncias extremamente curtas, a proximidade da imagem gêmea provavelmente seria muito mais problemática do que o aliasing. Realizamos experimentos nos quais foram gravadas imagens a distâncias menores do que a recomendada na tese citada, sem que isso provocasse nenhuma perda perceptível na qualidade da imagem. 


\subsection{Segmentação de região de interesse}

Para diminuir o tempo de processamento, o holograma é segmentado em diversas regiões de interesse, cada uma correspondendo idealmente a um único organismo. Esta segmentação envolve duas etapas: primeiro determinamos as coordenadas de um retângulo que envolve o organismo nos eixos $x$ e $y$, e depois determinamos a profundidade $z$ na qual ele se encontra melhor focalizado. Determinar as posições laterais na qual um objeto de interesse se encontra também ajuda a determinar a melhor distância de focalização.

\subsubsection{Reconstrução volumétrica}

Milgram e Li [ML02] sugeriram calcular a média de várias reconstruções em intervalos igualmente espaçados, entre as profundidades $z_{a}$ e $z_{b}$, e segmentar esta reconstrução média. Como isto é uma soma de convoluções onde um dos termos é o holograma, podemos somar as funções de transferência e realizar uma única convolução. E devido à forma da função de transferência, esta soma é uma série de potências que pode ser calculada analiticamente.

Se fizermos os intervalos entre as diferentes reconstruções tender a zero, o resultado é a integral [Loo11]

$$
\begin{aligned}
S K & =\frac{1}{z_{b}-z_{a}} \int_{z_{a}}^{z_{b}} \exp \left(-j \pi \lambda z\left(f_{X}^{2}+f_{Y}^{2}\right)\right) d z \\
& =\frac{\exp \left(-j \pi \lambda z_{b}\left(f_{X}^{2}+f_{Y}^{2}\right)\right)-\exp \left(-j \pi \lambda z_{a}\left(f_{X}^{2}+f_{Y}^{2}\right)\right)}{-j \pi \lambda\left(z_{b}-z_{a}\right)\left(f_{X}^{2}+f_{Y}^{2}\right)} .
\end{aligned}
$$

Observando o termo $\left(f_{X}^{2}+f_{Y}^{2}\right)$ do denominador, podemos ver que isso tem o efeito de um filtro passa-baixa, o que ajuda a visualizar objetos maiores e elimina oscilações rápidas e objetos muito pequenos.

Se considerarmos apenas a parte real da função de transferência, temos

$$
\begin{aligned}
S K_{\mathrm{REAL}} & =\frac{1}{z_{b}-z_{a}} \int_{z_{a}}^{z_{b}} \cos \left(\pi \lambda z\left(f_{X}^{2}+f_{Y}^{2}\right)\right) d z \\
& =\frac{\sin \left(\pi \lambda z_{b}\left(f_{X}^{2}+f_{Y}^{2}\right)\right)-\sin \left(\pi \lambda z_{a}\left(f_{X}^{2}+f_{Y}^{2}\right)\right)}{\pi \lambda\left(z_{b}-z_{a}\right)\left(f_{X}^{2}+f_{Y}^{2}\right)} .
\end{aligned}
$$

Supondo que $z_{a}=0$,

$$
\begin{aligned}
S K_{\mathrm{REAL}} & =\frac{\sin \left(\pi \lambda z_{b}\left(f_{X}^{2}+f_{Y}^{2}\right)\right)}{\pi \lambda z_{b}\left(f_{X}^{2}+f_{Y}^{2}\right)} \\
& =\operatorname{sinc}\left(\lambda z_{b}\left(f_{X}^{2}+f_{Y}^{2}\right)\right) .
\end{aligned}
$$

O holograma médio é então

$$
I_{\text {medio }}=I_{\text {holo }} * S K
$$

onde * denota convolução.

A imagem $I_{\text {medio }}$ é segmentada aplicando uma limiarização adaptativa. Primeiro a imagem é normalizada linearmente para o intervalo [0,255]. Então um filtro gaussiano com um valor elevado para $\sigma$ é aplicado, e a diferença entre a imagem filtrada e a original é limiarizada, utilizando um valor estático determinado experimentalmente. A esta segmentação são adicionados pixels com intensidades muito baixas na imagem $I_{\text {medio, }}$ pois a limiarização adaptativa acaba desconsiderando grandes regiões com baixa intensidade. Por fim, esta segmentação sofre uma pequena dilatação binária e objetos muito próximos da borda são removidos. 


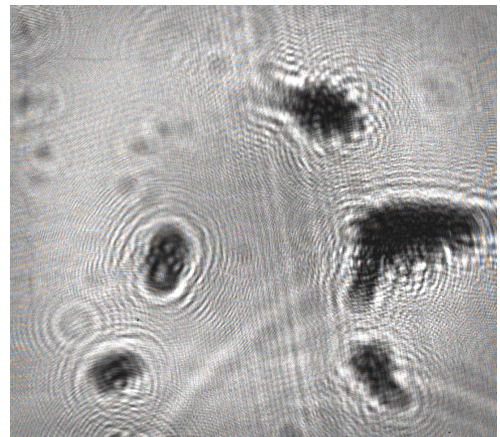

(a) Holograma original

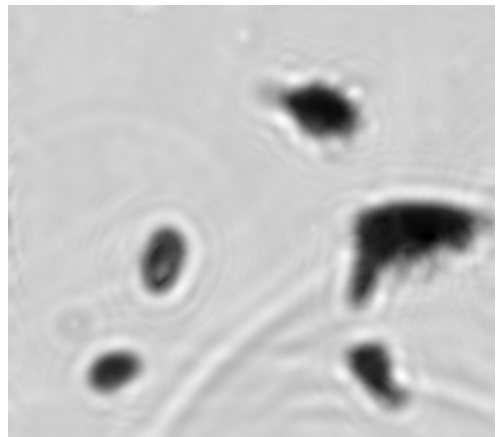

(b) Holograma médio

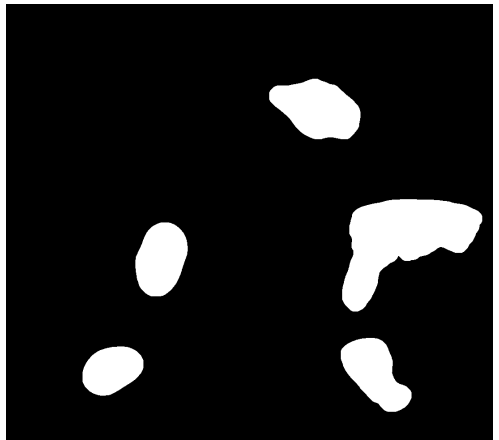

(c) Holograma segmentado

Figura 3.14: Segmentação de um holograma em regiões de interesse. O holograma médio foi calculado após a remoção do fundo do holograma original.

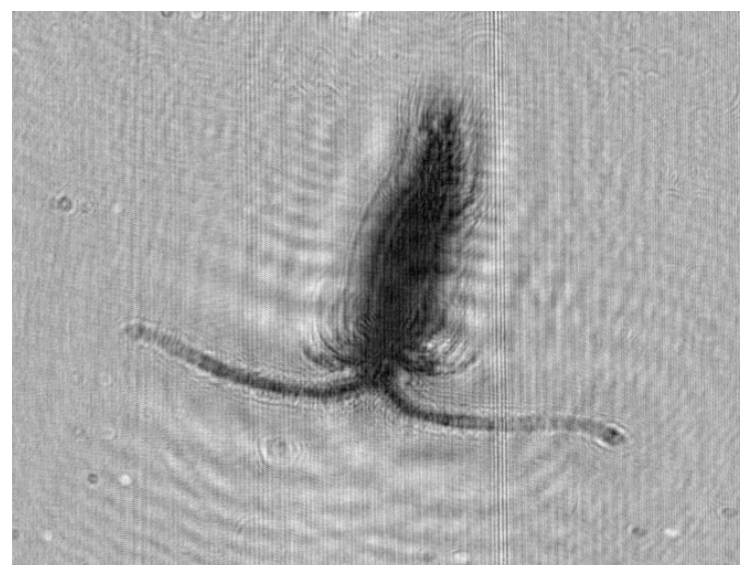

(a) Holograma não focalizado

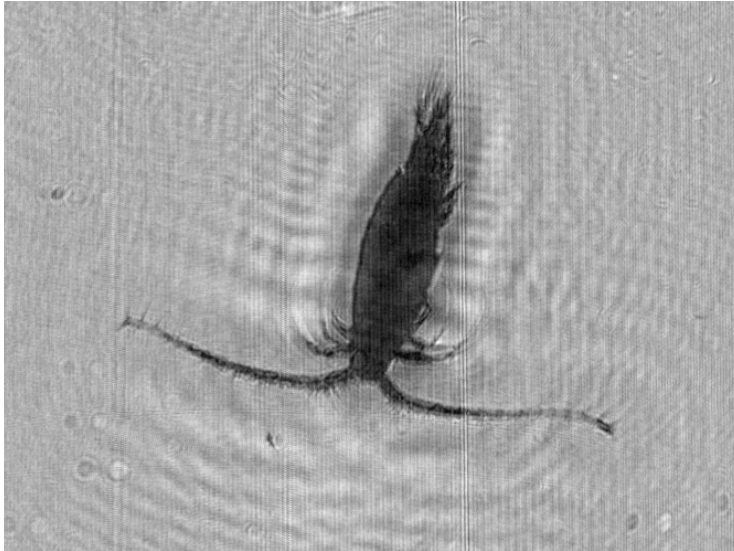

(b) Holograma focalizado

Figura 3.15: Focalização de um holograma segundo a medida de entropia. O holograma foi reconstruído a várias distâncias, e a imagem à direita é a que obteve o melhor foco, minimizando a entropia.

\subsubsection{Focalização}

Para calcular a melhor distância de focalização, uma região com 4 vezes a largura e altura segmentadas é reconstruída a várias distâncias, desde uma distância mínima $z_{a}$ até uma distância máxima $z_{b}$, que dependem das distâncias usadas no experimento. Em cada reconstrução, é aplicada uma medida de foco na região que foi segmentada originalmente. A imagem que maximiza (ou minimiza) esta medida é considerada a melhor focalização, e à região originalmente segmentada é adicionada uma borda fixa adicional de 50 pixels, determinada experimentalmente. A adição desta borda fixa é para evitar o corte excessivo de pequenos detalhes dos organismos, como as antenas, pois estas não podem ser detectadas na reconstrução volumétrica. O uso de uma região 4 vezes maior em largura e altura para a reconstrução tem o objetivo de não perder muita qualidade, pois como foi visto a dimensão lateral usada influencia diretamente nas frequências e detalhes presentes.

Várias medidas de foco podem ser usadas, e fazemos uma comparação experimental no Capítulo 5 .

\subsection{Segmentação Final}

Cada região focalizada é novamente segmentada, para determinar o formato e localização do organismo na imagem. A segmentação é similar à das regiões de interesse, com uma limiarização adaptativa, adição de pixels com intensidades muito baixas, e uma abertura morfológica. Isto pode gerar vários segmentos, e apenas o de maior área é considerado. Caso o maior segmento possua um centróide muito próximo da borda, ou uma área total muito pequena, esta imagem é desconsiderada 


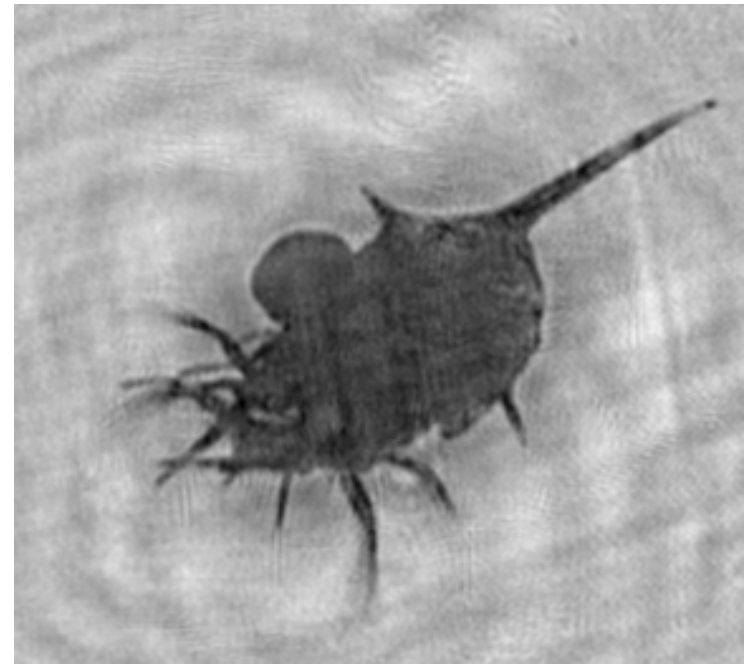

(a) Reconstrução focalizada

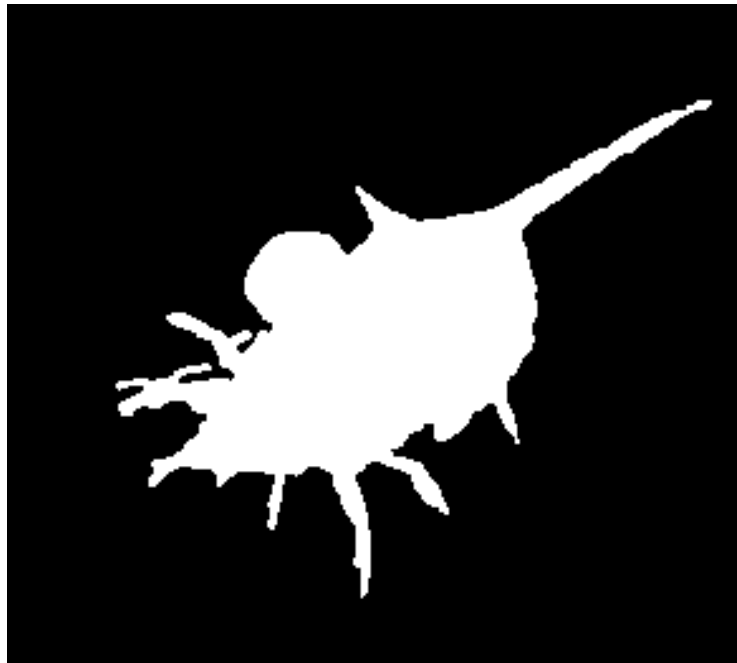

(b) Segmentação

Figura 3.16: Segmentação final de uma região de interesse focalizada.

por se tratar de um erro de segmentação, não contendo nenhum organismo de interesse. Um exemplo de segmentação pode ser visto na figura 3.16.

A partir desta segmentação poderiam ser extraídas várias características da região, e usadas em um classificador automático, determinando o tipo de organismo planctônico presente na imagem. Porém, não tratamos da classificação de organismos plânctonicos neste trabalho, deixando para um trabalho futuro.

\subsection{Outras considerações}

\subsubsection{Custo computacional}

Não foram feitas medidas do custo computacional das diferentes etapas de processamento, mas sabe-se que o maior gasto de tempo decorre do cálculo da FFT e sua inversa, que em uma imagem de tamanho $N \times N$ gasta $O\left(N^{2} \log N\right)$ operações. Cálculos como a limiarização da imagem possuem custo $O\left(N^{2}\right)$.

Para reduzir o tempo de processamento, uma estratégia é diminuir o número de transformadas de Fourier que precisam ser calculadas, ou diminuir o tamanho de cada uma. A segmentação inicial do holograma em regiões de interesse segue esta ideia, pois cada segmento costuma ser significativamente menor do que a imagem total, diminuindo o tempo de processamento da reconstrução. Ainda assim, a reconstrução de cada segmento a diferentes distâncias gasta um tempo considerável.

Outra opção é paralelizar o processamento, já que, exceto na obtenção do holograma da imagem de fundo, todos os hologramas podem ser processados separadamente, e muitos dos cálculos podem ser feitos de forma paralela. A implementação de parte do processamento em uma GPU já obteria ganhos de tempo consideráveis [Loo11], embora esteja fora do escopo deste trabalho.

\subsubsection{Processamentos adicionais}

Além dos processamentos que foram realizados, existem vários outros que podem ser aplicados para melhorar a qualidade das imagens obtidas. Embora a imagem gêmea não cause problemas em alguns casos, quando temos uma maior quantidade de objetos sendo observados a imagem reconstruída de um objeto não terá apenas o ruído de sua própria imagem gêmea, mas também das imagens gêmeas de todos os outros objetos próximos. Existem diversas técnicas para diminuir o efeito da imagem gêmea, e um resumo de várias delas pode ser visto no artigo de Hennelly et al. [HKPM09]. 


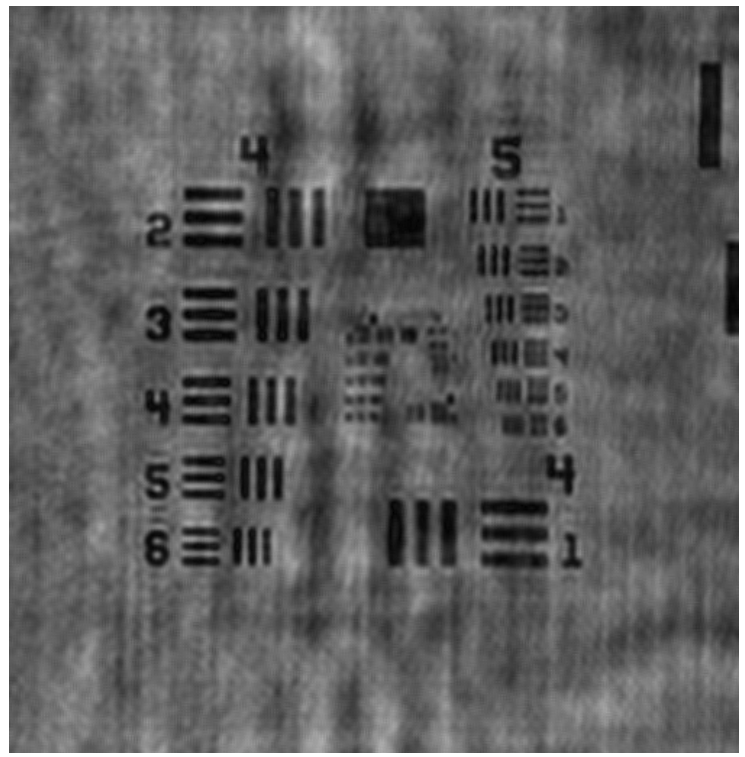

(a) Reconstrução padrão

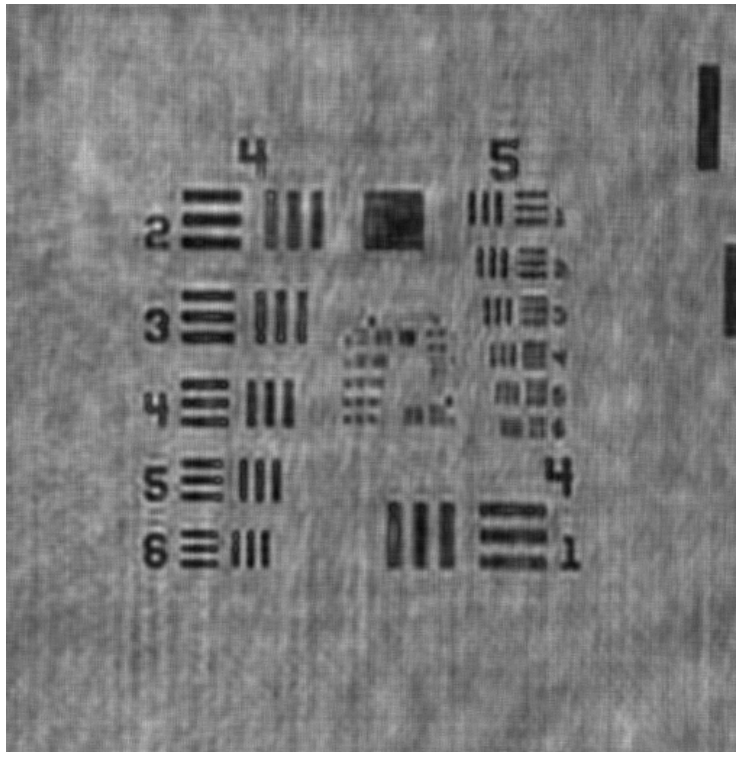

(b) Supressão da imagem gêmea

Figura 3.17: Ilustração do efeito da imagem gêmea. A segunda imagem foi calculada a partir da primeira, realizando-se uma limiarização, propagando-se esta imagem binarizada para calcular uma estimativa da imagem gêmea, e subtraindo esta imagem gêmea da imagem original. Com isso, podemos ter uma ideia do efeito da imagem gêmea na qualidade da reconstrução, principalmente em imagens como esta, em que existem vários elementos de tamanho razoável bloqueando a passagem da luz. Apenas a área central da reconstrução de um teste de resolução 1951 USAF é exibida.

Também existe o efeito de objetos fora de foco, que pode aparecer sobre objetos focalizados em outro plano. Para tentar resolver este problema foi sugerido que objetos focalizados sejam segmentados e removidos do holograma, para que no processamento dos outros objetos eles não apareçam desfocados [MDYL05].

Como é possível construir imagens focalizadas a várias distâncias, e normalmente várias destas imagens possuem informações importantes que aparecem fora de foco nos outros planos, na área de microscopia holográfica foi sugerido que se usasse uma medida de foco para combinar várias imagens a distâncias diferentes, formando uma única imagem que seria estudada sem precisar mudar o foco constantemente para observar outras características do objeto $\left[\mathrm{BCP}^{+} 09\right]$. Porém, isto foi feito para organismos transparentes, e faltam estudos sobre a aplicação desta ideia em organismos opacos.

Para tentar melhorar a qualidade da imagem reconstruída e a localização de partículas, foram propostas formas de realizar a desconvolução complexa de um volume formado pela reconstrução do holograma a diversas distâncias. Porém, as técnicas propostas parecem obter resultados melhores para partículas do que para objetos extensos [LGF10, DCG11].

Por fim, é importante ressaltar que várias destas técnicas estão intimamente relacionadas, com algoritmos de desconvolução sendo aplicados tanto para remover a imagem gêmea quanto para melhorar a localização de partículas e a qualidade das imagens individuais de um volume; imagens reconstruídas a diferentes profundidades sendo usadas para realizar a desconvolução, mas também para criar uma única imagem melhor focalizada; e algoritmos que alternam entre diferentes planos sendo aplicados na remoção da imagem gêmea e também em segmentações que diminuem os efeitos de interferência entre os diferentes objetos. O artigo de Denis et al. [DFFD08] unifica alguns algoritmos de remoção de imagem gêmea sob o ponto de vista da desconvolução, além propor um novo algoritmo e observar sua relação estrita com algoritmos de segmentação. 


\section{Capítulo 4}

\section{Efeito de borda}

A propagação do holograma gera efeitos de difração não apenas devido à imagem formada no sensor da câmera, mas também devido à borda do holograma. Neste capítulo, iremos tratar dos diferentes métodos para minimizar os efeitos de difração pela borda nas reconstruções holográficas.

\subsection{Introdução}

No caso mais simples, onde o holograma é formado por uma iluminação uniforme e nenhum objeto sendo observado, a reconstrução consiste na difração da luz por uma abertura retangular, pois, assim como na aproximação de Fresnel (2.2.3), supomos na simulação numérica que a luz é bloqueada na região exterior ao holograma. No caso de um organismo sendo reconstruído, temos como resultado a combinação da imagem deste organismo com a difração da luz pela borda do holograma. Isto gera diversos efeitos indesejáveis, alterando a fase e amplitude da imagem reconstruída de forma brusca, o que diminui a qualidade da imagem, dificulta a observação dos organismos e pode afetar o resultado de algoritmos de focalização e segmentação.

Na figura 4.1 é possível comparar duas reconstruções, nas quais o holograma original foi estendido para o dobro de sua largura e altura utilizando diferentes métodos. Na primeira imagem, o holograma é estendido preenchendo a área adicional com zeros, enquanto que na segunda imagem essa extensão é feita com a média do holograma, apresentando efeitos de difração pela borda bem menos visíveis. Na figura 3.12 também é possível ver o efeito da borda na intensidade da reconstrução, neste caso em apenas uma dimensão, o que torna o efeito ainda mais evidente. A intensidade original é igual a 1 em todas as curvas, mas ocorrem rápidas oscilações com a propagação, que são exibidas na figura.

Para resolver este problema, na área de óptica costuma-se utilizar a técnica conhecida como apodização, e que corresponde na área de processamento de sinais à aplicação de uma janela. Esta janela torna a borda do holograma mais suave, evitando que ela contenha muitas frequências altas, que são as mais problemáticas. Cuche et al. [CMD00] sugerem uma janela similar à de Tukey, mas usando interpolação por uma função spline cúbica. Zhang et al. [ZFL $\left.{ }^{+} 13\right]$ propõem uma outra janela, calculada a partir da convolução da função retângulo com uma janela cosseno, e otimizando os parâmetros.

Porém, técnicas de apodização e suas equivalentes digitais geram novas complicações, pois reduzem a visibilidade da região da borda, removendo informação da reconstrução que poderia ser recuperada sem a janela. Para evitar esta perda de informação, existe uma alternativa digital que seria de difícil execução através de instrumentos ópticos: pode-se estender o holograma artificialmente, adicionando-se pixels na região externa que extrapolam o que foi observado. Isto deve ser feito sem que surjam frequências altas, para evitar o aparecimento de artefatos. A forma mais simples de extrapolar o holograma é utilizando a média no lugar de zeros na região externa. Dyomin et al. [DO08] fazem uma aproximação por uma função spline bicúbica para estender o holograma, e Dubois et al. [DMYL02] propõem um método de estender o holograma minimizando frequências espaciais altas. 


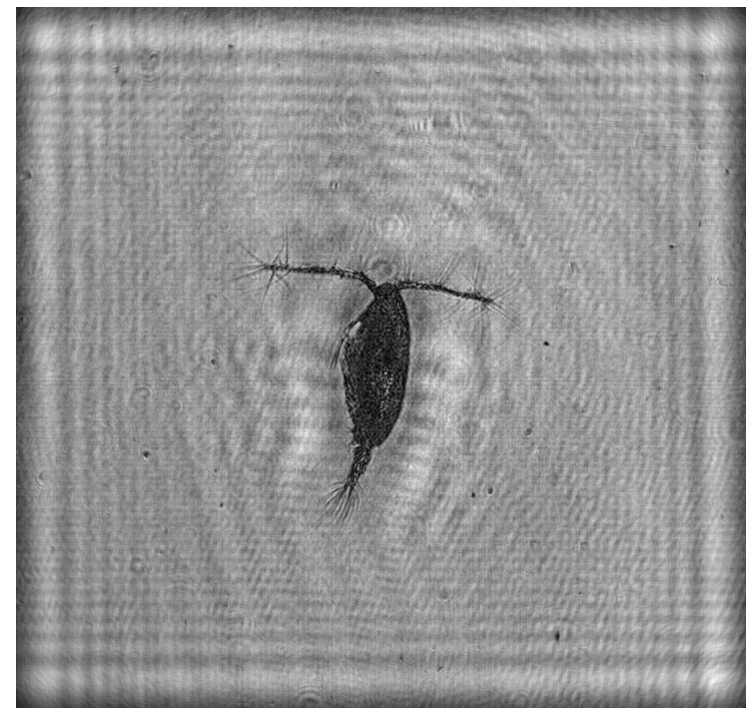

(a) Holograma estendido com zeros

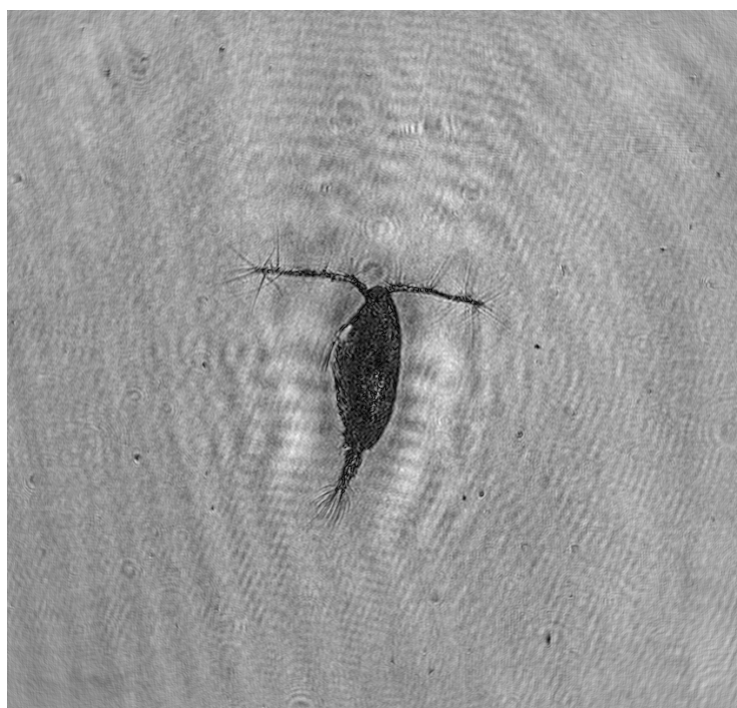

(b) Holograma estendido com a média

Figura 4.1: Efeito da borda na reconstrução holográfica. A primeira reconstrução exibe os efeitos da difração da borda, pois no cálculo da convolução o holograma foi estendido com zeros. Na segunda reconstrução, o holograma foi estendido com a média, apresentando efeitos menos significativos devido à borda.

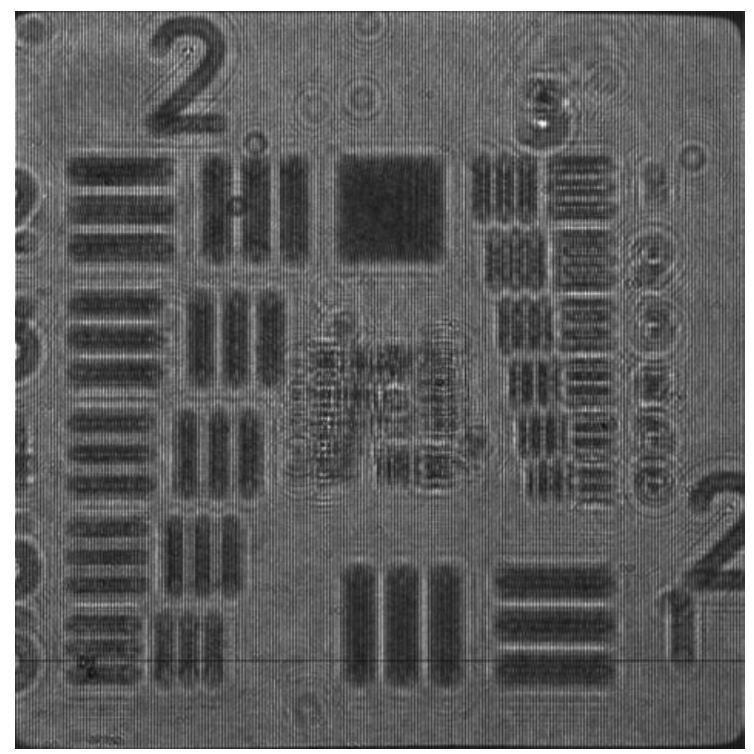

(a) Holograma original

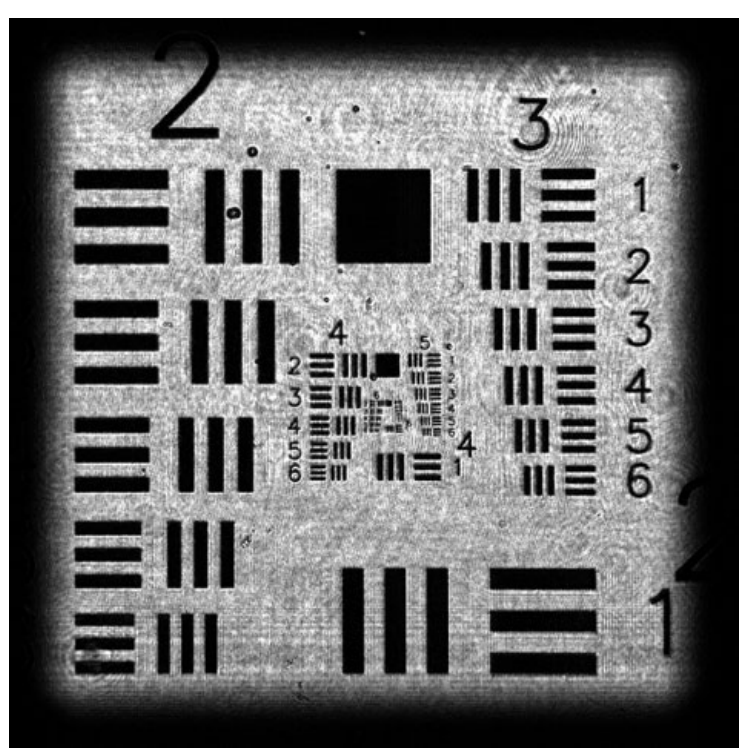

(b) Holograma reconstruído com apodização

Figura 4.2: Apodização do holograma para evitar efeito da borda. É possível ver que a aplicação da janela remove informação da região próxima à borda que está presente no holograma original. (Imagens obtidas do artigo de Kebbel et al. [KHJ01]) 


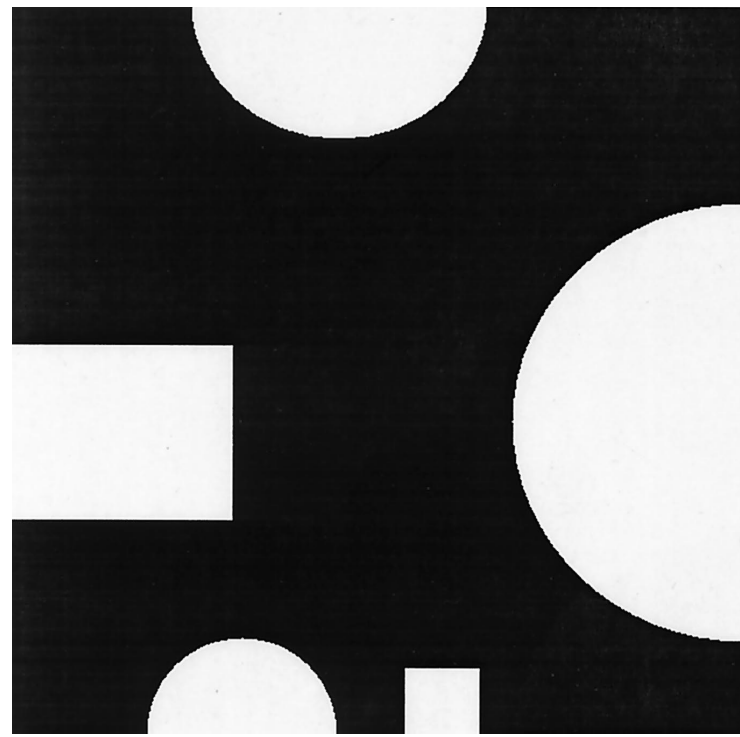

(a) Imagem original

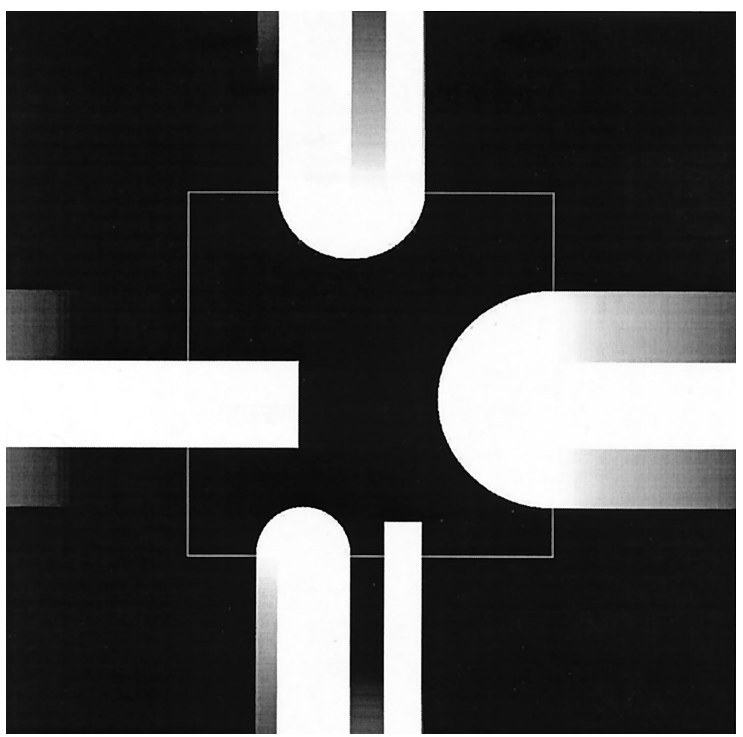

(b) Imagem estendida

Figura 4.3: Extensão de holograma para evitar efeito da borda, utilizando o algoritmo proposto por Dubois et al. O quadrado na segunda imagem indica a área original que foi estendida. (Imagens obtidas do artigo de Dubois et al. [DMYL02])

Por fim, pode-se combinar as duas ideias e estender o holograma e aplicar uma janela nesta extensão. Zhang et al. $\left[\mathrm{ZZF}^{+}\right.$09] estendem o holograma copiando os valores da borda, o que é computacionalmente mais eficiente do que calcular a extensão proposta por Dubois et al., e então aplicam uma janela para diminuir o efeito destes novos valores, mas sem afetar a área original do holograma. Com isso, resolve-se o problema da baixa visibilidade na região da borda, que ocorre com a simples aplicação de uma janela, e do elevado custo computacional, que ocorre em extensões mais elaboradas.

Porém, não está claro qual método resulta nos menores erros, pois vários artigos exibem apenas uma comparação visual entre a extensão sendo proposta e a extensão com zeros, ou nenhuma extensão [DMYL02, $\mathrm{ZZF}^{+}$09]. Assim, fazemos a seguir uma comparação experimental de diversos métodos para avaliar os resultados obtidos e a complexidade computacional.

\subsection{Métodos}

Todos os métodos recebem um holograma de tamanho $M \times N$ e devolvem um holograma estendido de tamanho $2 M \times 2 N$, onde os pixels de $[0,0]$ a $[M-1, N-1]$ são idênticos aos do holograma original. Ou seja, trataremos aqui apenas de métodos que preenchem os pixels adicionais do holograma estendido, sem modificar os valores presentes na região original do holograma.

Também poderíamos considerar métodos que aplicam uma janela ao holograma, fazendo os valores da borda diminuirem gradativamente de magnitude até o valor zero. A aplicação de uma janela poderia remover a necessidade de estender o holograma, o que seria desejável pois esta extensão aumenta o custo computacional da reconstrução. Mas, conforme discutido anteriormente, para evitar os efeitos de reconstruções "fantasmas" é necessário estender o holograma antes de reconstruí-lo, ou seja, a aplicação da janela não seria suficiente e ainda seria necessário estender o holograma com zeros. Estes métodos não trariam ganhos computacionais, além de remover informação presente na borda e, por estes motivos, métodos que alterem a região original do holograma não serão analisados.

A seguir listamos as extensões de borda que serão comparadas. 


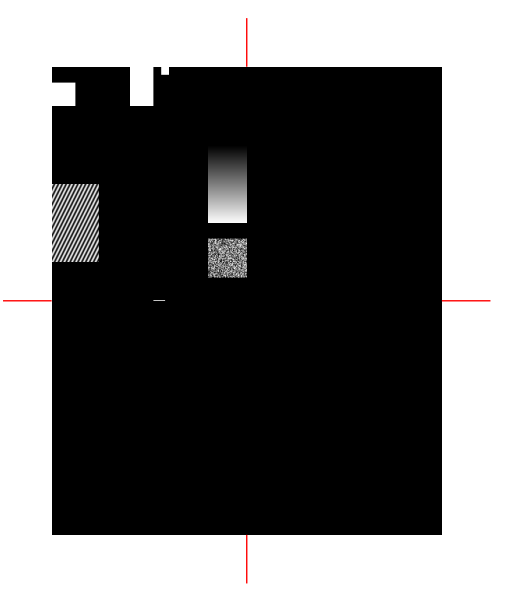

(a) Zeros

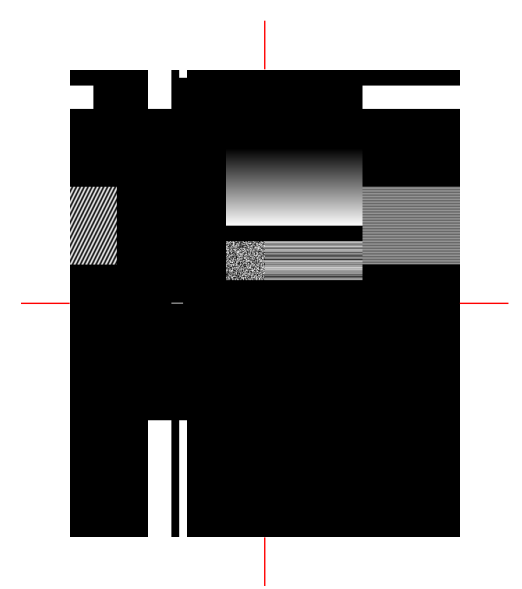

(d) Mediana da borda

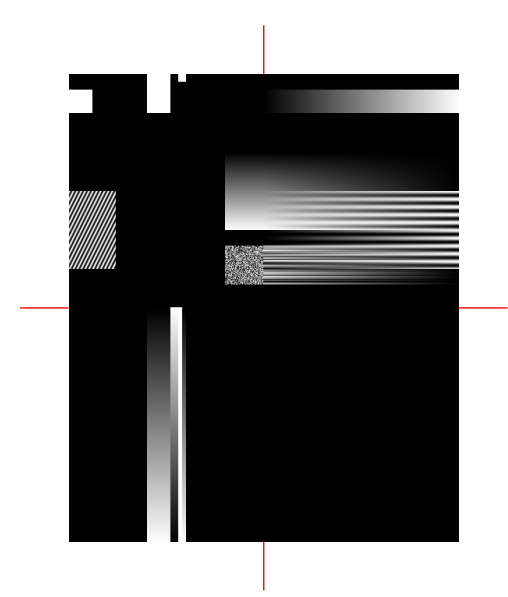

(g) Rampa linear circular

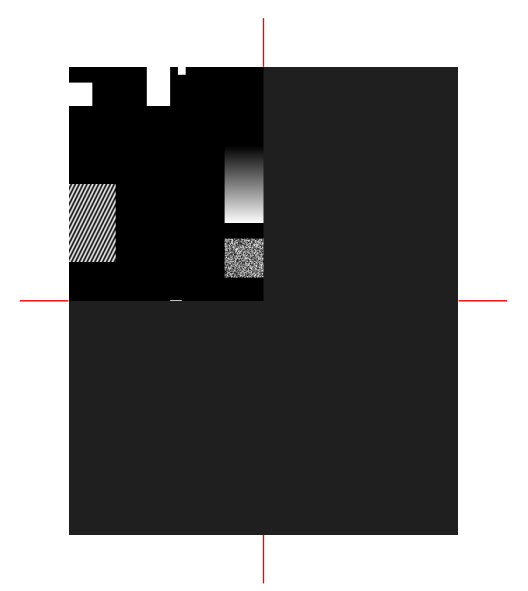

(b) Média

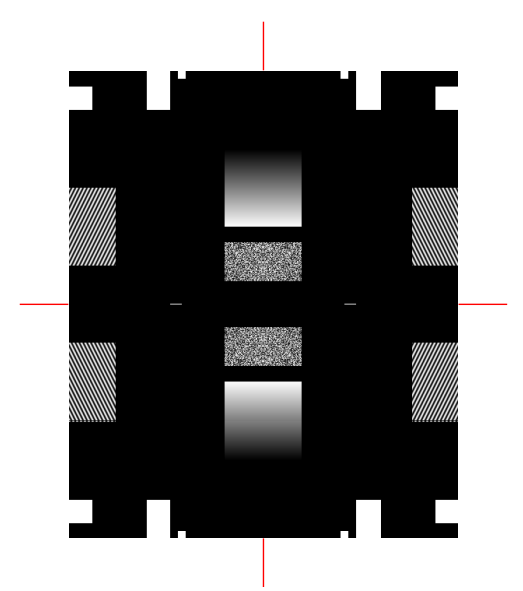

(e) Reflexão

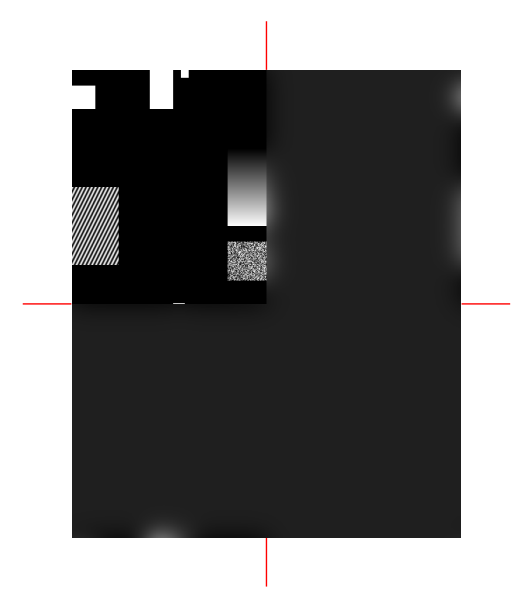

(h) Filtro gaussiano com $\sigma=16$

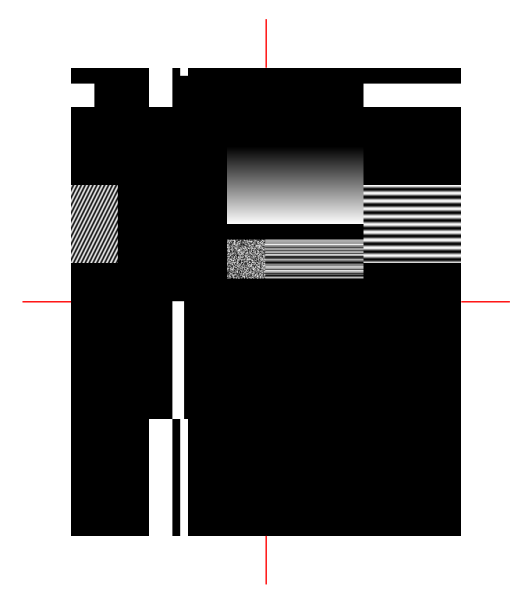

(c) Cópia da borda

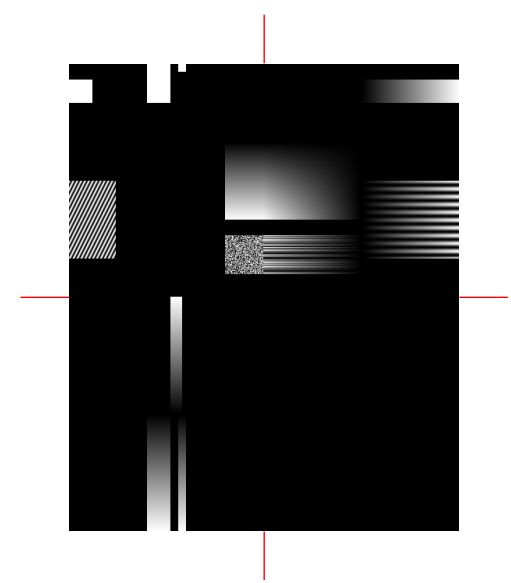

(f) Rampa linear

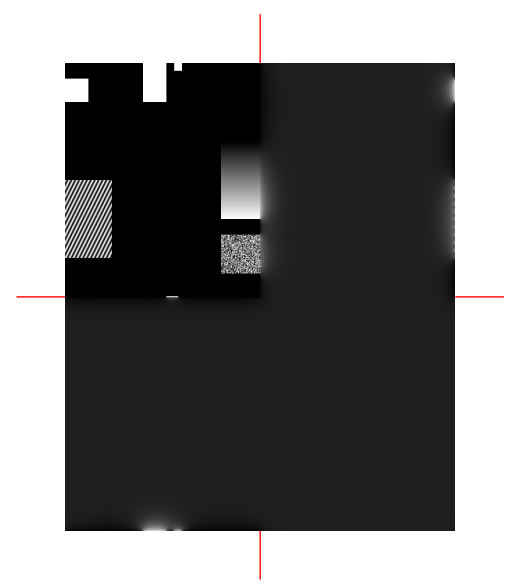

(i) Filtro gaussiano iterativo

Figura 4.4: Métodos de extensão de borda. A região superior esquerda contém a imagem original de tamanho $N \times N$, e as três regiões restantes, também de tamanho $N \times N$ cada uma, contêm a extensão da borda. 


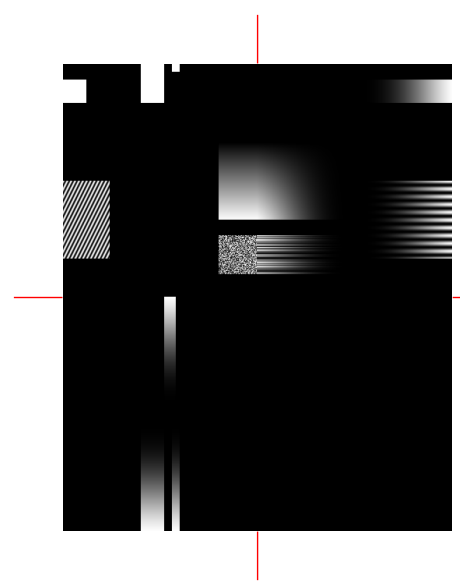

(a) Rampa linear com janela de Tukey

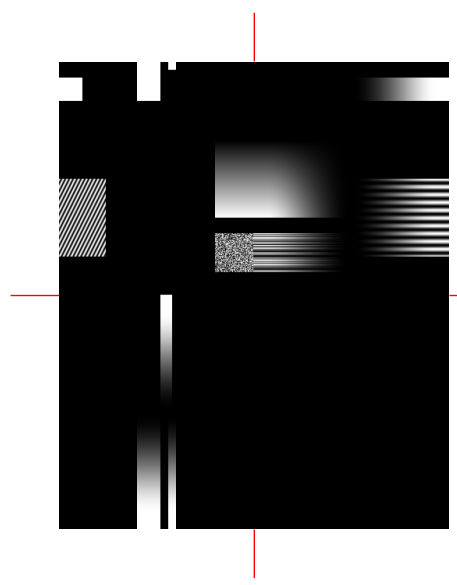

(b) Cópia da borda com janela Spline

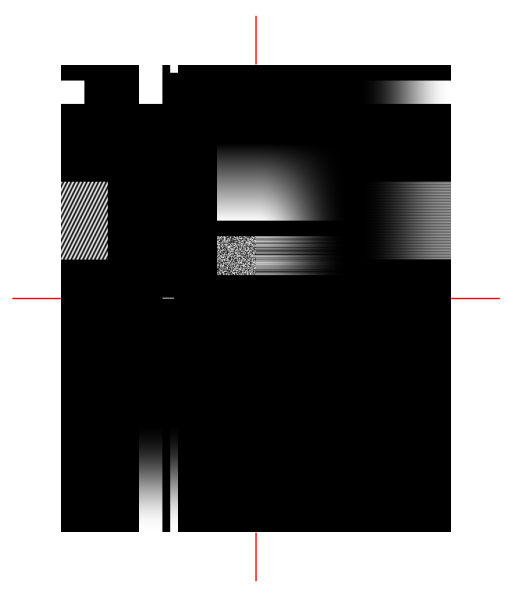

(c) Mediana com janela de cosseno

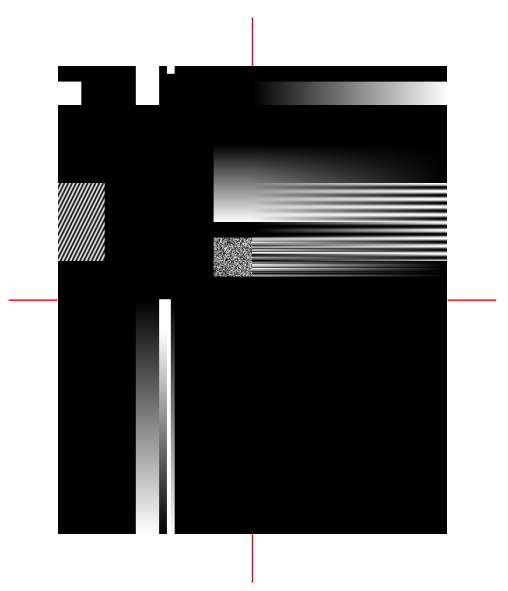

(d) Minimização de frequências al-

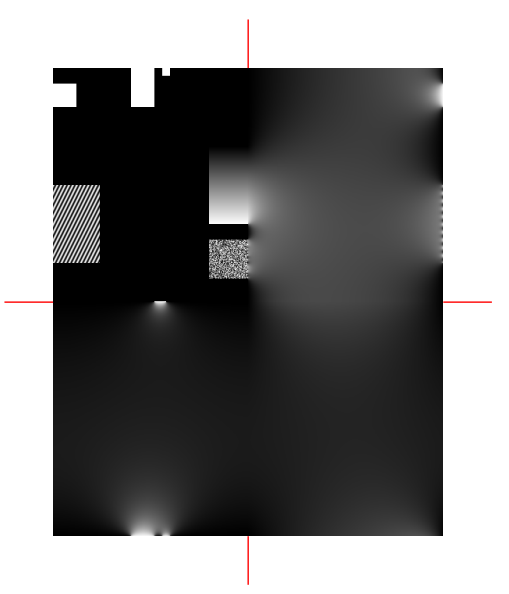

(e) Minimização do Laplaciano

Figura 4.5: Métodos de extensão de borda. A região superior esquerda contém a imagem original de tamanho $N \times N$, e as três regiões restantes, também de tamanho $N \times N$ cada uma, contêm a extensão da borda. 


\subsubsection{Zeros}

Esta é uma das extensões mais simples, que apenas preenche os pixels adicionais com o valor 0.

\subsubsection{Média}

Outra extensão simples, preenchendo os pixels adicionais com a média da imagem.

\subsubsection{Cópia da borda}

Os pixels de cada uma das quatro bordas são copiados. Ou seja, a primeira e a última coluna são copiadas à esquerda e à direita da imagem, e a primeira e última linhas são copiadas acima e abaixo da imagem, respectivamente. Isto pode provocar uma descontinuidade no local da imagem em que estas novas bordas estendidas se encontram, porém ela ocorre a uma certa distância do holograma original.

\subsubsection{Mediana da borda}

Similar à cópia da borda, mas ao invés de utilizar o valor do primeiro e último pixel de cada linha e coluna, utiliza os valores das medianas dos primeiros e últimos $k$ pixels de cada linha e coluna. Assim como na cópia da borda, pode provocar uma descontinuidade no encontro destas novas bordas, pois a mediana dos primeiros pixels em geral é diferente da mediana dos últimos pixels de uma mesma linha ou coluna. A mediana é usada para tentar diminuir o efeito do ruído da imagem na extensão da borda.

\subsubsection{Reflexão}

A imagem é refletida em torno das bordas. Embora isto possa diminuir a descontinuidade na borda, faz com que apareçam reconstruções "fantasmas" sobre a imagem.

\subsubsection{Rampa linear}

Similar à cópia da borda, mas os valores dos pixels vão diminuindo gradativamente de magnitude até o valor 0 , de forma linear. Assim, não ocorre uma descontinuidade no encontro destas novas bordas, pois nesta região ambas possuem o valor 0 .

\subsubsection{Rampa linear circular}

É feita uma rampa linear entre os valores do primeiro e último pixel de cada linha e coluna. Desta forma, a extensão faz com que a última coluna se transforme gradativamente na primeira coluna da imagem, de forma linear, e o mesmo ocorre com a primeira e a última linha.

\subsubsection{Filtro gaussiano}

A imagem é inicialmente estendida com sua média, e então é aplicado um filtro gaussiano com parâmetro $\sigma$. Após aplicar o filtro, a região correspondente à imagem sendo estendida é restaurada aos seus valores originais.

\subsubsection{Filtro gaussiano iterativo}

A imagem é inicialmente estendida com sua média, e então é aplicado um filtro gaussiano de forma iterativa. Para um parâmetro $\sigma$, a i-ésima iteração aplica o filtro gaussiano com $\sigma_{i}=\frac{\sigma}{2^{i}}$, $i=0 \ldots\left\lfloor\log _{2}(\sigma)+1\right\rfloor$, e então substitui os valores na região da imagem original pelos do holograma não estendido. Por causa desta substituição da área do holograma original a cada iteração, este método não é equivalente a aplicar um único filtro gaussiano com o parâmetro $\sigma$ apropriado. 


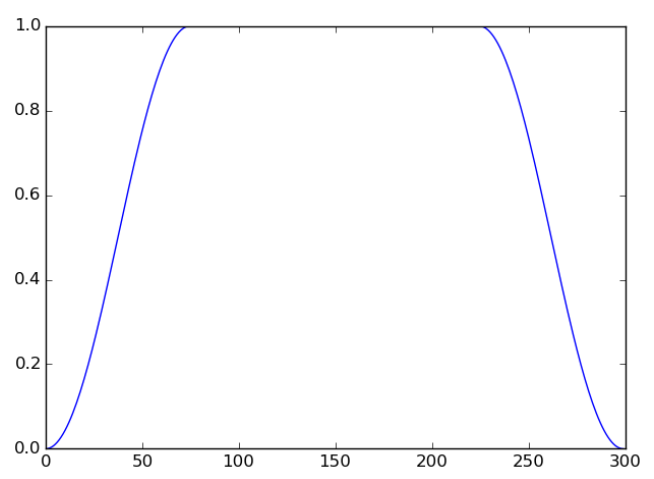

Figura 4.6: Janela de Tukey para $\alpha=0.5$.

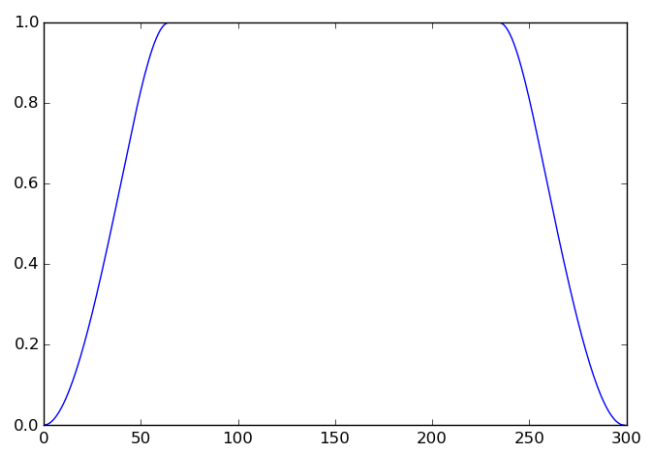

Figura 4.7: Janela de spline cúbica. Os parâmetros utilizados foram $x_{0}=0, x_{1}=42, x_{2}=65, T\left(x_{0}\right)=0$, $T\left(x_{1}\right)=0.65, T\left(x_{2}\right)=1, T^{\prime}\left(x_{0}\right)=0$ e $T^{\prime}\left(x_{2}\right)=0$.

\subsubsection{Rampa linear com janela de Tukey}

Após realizar a extensão com a rampa linear, é aplicada uma janela de Tukey na imagem estendida.

A janela de Tukey com parâmetro $\alpha$ é

$$
\text { Tukey }(x)= \begin{cases}\frac{1}{2}\left\{1+\cos \left(\frac{2 \pi}{\alpha}\left[x-\frac{\alpha}{2}\right]\right)\right\} & \text { se } 0 \leq x<\frac{\alpha}{2} \\ 1 & \text { se } \frac{\alpha}{2} \leq x<1-\frac{\alpha}{2} \\ \frac{1}{2}\left\{1+\cos \left(\frac{2 \pi}{\alpha}\left[x-1+\frac{\alpha}{2}\right]\right)\right\} & \text { se } 1-\frac{\alpha}{2} \leq x \leq 1\end{cases}
$$

\subsubsection{Cópia da borda com janela Spline}

Após realizar a extensão com a cópia da borda, é aplicada uma janela de spline cúbica na imagem estendida. Esta janela utiliza interpolação por uma spline cúbica nas regiões de transição entre os valores 0 e 1 .

A função interpolada $T(x)$, utilizada no lado esquerdo (começo) da janela, é definida pelos pontos $\left\{x_{0}, x_{1}, x_{2}\right\}$, os valores $T\left(x_{0}\right), T\left(x_{1}\right), T\left(x_{2}\right)$ e as derivadas $T^{\prime}\left(x_{0}\right)$ e $T^{\prime}\left(x_{2}\right)$. A spline espelhada é utilizada no lado direito (final) da janela, e os valores no trecho entre as duas splines são iguais a 1.

Maiores detalhes sobre esta janela podem ser encontrados no artigo de Cuche et al. [CMD00]. 


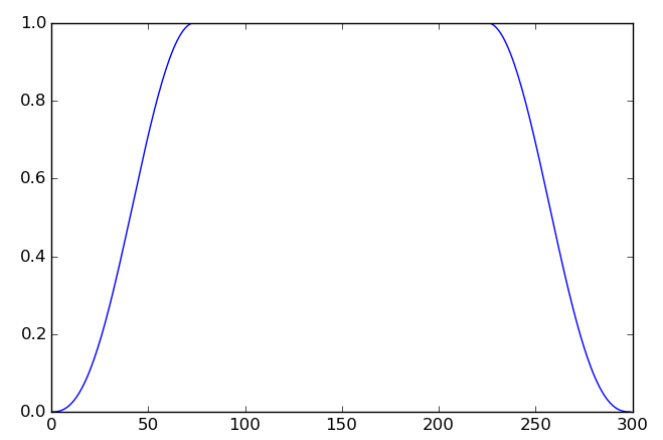

Figura 4.8: Janela de cosseno com $k=2.5, L_{0}=150, L=300$.

\subsubsection{Mediana com janela de cosseno}

Após realizar a extensão com a mediana, é aplicada uma janela de cosseno na imagem estendida. Esta janela com parâmetro $k$ é definida como

$$
W(l)= \begin{cases}\cos ^{k}\left[a\left(\frac{2 l}{L-L_{0}}-1\right)\right] & \text { se } 1 \leq l<\frac{L-L_{0}}{2} \\ 1 & \text { se } \frac{L-L_{0}}{2}+1 \leq l<\frac{L+L_{0}}{2} \\ \cos ^{k}\left[b\left(\frac{2 l}{L+L_{0}+2}-1\right)\right] & \text { se } \frac{L+L_{0}}{2} \leq l \leq L\end{cases}
$$

onde $L_{0}$ e $L$ são os números de pixels horizontais ou verticais no holograma original e no holograma estendido, respectivamente. Os valores $a$ e $b$ são definidos como

$$
a=-\frac{\pi}{2} \cdot \frac{L-L_{0}}{L_{0}+2-L}, \quad b=\frac{\pi}{2} \cdot \frac{L+L_{0}+2}{L-L_{0}-2} .
$$

Maiores detalhes sobre esta janela podem ser encontrados no artigo de Zhang et al. [ZZF $\left.{ }^{+} 09\right]$.

\subsubsection{Minimização de frequências altas}

Para criar uma extensão de borda suave, pode-se minimizar as frequências mais altas do holograma estendido, como é sugerido por Dubois et al. [DMYL02]. Iremos apresentar apenas uma ideia do algoritmo, que envolve o cálculo de diversas matrizes, e os detalhes podem ser encontrados no artigo citado.

Seja $w^{\prime}$ o vetor de uma linha ou coluna do holograma estendido, com a restrição de que a região original do holograma não pode ser modificada. Queremos minimizar

$$
\Phi=a\left|W^{\prime}(0)\right|^{2}+\sum_{U=1}^{N-1} U^{2}\left|W^{\prime}(U)\right|^{2}+\sum_{U=N}^{2 N-1}(2 N-U)^{2}\left|W^{\prime}(U)\right|^{2},
$$

onde $W^{\prime}(U)$ são os componentes da transformada discreta de Fourier de $w^{\prime}(z)$ e $a$ é uma constante real não nula, necessária para a solução do problema matemático. Os dois somatórios estão separados devido à forma cíclica da transformada de Fourier.

Primeiro a linha ou coluna $w^{\prime}$ é estendida com zeros, ficando com tamanho $2 N$, e calcula-se uma matriz $A$ de tamanho $2 N \times 2 N$. O cálculo desta matriz envolve a multiplicação de algumas matrizes de tamanho $\Theta\left(N^{2}\right)$, além do cálculo da inversa de uma matriz de mesmo tamanho. Calculase $W^{\prime}=\mathrm{FFT}\left(w^{\prime}\right)$ e então $G=A W^{\prime}-W^{\prime}$. Por fim, a transformada inversa $g=\operatorname{IFFT}(G)$ é utilizada como o valor final da linha ou coluna sendo estendida. Note que o cálculo de $A$ não depende dos valores da linha ou coluna sendo estendida, mas depende apenas do tamanho $2 \mathrm{~N}$ e do parâmetro $a$ mencionado acima. 


\subsubsection{Minimização do Laplaciano}

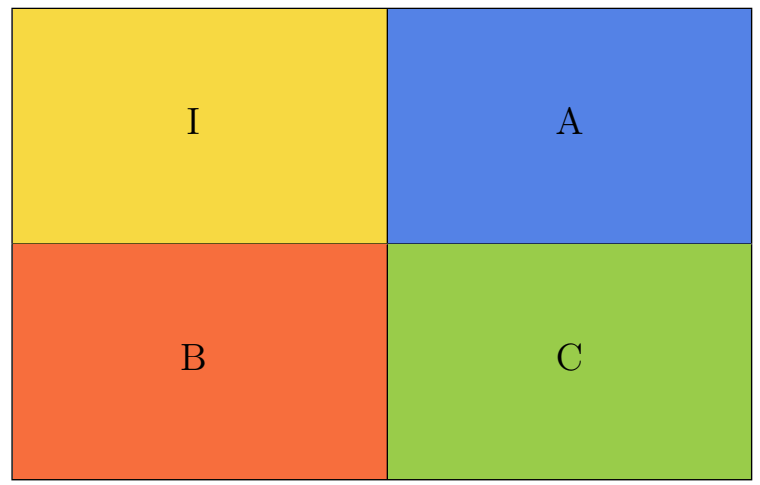

Figura 4.9: Minimização do Laplaciano. A imagem $I$ é estendida calculando-se as regiões $A, B$ e $C$ separadamente.

O artigo de Liu e Jia [LJ08] propõe criar uma extensão suave de borda que minimiza a soma das derivadas parciais de segunda ordem. Para isso, este método minimiza o Laplaciano no interior da extensão, com a restrição de que a borda desta nova região deve ser similar à borda da imagem, garantindo uma transição suave entre a imagem e a extensão. Isto cria uma imagem estendida circular adequada ao uso de algoritmos que dependam do cálculo da FFT da imagem.

A extensão é feita em três regiões separadas: em um bloco A à direita da imagem original; em um bloco B abaixo da imagem original; e em um bloco $\mathrm{C}$ na diagonal, preenchendo a área restante. Detalharemos como obter o bloco $A$, pois os outros podem ser obtidos de forma similar, sendo que o bloco $C$, computado por último, possuirá as quatro bordas restringidas, e não apenas duas bordas opostas como nos blocos $A$ e $B$.

Primeiro é utilizado um filtro gaussiano para suavizar a imagem $I$, de tamanho $M \times N$. Apenas estes valores suavizados serão utilizados no cálculo dos blocos da extensão, mas a imagem final estendida continuará com os valores originais no lugar de $I$. Para obter o bloco $A$, de tamanho $M \times(N+2 \alpha)$, primeiro definimos um bloco $A^{\prime}$, também com tamanho $M \times(N+2 \alpha)$. As primeiras e últimas $\alpha$ colunas de $A^{\prime}$, que formam a borda $\partial A$, são iguais às últimas e primeiras $\alpha$ colunas da imagem suavizada $I$, respectivamente. O método consiste então em resolver o seguinte problema de mínimos quadrados regularizados:

$$
\min \left(\|\Delta A\|^{2}+\lambda\left\|A-A^{\prime}\right\|_{\partial A}^{2}\right)
$$

onde $\Delta \bullet=\frac{\partial^{2} \bullet}{\partial x^{2}}+\frac{\partial^{2} \bullet}{\partial y^{2}}$ é o operador laplaciano, e $\lambda$ é um peso que controla a suavidade do bloco $A$ e sua transição para a imagem $I$. As colunas que formam a borda $\partial A$ são descartadas, resultando em um bloco $A$ de tamanho $M \times N$.

A principal desvantagem do método proposto por Liu e Jia é o alto custo computacional para resolver o problema de mínimos quadrados regularizados. Se este método fosse utilizado no processamento de hologramas digitais, o tempo gasto no cálculo da extensão da borda seria maior do que em todas as outras etapas de processamento juntas. Por este motivo, propomos um novo algoritmo de extensão de borda, que mantém a ideia principal de minimizar o Laplaciano, mas possui um custo computacional consideravelmente menor.

\section{Descrição da extensão proposta}

Criamos uma extensão suave da borda através da minimização do Laplaciano no interior da extensão, com a restrição de que a borda desta região, com 1 pixel de largura, deve ser igual à borda da imagem. Ou seja, comparando com o método proposto por Liu e Jia, fazemos com que $\alpha=1$ e conseguimos obter $\min \left(\|\Delta A\|^{2}+\lambda\left\|A-A^{\prime}\right\|_{\partial A}^{2}\right)=0$. Neste caso, em que a borda $\partial A$ só possui 1 pixel de largura, não calculamos $\Delta A$ nos pixels da borda, mas apenas no interior de $A$, 
onde o operador laplaciano está bem definido e podemos utilizar um pixel e seus 4 pixels adjacentes para calcular a versão discretizada do laplaciano. O artigo de Liu e Jia não deixa claro se o operador laplaciano deve ser calculado nos pixels da borda de $A$ e, em caso afirmativo, qual seria a definição utilizada para lidar com a falta de um dos pixels. Outra diferença é que não aplicamos um filtro gaussiano na imagem antes de realizar a extensão, optando pelo ganho de desempenho em não realizar este passo.

A extensão que propomos também é feita em três regiões separadas. Resolvemos a equação de Laplace no interior do bloco da extensão:

$$
\Delta u=0,
$$

onde $\Delta$ é o Laplaciano. Para o retângulo A (e de forma análoga para B), duas bordas opostas da imagem $I$ determinam a condição de contorno de Dirichlet,

$$
u(i, 0)=I(i, N-1), \quad u(i, N-1)=I(i, 0), \quad i \in\{0, \ldots, M-1\},
$$

e impomos a condição de contorno de Neumann nas duas bordas restantes:

$$
u^{\prime}(0, i)=u^{\prime}(M-1, i)=0, \quad i \in\{0, \ldots, N-1\} .
$$

Note que o método proposto por Liu e Jia não deixa claro qual a restrição que deve ser utilizada nestas duas bordas que não fazem fronteira com a imagem. Dependendo da restrição escolhida e da fórmula utilizada para calcular (ou não) o operador laplaciano nestas bordas, o método de Liu e Jia pode ter diferentes resultados, incluindo casos com infinitas soluções. As restrições que utilizamos nas quatro bordas garantem que a solução é única e escolhemos a condição de contorno de Neumann de forma a obter uma solução suave.

Para o retângulo C, após determinar os valores de A e B é possível impor a condição de contorno de Dirichlet nas quatro bordas.

\section{Método da Transformada de Fourier}

Para o cálculo eficiente da extensão $u$, utilizaremos o Método da Transformada de Fourier [PTVF96]. Primeiro solucionamos a equação mais geral

$$
\frac{\partial^{2} u}{\partial x^{2}}+\frac{\partial^{2} u}{\partial y^{2}}=\rho(x, y)
$$

Note que, se fizermos $\rho(x, y)=0$, teremos a equação de Laplace.

A versão discretizada é

$$
u_{j+1, l}+u_{j-1, l}+u_{j, l+1}+u_{j, l-1}-4 u_{j, l}=\Delta^{2} \rho_{j, l}
$$

onde $\Delta=\Delta x=\Delta y$ é o espaçamento da grade.

Impomos a condição de contorno de Dirichlet $u=0$ nas quatro bordas do retângulo, e calculamos a transformada discreta inversa de seno em duas dimensões

$$
u_{j l}=\operatorname{IDST}(\hat{u})_{j l}=\frac{2}{J} \frac{2}{L} \sum_{m=1}^{J-1} \sum_{n=1}^{L-1} \hat{u}_{m n} \sin \frac{\pi j m}{J} \sin \frac{\pi l n}{L} .
$$

Isto satisfaz as condições $u=0$ em $j=0, J$ e em $l=0, L$.

Utilizando as identidades trigonométricas

$$
\begin{aligned}
& \sin (\alpha+\beta)=\sin \alpha \cos \beta+\cos \alpha \sin \beta \\
& \sin (\alpha-\beta)=\sin \alpha \cos \beta-\cos \alpha \sin \beta
\end{aligned}
$$


obtemos

$$
\begin{aligned}
u_{j+1, l} & =\frac{2}{J} \frac{2}{L} \sum_{m=1}^{J-1} \sum_{n=1}^{L-1} \hat{u}_{m n} \sin \frac{\pi(j+1) m}{J} \sin \frac{\pi l n}{L} \\
& =\frac{2}{J} \frac{2}{L} \sum_{m=1}^{J-1} \sum_{n=1}^{L-1} \hat{u}_{m n}\left[\sin \frac{\pi j m}{J} \cos \frac{\pi m}{J}+\cos \frac{\pi j m}{J} \sin \frac{\pi m}{J}\right] \sin \frac{\pi l n}{L} ; \\
u_{j-1, l} & =\frac{2}{J} \frac{2}{L} \sum_{m=1}^{J-1} \sum_{n=1}^{L-1} \hat{u}_{m n} \sin \frac{\pi(j-1) m}{J} \sin \frac{\pi l n}{L} \\
& =\frac{2}{J} \frac{2}{L} \sum_{m=1}^{J-1} \sum_{n=1}^{L-1} \hat{u}_{m n}\left[\sin \frac{\pi j m}{J} \cos \frac{\pi m}{J}-\cos \frac{\pi j m}{J} \sin \frac{\pi m}{J}\right] \sin \frac{\pi l n}{L} .
\end{aligned}
$$

Portanto,

$$
u_{j+1, l}+u_{j-1, l}=\frac{2}{J} \frac{2}{L} \sum_{m=1}^{J-1} \sum_{n=1}^{L-1} \hat{u}_{m n} 2 \cos \frac{\pi m}{J} \sin \frac{\pi j m}{J} \sin \frac{\pi l n}{L}
$$

e, analogamente,

$$
u_{j, l+1}+u_{j, l-1}=\frac{2}{J} \frac{2}{L} \sum_{m=1}^{J-1} \sum_{n=1}^{L-1} \hat{u}_{m n} 2 \cos \frac{\pi n}{L} \sin \frac{\pi j m}{J} \sin \frac{\pi l n}{L}
$$

Substituindo as equações 4.4 e 4.5 na equação 4.3, e calculando a transformada inversa discreta de seno no lado direito da equação, temos

$$
\frac{2}{J} \frac{2}{L} \sum_{m=1}^{J-1} \sum_{n=1}^{L-1} \hat{u}_{m n} 2\left(\cos \frac{\pi m}{J}+\cos \frac{\pi n}{L}-2\right) \sin \frac{\pi j m}{J} \sin \frac{\pi l n}{L}=\frac{2}{J} \frac{2}{L} \sum_{m=1}^{J-1} \sum_{n=1}^{L-1} \Delta^{2} \hat{\rho}_{m n} \sin \frac{\pi j m}{J} \sin \frac{\pi l n}{L} .
$$

Devido à unicidade da transformada discreta de seno e sua inversa, isto é equivalente a igualar os coeficientes

$$
\begin{array}{r}
\hat{u}_{m n} 2\left(\cos \frac{\pi m}{J}+\cos \frac{\pi n}{L}-2\right)=\Delta^{2} \hat{\rho}_{m n} \\
\hat{u}_{m n}=\frac{\Delta^{2} \hat{\rho}_{m n}}{2\left(\cos \frac{\pi m}{J}+\cos \frac{\pi n}{L}-2\right)} .
\end{array}
$$

O algoritmo para obter $u$ consiste em primeiro calcular $\hat{\rho}=\operatorname{DST}(\rho)$, utilizar a fórmula acima para obter $\hat{u}$, e por fim calcular $u=\operatorname{IDST}(\hat{u})$.

No caso em que $u=0$ em todas as bordas, exceto na borda $x=J \Delta$, em que $u=f(y)$, podemos reescrever $u$ como

$$
u=u^{\prime}+u^{B}
$$

onde $u^{\prime}=0$ na borda; e $u^{B}=0$ em toda a região, exceto na borda, onde possui os valores $f(y)$.

A equação 4.3 torna-se

$$
u_{j+1, l}^{\prime}+u_{j-1, l}^{\prime}+u_{j, l+1}^{\prime}+u_{j, l-1}^{\prime}-4 u_{j, l}^{\prime}=-\left(u_{j+1, l}^{B}+u_{j-1, l}^{B}+u_{j, l+1}^{B}+u_{j, l-1}^{B}-4 u_{j, l}^{B}\right)+\Delta^{2} \rho_{j, l} .
$$

Todos os termos $u^{B}$ desta equação desaparecem, exceto quando $j=J-1$, onde

$$
u_{J, l}^{\prime}+u_{J-2, l}^{\prime}+u_{J-1, l+1}^{\prime}+u_{J-1, l-1}^{\prime}-4 u_{J-1, l}^{\prime}=-f(l)+\Delta^{2} \rho_{J-1, l} .
$$

Como os valores de $f$ são conhecidos, isto é equivalente ao problema anterior com $u=0$ em todas 
as bordas, bastando fazer a substituição

$$
\Delta^{2} \rho_{J-1, l} \rightarrow-f(l)+\Delta^{2} \rho_{J-1, l} .
$$

Podemos utilizar o mesmo raciocínio para impor a condição de contorno de Dirichlet nas quatro bordas ao mesmo tempo, com os valores desejados, bastando fazer as substituições adequadas para os valores de $\rho$.

Consideramos agora o caso em que duas das bordas possuem a condição de contorno de Neumann

$$
\frac{\partial u_{0, l}}{\partial x}=0, \frac{\partial u_{J, l}}{\partial x}=0, \quad l \in\{1, \ldots, L-1\} .
$$

Calculamos a tranformada discreta inversa de cosseno no eixo em que impomos a condição de contorno de Neumann, mantendo a transformada discreta inversa de seno no outro eixo, onde continuaremos impondo a condição de contorno de Dirichlet:

$$
u_{j l}=\frac{2}{J} \frac{2}{L} \sum_{m=0}^{J} \sum_{n=1}^{\prime \prime} \hat{u}_{m n} \cos \frac{\pi j m}{J} \sin \frac{\pi l n}{L},
$$

onde as linhas duplas no somatório indicam que o primeiro e o último termo (quando $m=0$ e $m=J$ ) devem ser multiplicados por $\frac{1}{2}$.

Os cálculos são análogos aos realizados para a condição de contorno de Dirichlet. Utilizamos as identidades trigonométricas

$$
\begin{aligned}
\cos (\alpha+\beta) & =\cos \alpha \cos \beta-\sin \alpha \sin \beta \\
\cos (-\alpha) & =\cos \alpha \\
\sin (-\alpha) & =-\sin \alpha
\end{aligned}
$$

e obtemos novamente a fórmula

$$
\hat{u}_{m n}=\frac{\Delta^{2} \hat{\rho}_{m n}}{2\left(\cos \frac{\pi m}{J}+\cos \frac{\pi n}{L}-2\right)},
$$

com a diferença de que utilizamos a transformada discreta de cosseno no eixo em que queremos a condição de contorno de Neumann. Como não estamos interessados em derivadas diferentes de zero, podemos parar por aqui, não sendo necessário reescrever $u$ como na equação 4.6.

\section{Detalhes de implementação}

As definições utilizadas acima para as transformadas de seno e cosseno são levemente diferentes das normalmente encontradas em bibliotecas numéricas. Como exemplo, a biblioteca SciPy fornece as seguintes transformadas inversas de seno e cosseno, ambas de Tipo I e para uma dimensão:

$$
\begin{aligned}
u_{l} & =\operatorname{IDST}(\hat{u})_{l}=2 \sum_{n=0}^{L-1} \hat{u}_{n} \sin \frac{\pi(l+1)(n+1)}{L+1} \\
u_{l} & =\operatorname{IDCT}(\hat{u})_{l}=2 \sum_{n=0}^{L-1} \hat{u}_{n} \cos \frac{\pi l n}{L-1}=\hat{u}_{0}+(-1)^{l} \hat{u}_{L-1}+2 \sum_{n=1}^{L-2} \hat{u}_{n} \cos \frac{\pi l n}{L-1}
\end{aligned}
$$

Para obter os resultados corretos, alguns cuidados devem ser tomados. Os valores devem ser divididos por 2 , removendo esta constante da fórmula. Além disso, realizando algumas substituições 
de variáveis chegamos na seguinte fórmula para a condição de contorno de Dirichlet:

$$
\hat{u}_{m n}=\frac{\Delta^{2} \hat{\rho}_{m n}}{2\left(\cos \frac{\pi(m+1)}{J+1}+\cos \frac{\pi(n+1)}{L+1}-2\right)} ; \quad m=0, \ldots, J-1 ; \quad n=0, \ldots, L-1 .
$$

Para a condição de contorno de Neumann em um dos eixos, e de Dirichlet no outro eixo, a fórmula utilizada é

$$
\hat{u}_{m n}=\frac{\Delta^{2} \hat{\rho}_{m n}}{2\left(\cos \frac{\pi m}{J-1}+\cos \frac{\pi(n+1)}{L+1}-2\right)} ; \quad m=0, \ldots, J-1 ; \quad n=0, \ldots, L-1 .
$$

Como estamos resolvendo a equação de Laplace, é possível realizar algumas otimizações no cálculo de $\hat{\rho}$. O cálculo sem otimizações consiste em:

1. Criar a variável $\rho$ com tamanho $J \times L$, preenchida com zeros.

2. Nas bordas em que impomos a condição de contorno de Dirichlet, subtraímos os valores desejados. Note que, caso utilizemos a condição de Dirichlet nas quatro bordas, ocorrerão duas subtrações nos quatro cantos de $\rho$, cada uma referente a uma das bordas vizinhas.

3. Calculamos a transformada discreta de seno no(s) eixo(s) em que impomos a condição de Dirichlet nas duas bordas, e a transformada discreta de cosseno no eixo em que impomos a condição de Neumann com valor zero nas duas bordas.

Ou seja, o valor de $\rho$ é diferente de zero apenas nos pixels vizinhos às bordas em que impomos a condição de Dirichlet.

Quando impomos a condição de contorno de Dirichlet nas quatro bordas, podemos calcular a transformada discreta de seno nas colunas de forma direta, com exceção da primeira e última coluna, cujos valores em geral são diferentes de zero. Primeiro calculamos normalmente a transformada discreta de seno apenas na primeira e última coluna. Nas colunas restantes, notando que a fórmula da transformada se reduz à soma do primeiro e último termo do somatório, pois os restantes são nulos, calculamos a transformada diretamente somando estes dois termos. Por fim calculamos a transformada discreta de seno no outro eixo. Este procedimento faz com que o cálculo de $\hat{\rho}$ passe de $O\left(N^{2} \log N\right)$ para $O\left(N^{2}\right)$ em um dos eixos, permanecendo com custo $O\left(N^{2} \log N\right)$ no outro eixo.

Quando impomos a condição de contorno de Neumann em duas das bordas, podemos calcular a transformada discreta de cosseno primeiro. Desta forma, basta calcular a transformada na primeira e última linha, onde impomos a condição de contorno de Dirichlet e o valor de $\rho$ é em geral diferente de zero. Todas as outras linhas continuarão iguais a zero. A seguir, calculamos a transformada discreta de seno nas colunas como descrito acima, somando o primeiro e último termo do somatório. Desta forma, o cálculo total de $\hat{\rho}$ passa de $O\left(N^{2} \log N\right)$ para $O\left(N^{2}\right)$.

Realizando alguns testes, observamos que estas otimizações fazem com que o tempo total do cálculo da extensão seja pouco menos de $70 \%$ do tempo gasto sem as otimizações, considerando o cálculo das três regiões e a criação da imagem estendida. Não é feita nenhuma otimização no cálculo das transformadas inversas, sendo utilizados os algoritmos usuais.

\subsection{Complexidade computacional}

Iremos considerar a extensão de uma imagem de tamanho $N \times N$ para uma de tamanho $2 N \times 2 N$. Embora nenhum dos algoritmos tenha alguma restrição sobre o tamanho final da imagem estendida, este é o mais apropriado no caso de holografia digital, para evitar os efeitos de convolução circular e de aliasing, conforme discutido anteriormente.

Os seguintes algoritmos possuem complexidade $O\left(N^{2}\right)$ : zeros, média, cópia da borda, mediana da borda, reflexão, rampa linear, rampa linear circular, rampa linear com janela de Tukey, cópia da borda com janela Spline e mediana com janela de cosseno. Supondo que $\sigma$ seja um valor menor 


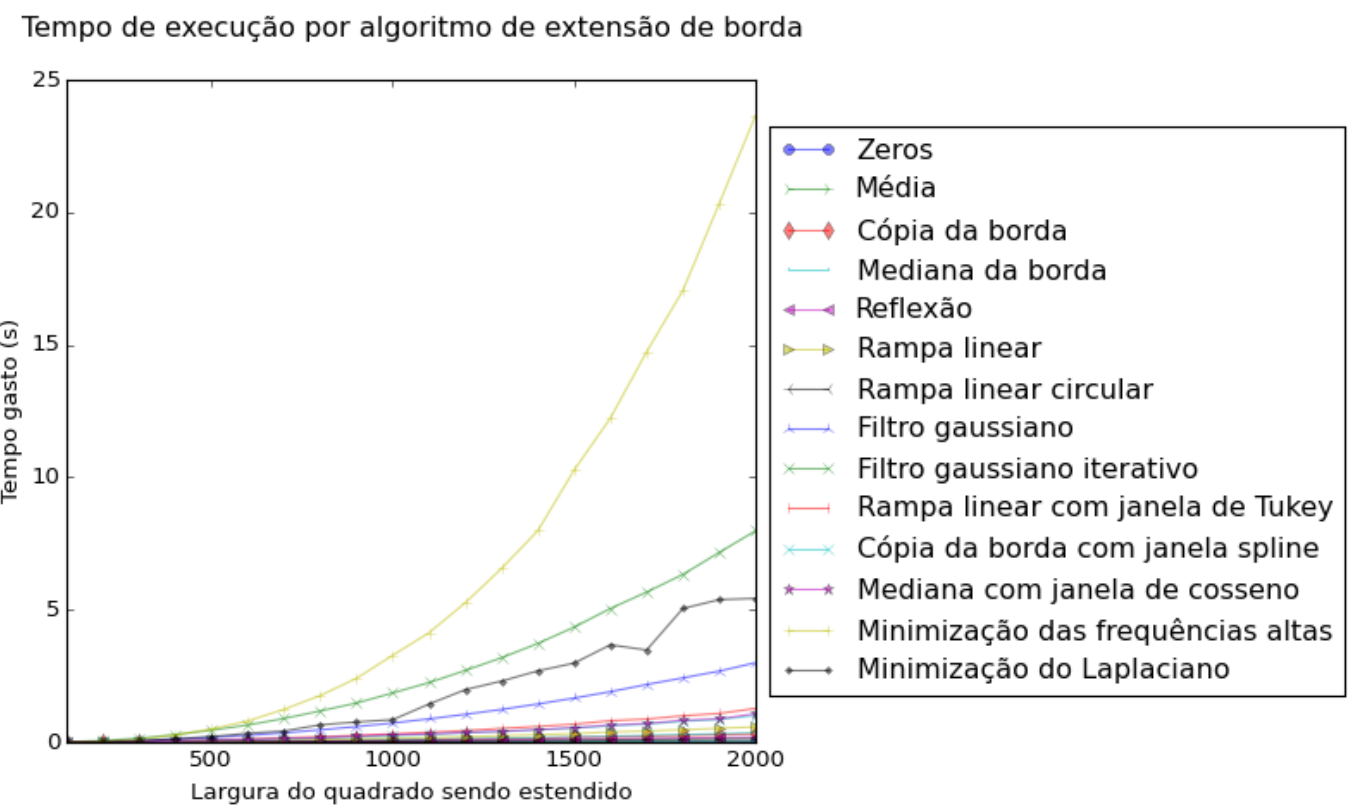

Figura 4.10: Tempo de execução dos algoritmos de extensão de borda.

do que uma constante $K$ razoável, digamos $\sigma \leq 32$, o filtro gaussiano e o filtro gaussiano iterativo também possuem complexidade $O\left(N^{2}\right)$.

O algoritmo de minimização das frequências altas proposto por Dubois et al. [DMYL02] depende dos algoritmos utilizados para realizar as multiplicações de matrizes e a inversão da matriz. Na prática, os algoritmos utilizados possuem complexidade $O\left(N^{3}\right)$. É possível fixar o parâmetro $a$ e pré-computar as matrizes $A$ do algoritmo para vários valores de $N$, o que diminui o tempo gasto, porém não altera a complexidade do algoritmo e utiliza uma quantidade considerável de memória adicional.

Para resolver a equação de Laplace em um retângulo, utilizamos o método de Fourier, que realiza o cálculo de transformadas discretas de cosseno e seno, além das respectivas transformadas inversas. Portanto, este método de extensão da borda possui complexidade $O\left(N^{2} \log N\right)$.

Nos gráficos 4.10 e 4.11 é possível ver os tempos de execução para todos os métodos, que foram implementados em Python 2 utilizando as bibliotecas SciPy [JOP ${ }^{+}$], NumPy [VDWCV11] e FFTW [FJ98]. Os algoritmos foram executados em um MacBook Pro com processador Intel Core i5 de 2,5 GHz e 8 GB de memória DDR3 1600 MHz. A Minimização das Frequências Altas possui o pior desempenho, não sendo recomendável caso se deseje um baixo tempo de execução. O Filtro Gaussiano Iterativo também tem um custo alto, mas bem abaixo da Minimização das Frequências Altas. A Minimização do Laplaciano é relativamente rápida para quadrados de até 1000 pixels de largura, mas seu custo aumenta consideravelmente para imagens maiores. O Filtro Gaussiano possui um custo ligeiramente elevado para imagens maiores do que 1000 pixels de largura, mas com desempenho melhor do que a Minimização do Laplaciano. Os métodos restantes são extremamente rápidos, conforme pode ser visto na Figura 4.11, com os preenchimentos com zeros ou a média sendo quase instantâneos. Como observado na figura, as diferenças de desempenho entre estes últimos métodos decorrem principalmente de detalhes de implementação, e seria possível obter resultados bem similares entre eles com uma implementação mais cuidadosa, com exceção dos Zeros e da Média, que exigem menos processamento e continuariam sendo os mais rápidos.

A Minimização das Frequências Altas e a Minimização do Laplaciano utilizaram duas threads, enquanto que os outros métodos utilizaram uma única thread. A biblioteca FFTW foi utilizada na Minimização do Laplaciano para os cálculos das transformadas, pois possui um desempenho bem superior ao das bibliotecas NumPy e SciPy no cálculo da Transformada de Fourier. 
Tempo de execução por algoritmo de extensão de borda

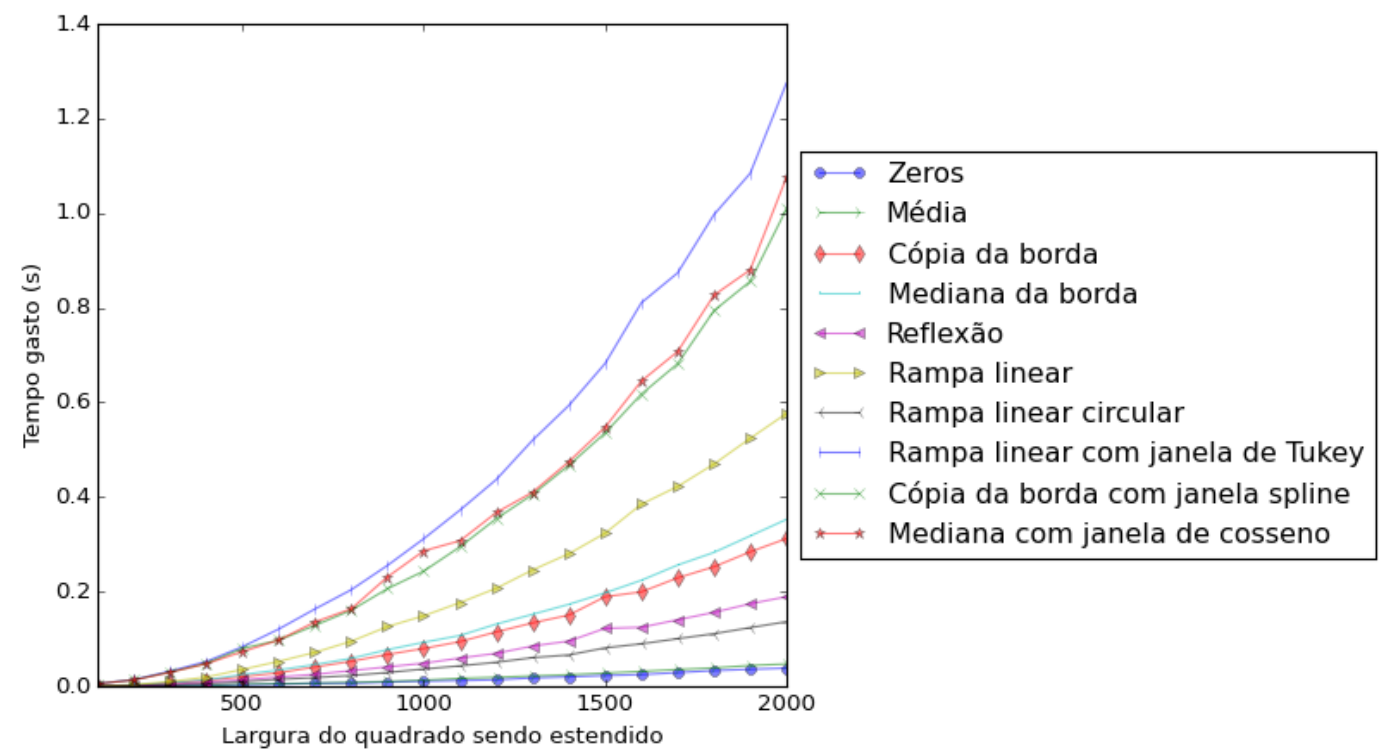

Figura 4.11: Tempo de execução dos algoritmos de extensão de borda (detalhe). Os métodos mais rápidos são o preenchimento com zeros ou com a média, que não exigem muitas operações. Em seguida, a rampa linear circular, que foi implementada de forma mais cuidadosa. Os métodos restantes em geral utilizam funções das bibliotecas SciPy e NumPy, além de algumas funções auxiliares no caso da aplicação de janelas e, por serem mais gerais, estas funções acabam aumentando o custo computacional. Ou seja, as diferenças de tempo entre estes últimos métodos e a rampa linear circular decorrem principalmente de detalhes de implementação, e não de alguma característica intrínseca do método.

\subsection{Resultados experimentais}

Os algoritmos serão avaliados de acordo com a raiz do erro quadrático médio (RMSE):

$$
\operatorname{RMSE}(\hat{I})=\sqrt{\frac{\sum_{x=1}^{M} \sum_{y=1}^{N}\left|\hat{I}_{x, y}-I_{x, y}\right|^{2}}{M N}},
$$

onde $\hat{I}$ é a reconstrução obtida utilizando algum algoritmo de extensão da borda e $I$ é a reconstrução de referência, com tamanho $M \times N$. Embora a reconstrução seja realizada com uma imagem estendida de tamanho $2 M \times 2 N$, apenas a região correspondente ao holograma original é considerada. Note que a fórmula utilizada também é válida para números complexos, resultando em um valor real.

Como serão utilizadas imagens obtidas experimentalmente, não é possível ter uma imagem de referência $I$ que não apresente nenhum efeito de difração da borda. Portanto cada holograma será reconstruído utilizando a extensão com zeros, mas apenas um retângulo na região central do holograma reconstruído será utilizado como a imagem de referência $I$. Esta mesma região retangular do holograma original será estendida com algum algoritmo e sua reconstrução holográfica $\hat{I}$ será comparada com a imagem $I$.

Por fim, ordenamos os algoritmos de acordo com a magnitude dos erros. O valor RMSE depende não só do algoritmo de extensão da borda utilizado, mas também dos vários parâmetros da reconstrução, aumentando, por exemplo, com a distância $z$ da reconstrução. Além disso, parte do erro representa a perda de informação ao utilizar uma região menor do holograma para a extensão sendo avaliada, em comparação com a reconstrução de referência que utiliza o holograma inteiro. Por estes motivos os erros são normalizados para cada imagem, subtraindo dos valores RMSE o menor valor obtido. Ou seja, o algoritmo com o menor erro para aquela imagem passa a ter erro igual a zero. Após esta normalização, ordenamos os algoritmos pela média dos erros, e também 


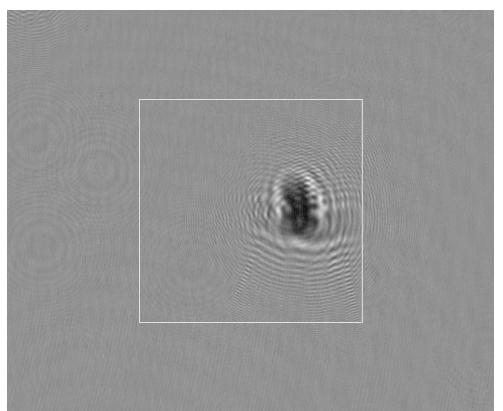

(a) Holograma

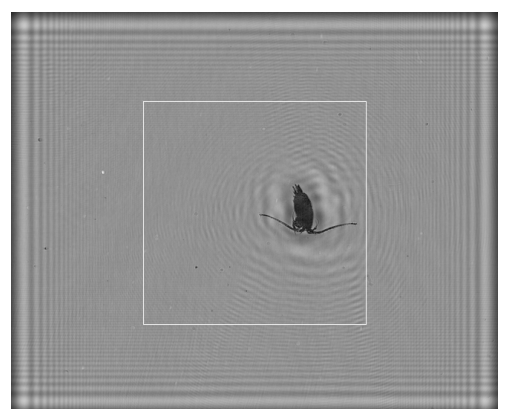

(b) Reconstrução

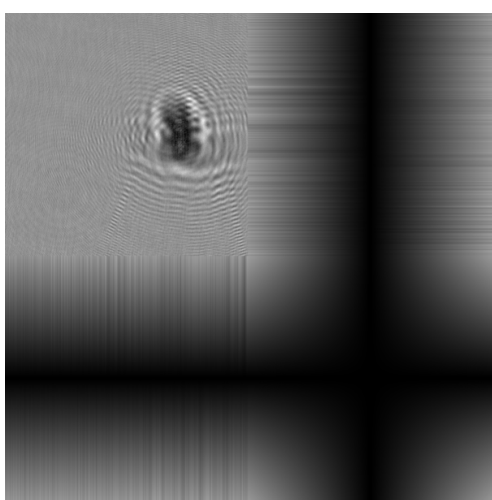

(c) Extensão com rampa linear

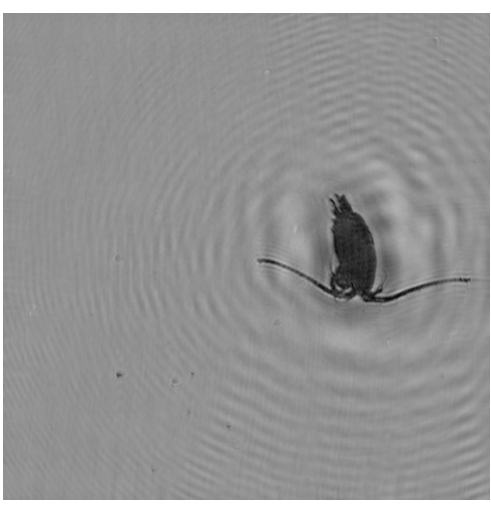

(d) Reconstrução da extensão

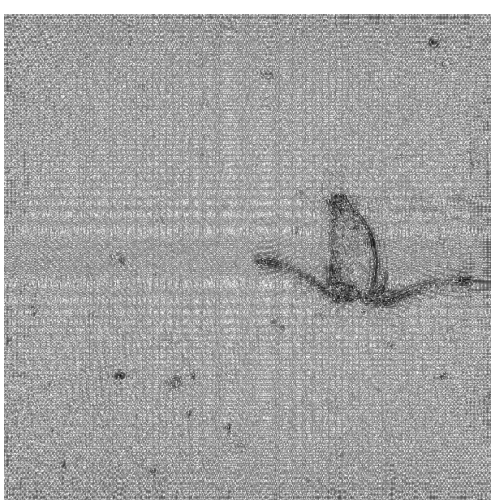

(e) Diferença das reconstruções

Figura 4.12: Cálculo do erro dos métodos de extensão de borda. O holograma (a) foi estendido com zeros e reconstruído com $z=19 \mathrm{~cm}$, resultando na imagem (b). A região destacada no holograma (a) foi estendida com a rampa linear, resultando na imagem estendida (c). Esta imagem estendida foi reconstruída e a região original recortada, obtendo-se a imagem (d). No cálculo do valor RMSE, a região destacada na imagem (b) é utilizada como referência para calcular o erro da imagem (d). A diferença entre estas duas imagens pode ser observada na imagem (e), onde as regiões mais escuras representam as maiores diferenças e a escala é logarítmica para facilitar a visualização. A maior parte do erro se deve à perda de informação provocada pela utilização de uma região menor do holograma na reconstrução, o que pode ser visto nas bordas do organismo. Porém, também é possível observar interferências horizontais e verticais na imagem (e), causadas pela difração da borda da imagem. 


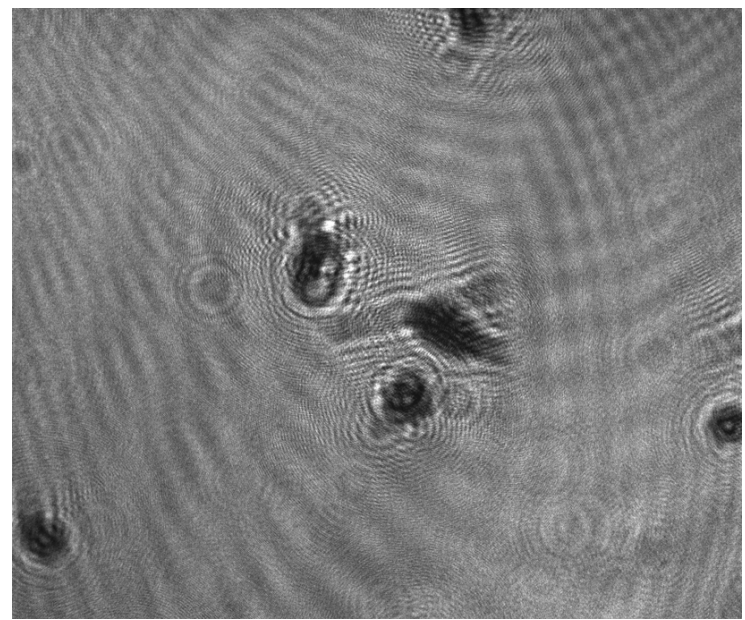

(a) Holograma

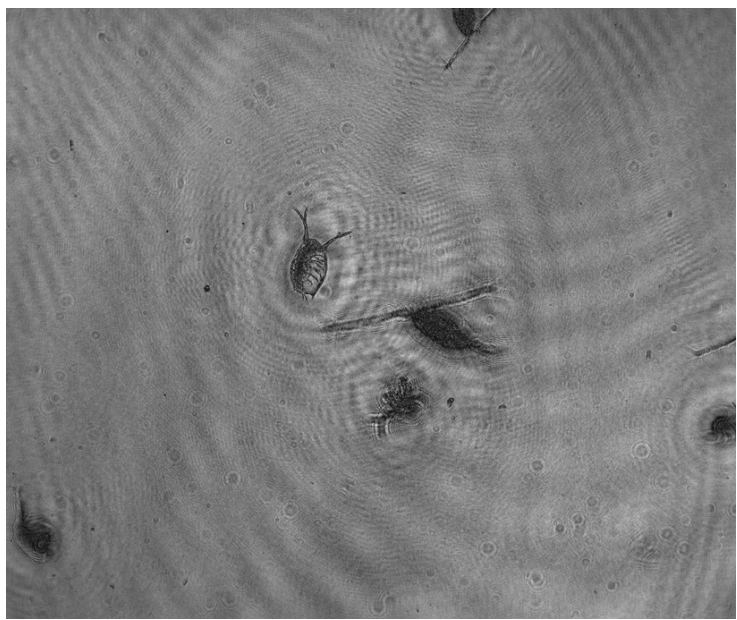

(b) Reconstrução com $z=6.2 \mathrm{~cm}$

Figura 4.13: Holograma utilizado nos gráficos de erro por distância e erro por tamanho da reconstrução (figuras 4.14 e 4.17 ).

calculamos a raiz da média dos quadrados destes erros (RMS dos erros). Assim, podemos avaliar quais algoritmos obtêm o menor erro em média, e também quais não se distanciam muito do menor erro obtido pelos algoritmos considerados.

A normalização não altera a ordenação dos algoritmos pela média dos erros, pois apenas subtrai uma mesma constante dos erros de todos os algoritmos, mas pode alterar a ordenação pelo RMS dos erros. A ideia é que, após a normalização, um erro igual a zero indica que o método foi melhor do que todos os outros para todas as imagens. Um valor acima de zero indica o quão distante o método está de ser melhor do que todos os outros, utilizando duas formas diferentes de medir esta distância (erro médio ou RMS dos erros).

\subsubsection{Resultados}

Inicialmente, foram usadas 36 imagens na comparação dos diferentes métodos, com reconstruções de diferentes tamanhos e distâncias, que podem ser visualizadas no Apêndice A. As imagens foram feitas com duas câmeras diferentes, com tamanho de pixels e resolução distintas, e capturadas em alguns dias, com diferentes amostras. A primeira câmera possui resolução de $1312 \times 1082$ pixels, com pixels quadrados de largura $8.5 \mu \mathrm{m}$. A segunda câmera possui resolução de $2448 \times 2050$ pixels, com pixels quadrados de largura $3.45 \mu \mathrm{m}$. Também foi utilizado um holograma com resolução de $1000 \times 686$ pixels, e outro com resolução de $1024 \times 1024$ pixels, sendo que ambos foram capturados com a primeira câmera e depois recortados para ficarem com estas resoluções. O laser utilizado possui comprimento de onda igual a $660 \mathrm{~nm}$, e as distâncias de reconstrução utilizadas foram entre $3.65 \mathrm{~cm}$ e $19 \mathrm{~cm}$.

Em um segundo experimento foram utilizadas 200 imagens na comparação dos diferentes métodos, com reconstruções de diferentes tamanhos e distâncias. As imagens foram capturadas no mesmo dia e com a mesma amostra de plâncton, e feitas com uma única câmera, que possui resolução de $2448 \times 2050$ pixels, com pixels quadrados de largura $3.45 \mu \mathrm{m}$. O laser utilizado possui comprimento de onda igual a $660 \mathrm{~nm}$, e as distâncias de reconstrução utilizadas foram entre $5 \mathrm{~cm}$ e $7 \mathrm{~cm}$, escolhidas aleatoriamente. O tamanho da região central utilizada na reconstrução foi escolhido aleatoriamente entre $748 \times 550$ e $1648 \times 1250$ pixels, sempre com uma distância mínima de 400 pixels para qualquer uma das bordas da imagem.

Na mediana da borda, foi utilizado o parâmetro $k=5$ pixels. Na rampa linear com janela de Tukey foi utilizado o parâmetro $\alpha=0.5$. Na cópia da borda com janela Spline, os parâmetros utilizados para uma janela de largura $L$ foram $x_{0}=0, x_{1}=\frac{0.677 L}{4.85}, x_{2}=\frac{1.042 L}{4.85}, T\left(x_{0}\right)=0$, $T\left(x_{1}\right)=0.65, T\left(x_{2}\right)=1, T^{\prime}\left(x_{0}\right)=0$ e $T^{\prime}\left(x_{2}\right)=0$. Na mediana com janela de cosseno, o único parâmetro $k$ utilizado para a janela foi 2.5 , com $k=5$ pixels para o cálculo da mediana. No filtro 
Erros de borda por distância da imagem reconstruída

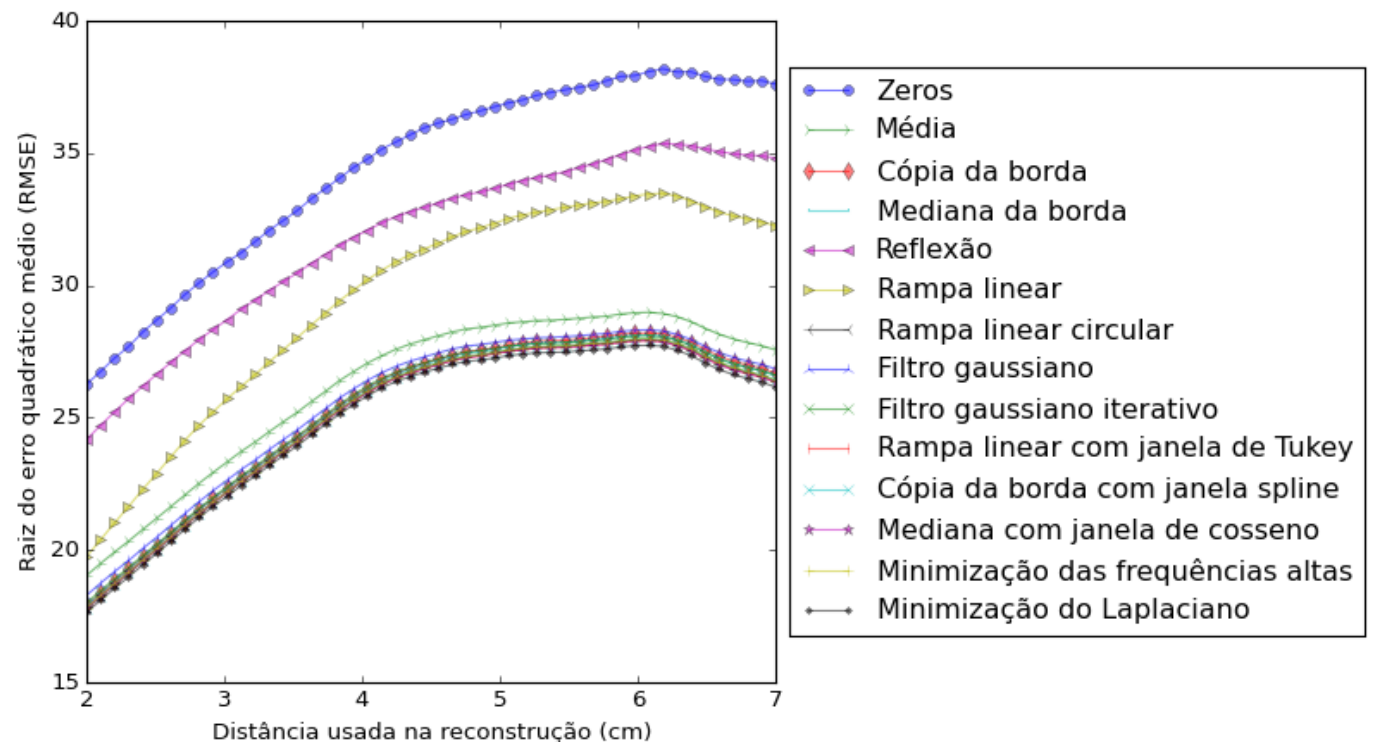

Figura 4.14: Comparação entre extensões de borda para diferentes distâncias de reconstrução. Um holograma de tamanho $2448 \times 2050$ foi reconstruído para cada uma das distâncias, sendo estendido com a minimização do Laplaciano e usado como referência. Os valores dos pixels do holograma estão no intervalo [0,255]. Um quadrado de 512 pixels de largura no centro deste holograma foi reconstruído a várias distâncias, de $2 \mathrm{~cm}$ a $7 \mathrm{~cm}$, utilizando os diferentes métodos de extensão de borda. Para cada um dos métodos e distâncias utilizados, foi calculada a raiz do erro quadrático médio utilizando o quadrado central da reconstrução de referência. É possivel ver que a extensão com zeros, a extensão com reflexão da imagem e a rampa linear obtêm erros bem maiores do que os outros métodos. Três organismos aparecem parcialmente no quadrado utilizado na comparação. Um destes entra em foco a cerca de $5.75 \mathrm{~cm}$ de distância, outro a cerca de $6.2 \mathrm{~cm}$ e o restante a cerca de $6.7 \mathrm{~cm}$.

Erros de borda por distância da imagem reconstruída

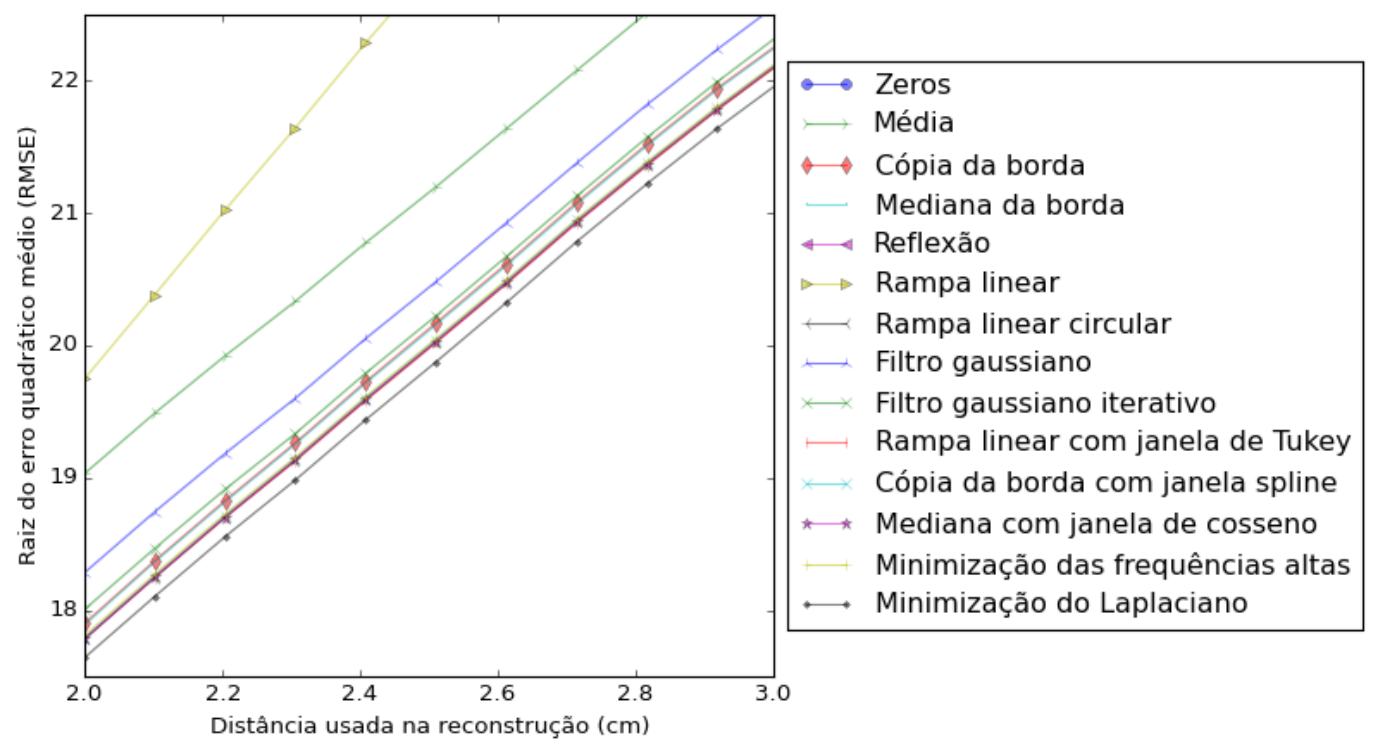

Figura 4.15: Comparação entre extensões de borda para diferentes distâncias de reconstrução (detalhe da figura 4.14). As reconstruções com zeros e reflexão possuem erros muito elevados e não aparecem na figura. A rampa linear obtém um erro maior, seguida pela média e filtro gaussiano. Os outros métodos possuem erros similares, com a minimização do Laplaciano obtendo os menores erros. 
Erros de borda por distância da imagem reconstruída

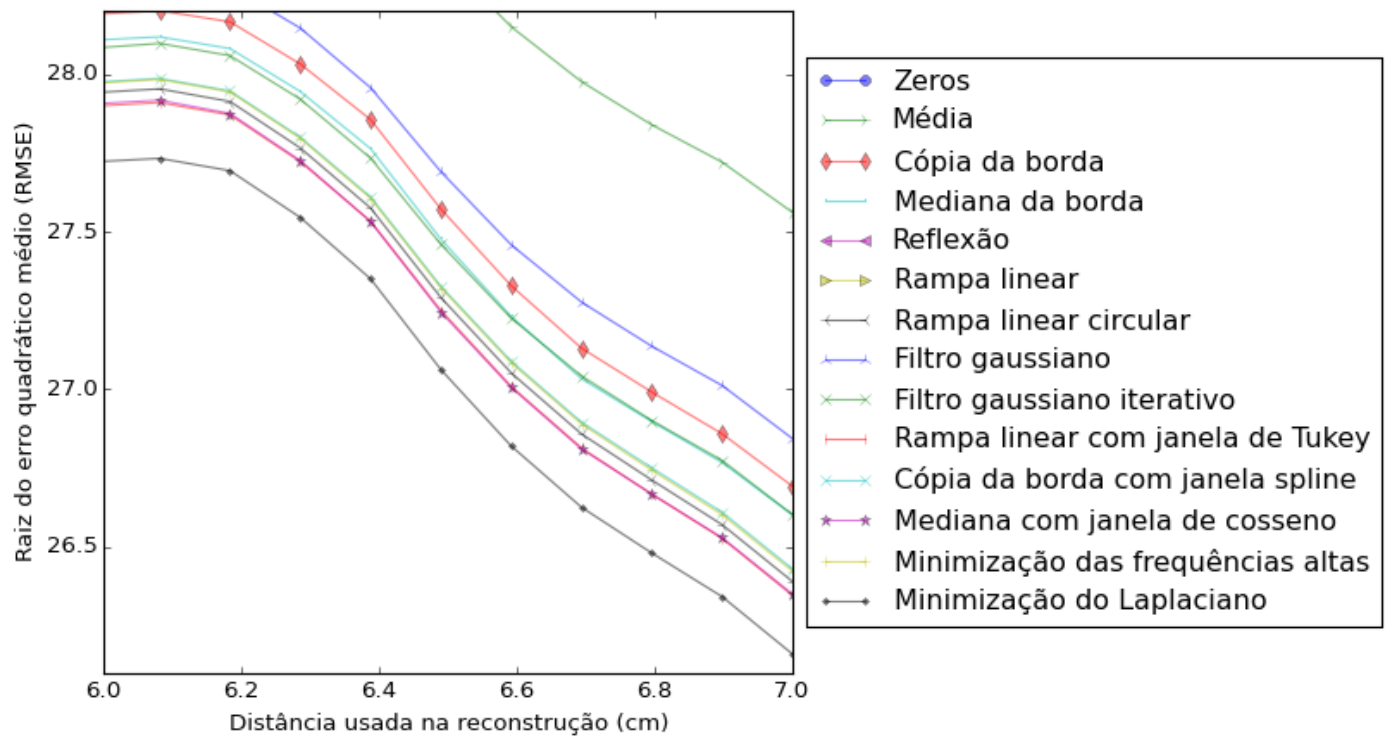

Figura 4.16: Comparação entre extensões de borda para diferentes distâncias de reconstrução (detalhe da figura 4.14). As reconstruções com zeros, reflexão e rampa linear possuem erros muito elevados e não aparecem na figura. A média obtém um erro maior, seguida pelo filtro gaussiano e pela cópia da borda. A mediana da borda obtém um erro similar ao filtro gaussiano iterativo. Os métodos restantes possuem erros similares entre si, com exceção da minimização do Laplaciano que possui os menores erros.

Erros de borda por tamanho da imagem reconstruída

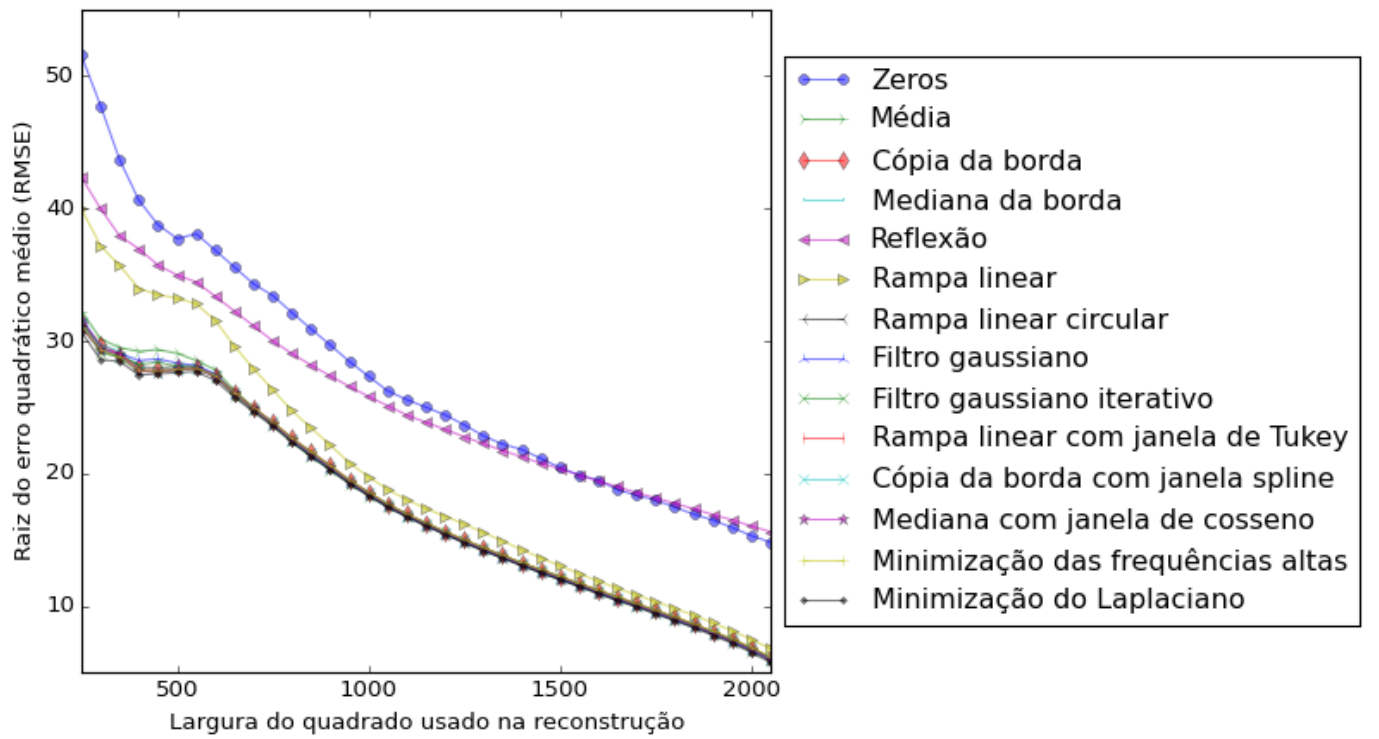

Figura 4.17: Comparação entre extensões de borda para diferentes tamanhos de imagem. Um holograma foi reconstruído com a minimização do Laplaciano e utilizado como referência. Os valores dos pixels da imagem estão no intervalo [0,255]. Vários quadrados com larguras diferentes foram reconstruídos no centro do holograma, e foi calculada a raiz do erro quadrático médio para diferentes métodos de extensão de borda. É possível ver que as extensões com zeros, com reflexão da imagem e com rampa linear obtêm erros bem maiores do que os outros métodos, e para quadrados com largura maior do que 700 pixels não há muita diferença entre estes outros métodos. 
Erros de borda por tamanho da imagem reconstruída

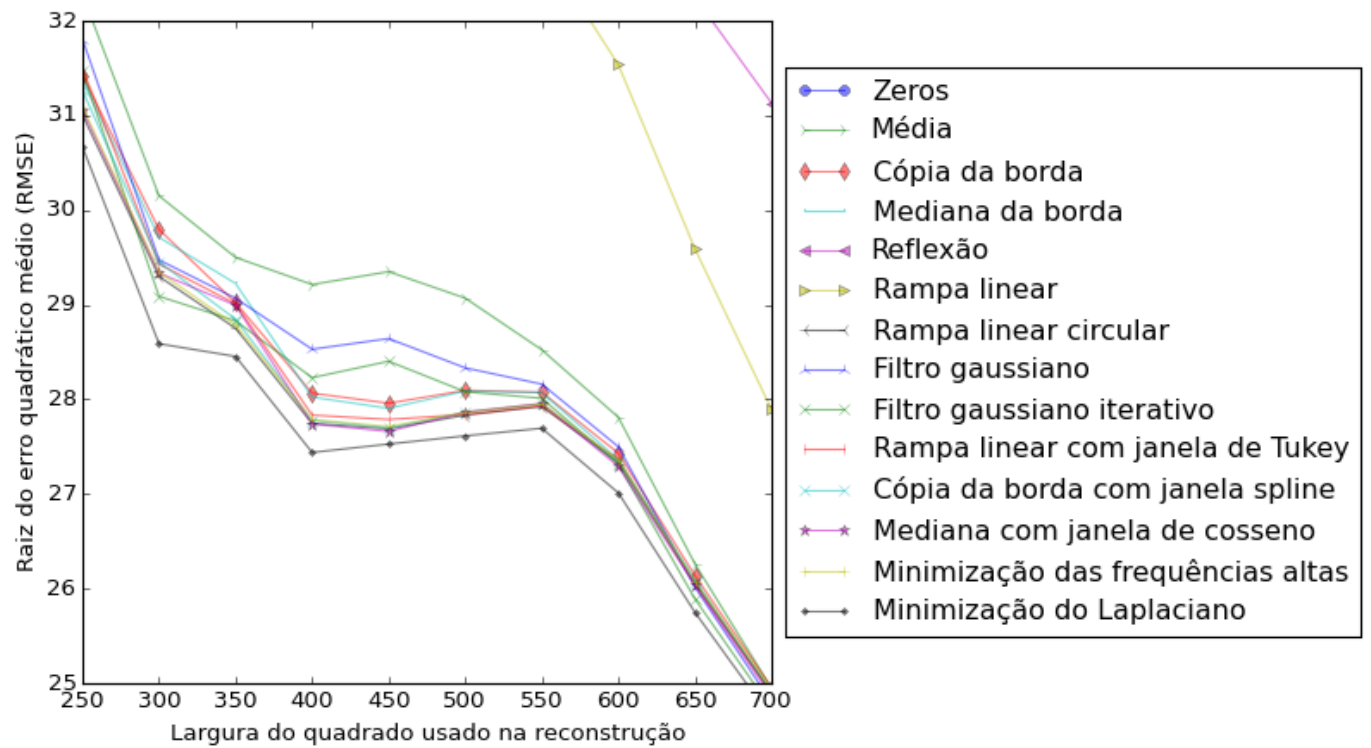

Figura 4.18: Comparação entre extensões de borda para diferentes tamanhos de imagem (detalhe da figura 4.17). Neste gráfico é possivel ver que a minimização do Laplaciano obtém o menor erro para todas as reconstruções com largura entre 250 e 700 pixels. Os erros da extensão com reflexão (canto superior direito) ou com rampa linear são bem elevados. Dentre os métodos restantes, a média e o filtro gaussiano obtêm em geral erros um pouco maiores do que os outros métodos, que têm erros bem similares e ligeiramente superiores aos da minimização do Laplaciano.

Erros de borda por tamanho da imagem reconstruída

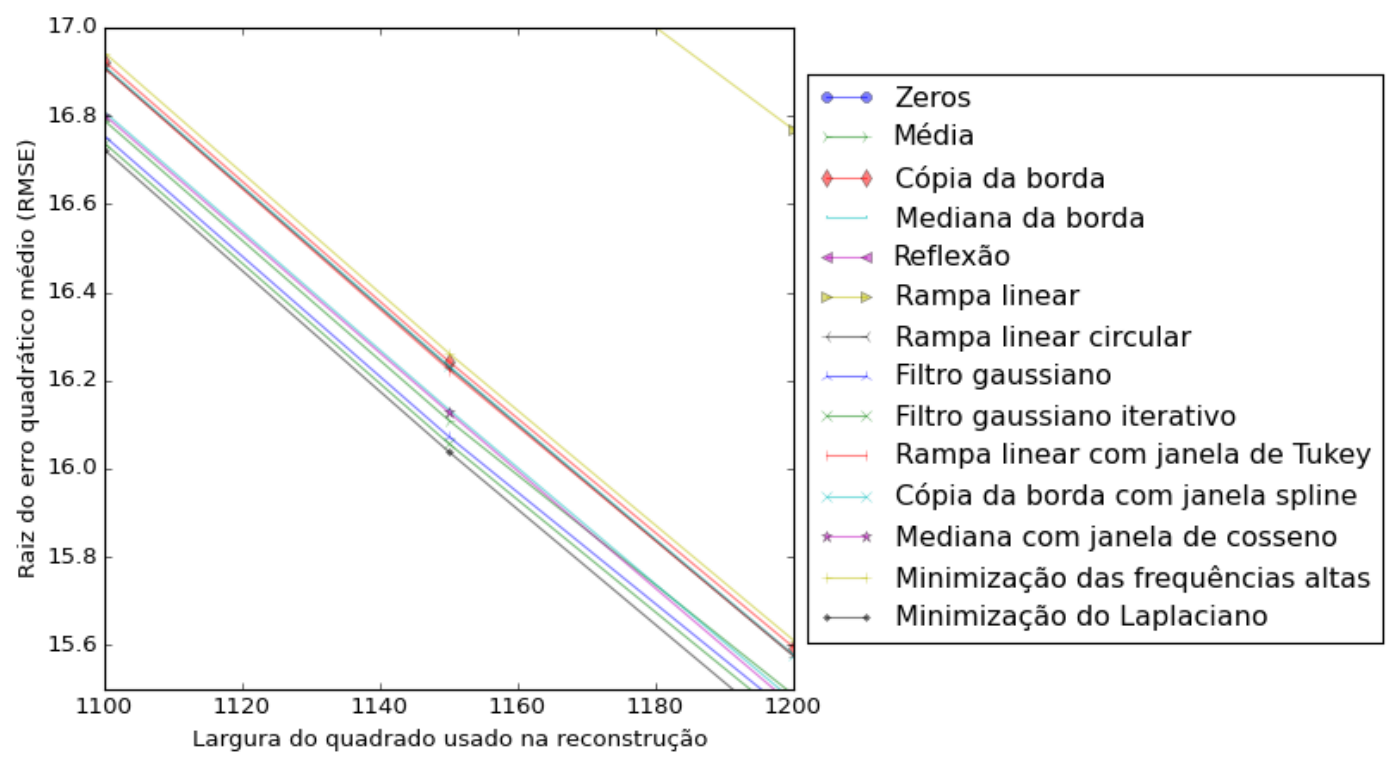

Figura 4.19: Comparação entre extensões de borda para diferentes tamanhos de imagem (detalhe da figura 4.17). Neste gráfico é possivel ver que os erros de diversos métodos são bem similares, com o filtro gaussiano, o filtro gaussiano iterativo e a minimização do Laplaciano possuindo os menores erros. As extensões com zeros e com reflexão não aparecem na figura, pois os erros são bem elevados, e a extensão com rampa linear aparece no canto superior direito. A minimização do Laplaciano obtém erros menores do que os outros métodos. 
gaussiano e no filtro gaussiano iterativo foi utilizado $\sigma=16$.

Tabela 4.1: Erros das extensões (36 imagens)

\begin{tabular}{|l|r|r|}
\hline Método & RMS dos erros & Erro médio \\
\hline \hline Minimização do Laplaciano & 0.0141082577 & 0.0057092772 \\
Filtro gaussiano iterativo $(\sigma=16)$ & 0.1338226195 & 0.0869404209 \\
Filtro gaussiano $(\sigma=16)$ & 0.2708025712 & 0.1637602514 \\
Mediana com janela de cosseno & 0.2353874979 & 0.1675396627 \\
Mediana da borda & 0.2704227127 & 0.1882365677 \\
Rampa linear circular & 0.2447774611 & 0.2095109489 \\
Cópia da borda com janela Spline & 0.2552086359 & 0.2169131570 \\
Rampa linear com janela de Tukey & 0.2645534074 & 0.2282238668 \\
Minimização das frequências altas & 0.2679204009 & 0.2343276076 \\
Cópia da borda & 0.2918432957 & 0.2436156405 \\
Média & 0.4610219089 & 0.2895375755 \\
Rampa linear & 4.4178637247 & 3.4239223930 \\
Reflexão & 5.4039674754 & 4.7871119578 \\
Zeros & 15.3849337862 & 14.2193549607 \\
\hline
\end{tabular}

Tabela 4.2: Erros das extensões (200 imagens)

\begin{tabular}{|l|r|r|}
\hline Método & RMS dos erros & Erro médio \\
\hline \hline Minimização do Laplaciano & 0.3518018652 & 0.214208946 \\
Filtro gaussiano $(\sigma=16)$ & 0.4702341748 & 0.320962085 \\
Filtro gaussiano iterativo $(\sigma=16)$ & 0.4738536993 & 0.324729852 \\
Média & 0.4818261562 & 0.332819976 \\
Rampa linear circular & 0.5811989071 & 0.420472612 \\
Minimização das frequências altas & 0.6316798803 & 0.463814411 \\
Mediana da borda & 0.9714098964 & 0.684723224 \\
Cópia da borda & 1.0367849283 & 0.759131488 \\
Reflexão & 2.0498254644 & 1.648931627 \\
Rampa linear & 12.0247648276 & 9.650624437 \\
Cópia da borda com janela Spline & 17.1005024836 & 15.931436500 \\
Mediana com janela de cosseno & 17.9511958961 & 17.086757526 \\
Rampa linear com janela de Tukey & 19.3300137749 & 17.824049186 \\
Zeros & 43.9944100212 & 43.904314537 \\
\hline
\end{tabular}

$\mathrm{Na}$ tabela 4.1 estão os resultados do primeiro experimento, com 36 imagens. Os resultados do segundo experimento, com 200 imagens, podem ser vistos na tabela 4.2. Em ambos o método com o menor erro foi a minimização do Laplaciano, seguido pelos filtros gaussianos, e o maior erro foi a extensão com zeros. Embora a minimização das frequências altas tenha sido criada especificamente para o processamento de hologramas, em ambos os experimentos obteve resultados piores do que uma simples rampa linear circular, que é um método bem mais eficiente em tempo de processamento e uso de memória.

Nas figuras 4.14, 4.15 e 4.16 é possível ver que o erro de reconstrução devido à borda depende da distância utilizada na reconstrução. Já as figuras 4.17, 4.18 e 4.19 mostram como a utilização de uma região maior do holograma na reconstrução diminui o erro, pois há uma menor perda de informação, e a área central da imagem que é menos afetada pelos erros de borda é proporcionalmente maior. 
Outros parâmetros que influenciam o erro são o tamanho do pixel da câmera e o comprimento de onda do laser. Ignorando o conteúdo da imagem sendo reconstruída e analisando apenas a função de transferência usada na reconstrução (equação 3.5), podemos ver que aumentar o comprimento de onda é similar a aumentar a distância de reconstrução, provocando um maior erro devido à borda. Já o tamanho do pixel é inversamente proporcional à distância, e a diminuição do tamanho dos pixels é similar ao aumento da distância de reconstrução, com um fator quadrático, caso a quantidade de pixels seja mantida constante.

Não realizamos um estudo mais aprofundado de como cada um destes fatores influencia o erro de borda. Porém, os testes que realizamos mostraram que a extensão que realiza a minimização do Laplaciano obtém resultados consistentemente melhores do que os outros métodos, e que mesmo nos poucos casos em que não é o melhor, ainda consegue obter um erro bem próximo ao melhor método dentre os considerados. Os gráficos de erro por distância e erro por tamanho da imagem, apesar de serem específicos para um único holograma, indicam que, em geral, os melhores métodos possuem um comportamento bem similar entre si. Portanto, embora exista a possibilidade de que algum método obtenha erros menores para certos casos, é razoável escolher a minimização do Laplaciano como um método geral para diminuir o erro de reconstrução de hologramas de plâncton devido à descontinuidade da borda.

Por fim, é interessante notar que os métodos com menor erro médio tratam a imagem de forma bidimensional. A grande maioria dos métodos considerados realiza a extensão linha a linha e coluna a coluna, ou seja, os valores de uma linha ou coluna da imagem não influenciam a extensão de outra linha ou coluna. Isto provoca o surgimento de várias frequências perpendiculares à direção sendo estendida, como pode ser observado na figura 4.12c, onde a rampa linear cria faixas verticais na região inferior esquerda da figura, e faixas horizontais na região superior direita. Já no caso da minimização do Laplaciano, do filtro gaussiano e do filtro gaussiano iterativo, a extensão também é suave na direção perpendicular à que está sendo estendida, pois estes métodos tratam a imagem como um objeto bidimensional, e não como um conjunto de linhas ou colunas independentes. Isto pode ser observado na figura 4.5e, onde a região da extensão é bem suave em todas as direções, possuindo apenas frequências baixas, além de ter uma transição suave entre a imagem original e a extensão. 


\section{Capítulo 5}

\section{Focalização}

A maior vantagem proporcionada pela holografia digital no estudo de plâncton decorre da possibilidade de realizar a focalização da imagem após sua aquisição, o que permite a observação de um maior volume de água. Esta característica é vantajosa para a identificação de organismos planctônicos ou a análise do comportamento e da interação destes organismos em diferentes profundidades. Porém, para isto é necessário que a focalização das regiões de interesse seja feita de forma automática, caso contrário o tempo gasto realizando a focalização manual tornaria o uso da holografia inviável em diversos casos.

A abordagem que utilizamos para realizar a focalização automática consiste no uso de uma medida de foco que é calculada sobre o holograma reconstruído. Ao variar a distância de reconstrução em um determinado intervalo, a imagem que maximiza (ou minimiza) esta medida é considerada a melhor focalizada. Embora existam diversos artigos comparando medidas de foco no caso de fotografia digital, as comparações realizadas para holografia digital de plâncton são mais limitadas.

Uma exceção é a tese de Loomis, que realiza um estudo detalhado de várias medidas de foco [Loo11]. Em sua tese, um valor de foco é atribuído para cada pixel, onde este valor é o resultado da medida calculada em uma pequena janela centralizada neste mesmo pixel. Os valores de foco são calculados para várias distâncias, e a profundidade do pixel é a que maximiza a medida utilizada. Com isso, é possível obter um mapa de profundidade (depth map), e uma imagem onde todos os pixels maximizam a medida de foco sendo estudada.

O problema deste método é que, em imagens de holografia digital em linha, apenas pixels próximos a bordas possuem valores confiáveis de foco. Enquanto que em imagens de fotografia digital a textura dos objetos pode auxiliar em sua focalização, nesta configuração holográfica o interior dos objetos ou não possui nenhuma informação, pois toda a luz foi absorvida pelo objeto, ou pos-

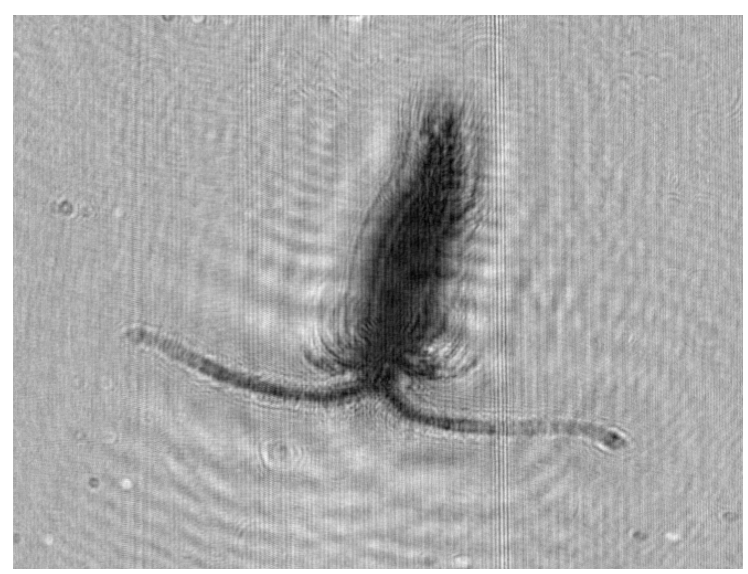

(a) Holograma não focalizado

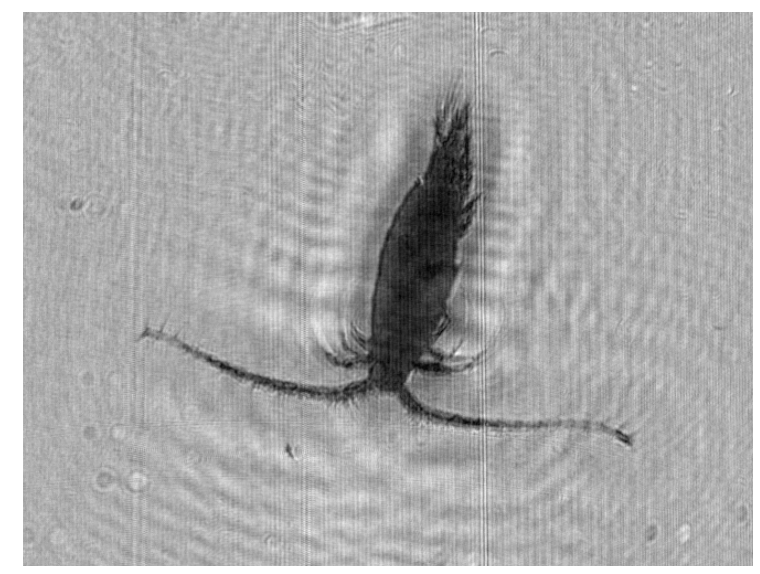

(b) Holograma focalizado

Figura 5.1: Focalização de um holograma segundo a medida de entropia. O holograma foi reconstruído a várias distâncias, e a imagem à direita é a que obteve o melhor foco, minimizando a entropia. 
sui padrões de difícil focalização, devido às refrações e dispersão da luz provocadas por um objeto transparente. Além disso, grande parte da imagem é formada pelo fundo que não pode ser focalizado por definição, pois é a ausência de objetos e não uma superfície. Ou seja, os pixels que não estão próximos a bordas e que formam a maior parte da imagem acabam sendo focalizados em distâncias incorretas, adicionando ruído à imagem final. Ondas de difração de objetos próximos, por exemplo, podem ser consideradas melhor focalizadas do que o fundo uniforme da imagem. Sobre estas dificuldades, Loomis comenta que imagens poucos milímetros fora de foco podem exibir gradientes mais fortes do que a imagem focalizada, e ilustra esta situação com uma imagem holográfica de um copépodo, onde a difração de suas antenas finas gera gradientes fortes quando levemente desfocadas. Também menciona que algumas medidas geram ruído próximo ao organismo devido aos efeitos de desfocalização e a imagem gêmea.

Para evitar estes problemas, na aplicação demonstrada na tese de Loomis, que consiste em detectar e classificar partículas de petróleo, é feita uma limiarização e apenas os pixels com maior resposta à medida de foco são considerados. Os valores da medida nestes pixels são então usados conjuntamente para determinar a profundidade da partícula. Uma diferença importante em relação ao presente trabalho é que Loomis utiliza as medidas de foco não apenas para determinar a profundidade de um objeto, mas também para detectar a presença destes objetos nas imagens reconstruídas. Ou seja, as medidas são utilizadas como um filtro que é aplicado em todas as reconstruções para segmentar objetos, determinando suas posições nos três eixos.

Em hologramas de rostos humanos, Thelen et al. [TFHH09] utilizam diversas técnicas para lidar com estes problemas na focalização de pixels. É calculada uma medida de confiança para os resultados obtidos pela medida de foco, e caso esta confiança esteja abaixo do valor de uma fórmula determinada experimentalmente, é selecionada uma janela maior em torno do pixel para a focalização. Isto é feito utilizando janelas de vários tamanhos, e caso nenhuma destas possua um valor aceitável para a medida de confiança, ao final do algoritmo é calculada uma média ponderada na janela de maior tamanho usando os valores de confiança como peso, preenchendo assim estas lacunas com valores similares ao da região na qual estão localizadas. Também é feito um ajuste gaussiano na medida de foco ao determinar a distância de cada pixel. Desta forma, as distâncias obtidas não ficam restritas às utilizadas no algoritmo de focalização, resultando em uma superfície mais suave, sem os degraus típicos de uma focalização realizada em passos discretos uniformemente espaçados. E por fim é feita uma suavização anisotrópica para diminuir o ruído presente na superfície.

Podemos notar que existe uma grande dificuldade de se obter uma boa focalização para pixels individuais, sem ruído excessivo, sendo necessários vários algoritmos para se chegar ao resultado desejado. Vale ressaltar que estas imagens holográficas de rostos humanos são distintas das imagens de plâncton em vários aspectos, alguns dos quais facilitam a focalização. A configuração holográfica não é em linha, a reconstrução realizada é óptica e as imagens resultantes não possuem fortes ondas de difração e imagens gêmeas como na holografia de plâncton. Além disso, praticamente toda a imagem contém a superfície formada pelo rosto, e não um fundo sem objetos.

Neste trabalho, realizamos a comparação de medidas de foco para determinar a profundidade da imagem como um todo, e não de cada pixel individualmente. A vantagem é que não há a criação de um ruído adicional na imagem como na focalização de pixels, porém é possível que organismos maiores fiquem parcialmente desfocados. Além disso, caso existam organismos muito próximos estes poderão afetar o resultado da focalização, inclusive fazendo com que outros organismos fiquem focalizados no lugar do organismo sendo processado. Ainda assim, caso os organismos tenham sido corretamente segmentados, acreditamos que esta abordagem proporciona um resultado superior a uma simples focalização de pixels.

Um dos problemas da focalização de hologramas de organismos planctônicos é o tempo gasto para realizar as reconstruções a várias distâncias e calcular a medida de foco. Para diminuir o tempo de processamento, pode-se reconstruir o holograma a uma quantidade menor de distâncias e, a partir dos valores da medida de foco, realizar mais reconstruções apenas na região em que se acredita que o holograma estará bem focalizado. Ou seja, a focalização é realizada em algumas etapas: primeiro é feita uma focalização grosseira, com uma distância maior entre as reconstruções; e 
em seguida é feita uma focalização mais fina, diminuindo-se a distância entre as reconstruções, mas realizando-as apenas na região que obteve o melhor foco na etapa anterior. Pode-se realizar quantas etapas forem necessárias para se obter uma boa focalização, terminando com uma distância bem pequena entre cada reconstrução. Um algoritmo extremamente similar foi utilizado por DomínguezCaballero [DC06], porém avaliaremos o uso de diferentes medidas de foco neste algoritmo, enquanto que Domínguez-Caballero utilizou uma única medida de foco, baseada no laplaciano da imagem.

\subsection{Medidas de foco}

A seguir detalhamos as medidas que foram estudadas.

\subsubsection{Medidas estatísticas}

Estas medidas realizam algum cálculo estatístico sobre os valores dos pixels, ignorando a posição destes na imagem.

\section{Entropia}

A distância de focalização escolhida é a que minimiza a entropia da imagem [GK89], que é calculada utilizando seu histograma. Para uma imagem com $N$ níveis de cinza, a entropia é definida como

$$
\text { Entropia }=-\sum_{n=1}^{N} P_{n} \log P_{n}
$$

onde $P_{n}$ é a probabilidade do $n$-ésimo nível de cinza, definida como sua frequência relativa na imagem.

\section{Amplitude}

A amplitude de uma imagem $I$ de tamanho $M \times N$ é [DSCY06]

$$
\text { Amplitude }=\sum_{i=1}^{M} \sum_{j=1}^{N}|I(i, j)| .
$$

\section{Variância}

Utilizada em diversos artigos de processamento de imagens [GYL85, MHN08, LJ05, TBG ${ }^{+}$05, LSHW09, BCP ${ }^{+}$09, PPCCMFV00, HJ07], a variância ${ }^{1}$ de uma imagem $I$ de tamanho $M \times N$ é

$$
\operatorname{Var}(I)=\frac{1}{M N} \sum_{i=1}^{M} \sum_{j=1}^{N}[I(i, j)-I]^{2},
$$

onde $\bar{I}$ é a média de intensidades da imagem $I$. Alguns autores também utilizam o desvio padrão [Loo11], mas como os valores são considerados de forma relativa, obtendo portanto resultados idênticos aos da variância, não utilizaremos o desvio padrão como medida de foco.

\section{Contraste de Tamura}

Seja $\alpha_{4}$ a medida de curtose, isto é,

$$
\alpha_{4}=\frac{\mu_{4}}{\sigma^{4}}
$$

\footnotetext{
${ }^{1}$ Usamos o termo "variância" por ser comumente utilizado na área de processamento de imagens, mas é bom deixar claro que não estamos realizando qualquer tipo de análise estatística das imagens.
} 
onde $\mu_{4}$ é o quarto momento central e $\sigma^{2}$ é a variância. O contraste de uma imagem $I$, segundo as medidas de textura propostas por Tamura et al. [TMY78], é definido como

$$
\text { Tamura }=\frac{\sigma}{\left(\alpha_{4}\right)^{n}}
$$

onde $\sigma$ é o desvio padrão de $I$ e o valor $n$ é igual a 0.25 (recomendado).

Uma aproximação deste coeficiente utilizada por Memmolo et al. $\left[\mathrm{MDP}^{+} 11\right]$ é

$$
\operatorname{Tamura}_{\text {aprox }}=\sqrt{\frac{\sigma}{\bar{I}}}
$$

Esta aproximação é similar à medida de variância, mas com um peso levemente maior para imagens mais escuras, que possuem média mais próxima a zero. Uma outra versão equivalente a esta aproximação, mas sem a raiz quadrada, é chamada de Desvio Padrão Normalizado [GYL85].

\section{Momento Central Absoluto}

O Momento Central Absoluto (Absolute Central Moment) de uma imagem I é [LJ05]

$$
\mathrm{ACM}=\sum|i-\bar{I}| p(i)
$$

onde $i$ é o nível de cinza e $p(i)$ é a probabilidade do i-ésimo valor de cinza na imagem, segundo sua frequência relativa. Ou seja, esta medida é calculada a partir do histograma da imagem $I$.

Uma definição equivalente é

$$
\mathrm{ACM}_{2}=\frac{1}{M N} \sum_{i=1}^{M} \sum_{j=1}^{N}|I(i, j)-\bar{I}|,
$$

onde $\bar{I}$ é a média de intensidades da imagem $I$. Esta definição é chamada de Amplitude [CNAJ01] ou Variação Absoluta [GYL85].

\subsubsection{Medidas com filtro espacial}

Estas medidas utilizam algum tipo de filtro espacial, com o objetivo de detectar a presença de bordas e assim determinar se uma imagem está focalizada.

\section{Variação Total}

A Variação Total (anisotrópica) de uma imagem $I$ é

$$
\operatorname{TV}(I)=\sum_{i=1}^{M} \sum_{j=1}^{N}|I(i+1, j)-I(i, j)|+|I(i, j+1)-I(i, j)| .
$$

Esta medida também é chamada de Sum Modulus Difference (SMD) [Jar76, CNAJ01] e Energy of Gradient Absolute (EOGA) [BCP ${ }^{+}$09].

\section{Índice $S$}

O Índice S [LM15] se baseia na ideia de que alterações aleatórias na fase de uma imagem em geral aumentam a Variação Total medida, mas isto ocorre de forma mais drástica para imagens 
nítidas. O Índice $\mathrm{S}$ de uma imagem $I$ é

$$
\begin{aligned}
& \mathrm{S}(I)=-\log _{10} \Phi\left(\frac{\mu-\mathrm{TV}(I)}{\sigma_{a}}\right), \\
& \Phi(t)=\frac{1}{\sqrt{2 \pi}} \int_{t}^{\infty} e^{\frac{-s^{2}}{2}} d s,
\end{aligned}
$$

onde $\mu$ e $\sigma_{a}$ são definidos pelas equações (10) e (14) no artigo de Leclaire e Moisan [LM15], respectivamente.

O cálculo de $\mathrm{S}$ é mais complexo do que o das outras medidas apresentadas aqui, e envolve o uso de uma FFT. Além disso, como a imagem é tratada de forma periódica, bordas opostas da imagem podem gerar descontinuidades. Para evitar isso, os autores sugerem que seja usada uma decomposição periódica da imagem original, cujo cálculo envolve o uso de uma FFT e uma IFFT. Com isso, temos o equivalente a três usos da FFT para o cálculo desta medida.

\section{Momento Central Absoluto com Filtro Passa-altas}

Baseada no Momento Central Absoluto, mas com a aplicação de um filtro passa-altas [LJ05]. A imagem filtrada é

$$
I(i, j)_{H P}=\{I(i, j)|| I(i, j)-I(i-s, j) \mid \geq T\}
$$

O valor $s$ é o passo do filtro e $T$ é um valor de limiarização, que descarta parte dos pixels. A imagem filtrada é um conjunto de pixels, podendo inclusive ser vazia, sendo que neste caso o valor da medida é 0 por definição.

O Momento Central Absoluto com Filtro Passa-altas (HPACM) é

$$
\operatorname{HPACM}(I)=\operatorname{ACM}\left(I_{H P}\right),
$$

ou seja, utilizamos a medida ACM definida anteriormente na imagem filtrada.

\section{Magnitude do Gradiente Gaussiano}

A partir da função gaussiana em duas dimensões

$$
G_{\sigma}(x, y)=\frac{1}{2 \pi \sigma^{2}} \exp ^{-\frac{x^{2}+y^{2}}{2 \pi \sigma}},
$$

onde $\sigma$ é o desvio padrão, obtemos o gradiente

$$
\nabla G_{\sigma}=\left[\frac{\partial G_{\sigma}}{\partial x}, \frac{\partial G_{\sigma}}{\partial y}\right]^{T}
$$

Podemos realizar a convolução deste gradiente gaussiano com a imagem $I$ e utilizar o resultado para obter a magnitude do gradiente gaussiano

$$
\mathrm{GGM}=\sqrt{\left(\frac{\partial G_{\sigma}}{\partial x} * I\right)^{2}+\left(\frac{\partial G_{\sigma}}{\partial y} * I\right)^{2}} .
$$

Como medida de focalização, podemos utilizar o somatório

$$
\text { GGMSUM }=\sum_{i} \sum_{j} G G M
$$

ou a variância

$$
\text { GGMVAR }=\sum_{i} \sum_{j}(G G M(i, j)-\overline{G G M})^{2} .
$$




\section{Máximo Orientado da Intensidade}

Esta medida foi criada originalmente para determinar o valor de focalização de pixels, e não da imagem como um todo [Loo11]. Porém, podemos utilizar o somatório dos valores de todos os pixels para obter a medida de foco

$$
\operatorname{SIM}(I)=\sum_{i, j} S_{M}(i, j)\left[I_{\max }-I(i, j)\right]
$$

onde $S_{M}$ é a magnitude do gradiente gaussiano da imagem, e $I_{\max }$ é uma constante maior do que qualquer valor $I(i, j)$. Utilizaremos $I_{\max }=255$, supondo que os valores da imagem estão no intervalo $[0,255]$. Também podemos calcular a variância, ao invés de utilizar a soma dos valores:

$$
\operatorname{SIMVAR}(I)=\operatorname{Var}\left(S_{M}(i, j)\left[I_{m a x}-I(i, j)\right]\right) .
$$

Não temos conhecimento do uso da medida SIMVAR na literatura.

\section{Correlação do Desvio Padrão}

Esta medida é baseada em correlação para diferenciar imagens bem focalizadas das que estão fora de foco. É calculada a partir da fórmula [LSHW09]

$$
\mathrm{SDC}=\frac{1}{(M-1) N} \sum_{i=1}^{M-1} \sum_{j=1}^{N} I(i+1, j) I(i, j)-\bar{I}^{2},
$$

onde $I$ é uma imagem de tamanho $M \times N$.

\section{Soma do Laplaciano Modificado}

Originalmente foi definida para uma janela ao redor de cada pixel, mas aqui utilizaremos a imagem como um todo. Para evitar o cancelamento de termos, o operador laplaciano é modificado para utilizar valores absolutos:

$$
\nabla^{2} I(i, j)=|2 I(i, j)-I(i-1, j)-I(i+1, j)|+|2 I(i, j)-I(i, j-1)-I(i, j+1)|
$$

O valor da medida é [NN94]

$$
\mathrm{SML}=\sum_{i, j} \nabla^{2} I(i, j), \quad \text { para } \nabla^{2} I(i, j) \geq T,
$$

onde $T$ é um valor de limiarização.

\section{Soma Cruzada do Laplaciano Modificado}

Similar à Soma do Laplaciano Modificado, mas também considera os pixels nas diagonais e utiliza um passo $s$ :

$$
\begin{aligned}
\nabla_{X S M L}^{2} I(i, j)= & |2 I(i, j)-I(i-s, j)-I(i+s, j)|+|2 I(i, j)-I(i, j-s)-I(i, j+s)| \\
& +\frac{1}{\sqrt{2}}|2 I(i, j)-I(i-s, j-s)-I(i+s, j+s)| \\
& +\frac{1}{\sqrt{2}}|2 I(i, j)-I(i-s, j+s)-I(i+s, j-s)|
\end{aligned}
$$


O valor da medida é [TFHH09]

$$
\mathrm{XSML}=\sum_{i, j} \nabla_{X S M L}^{2} I(i, j), \quad \text { para } \nabla_{X S M L}^{2} I(i, j) \geq T,
$$

onde $T$ é um valor de limiarização.

\section{Medida de Pieper e Korpel}

O método de Pieper e Korpel utiliza um operador diferencial não-direcional $\left[\mathrm{BCP}^{+} 09\right]$

$$
\begin{aligned}
\operatorname{PK}(i, j)= & |I(i-1, j+1)-I(i+1, j-1)|+|I(i+1, j+1)-I(i-1, j-1)| \\
& +|I(i, j+1)-I(i, j-1)|+|I(i-1, j)-I(i+1, j)|
\end{aligned}
$$

O valor da medida é

$$
\mathrm{PK}=\sum_{i, j} P K(i, j)
$$

\section{Tenengrad}

O método de Tenengrad utiliza o filtro passa-altas de Sobel

$$
\nabla S(i, j)=\sqrt{\nabla S_{x}(i, j)^{2}+\nabla S_{y}(i, j)^{2}},
$$

onde $\nabla S_{x}(i, j)$ e $\nabla S_{y}(i, j)$ são os filtros horizontal e vertical de Sobel, respectivamente, calculados através das máscaras de convolução

$$
S_{x}=\left(\begin{array}{ccc}
1 & 0 & -1 \\
2 & 0 & -2 \\
1 & 0 & -1
\end{array}\right) ; \quad S_{y}=\left(\begin{array}{ccc}
1 & 2 & 1 \\
0 & 0 & 0 \\
-1 & -2 & -1
\end{array}\right) .
$$

$\mathrm{O}$ valor da medida é $\left[\mathrm{BCP}^{+} 09\right]$

$$
\text { Tenengrad }=\sum_{i=2}^{M-1} \sum_{j=2}^{N-1}(\nabla S(i, j))^{2}, \quad \text { para } \nabla S(i, j) \geq T,
$$

onde $T$ é um valor de limiarização.

\section{Boddeke}

Este método utiliza um filtro passa-altas em uma dimensão

$$
\nabla B(i, j)=I(i+1, j)-I(i-1, j)
$$

para obter a medida $\left[\mathrm{BIA}^{+} 05\right]$

$$
\text { Boddeke }=\sum_{i=2}^{M-1} \sum_{j=1}^{N}[\nabla B(i, j)]^{2} .
$$

\section{Laplaciano}

Após aplicar o filtro laplaciano utilizando a máscara de convolução

$$
L=\left(\begin{array}{ccc}
0 & -1 & 0 \\
-1 & 4 & -1 \\
0 & -1 & 0
\end{array}\right)
$$


obtém-se o valor da medida $\left[\mathrm{BIA}^{+} 05\right]$

$$
\text { Laplaciano }=\sum_{i=2}^{M-1} \sum_{j=2}^{N-1}|\nabla L(i, j)|, \quad \text { para }|\nabla L(i, j)| \geq T,
$$

onde $T$ é um valor de limiarização.

\section{Energia do Laplaciano}

Nesta medida o filtro laplaciano é utilizado com a máscara de convolução

$$
L=\left(\begin{array}{ccc}
-1 & -4 & -1 \\
-4 & 20 & -4 \\
-1 & -4 & -1
\end{array}\right)
$$

para obter o valor da medida [HJ07]

$$
\mathrm{EOL}=\sum_{i=2}^{M-1} \sum_{j=2}^{N-1}(\nabla L(i, j))^{2} .
$$

\section{Energia Quadrática do Gradiente}

A Energia Quadrática do Gradiente é $\left[\mathrm{BCP}^{+}\right.$09, HJ07]

$$
\begin{aligned}
\text { EOGS } & =\sum_{i=2}^{M} \sum_{j=2}^{N}\left(f_{x}(i, j)^{2}+f_{y}(i, j)^{2}\right), \\
f_{x}(i, j) & =I(i, j)-I(i-1, j), \\
f_{y}(i, j) & =I(i, j)-I(i, j-1) .
\end{aligned}
$$

Uma definição similar é chamada de Frequência Espacial (spatial frequency) [HJ07, LY08]:

$$
\begin{aligned}
\mathrm{SF} & =\sqrt{(R F)^{2}+(C F)^{2}}, \\
\mathrm{RF} & =\sqrt{\frac{1}{M N} \sum_{i=1}^{M} \sum_{j=2}^{N}[I(i, j)-I(i, j-1)]^{2}}, \\
\mathrm{CF} & =\sqrt{\frac{1}{M N} \sum_{i=2}^{M} \sum_{j=1}^{N}[I(i, j)-I(i-1, j)]^{2}} .
\end{aligned}
$$

Como utilizamos os valores das medidas de forma relativa, buscando o valor máximo, as duas definições são equivalentes e apenas a medida EOGS será considerada.

\section{Variância de Sobel}

Similar à medida Tenengrad, porém calcula a variância do gradiente da imagem após aplicar o filtro de Sobel [PPCCMFV00]:

$$
\operatorname{SOBVAR}=\sum_{i=2}^{M-1} \sum_{j=2}^{N-1}(\nabla S(i, j)-\overline{\nabla S})^{2}, \quad \text { para } \nabla S(i, j) \geq T,
$$

onde $T$ é um valor de limiarização. 


\section{Variância do Laplaciano}

Similar à medida Laplaciano, porém calcula a variância do gradiente da imagem após aplicar o filtro laplaciano [PPCCMFV00]:

$$
\text { LAPVAR }=\sum_{i=2}^{M-1} \sum_{j=2}^{N-1}(|\nabla L(i, j)|-\overline{\nabla L})^{2}, \quad \text { para }|\nabla L(i, j)| \geq T,
$$

onde $T$ é um valor de limiarização e $\overline{\nabla L}$ é a média dos valores absolutos de $\nabla L(i, j)$.

\subsubsection{Medidas com janelas}

Estas medidas realizam cálculos primeiramente em uma janela ao redor de cada pixel, e depois agregam os resultados de todas as janelas. Nos métodos considerados existem três passos: o primeiro, opcional, é a aplicação de algum filtro na imagem; o segundo calcula a variância em uma janela de tamanho fixo ao redor de cada pixel; e o terceiro calcula a soma ou variância de todos os valores. O segundo passo resulta em uma imagem ligeiramente menor dependendo do tamanho da janela, pois são usadas apenas janelas contidas inteiramente na imagem.

Como estes algoritmos calculam a variância de janelas na imagem, é importante que a implementação seja feita de forma eficiente. No artigo de Bueno-Ibarra et. al [BIA+ 05], por exemplo, o cálculo da Variância Global em uma imagem de 3.2 MP possui tempo de execução de quase 28 segundos, muito maior do que outros algoritmos testados no artigo. Uma forma simples de realizar o cálculo da variância em janelas de forma mais eficiente é através da fórmula

$$
\operatorname{Var}(I)=\mathrm{E}\left[I^{2}\right]-(\mathrm{E}[I])^{2} .
$$

Ou seja, primeiro calcula-se a imagem com os valores ao quadrado $I^{2}$, e depois calcula-se a média em janelas nesta imagem para se obter $\mathrm{E}\left[I^{2}\right]$ para cada janela. Então calcula-se a média em janelas na imagem original e subtrai-se os valores ao quadrado $(\mathrm{E}[I])^{2}$ dos valores obtidos no passo anterior, resultando nas variâncias das janelas $\operatorname{Var}(I)$.

O cálculo da média em janelas pode ser feito em duas etapas, uma para cada dimensão da imagem. Em cada dimensão é calculada a média móvel, que pode ser obtida de forma iterativa subtraindo o último elemento da janela e somando o próximo, dividindo o resultado pela largura da janela e somando este valor à média da janela anterior. Ou seja, não é necessário somar todos os elementos da janela novamente a cada passo, bastando calcular uma subtração, uma divisão e uma soma por passo. Na biblioteca SciPy a média móvel em duas dimensões é calculada pela função uniform_filter, através da qual se obtém a Variância Global de uma imagem de $3.2 \mathrm{MP}$ em cerca de $272 \mathrm{~ms}$, quando calculada em um MacBook Pro com processador Intel Core i5 de $2.5 \mathrm{GHz}$ e $8 \mathrm{~GB}$ de memória DDR3 $1600 \mathrm{MHz}$.

\section{Variância Global}

A Variância Global [PPCCMFV00, BIA ${ }^{+} 05$ ] primeiro calcula a variância da imagem $I$ em janelas de largura e altura $r$, resultando em uma imagem de variâncias locais $I_{L V}$. Por fim é calculado o valor da medida

$$
\operatorname{GBLVAR}=\operatorname{Var}\left(I_{L V}\right) .
$$

\section{Variância Global do Gradiente Gaussiano}

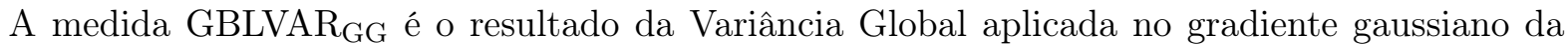
imagem. Não temos conhecimento do uso desta medida na literatura. 


\section{Variância Total do Gradiente Gaussiano}

Esta medida é similar à Variância Global do Gradiente Gaussiano, mas utiliza um somatório no último passo, ao invés da variância. Primeiro é calculado o gradiente gaussiano da imagem, e então calcula-se a variância deste gradiente em janelas de altura e largura $r$, resultando em uma imagem de variâncias locais $I_{L V}$. Por fim é calculado o valor da medida

$$
\text { TOTVAR }=\sum I_{L V} .
$$

Não temos conhecimento do uso desta medida na literatura.

\section{Variância Global do Laplaciano do Gaussiano}

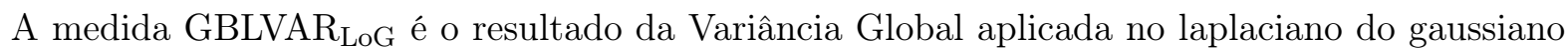
da imagem. Não temos conhecimento do uso desta medida na literatura.

\subsection{Complexidade computacional}

Iremos supor que o gradiente gaussiano é utilizado com um parâmetro $\sigma$ de valor inferior a uma constante razoável, digamos $\sigma \leq 32$. Para uma imagem de tamanho $N \times N$, os algoritmos das medidas de foco possuem complexidade $O\left(N^{2}\right)$, com exceção do Índice S, que utiliza a FFT e possui complexidade $O\left(N^{2} \log N\right)$.

Portanto, o maior gasto computacional na focalização decorre das reconstruções holográficas a diversas distâncias, e não do cálculo de uma medida de foco (desconsiderando o Índice S).

\subsection{Resultados experimentais}

As medidas de focalização serão avaliadas de acordo com o erro médio (ME) e a raiz do erro quadrático médio (RMSE). Para cada imagem, o erro é calculado como a diferença absoluta entre a distância obtida pela medida de foco e a distância de referência, em milímetros.

Como serão utilizadas imagens obtidas experimentalmente, não é possível saber a distância correta de cada objeto. Por este motivo, cada imagem foi focalizada manualmente, e a distância escolhida é utilizada como referência. Existe alguma subjetividade neste processo, pois pessoas diferentes poderiam focalizar a mesma imagem em distâncias diferentes. Porém, como cada imagem foi reconstruída em vários passos uniformemente espaçados, e considerando as distâncias destes passos que foram usadas nos experimentos entre uma reconstrução holográfica e a reconstrução imediatamente seguinte, para grande parte das imagens existe apenas uma distância que está claramente melhor focalizada do que as demais. Além disso, o próprio problema sendo analisado possui certa ambiguidade, pois como os objetos sendo focalizados são tridimensionais, é comum que diferentes segmentos do objeto estejam bem focalizados a distâncias distintas, não havendo uma única distância que seja a correta. Desta forma, acreditamos que o uso de distâncias escolhidas manualmente é razoável, desde que se tenha em mente que diferenças muito pequenas entre os erros das medidas de foco podem ser o resultado desta subjetividade ou da ambiguidade do problema de focalização.

Para obter as imagens que serão focalizadas, cada holograma foi estendido com a Minimização do Laplaciano, descrita no Capítulo 4, e reconstruído a 30 distâncias diferentes, espaçadas de forma uniforme. As reconstruções foram limiarizadas para que as intensidades ficassem no intervalo [0, 255]. Algumas regiões que continham algum objeto foram escolhidas para serem focalizadas, evitando regiões com mais de um objeto, exceto quando um destes é muito maior do que os demais, caso em que este objeto maior é o que foi focalizado. As medidas de foco foram aplicadas nestas regiões, e a distância que maximiza (ou minimiza) o valor da medida é considerada como a melhor focalizada segundo a medida sendo avaliada. 


\subsubsection{Resultados}

Foram utilizados três conjuntos de imagens, obtidas experimentalmente de amostras diferentes de organismos planctônicos. Nos três conjuntos, a câmera utilizada possui pixels quadrados de $3.45 \mu \mathrm{m}$ de largura. No conjunto A, o laser utilizado possui comprimento de onda de $660 \mathrm{~nm}$ e os hologramas foram reconstruídos entre $5 \mathrm{~cm}$ e $7 \mathrm{~cm}$. No conjunto B, o laser utilizado possui comprimento de onda de $660 \mathrm{~nm}$ e os hologramas foram reconstruídos entre $6 \mathrm{~cm}$ e $8 \mathrm{~cm}$. No conjunto C, o laser utilizado possui comprimento de onda de $633 \mathrm{~nm}$ e os hologramas foram reconstruídos entre $2.5 \mathrm{~cm}$ e $4 \mathrm{~cm}$. Com isso, os hologramas dos conjuntos A e B foram reconstruídos com aproximadamente $0.6897 \mathrm{~mm}$ de distância entre cada reconstrução, e os hologramas do conjunto C com aproximadamente $0.5172 \mathrm{~mm}$ de distância entre cada reconstrução. O conjunto A possui 19 imagens, o conjunto B possui 50 imagens e o conjunto $\mathrm{C}$ possui 118 imagens, em um total de 187 imagens. Algumas destas imagens podem ser visualizadas no Apêndice B, que contém reconstruções realizadas à distância escolhida manualmente como sendo a correta.

Ao exibir os erros das medidas, iremos desconsiderar medidas com erro médio superior a dois passos da distância de referência, ou seja, com erro médio superior a $2 \times 0.6897 \mathrm{~mm}=1.3794 \mathrm{~mm}$ para os conjuntos $\mathrm{A}$ e $\mathrm{B}$, superior a $2 \times 0.5172 \mathrm{~mm}=1.0344 \mathrm{~mm}$ para o conjunto $\mathrm{C}$, e superior a $1.1617 \mathrm{~mm}$ para a união dos três conjuntos. Uma grande quantidade das medidas avaliadas mostrouse inadequada para a focalização de imagens holográficas de organismos planctônicos, e omiti-las facilitará a interpretação dos resultados.

As seguintes medidas foram maximizadas: SIMVAR, GBLVAR, TOTVAR, GGMVAR, SOBVAR, GBLVAR $_{\mathrm{GG}}$, GBLVAR$_{\mathrm{LoG}}$, HPACM, LAPVAR, Amplitude, Laplaciano, Índice S, SDC, Variância, Tamura $_{\text {aprox }}$, SML, Tenengrad, EOL, EOGS, XSML, Boddeke, TV.

As seguintes medidas foram minimizadas: Entropia, GGMSUM, SIM, ACM, Tamura, PK.

Foi utilizado o parâmetro $\sigma=1$ para as medidas TOTVAR, SIMVAR, GGMVAR, e GBLVAR GG; $_{\text {; }}$ o parâmetro $\sigma=1.5$ para a medida GBLVAR $_{\text {LoG }}$; e $\sigma=2$ para as medidas GGMSUM e SIM. Foram utilizadas janelas de largura e altura igual a 6 pixels para as medidas GBLVAR e GBLVAR $_{\mathrm{GG}}$, e

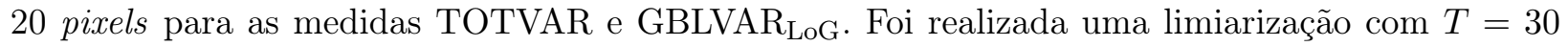
nas medidas SOBVAR, LAPVAR e Laplaciano; $T=32$ na medida HPACM; $T=40$ na medida SML; $T=70$ na medida XSML; e $T=100$ na medida Tenengrad. Na medida HPACM foi utilizado o passo $s=5$.

Na figura 5.2 são exibidas todas as reconstruções utilizadas no experimento para um dos organismos do conjunto C. Os valores de algumas medidas de foco para este organismo podem ser vistos na figura 5.3. Existem várias características que dificultam a focalização desta imagem: o organismo é pequeno, não possuindo muitas bordas bem definidas; existem padrões de difração no lado esquerdo da região inferior da imagem, que aparentam ser de outro organismo próximo que não aparece na reconstrução; e também existe um padrão de interferência formado por linhas quase horizontais que criam oscilações na intensidade. O resultado é que as medidas SOBVAR e HPACM são maximizadas em distâncias incorretas de focalização, além de apresentarem fortes oscilações em seus valores.

$\mathrm{Na}$ figura 5.4 são exibidas todas as reconstruções de outro organismo do conjunto C que foram utilizadas no experimento. Os valores de algumas medidas de foco para este organismo podem ser vistos na figura 5.5. Este exemplo também possui características que dificultam sua focalização: o organismo é transparente, possuindo intensidades que são em grande parte similares ao fundo; além disso, quando está fora de foco a sua forma esférica cria padrões de difração circulares, que algumas medidas não diferenciam da imagem focalizada. Neste caso, as medidas GBLVAR ${ }_{\mathrm{GG}}$, GBLVAR e GBLVAR $_{\text {LoG }}$ são maximizadas em distâncias incorretas de focalização, além de apresentarem fortes oscilações na região próxima ao valor máximo.

A tabela 5.1 apresenta os erros de focalização para o conjunto A. O uso das medidas TOTVAR e SIMVAR resultou na focalização incorreta de apenas 1 imagem em 19, com a escolha de outra distância imediatamente seguida, enquanto que para as medidas Amplitude e GBLVAR GG $_{\text {o mesmo }}$ ocorreu em 2 imagens.

Na tabela 5.2, podemos ver que o uso das medidas SIMVAR e GGMVAR resultou nos menores 

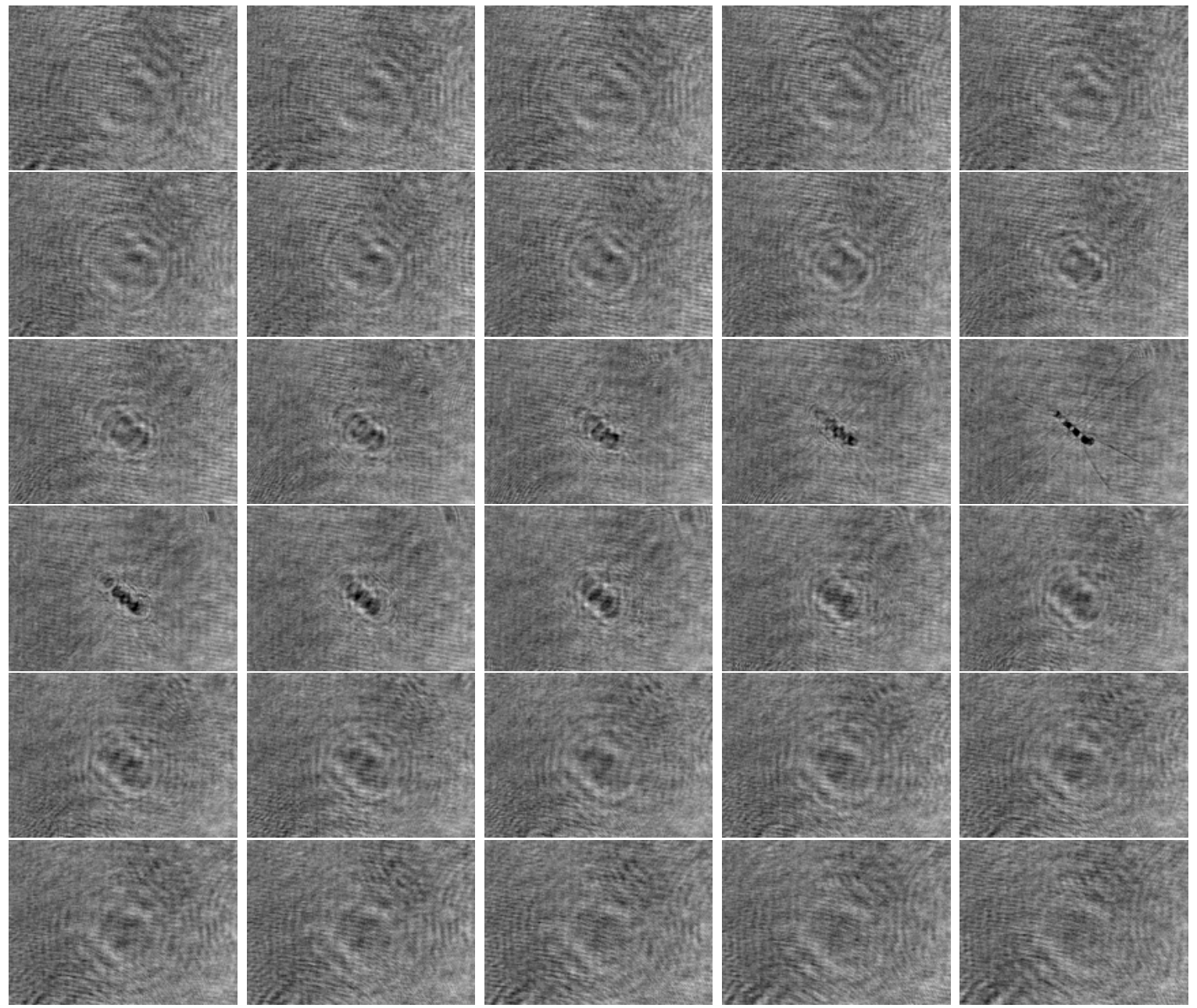

Figura 5.2: Exemplo de organismo sendo focalizado. Este organismo pertence ao conjunto $C$, e é de difícil focalização por ser extremamente pequeno para a câmera e possuir poucos detalhes. Todas as reconstruções utilizadas no experimento de focalização são exibidas, com a distância de reconstrução aumentando da esquerda para a direita, de cima para baixo. A imagem escolhida manualmente como a melhor focalizada é a quinta da terceira linha.

Tabela 5.1: Erros de focalização - Conjunto $A$

\begin{tabular}{|c|c|c|}
\hline Medida & RMSE (mm) & Erro médio $(\mathrm{mm})$ \\
\hline TOTVAR & 0.15822 & 0.03630 \\
\hline SIMVAR & 0.15822 & 0.03630 \\
\hline Amplitude & 0.22375 & 0.07260 \\
\hline GBLVAR $_{\mathrm{GG}}$ & 0.22375 & 0.07260 \\
\hline GGMVAR & 0.27404 & 0.10889 \\
\hline SOBVAR & 0.27404 & 0.10889 \\
\hline GBLVAR & 0.27404 & 0.10889 \\
\hline GBLVAR $_{\text {LoG }}$ & 0.27404 & 0.10889 \\
\hline Entropia & 0.67126 & 0.21779 \\
\hline HPACM & 1.14092 & 0.36298 \\
\hline GGMSUM & 0.86659 & 0.72595 \\
\hline LAPVAR & 2.03849 & 0.79855 \\
\hline Laplaciano & 2.55118 & 1.37931 \\
\hline
\end{tabular}



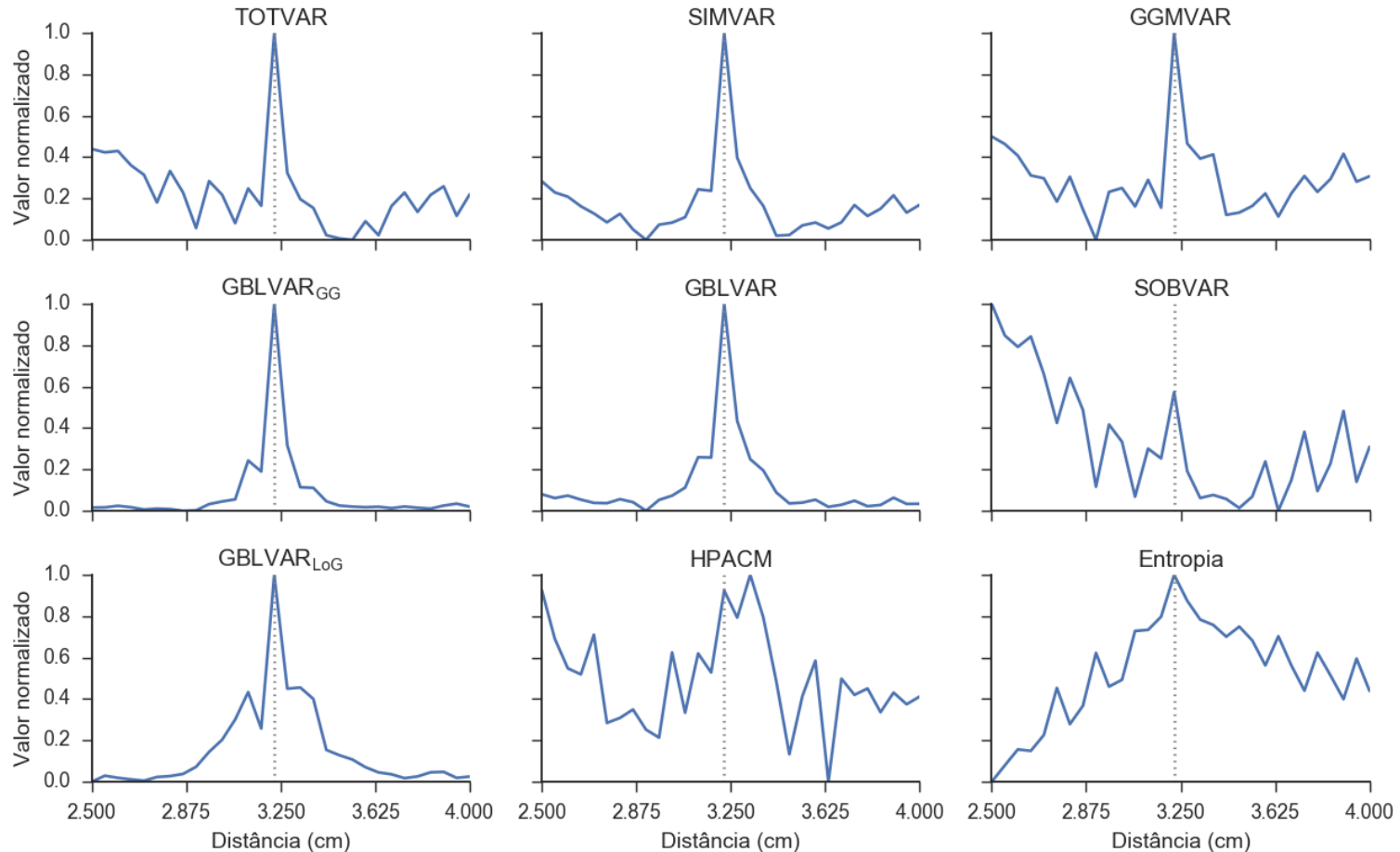

Figura 5.3: Valores de medidas de foco para um organismo. O organismo sendo focalizado é o exibido na figura 5.2, e a linha vertical pontilhada representa a distância escolhida manualmente. O gráfico exibe o negativo da Entropia, desta forma a distância escolhida é a que maximiza a medida.

Tabela 5.2: Erros de focalização - Conjunto B

\begin{tabular}{|l|r|r|}
\hline Medida & RMSE $(\mathrm{mm})$ & Erro médio $(\mathrm{mm})$ \\
\hline \hline SIMVAR & 0.19506 & 0.05517 \\
GGMVAR & 0.19506 & 0.05517 \\
TOTVAR & 0.21809 & 0.06897 \\
GBLVAR $_{\mathrm{GG}}$ & 0.21809 & 0.06897 \\
GBLVAR $^{\text {SOBVAR }}$ & 0.23890 & 0.08276 \\
GBLVAR $_{\mathrm{LoG}}$ & 0.25805 & 0.09655 \\
Laplaciano & 0.32348 & 0.12414 \\
LAPVAR & 0.60909 & 0.26207 \\
Entropia & 0.71671 & 0.30345 \\
HPACM & 2.26013 & 0.42759 \\
SDC & 2.19609 & 0.56552 \\
\end{tabular}



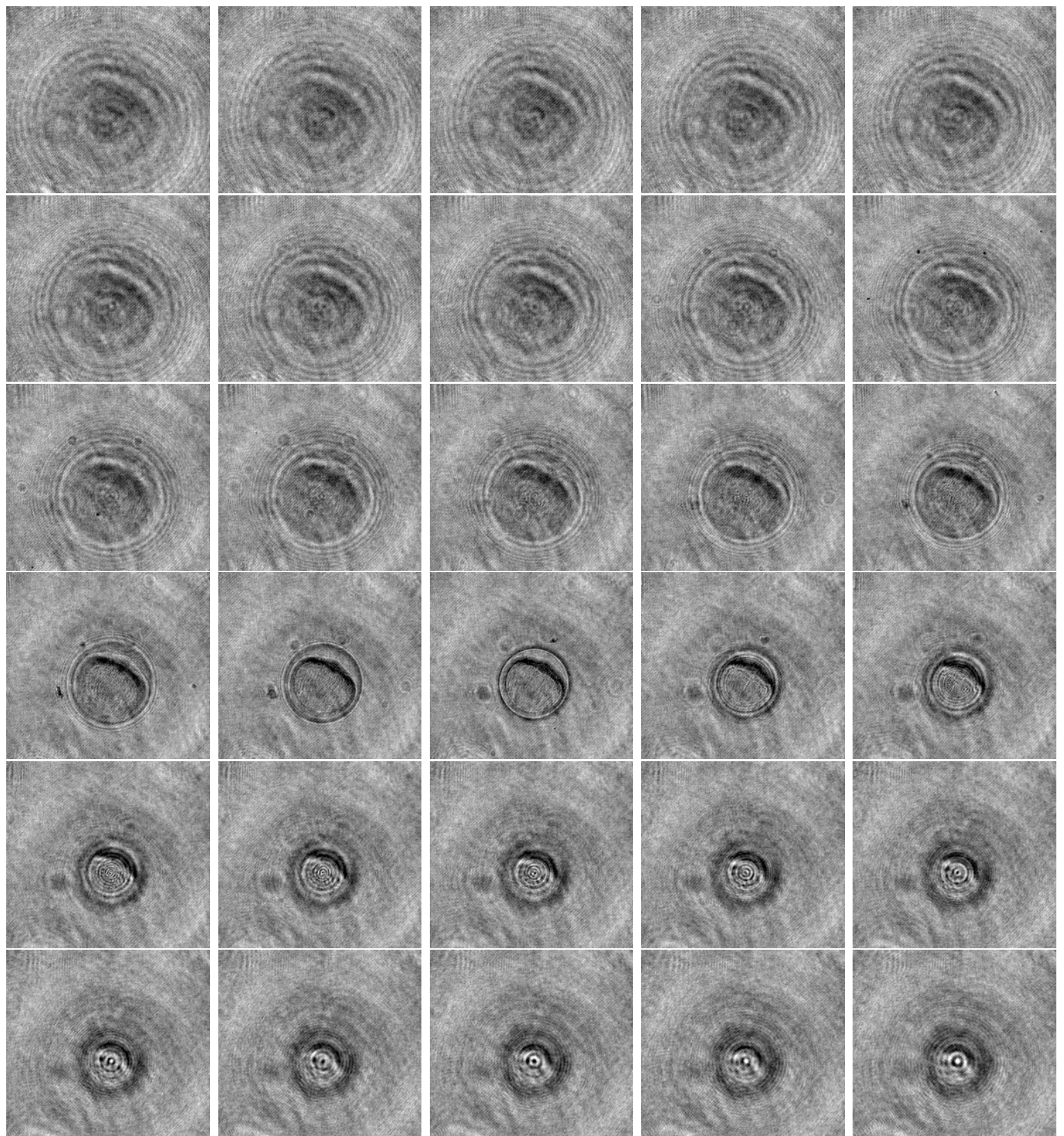

Figura 5.4: Exemplo de organismo sendo focalizado. Este organismo pertence ao conjunto $C$, e é de difícil focalização por ser transparente e esférico, criando padrões de difração que algumas medidas não diferenciam do organismo focalizado. Todas as reconstruções utilizadas no experimento de focalização são exibidas, com a distância de reconstrução aumentando da esquerda para a direita, de cima para baixo. A imagem escolhida manualmente como a melhor focalizada é a terceira da quarta linha. 


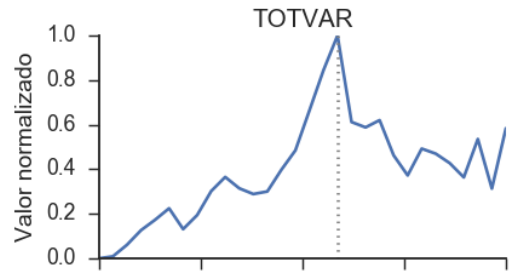

GBLVAR $_{\mathrm{GG}}$
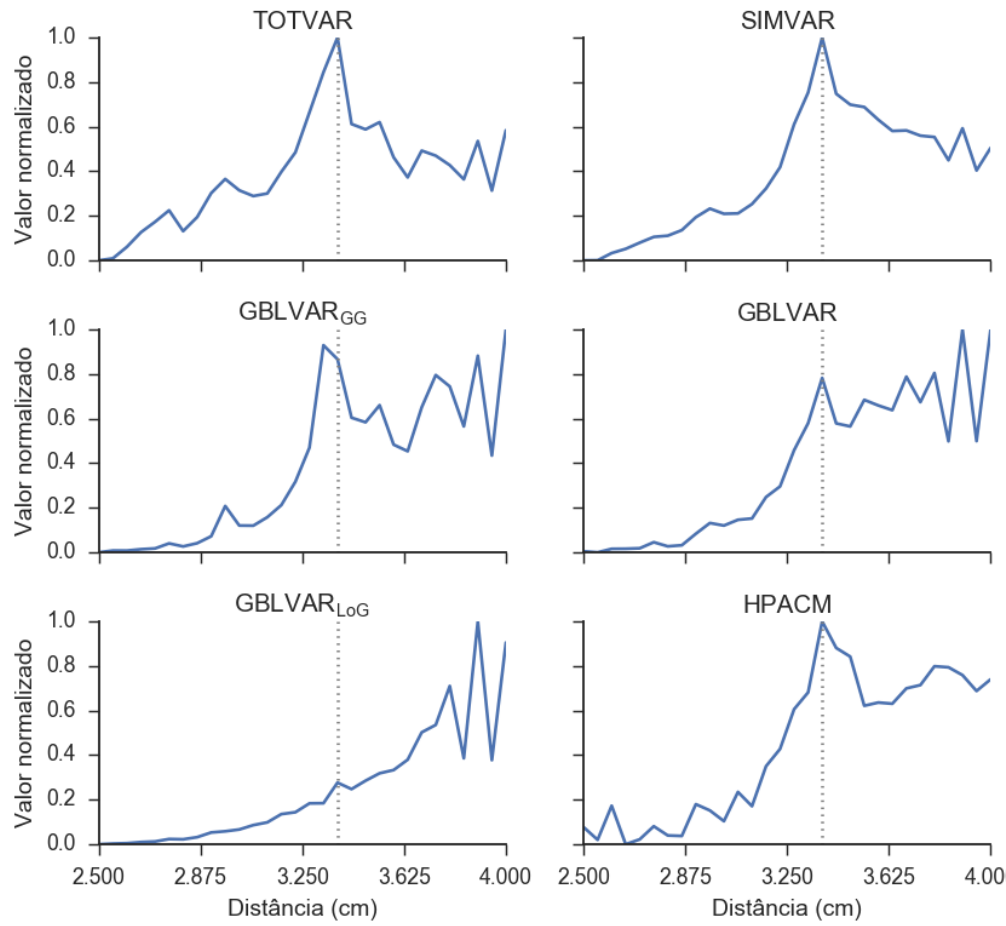

GBLVAR
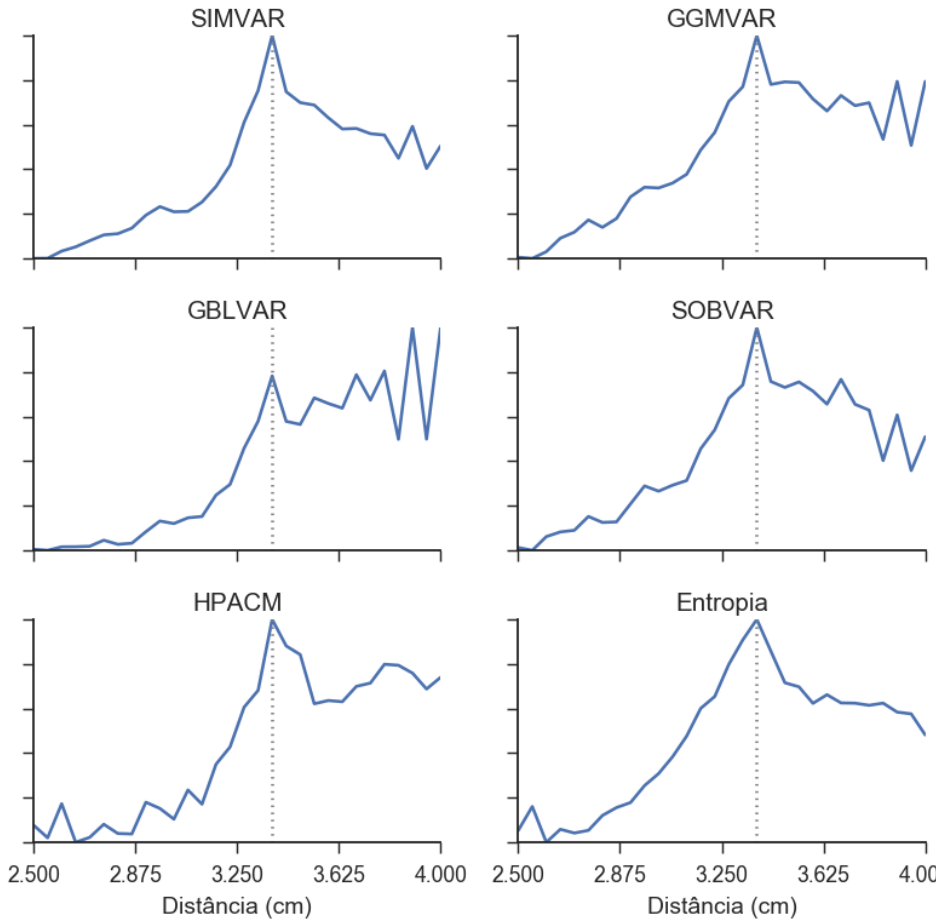

SOBVAR
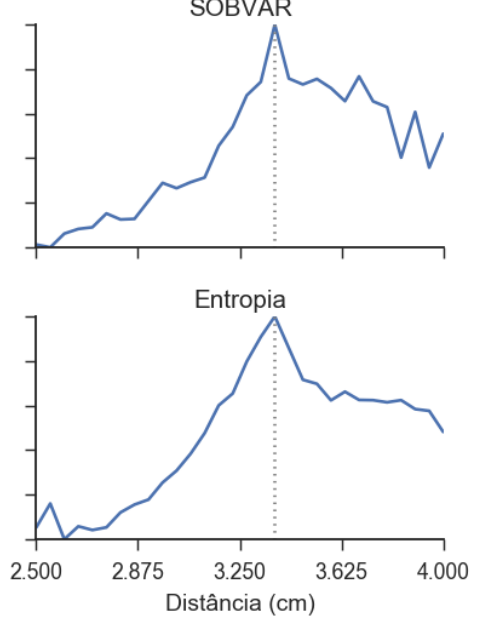

Figura 5.5: Valores de medidas de foco para um organismo. $O$ organismo sendo focalizado é o exibido na figura 5.4, e a linha vertical pontilhada representa a distância escolhida manualmente. O gráfico exibe o negativo da Entropia, desta forma a distância escolhida é a que maximiza a medida.

erros para as imagens do conjunto B. Com estas medidas obteve-se a focalização incorreta de 4 imagens em 50, nas quais foi escolhida outra distância imediatamente seguida, enquanto que para as medidas TOTVAR e GBLVAR $\mathrm{GG}_{\mathrm{O}}$ o mesmo ocorreu em 5 imagens.

Tabela 5.3: Erros de focalização - Conjunto $C$

\begin{tabular}{|l|r|r|}
\hline Medida & RMSE $(\mathrm{mm})$ & Erro médio $(\mathrm{mm})$ \\
\hline \hline TOTVAR & 0.17168 & 0.05698 \\
SIMVAR & 0.20202 & 0.07890 \\
GBLVAR & 0.50840 & 0.10520 \\
GGMVAR $^{\text {GBLVAR }}$ GG & 0.27353 & 0.10959 \\
SOBVAR & 0.59852 & 0.11397 \\
HPACM & 0.72370 & 0.17972 \\
Entropia & 0.55325 & 0.31999 \\
GBLVAR $_{\text {LoG }}$ & 1.50575 & 0.42957 \\
\hline
\end{tabular}

Na tabela 5.3 são apresentados os erros de focalização para as imagens do conjunto C. O uso da medida TOTVAR resultou na focalização incorreta de 13 imagens em 118, nas quais foi escolhida outra distância imediatamente seguida, e para a medida SIMVAR o mesmo ocorreu em 18 imagens.

A figura 5.6 exibe as distribuições de erros de focalização para cada uma das medidas testadas, considerando o conjunto total de 187 imagens. Enquanto que nas tabelas foram utilizados os erros absolutos, nesta figura existem erros positivos e negativos. Isto permite diferenciar o caso em que a distância de reconstrução escolhida foi próxima demais ao sensor da câmera do caso em que a distância foi muito distante. Através dos quartis, é possível notar no gráfico superior que várias das melhores medidas obtiveram a distância correta de focalização para pelo menos $50 \%$ das imagens. 

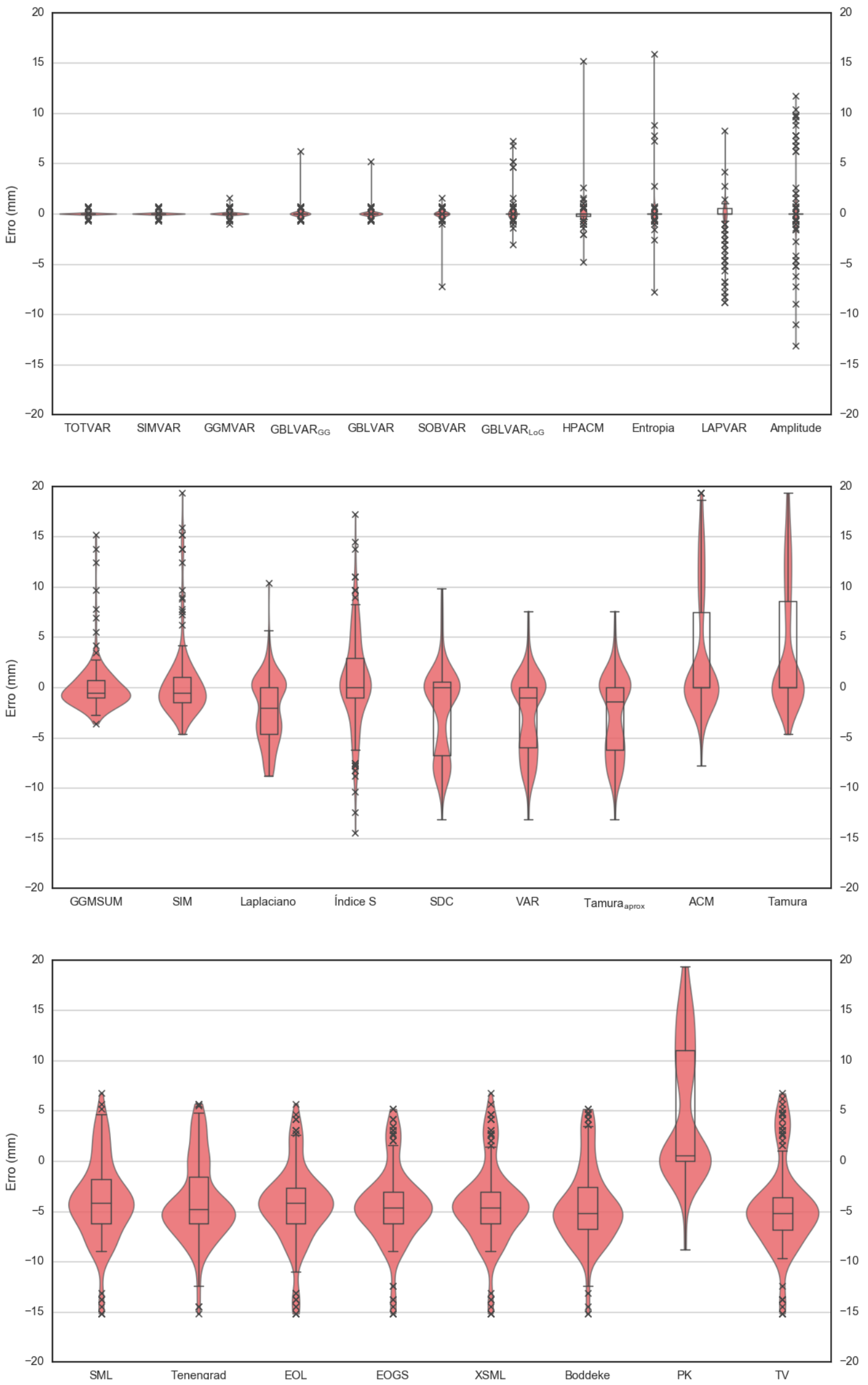

Figura 5.6: Distribuição dos erros de focalização. Erros negativos indicam uma reconstrução mais próxima ao sensor da câmera do que a distância de referência escolhida manualmente. 
Tabela 5.4: Erros de focalização - Total

\begin{tabular}{|l|r|r|}
\hline Medida & RMSE $(\mathrm{mm})$ & Erro médio $(\mathrm{mm})$ \\
\hline \hline TOTVAR & 0.18401 & 0.05809 \\
SIMVAR & 0.19614 & 0.06823 \\
GGMVAR GBLVAR $_{\mathrm{GG}}$ & 0.25498 & 0.09497 \\
GBLVAR & 0.49381 & 0.09773 \\
SOBVAR $^{\text {GBLVAR }}$ & 0.43126 & 0.09958 \\
HoG & 0.59659 & 0.15029 \\
HPACM & 1.08767 & 0.32086 \\
Entropia & 1.27080 & 0.39001 \\
LAPVAR & 1.68591 & 0.40752 \\
\hline
\end{tabular}

Nas duas medidas com menor erro médio, TOTVAR e SIMVAR, o maior erro foi de apenas um passo de focalização para mais ou para menos.

Conforme a tabela 5.4, a medida TOTVAR é a que obteve o melhor desempenho dentre as medidas avaliadas, possuindo o menor erro médio nos conjuntos de imagens A e C, e um erro médio apenas um pouco superior ao da melhor medida para o conjunto B. Porém, como foi dito anteriormente, estes pequenos erros da medida podem ser atribuídos à subjetividade das distâncias de referência e à ambiguidade do problema de focalização, e não é possível afirmar a partir destes resultados que seu desempenho é superior ao da medida SIMVAR. Todas as outras medidas obtiveram um erro de pelo menos dois passos de focalização para pelo menos uma das imagens. Portanto, concluímos que as medidas TOTVAR e SIMVAR empataram como as melhores medidas de foco avaliadas, tendo erros médios extremamente baixos. Lembrando que não temos conhecimento destas duas medidas que estão sendo propostas neste trabalho sendo utilizadas na literatura.

É interessante notar algumas semelhanças entre as medidas que obtiveram os menores erros. As quatro melhores medidas utilizam a magnitude do gradiente gaussiano em seu cálculo. E das sete melhores medidas de foco, todas exceto a TOTVAR podem ser interpretadas como a aplicação de um filtro na imagem seguida pelo cálculo da variância da imagem filtrada. Isto faz sentido quando comparamos visualmente imagens fora de foco com imagens bem focalizadas: as que estão focalizadas possuem algumas bordas fortes e a maior parte da imagem tem poucas variações, e conforme o objeto é desfocalizado as ondas de difração geram ondulações na intensidade de boa parte da imagem. Portanto, um filtro que responda a estas variações terá um valor bem elevado para algumas regiões e relativamente baixo para outras em uma imagem focalizada, ou seja, terá uma variância alta. Já em uma imagem fora de foco as ondas de difração irão gerar valores similares para este filtro em grande parte da imagem, e a variância será baixa. Outra característica que pode ser observada é que várias medidas combinam valores obtidos em diferentes escalas. A medida TOTVAR, por exemplo, utiliza os valores dos pixels para calcular a magnitude do gradiente gaussiano, que se torna menos local quanto maior for o valor de $\sigma$; depois utiliza esta magnitude para calcular a variância em janelas, resultando em valores menos localizados do que o gradiente; e finaliza calculando o somatório global para a imagem.

Também é possível combinar mais de uma medida de foco, ao invés de utilizar apenas uma. Não faremos um estudo detalhado das diferentes formas de realizar estas combinações, mas apenas mostraremos que mesmo uma técnica simples já pode trazer bons resultados. Ao invés de utilizar a distância escolhida por uma medida, utilizamos 5 medidas e escolhemos a mediana como distância final. Na tabela 5.5 está o resultado de utilizar a mediana das medidas SIMVAR, GBLVAR, TOTVAR, SOBVAR e Entropia. Neste caso, a medida TOTVAR foi calculada com o parâmetro $\sigma=2$. Os erros nos conjuntos A e B são idênticos aos da medida SIMVAR, porém há uma diminuição nos erros do conjunto C, que são menores do que os erros de qualquer medida individual. 
Tabela 5.5: Erros de focalização - Mediana

\begin{tabular}{|l|r|r|}
\hline Conjunto & RMSE $(\mathrm{mm})$ & Erro médio $(\mathrm{mm})$ \\
\hline \hline $\mathrm{A}$ & 0.15822 & 0.03630 \\
$\mathrm{~B}$ & 0.19506 & 0.05517 \\
$\mathrm{C}$ & 0.16495 & 0.05260 \\
Total & 0.17287 & 0.05163 \\
\hline
\end{tabular}

\section{Algoritmo de autofoco}

As medidas também foram avaliadas quando utilizadas em um algoritmo de autofoco que realiza a focalização em três etapas, com o objetivo de diminuir o número total de reconstruções. Para cada imagem são utilizadas as mesmas 30 reconstruções que nos experimentos anteriores, porém em cada etapa do algoritmo apenas um subconjunto destas reconstruções tem seu foco avaliado. Na primeira etapa é medido o foco das reconstruções cujos índices pertencem ao conjunto $\{0,5,10,15,20,25,29\}$. $\mathrm{Na}$ segunda etapa, além da reconstrução de índice $k$ escolhida na etapa anterior, também são consideradas as reconstruções de índice par e que pertencem ao intervalo $] k-5, k+5[$. Na terceira e última etapa são consideradas as reconstruções de índice $k-1, k$ e $k+1$, onde $k$ é o índice que obteve o melhor foco na etapa anterior.

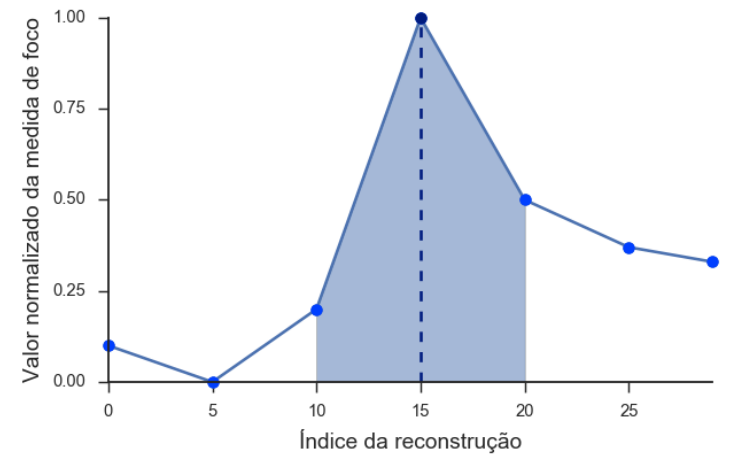

(a) Passo 1

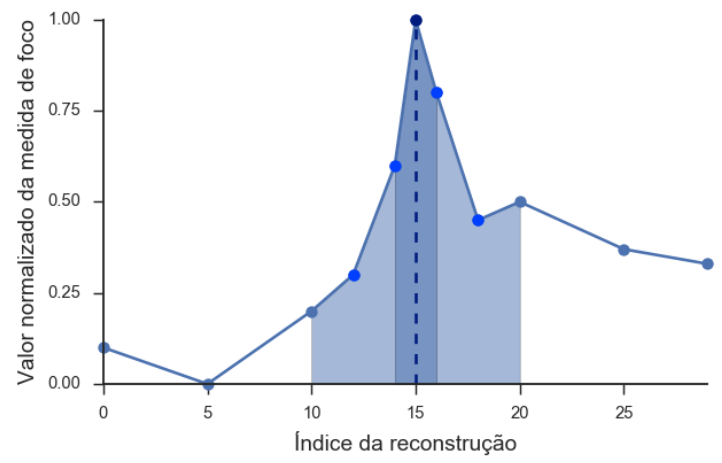

(b) Passo 2

Figura 5.7: Exemplo de execução do algoritmo de autofoco. No primeiro passo (a), o foco de algumas reconstruções é avaliado por uma medida de foco, e a reconstrução de índice 15 é a que obtém o melhor foco, indicado pela linha tracejada vertical. A região sombreada em torno deste índice é selecionada para o passo seguinte (b), no qual as reconstruções de indices 12, 14, 16 e 18 são avaliadas. A reconstrução de índice 15 continua sendo a melhor focalizada segundo a medida, e a região sombreada mais escura é selecionada para o passo 3. Porém, as reconstruções de índices 14, 15 e 16 que seriam avaliadas no passo 3 já foram examinadas, e o algoritmo termina escolhendo a reconstrução de índice 15 como a melhor focalizada por esta medida.

Como exemplo, suponha que das 7 reconstruções iniciais na primeira etapa, a que está melhor focalizada segundo a medida sendo avaliada é a de índice 15 , como ilustrado na figura $5.7 \mathrm{a}$. Na segunda etapa é avaliado o foco das reconstruções de índices 12, 14, 16 e 18, além da reconstrução 15 que já foi avaliada. Suponha que, dentre estas 5 reconstruções, a de índice 15 continue sendo a melhor, como ilustrado na figura 5.7b. Na terceira etapa são avaliadas as reconstruções 14,15 e 16. Como as três já foram avaliadas nas etapas anteriores, temos que a melhor reconstrução é a de índice 15. Neste exemplo foram feitas 7 reconstruções na primeira etapa, 4 reconstruções na segunda e nenhuma reconstrução na terceira. Com isso temos 11 reconstruções, ao invés das 30 que seriam feitas se a focalização tivesse uma única etapa.

Outro exemplo: na primeira etapa a reconstrução 10 obtém o melhor foco, conforme ilustrado na figura 5.8a. Na segunda etapa são avaliadas as reconstruções 6, 8, 12 e 14, além da reconstrução 10, 


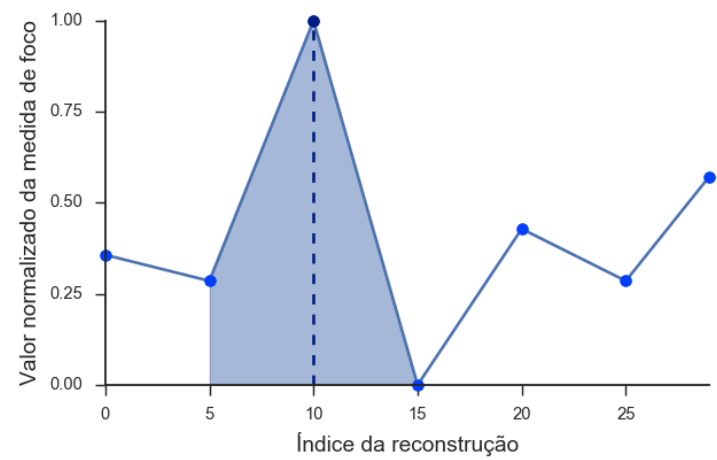

(a) Passo 1

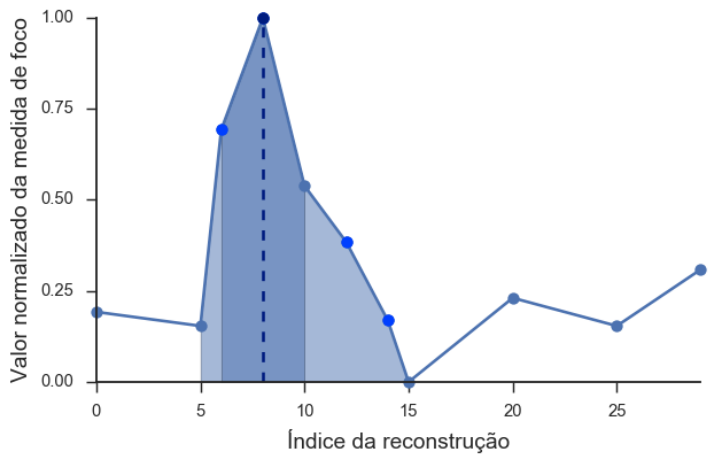

(b) Passo 2

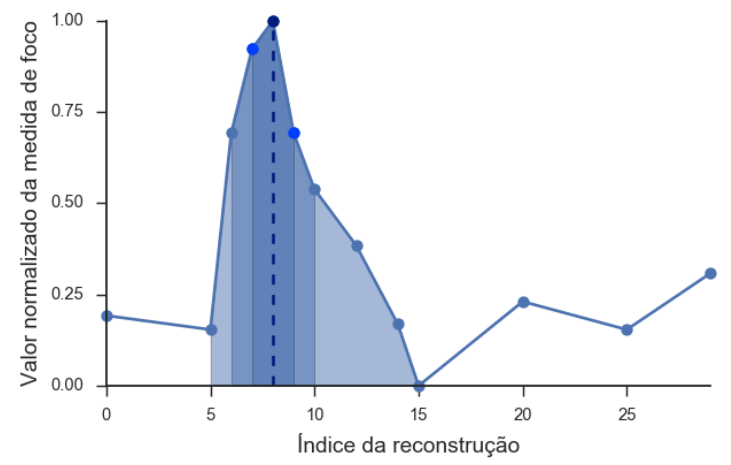

(c) Passo 3

Figura 5.8: Exemplo de execução do algoritmo de autofoco. No primeiro passo (a), o foco de algumas reconstruções é avaliado por uma medida de foco, e a reconstrução de índice 10 é a que obtém o melhor foco, indicado pela linha tracejada vertical. A região sombreada em torno deste índice é selecionada para o passo seguinte (b), no qual as reconstruções de indices 6, 8, 12 e 14 são avaliadas. A reconstrução de indice 8 torna-se a melhor focalizada segundo a medida, e a região sombreada mais escura é selecionada para o passo 3. Neste último passo, as reconstruções de índices 7 e 9 são avaliadas, e o algoritmo termina escolhendo a reconstrução de índice 8 como a melhor focalizada segundo a medida. 
conforme ilustrado na figura 5.8b. Supondo que a reconstrução 8 obteve o melhor foco, na terceira etapa são avaliadas as reconstruções 7,8 e 9, conforme ilustrado na figura 5.8c. Com relação ao número de reconstruções este é o pior caso, pois foram feitas 7 reconstruções na primeira etapa, 4 na segunda e 2 na terceira, totalizando 13 reconstruções.

Tabela 5.6: Erros de autofoco - Conjunto A

\begin{tabular}{|c|c|c|}
\hline Medida & RMSE (mm) & Erro médio $(\mathrm{mm})$ \\
\hline SIMVAR & 0.15822 & 0.03630 \\
\hline TOTVAR & 0.15822 & 0.03630 \\
\hline GBLVAR $_{\mathrm{GG}}$ & 0.22375 & 0.07260 \\
\hline SOBVAR & 0.27404 & 0.10889 \\
\hline GGMVAR & 0.27404 & 0.10889 \\
\hline GBLVAR & 0.27404 & 0.10889 \\
\hline GBLVAR $_{\text {LoG }}$ & 0.27404 & 0.10889 \\
\hline HPACM & 0.31644 & 0.14519 \\
\hline Entropia & 0.67126 & 0.21779 \\
\hline GGMSUM & 0.82212 & 0.68966 \\
\hline Amplitude & 3.01445 & 0.76225 \\
\hline LAPVAR & 2.12860 & 0.90744 \\
\hline Laplaciano & 2.55118 & 1.37931 \\
\hline
\end{tabular}

Tabela 5.7: Erros de autofoco - Conjunto B

\begin{tabular}{|c|c|c|}
\hline Medida & RMSE (mm) & Erro médio $(\mathrm{mm})$ \\
\hline SIMVAR & 0.19506 & $\overline{0.05517}$ \\
\hline GGMVAR & 0.19506 & 0.05517 \\
\hline GBLVAR $_{\mathrm{GG}}$ & 0.21809 & 0.06897 \\
\hline GBLVAR & 0.23890 & 0.08276 \\
\hline SOBVAR & 0.25805 & 0.09655 \\
\hline GBLVAR $_{\text {LoG }}$ & 0.57701 & 0.23448 \\
\hline Entropia & 2.26013 & 0.42759 \\
\hline LAPVAR & 1.35846 & 0.44138 \\
\hline TOTVAR & 2.68169 & 0.80000 \\
\hline HPACM & 2.85854 & 1.03448 \\
\hline Laplaciano & 3.39406 & 1.17241 \\
\hline
\end{tabular}

Nas tabelas 5.6, 5.7 e 5.8 são exibidos os erros de focalização ao utilizar este algoritmo de autofoco. A medida SIMVAR não só obteve os menores erros nos três conjuntos de imagens, mas os erros nos conjuntos A e B são iguais aos dos experimentos anteriores que utilizam 30 reconstruções, demonstrando a viabilidade de usar este algoritmo para obter focalizações mais rápidas sem que isto resulte em uma perda considerável de precisão. 
Tabela 5.8: Erros de autofoco - Conjunto $C$

\begin{tabular}{|l|r|r|}
\hline Medida & RMSE $(\mathrm{mm})$ & Erro médio $(\mathrm{mm})$ \\
\hline \hline SIMVAR & 0.40122 & 0.11835 \\
GBLVAR & 0.73612 & 0.17972 \\
GBLVAR $_{\mathrm{GG}}$ & 1.04213 & 0.23232 \\
SOBVAR $_{\text {GGMVAR }}$ & 0.89842 & 0.28930 \\
HPACM & 1.05939 & 0.32876 \\
TOTVAR & 1.09413 & 0.51724 \\
GBLVAR $_{\text {LoG }}$ & 1.60063 & 0.53477 \\
Entropia & 1.48299 & 0.60491 \\
\hline
\end{tabular}




\section{Capítulo 6}

\section{Sistema web}

Neste capítulo descrevemos o sistema que foi desenvolvido para o processamento de imagens de hologramas digitais de plâncton.

\subsection{Arquitetura}

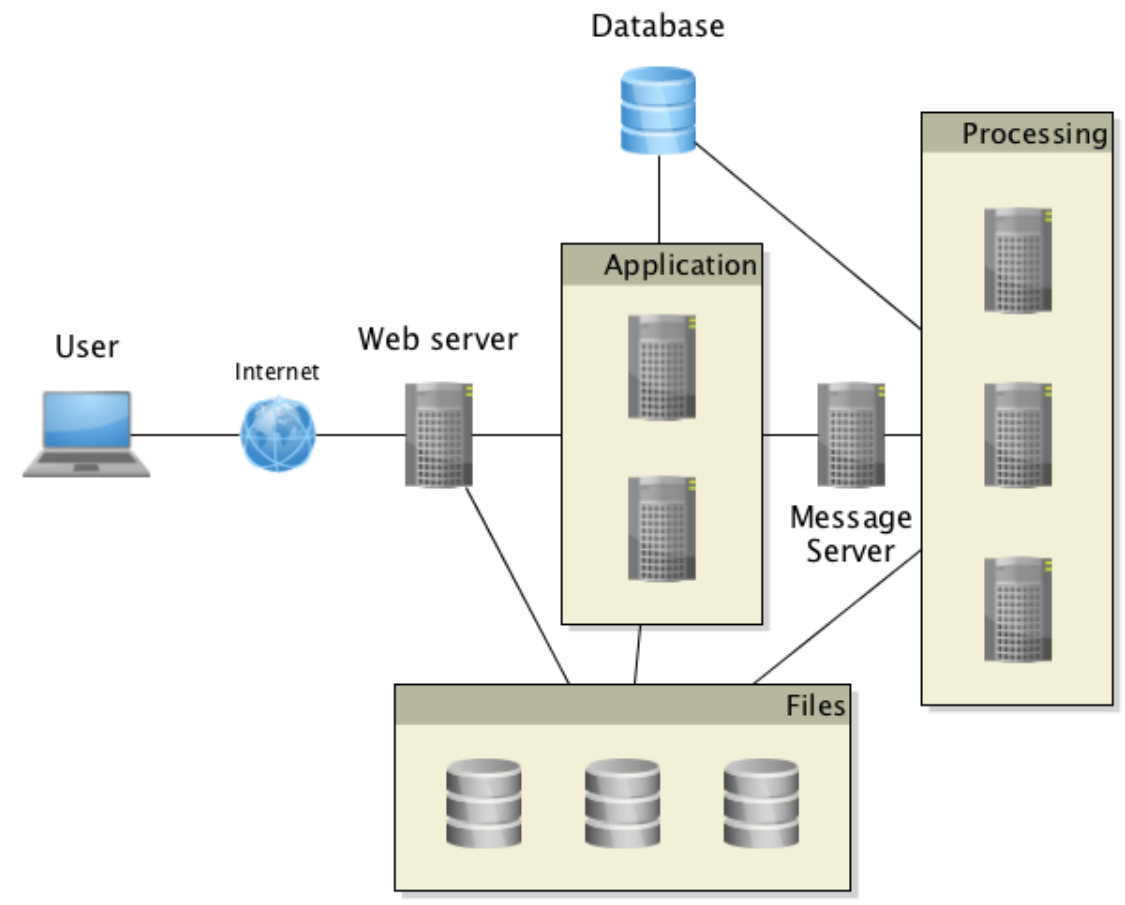

Figura 6.1: Arquitetura do sistema.

Foi desenvolvido um sistema web para o processamento distribuído de imagens holográficas, disponibilizado sob a licença GPLv2 ${ }^{1}$ ou versão posterior, cuja arquitetura pode ser vista na figura 6.1. O sistema usa o arcabouço Django ${ }^{2}$, sendo programado quase inteiramente na linguagem Python, exceto pela interface que utiliza HTML, CSS e JavaScript. Os arquivos de imagens são armazenados de forma distribuída no sistema de arquivos GlusterFS ${ }^{3}$ (Files). O Gunicorn ${ }^{4}$ é usado nos servidores de aplicação (Application) . O RabbitMQ ${ }^{5}$ é usado no servidor de mensagens

\footnotetext{
${ }^{1}$ https://www.gnu.org/licenses/gpl-2.0.html Acessado em 6 de julho de 2017.

${ }^{2}$ https://www.djangoproject.com/ Acessado em 27 de fevereiro de 2017.

${ }^{3}$ https://www.gluster.org/ Acessado em 27 de fevereiro de 2017.

${ }^{4}$ http://gunicorn.org/ Acessado em 27 de fevereiro de 2017.

${ }^{5}$ https://www.rabbitmq.com/ Acessado em 27 de fevereiro de 2017.
} 
(Message Server) para realizar a comunicação entre os servidores de aplicação e os servidores de processamento (Processing). Nos servidores de processamento, o Celery ${ }^{6}$ é usado para executar tarefas de processamento de forma distribuída. O status destas tarefas (e.g., "Em processamento" ou "Finalizada") é armazenado no Redis ${ }^{7}$, que também está localizado no servidor de mensagens. O banco de dados (Database) PostgreSQL ${ }^{8}$ armazena todos os dados do sistema, exceto as imagens, para as quais armazena apenas o caminho do arquivo. O servidor NGINX ${ }^{9}$ (Web server) recebe as requisições e as redireciona para os servidores de aplicação, além de servir os arquivos de imagem.

Esta arquitetura permite uma flexibilidade razoável no crescimento do sistema, podendo serem adicionadas novas máquinas onde forem mais necessárias. O processamento de imagens é uma tarefa que consome muitos recursos computacionais e é demorada, sendo realizado em máquinas separadas de forma assíncrona. Isto libera os servidores de aplicação destas tarefas, para que continuem respondendo de forma rápida, sem lentidões no uso da interface. Os arquivos de imagens, que representam a maior parte dos dados, são armazenados no GlusterFS, que permite distribuir e replicar os arquivos em vários dispositivos de armazenamento. Desta forma, mesmo que um dispositivo falhe ainda é possível acessar os arquivos sem a necessidade de recuperar um backup. Também facilita a adição de novos dispositivos de armazenamento, pois todos eles são vistos pelos clientes como um único sistema de arquivos. O arcabouço Django permite que novas funcionalidades sejam adicionadas ao sistema de forma modular, simplificando o compartilhamento e reaproveitamento de código entre diferentes sistemas. Portanto, a maior dificuldade de se adicionar uma nova funcionalidade ao sistema está em seu desenvolvimento, e não na sua integração ao resto do código, incentivando a adição de novas funcionalidades e a realização de melhorias.

Algumas dificuldades que surgem nos estudos de plâncton decorrem do uso de diversas máquinas e dispositivos de armazenamento, o que faz com que os dados não sejam facilmente localizados e compartilhados entre os diversos pesquisadores. Na prática, não existe uma política de gerenciamento destes dados, o que pode inclusive ocasionar a perda de meses de pesquisas caso uma máquina falhe e não existam outras cópias. Tendo em vista esta situação, e lembrando que a grande maioria dos pesquisadores envolvidos não é da área de Tecnologia da Informação, escolheu-se a arquitetura apresentada com o objetivo de centralizar e organizar o armazenamento de imagens holográficas. Apesar da instalação inicial ser um tanto complexa, a manutenção pode ser feita sem grandes esforços. Esta arquitetura já prevê situações como a falha em um disco rígido, e facilita o compartilhamento de dados até mesmo com grupos de pesquisa localizados em outros países, bastando fornecer credenciais de acesso ao sistema.

\subsection{Interface}

O sistema possui uma interface web, fazendo com que possa ser utilizado de praticamente qualquer computador de forma fácil, sem precisar ser instalado em cada máquina. A seguir ilustraremos as principais características do sistema e sua interface.

A tela inicial do sistema pode ser vista na figura 6.2. Os arquivos de imagens são organizados em experimentos, e nesta figura podem ser vistos alguns dos hologramas de dois experimentos diferentes.

Cada experimento possui um conjunto de parâmetros, como pode ser visto na figura 6.3. Estes parâmetros incluem as dimensões dos pixels da câmera, o comprimento de onda do laser, e as distâncias mínima e máxima entre a amostra sendo observada e o sensor da câmera, entre outros.

Após preencher os parâmetros do experimento, os hologramas podem ser enviados ao sistema, como ilustrado na figura 6.4. É possível realizar o upload de vários arquivos simultaneamente, e estes podem ser arrastados e soltados na tela de upload, facilitando o envio.

Os hologramas enviados podem ser visualizados na tela exibida na figura 6.5. É possível iniciar o processamento de todos os hologramas, ou exibí-los em lista, e então processar ou excluir alguns

\footnotetext{
${ }^{6}$ http://www.celeryproject.org/ Acessado em 27 de fevereiro de 2017.

${ }^{7}$ https://redis.io/ Acessado em 27 de fevereiro de 2017.

${ }^{8}$ https://www.postgresql.org/ Acessado em 27 de fevereiro de 2017.

${ }^{9}$ https://www.nginx.com/ Acessado em 27 de fevereiro de 2017.
} 
Acartia_test_2 (329 images)
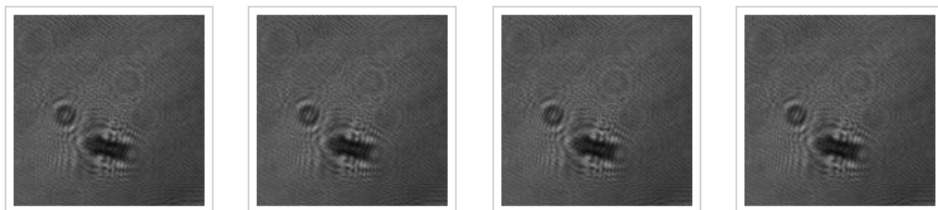

eve_July_b2 (31 images)
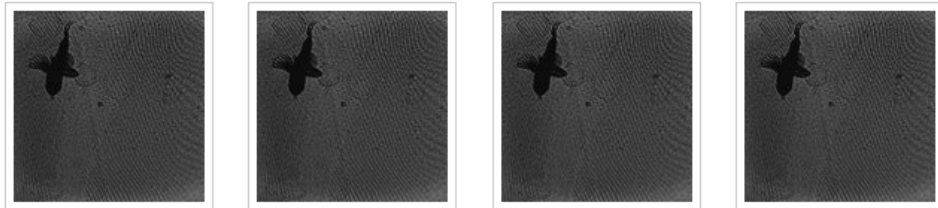

Figura 6.2: Tela inicial.

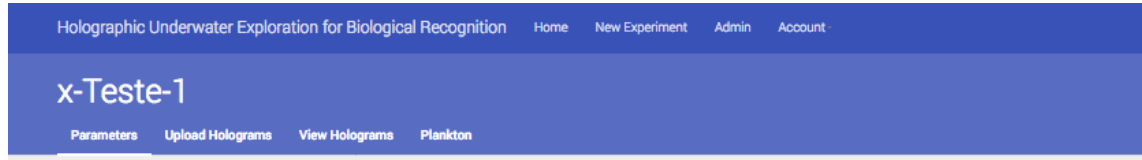

Parameters Upload Holograms View Holvorams Planktion

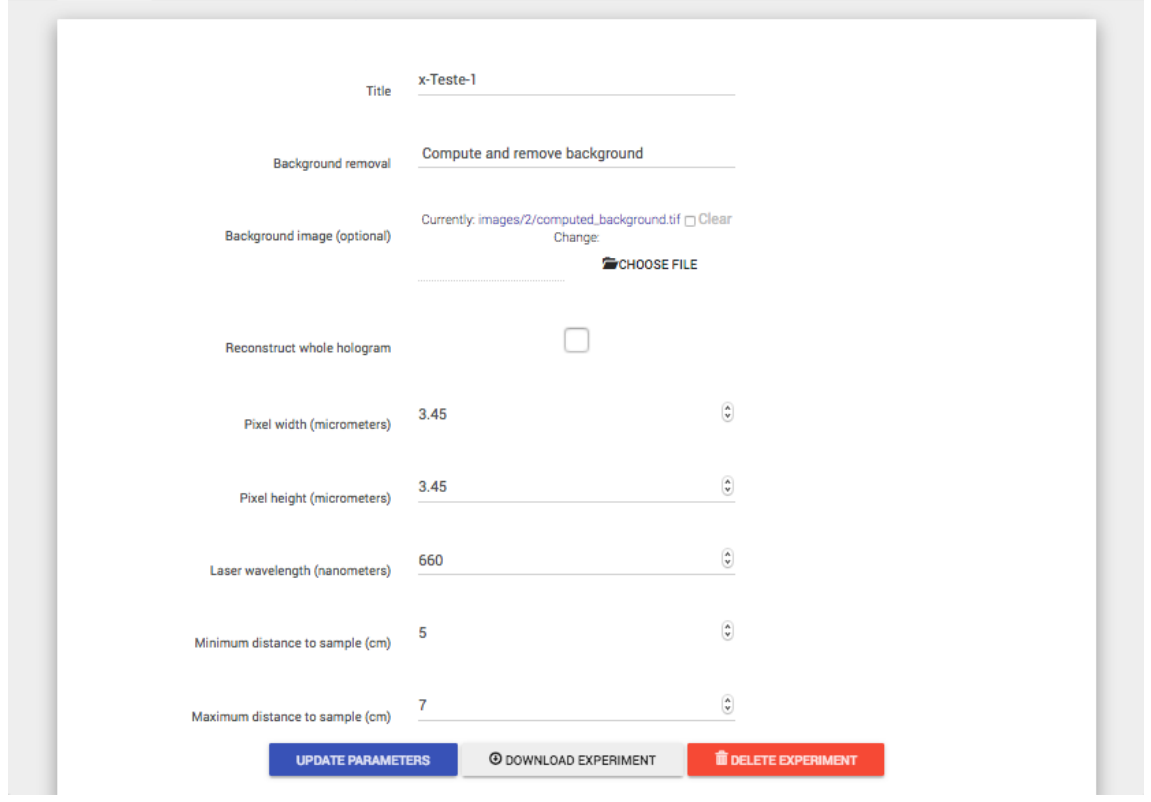

Figura 6.3: Parâmetros de um experimento. 


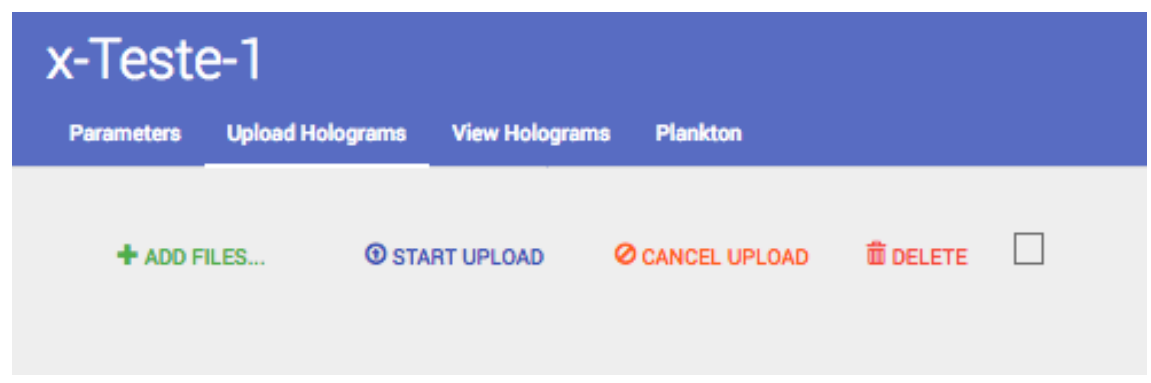

Figura 6.4: Tela para upload de hologramas.

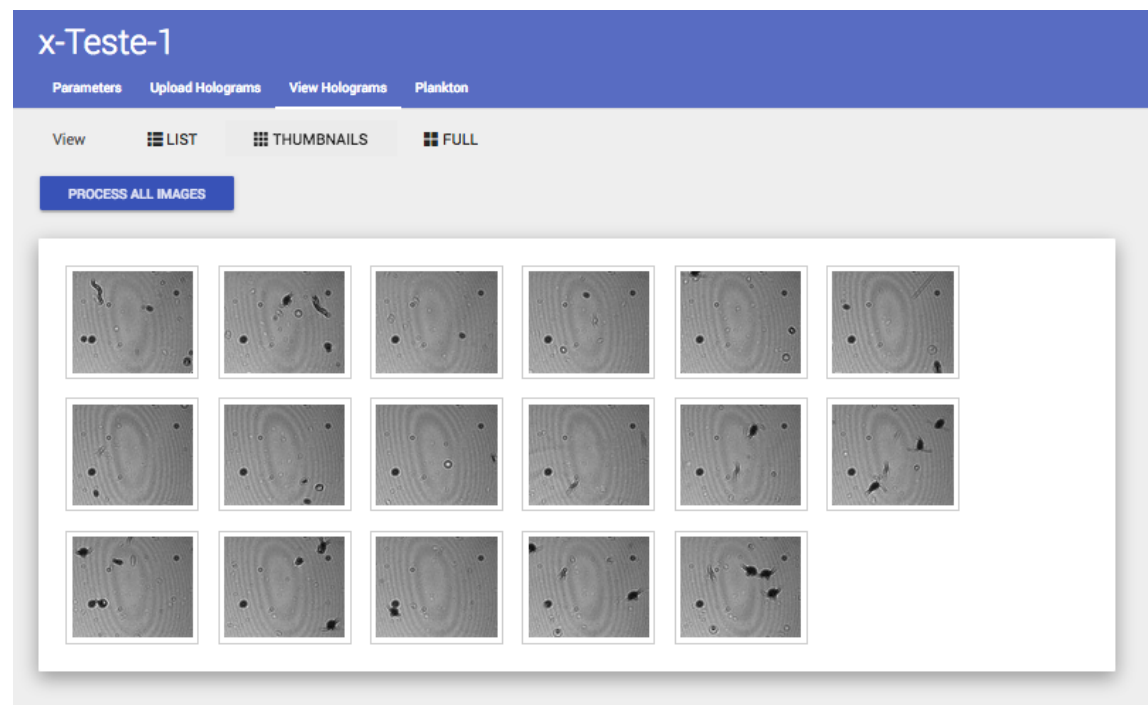

Figura 6.5: Visualização dos hologramas enviados. 
hologramas específicos.

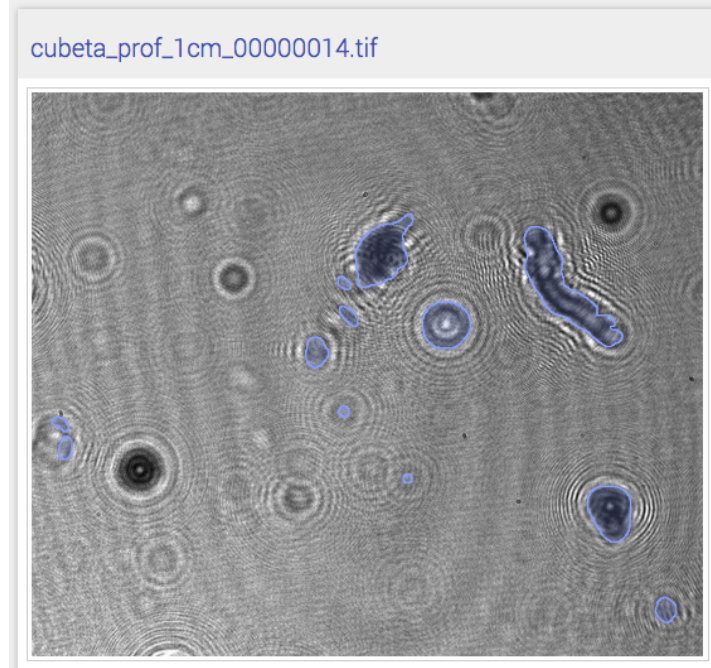

(a) Organismos segmentados

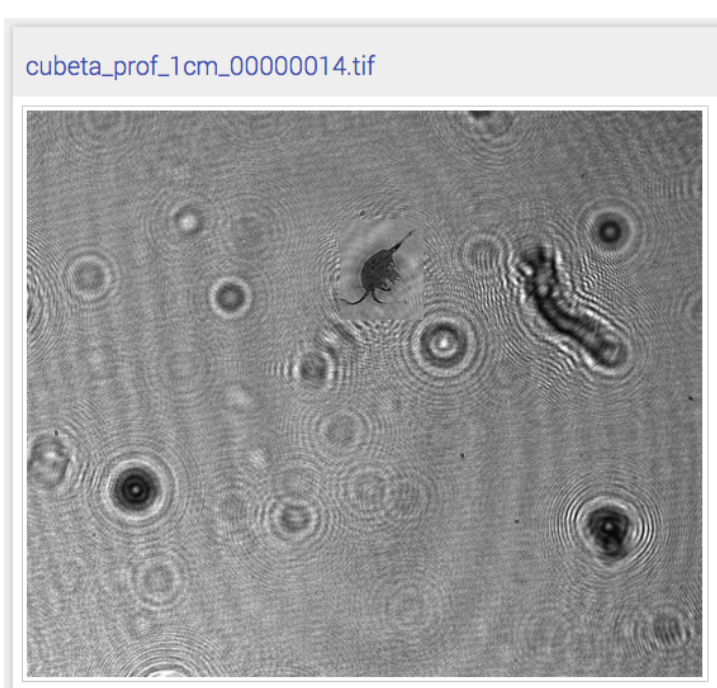

(b) Organismo reconstruído

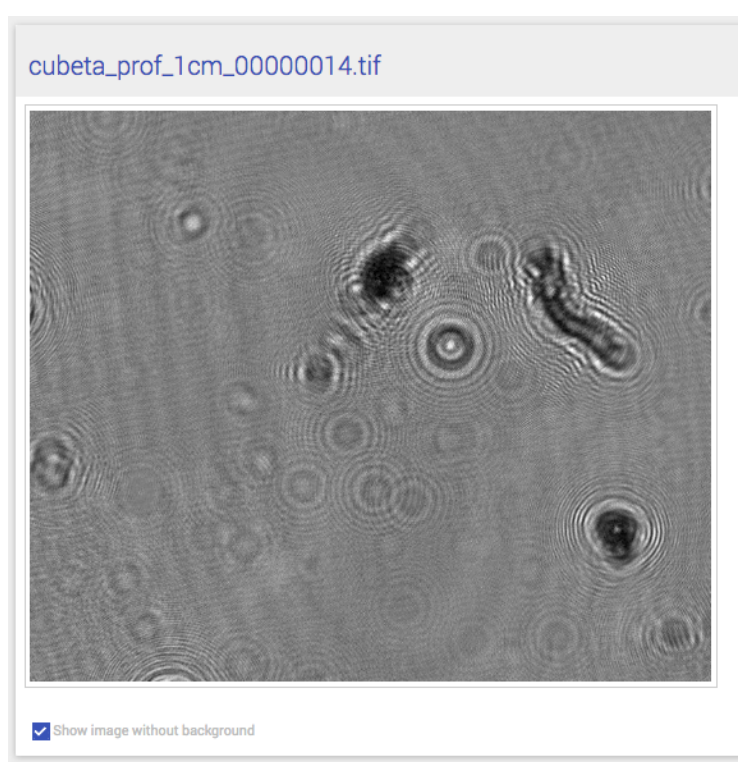

(c) Holograma com fundo removido

Figura 6.6: Visualização de um holograma.

Após serem processados, os resultados de cada holograma podem ser vistos como na figura 6.6. Ao mover o mouse sobre o holograma, as regiões segmentadas são destacadas, como na figura 6.6a. Quando o mouse é colocado sobre uma das regiões destacadas, a reconstrução focalizada desta região é exibida como na figura $6.6 \mathrm{~b}$, na qual o copépodo próximo ao centro está sendo visualizado. Existem alguns organismos que aparentemente não foram segmentados na figura 6.6a, mas grande parte destes são parte do fundo da imagem, ou seja, são padrões estáticos que foram removidos com o fundo. A imagem sem o fundo pode ser vista selecionando-se um checkbox, como na figura 6.6c.

As regiões de interesse que foram segmentadas e focalizadas automaticamente são exibidas em uma aba separada, ilustrada na figura 6.7. Os segmentos são separados em três grupos: os que não foram validados manualmente, os que precisam ser focalizados manualmente, e os que já foram validados. É possível realizar a validação manual de todas as imagens de uma só vez, seja aceitando os resultados automáticos, ou exigindo uma focalização manual para todas elas.

A figura 6.8 mostra a tela de focalização manual, na qual uma barra pode ser deslizada para modificar a distância de reconstrução. Quando estiver bem focalizado, basta clicar no botão OK para validar o organismo. 


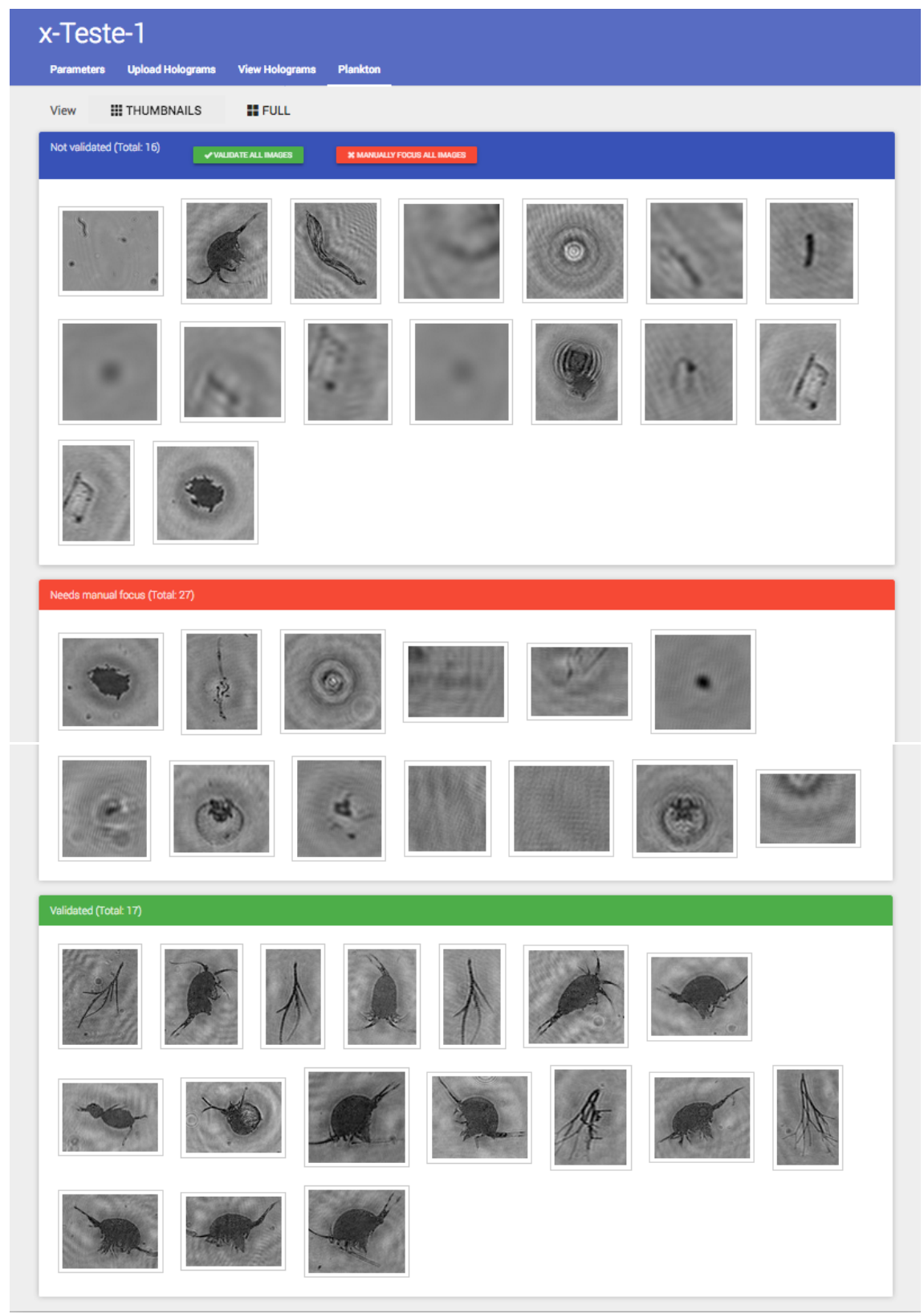

(a) Organismos segmentados

Figura 6.7: Visualização dos organismos segmentados. 


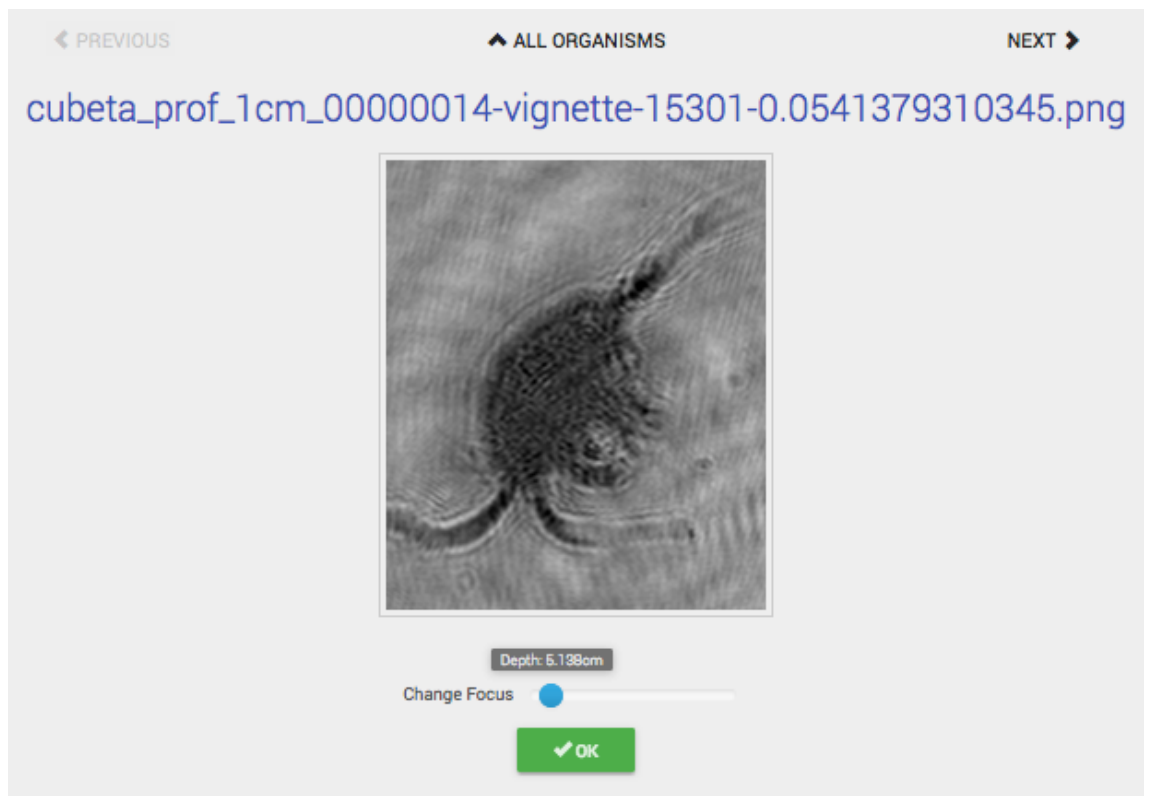

Figura 6.8: Focalização manual de um organismo.

Os resultados do processamento podem ser baixados de uma única vez na tela de parâmetros, no botão Download experiment. Assim, se desejar o usuário pode utilizar outro sistema para realizar a classificação das imagens, por exemplo. 


\section{Capítulo 7}

\section{Conclusão}

Criada várias décadas atrás, a holografia era uma técnica muito a frente de seu tempo, e ainda seriam necessários alguns avanços tecnológicos para sua adoção em maior escala. A invenção do laser permitiu a criação de hologramas ópticos de forma relativamente simples, e avanços em computadores e sensores digitais de câmeras tornaram a holografia digital uma alternativa prática. Porém, ainda resta o desenvolvimento de algoritmos e software que transformem os hologramas digitais em dados úteis para pesquisadores de forma simples.

As possibilidades oferecidas pelo processamento digital de hologramas são inúmeras, e nas seções abaixo recapitulamos as contribuições deste trabalho, além de indicar algumas possíveis linhas de pesquisa para estendê-lo.

\subsection{Contribuições}

Neste trabalho, detalhamos as diversas etapas de processamento de imagens de holografia digital de plâncton, partindo dos hologramas obtidos experimentalmente e chegando em imagens focalizadas e segmentadas de organismos planctônicos. Realizamos uma análise de diferentes algoritmos de reconstrução holográfica, verificando como diferentes frequências da imagem são afetadas e quais os cuidados necessários para evitar artefatos na imagem final. Tratamos os aspectos discretos dos algoritmos, notando os efeitos de amostragem de funções de transferência, e da convolução circular realizada através da FFT. Propomos algoritmos para melhorar a qualidade das imagens que dificilmente poderiam ser implementados com instrumentos ópticos: removemos o fundo dos hologramas, tornando a iluminação mais uniforme e suprimindo artefatos provenientes do sistema óptico; e estendemos a borda dos hologramas antes de sua reconstrução, obtendo imagens com menos ondulações provenientes da difração da borda retangular do holograma. Também comparamos diferentes medidas de foco, com as quais podemos obter imagens focalizadas dos organismos de forma automática.

No Capítulo 4, estudamos diversos algoritmos para estender imagens de holografia digital, e propomos um novo algoritmo: a Minimização do Laplaciano. Fizemos uma comparação experimental para determinar quais destes algoritmos obtêm os menores erros na imagem reconstruída, e a Minimização do Laplaciano mostrou-se superior aos outros algoritmos testados. Com isso, conseguimos diminuir consideravelmente o efeito de difração da borda do holograma, permitindo a visualização do objeto sendo observado sem estes artefatos que decorrem da natureza finita das dimensões da imagem.

No Capítulo 5, fizemos a comparação de diversas medidas de foco, além de propor algumas novas medidas, incluindo a Variância Total do Gradiente Gaussiano e a Variância do Máximo Orientado da Intensidade. Realizamos comparações experimentais das medidas, e estas duas medidas propostas mostraram-se superiores a todas as outras que foram avaliadas, com erros de focalização extremamente pequenos. Também apresentamos um algoritmo de autofoco, que realiza um número menor de reconstruções holográficas, diminuindo o tempo de processamento, com pouca perda de qualidade na focalização. Concluímos que a focalização totalmente automática de organismos planctônicos é 
perfeitamente factível, o que remove uma das principais dificuldades do uso da holografia no estudo de plâncton, que é a necessidade de focalizar as imagens após sua aquisição, algo que seria muito trabalhoso se precisasse ser feito de forma manual.

Por fim, no Capítulo 6 apresentamos o sistema web que foi desenvolvido para o processamento de imagens holográficas de plâncton. O sistema permite o processamento distribuído das imagens, diminuindo o tempo total de processamento. O uso de uma interface web faz com que o sistema possa ser usado em praticamente qualquer computador, sem a necessidade de instalar o programa em cada máquina, bastando a configuração dos servidores. E sua disponibilização como software livre facilita sua adoção por diversos pesquisadores, além de permitir futuras melhorias por seus usuários. Com isso, os resultados deste trabalho poderão ser utilizados no dia-a-dia do estudo de organismos planctônicos, sem que para isso seja necessário compreender todos os detalhes e complexidades da holografia digital.

\subsection{Trabalhos futuros}

Existem diversas formas de estender e aprimorar os resultados deste trabalho, e a seguir listamos algumas que julgamos serem interessantes.

Um aspecto pouco estudado na área de holografia digital de plâncton é o pós-processamento das imagens reconstruídas, que normalmente consiste apenas na segmentação e extração de características para classificação. Devido à capacidade de focalizar numericamente a qualquer distância desejada, é possível obter um volume que, após algum processamento, resultaria em uma imagem com qualidade superior a qualquer uma das imagens individuais que o compõem.

Uma das técnicas existentes é a desconvolução, que já foi utilizada em holografia com o objetivo de obter maior precisão na localização de partículas, e com alguns resultados limitados para objetos extensos [LGF10]. A desconvolução também pode ser usada para diminuir o efeito da imagem gêmea ou de objetos fora de foco. A maior desvantagem é que o gasto de memória e o tempo de processamento são extremamente elevados, diminuindo a utilidade prática desta técnica. Também é possível realizar a desconvolução de uma única imagem, e não de um volume, o que poderia ser uma alternativa com menor custo computacional.

Outro pós-processamento possível consiste na remoção ou supressão da imagem gêmea, e várias técnicas já foram propostas para realizar esta tarefa, com diferentes graus de sucesso [HKPM09]. Algumas delas possuem certas restrições, como a exigência de diferentes configurações ópticas, ou apenas objetos de amplitude.

Outra técnica é conhecida por composição focal (focus stacking) e permite combinar várias imagens, cada uma focalizada a uma distância diferente, em uma imagem final que é uma "colagem" de pedaços bem focalizados das imagens originais. Com isso, poderia-se obter uma imagem em que o organismo inteiro apareça focalizado, permitindo visualizar os detalhes de sua morfologia. A composição focal também poderia ser feita utilizando o resultado da desconvolução de um volume, caso esta desconvolução obtenha bons resultados. Na área de holografia, esta técnica e outras similares já foram utilizadas na microscopia holográfica digital de objetos de fase, para observar uma ameba $\left[\mathrm{BCP}^{+} 09\right]$, além de ter sido utilizada em objetos não biológicos, tanto macroscópicos quanto microscópicos [MHN08, $\mathrm{FGA}^{+}$05, DJ07, NNŠ+${ }^{+}$03], e rostos humanos [TFHH09]. Porém, nenhuma destas técnicas parece ter sido estudada no processamento de hologramas de plâncton.

Além do algoritmo de autofoco apresentado neste trabalho, também é possível utilizar outros algoritmos para diminuir o tempo gasto na focalização. Uma possibilidade seria diminuir a resolução dos hologramas em uma primeira etapa de focalização e, em etapas posteriores, utilizar resoluções maiores apenas nas distâncias em que a medida de foco indicar a existência de um objeto. Seria necessário estudar como esta resolução menor afeta as medidas de foco, para determinar como manter uma focalização confiável mesmo com a perda de detalhes nas primeiras etapas do algoritmo.

Neste trabalho focalizamos a imagem de um organismo como um todo, e não os pixels individualmente, ou pequenas regiões da imagem. Caso se deseje posteriormente fazer uma focalização mais local, os resultados obtidos no Capítulo 5 poderão auxiliar na escolha de medidas de foco, 
além de ajudar a clarificar quais são as características que distinguem imagens bem focalizadas das restantes. E como ilustrado por Thelen et al. [TFHH09], não é possível realizar uma focalização mais local em toda a imagem, sendo necessário em vários casos utilizar janelas maiores, nas quais os resultados obtidos aqui podem ser aplicados.

As técnicas utilizadas no artigo de Thelen et al. [TFHH09] poderiam ser analisadas em um trabalho futuro sobre holografia de plâncton, em especial o uso de alguma medida de confiança para determinar se o valor da medida de foco deve ser utilizado, ou se alguma outra operação deve ser realizada. Também poderia-se realizar o algoritmo inverso ao do artigo, começando pela focalização de todo o organismo com as medidas deste trabalho, e depois refinando esta focalização para regiões cada vez menores.

Outra forma de utilizar uma medida de confiança seria no algoritmo de autofoco. Caso a medida de foco tenha resultados que não sejam considerados confiáveis, o algoritmo poderia realizar uma focalização mais refinada em todo o intervalo de distâncias, e não apenas na região em que a medida de foco atinge seu valor máximo (ou mínimo). Isto aumentaria um pouco o tempo de processamento, mas poderia melhorar consideravelmente a qualidade de focalização. Uma medida de confiança também poderia ser usada ao combinar várias medidas de foco. Neste trabalho usamos a mediana das distâncias escolhidas por várias medidas, mas também poderia-se usar uma medida de confiança para descartar as medidas de foco que provavelmente não conseguiram focalizar o organismo.

Uma aplicação extremamente relevante do sistema apresentado neste trabalho é a classificação de plâncton. O sistema já permite obter imagens focalizadas e segmentadas dos organismos, e seria necessário realizar a extração de características e o treinamento de classificadores, tornando possível a classificação automática das imagens. Seria necessário determinar quais características são mais relevantes, e quais classificadores são mais precisos, o que demandaria um trabalho considerável, mas tornaria o sistema web apresentado uma excelente opção no estudo de plâncton, sem a necessidade de utilizar um sistema secundário para a classificação. Também seria recomendável analisar o efeito de diferentes segmentações na qualidade da classificação.

Futuramente também seria interessante realizar a observação in situ dos organismos, e o rastreamento destes nas imagens, levando em consideração o aspecto sequencial das imagens capturadas e tratando-as como um vídeo.

Apesar das vantagens apresentadas na arquitetura do sistema web desenvolvido neste trabalho, existem situações nas quais esta arquitetura não é a ideal. Caso se queira realizar o processamento das imagens a bordo de uma embarcação, uma aplicação desktop seria mais apropriada. Outro caso seria o de um laboratório sem conexão rápida à internet, e no qual não seja viável instalar e manter um servidor com o sistema. E um terceiro caso seria o processamento em um veículo subaquático autônomo, no qual seria necessário um sistema embarcado.

No caso do sistema embarcado, mesmo que seja possível realizar a implementação na liguagem de programação Python, apenas os trechos de código referentes ao processamento de imagens poderiam ser reaproveitados. Como uma parte considerável do sistema é a interface com o usuário, não seria vantajoso tentar modificá-lo para que funcione de modo embarcado. Se não forem necessárias muitas modificações no código de processamento, este poderia ser extraído como uma biblioteca que seria utilizada pelos dois sistemas.

Para utilizar o sistema como uma aplicação desktop, com uma instalação mais simples, porém local, seriam necessárias algumas alterações que demandariam certo esforço ${ }^{1}$. Dependendo do sistema operacional a ser utilizado, o sistema poderia ser empacotado em um aplicativo utilizando ferramentas como o py2app ${ }^{2}$, Pynsist ${ }^{3}$, py2exe ${ }^{4}$ ou PyInstaller ${ }^{5}$. O arcabouço Django continuaria

\footnotetext{
${ }^{1}$ https://moosystems.com/articles/14-distribute-django-app-as-native-desktop-app-01.html Acessado em 6 de julho de 2017.

${ }^{2}$ https://pythonhosted.org/py2app/ Acessado em 6 de julho de 2017.

${ }^{3}$ https://pynsist.readthedocs.io/ Acessado em 6 de julho de 2017.

${ }^{4}$ http://py2exe.org/ Acessado em 6 de julho de 2017.

${ }^{5}$ http://www.pyinstaller.org/ Acessado em 6 de julho de 2017.
} 
sendo utilizado, mas com o banco de dados SQLite ${ }^{6}$, que é mais adequado para uma aplicação desktop. O GlusterFS e o NGINX não precisariam ser usados, e o Gunicorn seria substituído pelo CherryPy ${ }^{7}$, que faria o papel de servidor web. Para mostrar as páginas HTML da interface, uma forma seria usar o pywebview ${ }^{8}$, que exibe o conteúdo das páginas em uma janela através de componentes nativos do sistema operacional. Também poderia-se usar o Chromium Embedded Framework ${ }^{9}$, que permite embarcar um navegador web na aplicação. Isto possui a desvantagem de aumentar consideravelmente o tamanho do aplicativo, porém facilitaria a manutenção da interface, já que os componentes nativos utilizados pelo pywebview poderiam renderizar as páginas de forma distinta em cada sistema operacional.

Em suma, a área de holografia digital abre diversas possibilidades no estudo de plâncton e, apesar de todos os avanços obtidos neste e em outros trabalhos, ainda existem diversas ideias a serem exploradas, tornando esta uma área fértil para futuras pesquisas.

\footnotetext{
${ }^{6}$ https://sqlite.org Acessado em 6 de julho de 2017.

${ }^{7}$ http://www.cherrypy.org/ Acessado em 6 de julho de 2017.

${ }^{8}$ https://github.com/r0x0r/pywebview Acessado em 6 de julho de 2017.

${ }^{9}$ https://bitbucket.org/chromiumembedded/cef Acessado em 6 de julho de 2017.
} 


\section{Apêndice A}

\section{Imagens utilizadas no experimento de extensões de borda}

As 36 imagens deste apêndice foram utilizadas no primeiro experimento comparando os erros das diferentes extensões de borda. São exibidos os hologramas originais e suas reconstruções, que foram utilizadas como referência, utilizando os mesmos parâmetros usados no experimento. Um retângulo branco nos hologramas mostra a região da imagem que foi estendida com cada método antes de ser reconstruída para a comparação. Um retângulo branco na reconstrução mostra a região da imagem utilizada como referência no cálculo do erro.
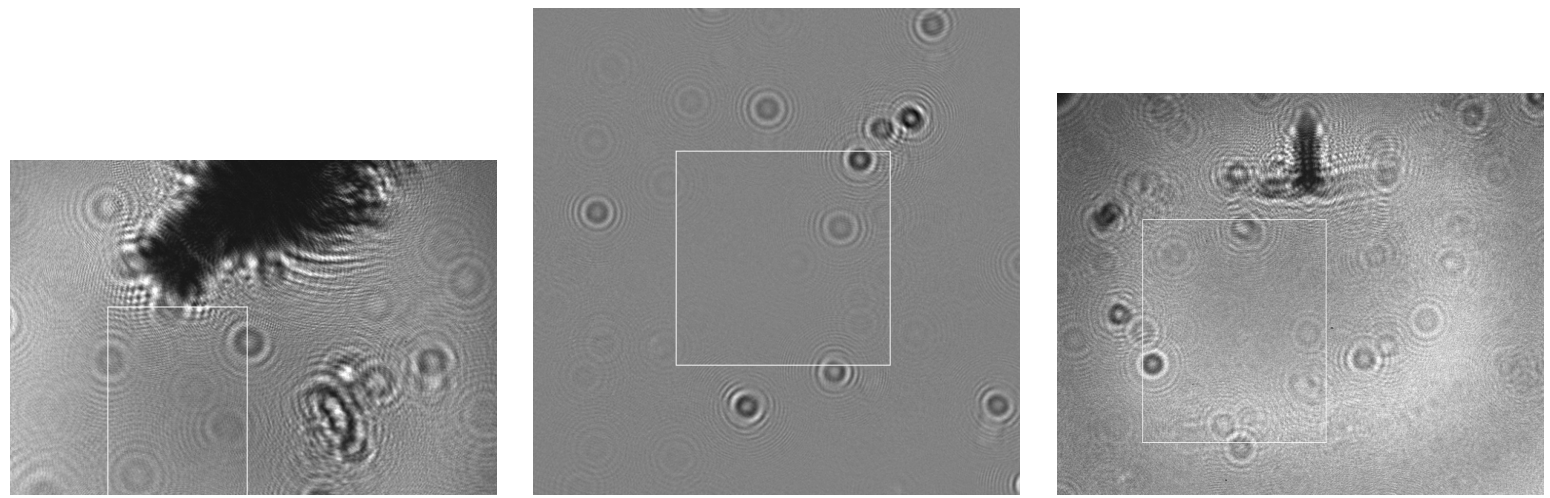

Figura A.1: Hologramas utilizados no experimento de extensão de borda. A região destacada foi estendida e reconstruída utilizando os vários métodos de extensão de borda, e o holograma inteiro foi reconstruído com a extensão com zeros para obter a região utilizada como referência no cálculo do RMSE. 

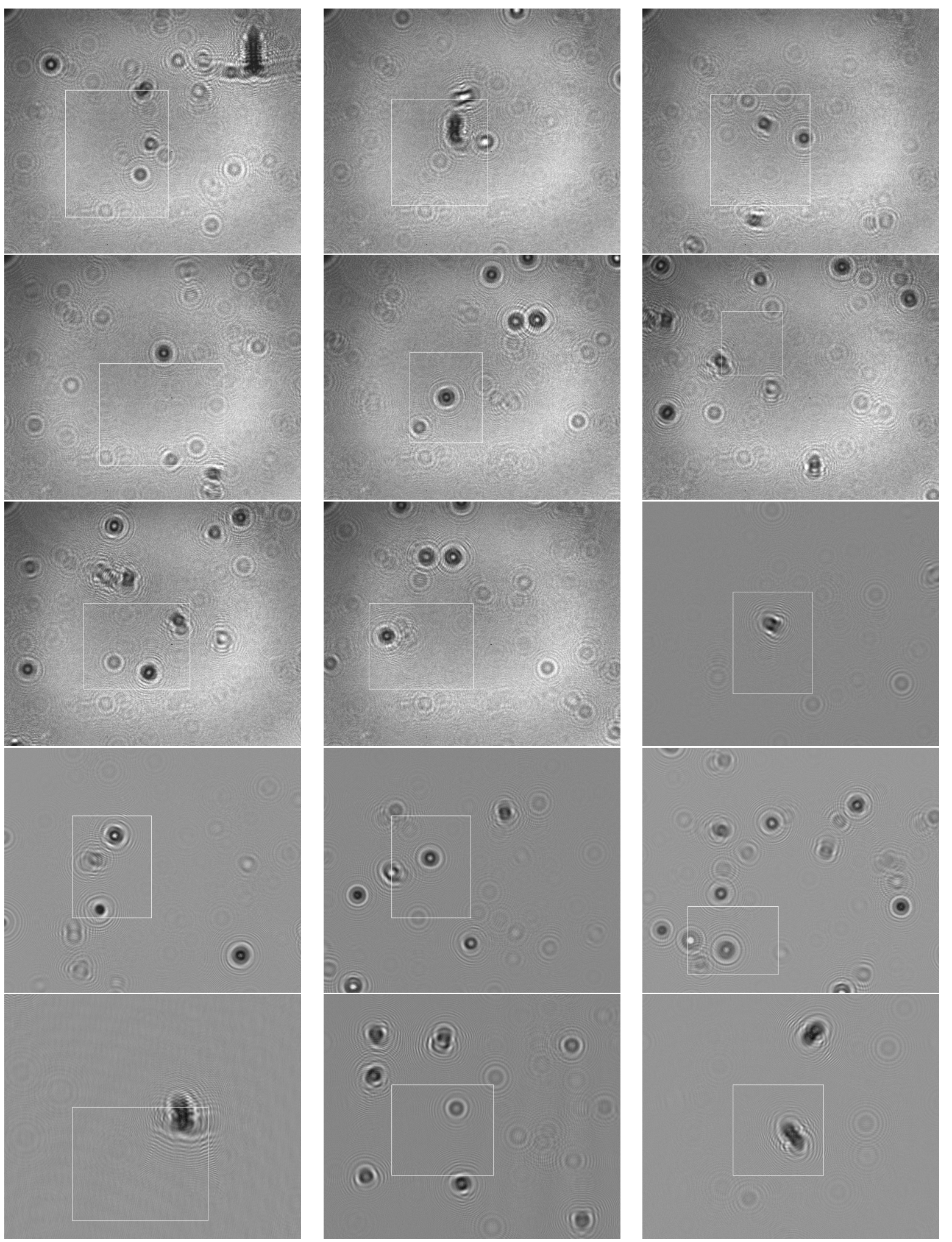

Figura A.2: Hologramas utilizados no experimento de extensão de borda. A região destacada foi estendida e reconstruída utilizando os vários métodos de extensão de borda, e o holograma inteiro foi reconstruído com a extensão com zeros para obter a região utilizada como referência no cálculo do RMSE. 

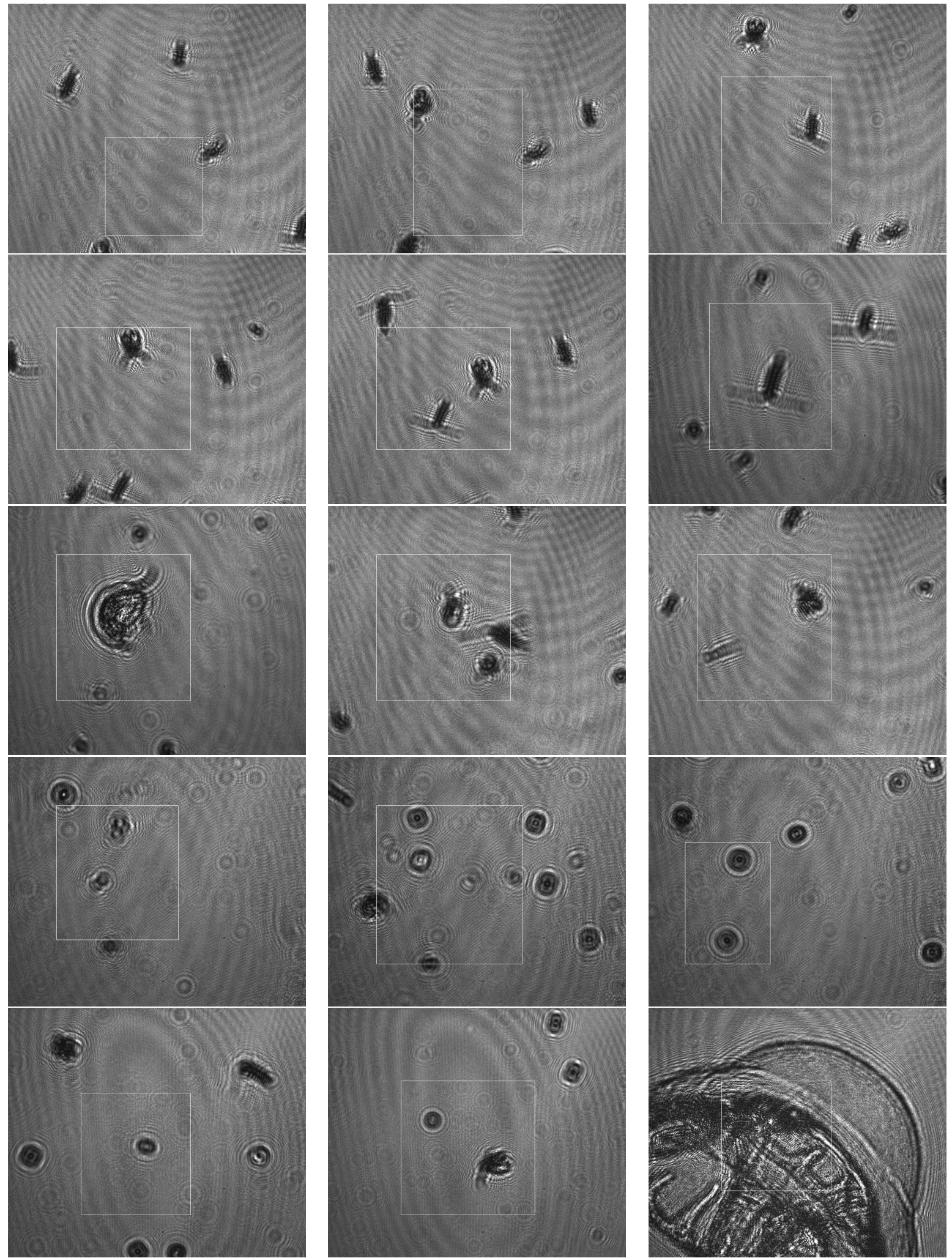

Figura A.3: Hologramas utilizados no experimento de extensão de borda. A região destacada foi estendida e reconstruída utilizando os vários métodos de extensão de borda, e o holograma inteiro foi reconstruído com a extensão com zeros para obter a região utilizada como referência no cálculo do RMSE. 

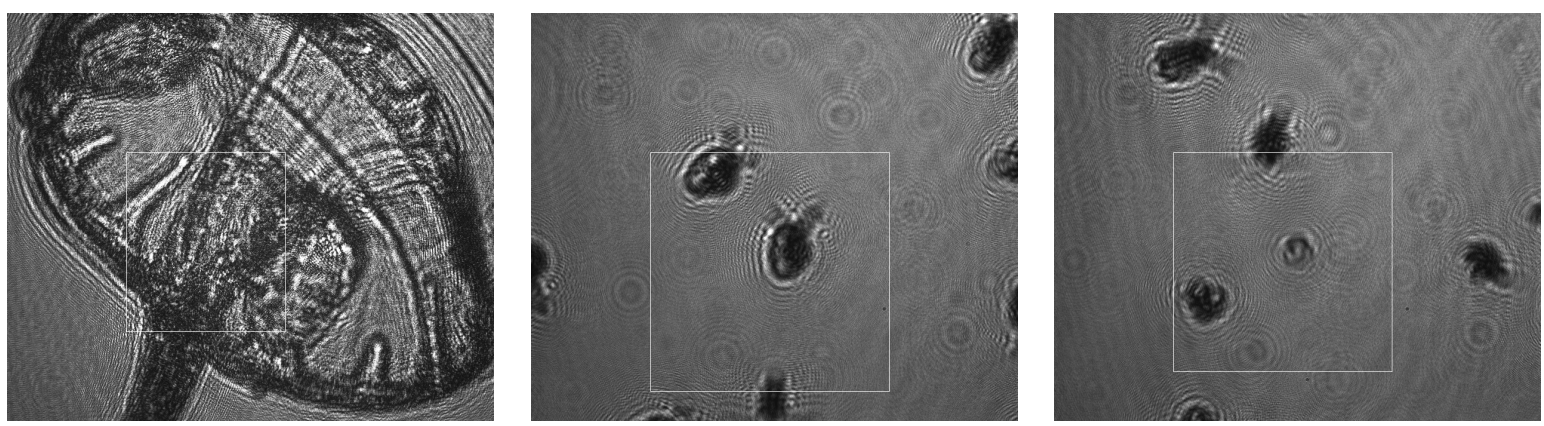

Figura A.4: Hologramas utilizados no experimento de extensão de borda. A região destacada foi estendida e reconstruída utilizando os vários métodos de extensão de borda, e o holograma inteiro foi reconstruído com a extensão com zeros para obter a região utilizada como referência no cálculo do RMSE.
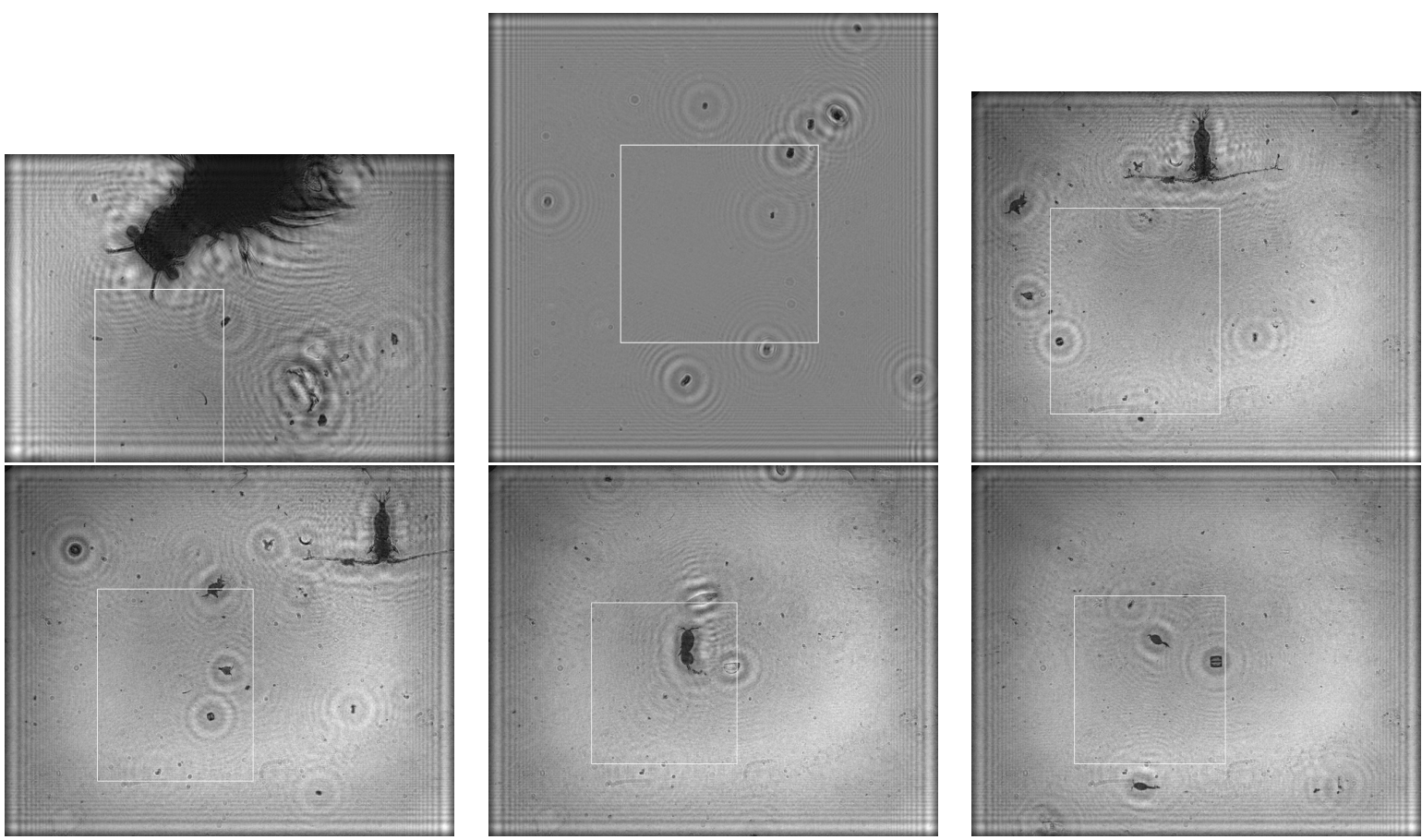

Figura A.5: Reconstruções dos hologramas utilizados no experimento de extensão de borda. O holograma inteiro foi reconstruído após ser estendido com zeros, e a região destacada foi utilizada como referência no cálculo do RMSE dos diversos métodos de extensão de borda. 

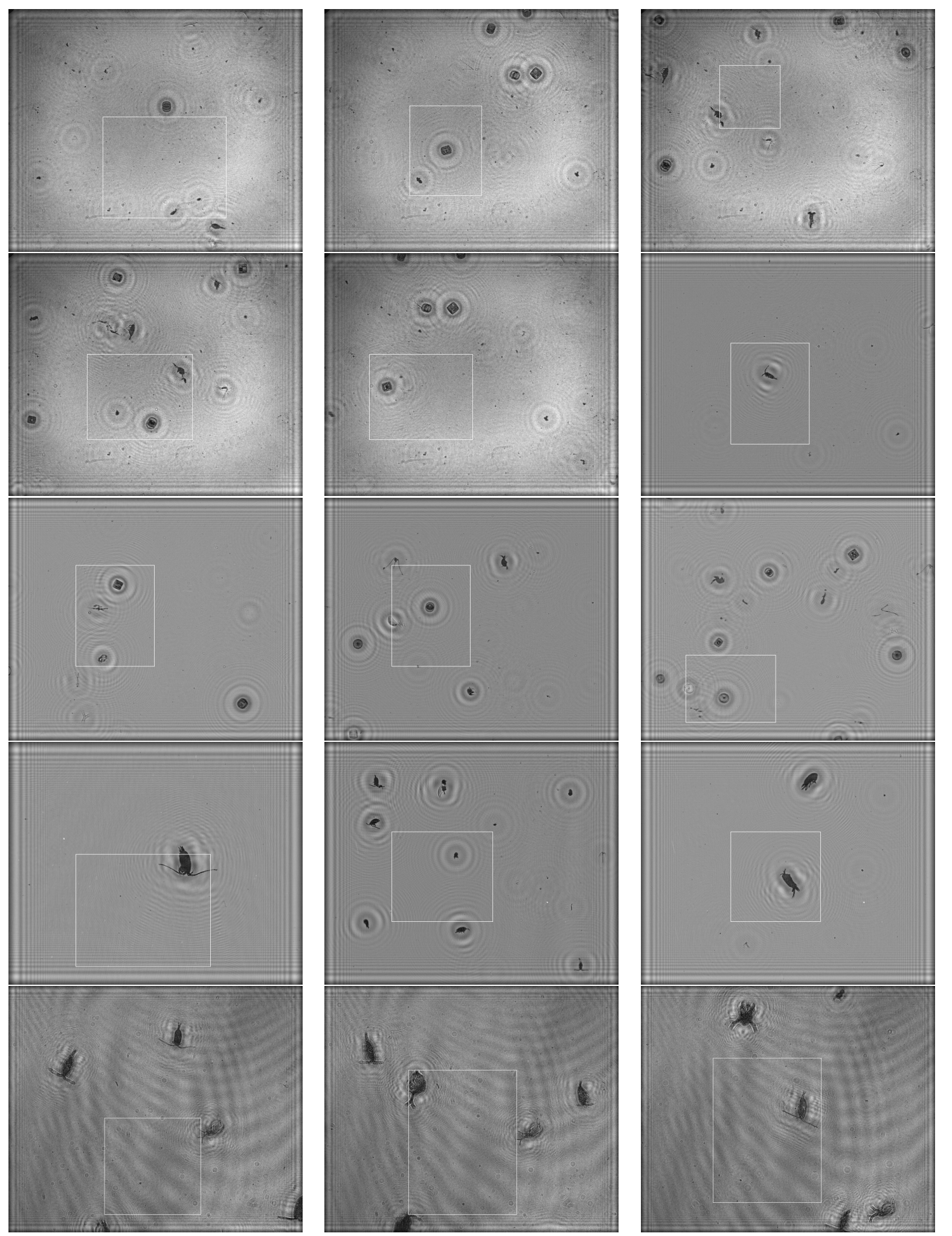

Figura A.6: Reconstruções dos hologramas utilizados no experimento de extensão de borda. O holograma inteiro foi reconstruído após ser estendido com zeros, e a região destacada foi utilizada como referência no cálculo do RMSE dos diversos métodos de extensão de borda. 

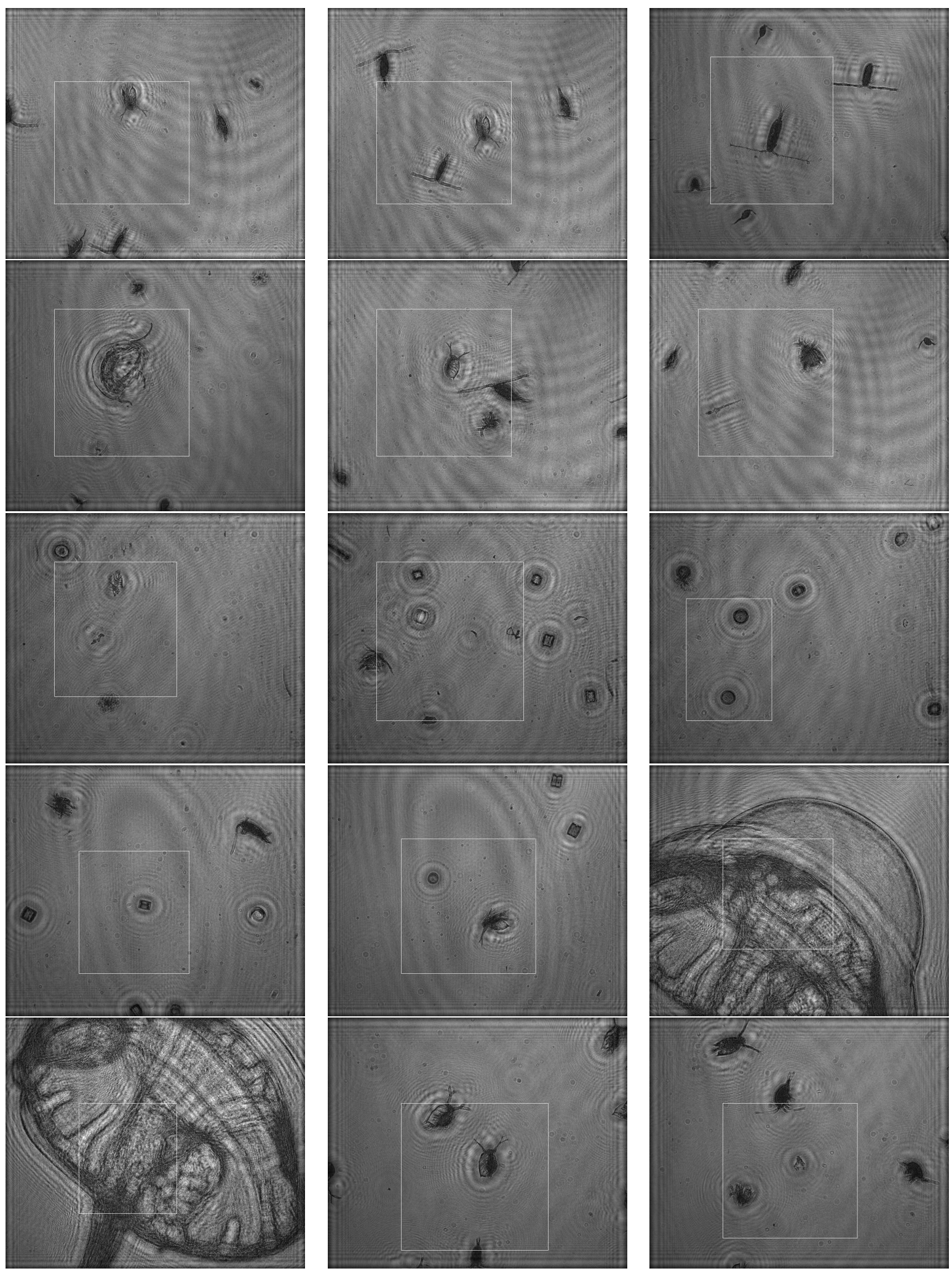

Figura A.7: Reconstruções dos hologramas utilizados no experimento de extensão de borda. O holograma inteiro foi reconstruído após ser estendido com zeros, e a região destacada foi utilizada como referência no cálculo do RMSE dos diversos métodos de extensão de borda. 


\section{Apêndice B}

\section{Imagens utilizadas no experimento de focalização}

As imagens deste apêndice foram utilizadas nos experimentos do Capítulo 5, que comparam as medidas de foco. São exibidas algumas das imagens utilizadas como referência, ou seja, reconstruídas à distância que foi considerada nos experimentos como sendo a correta. 

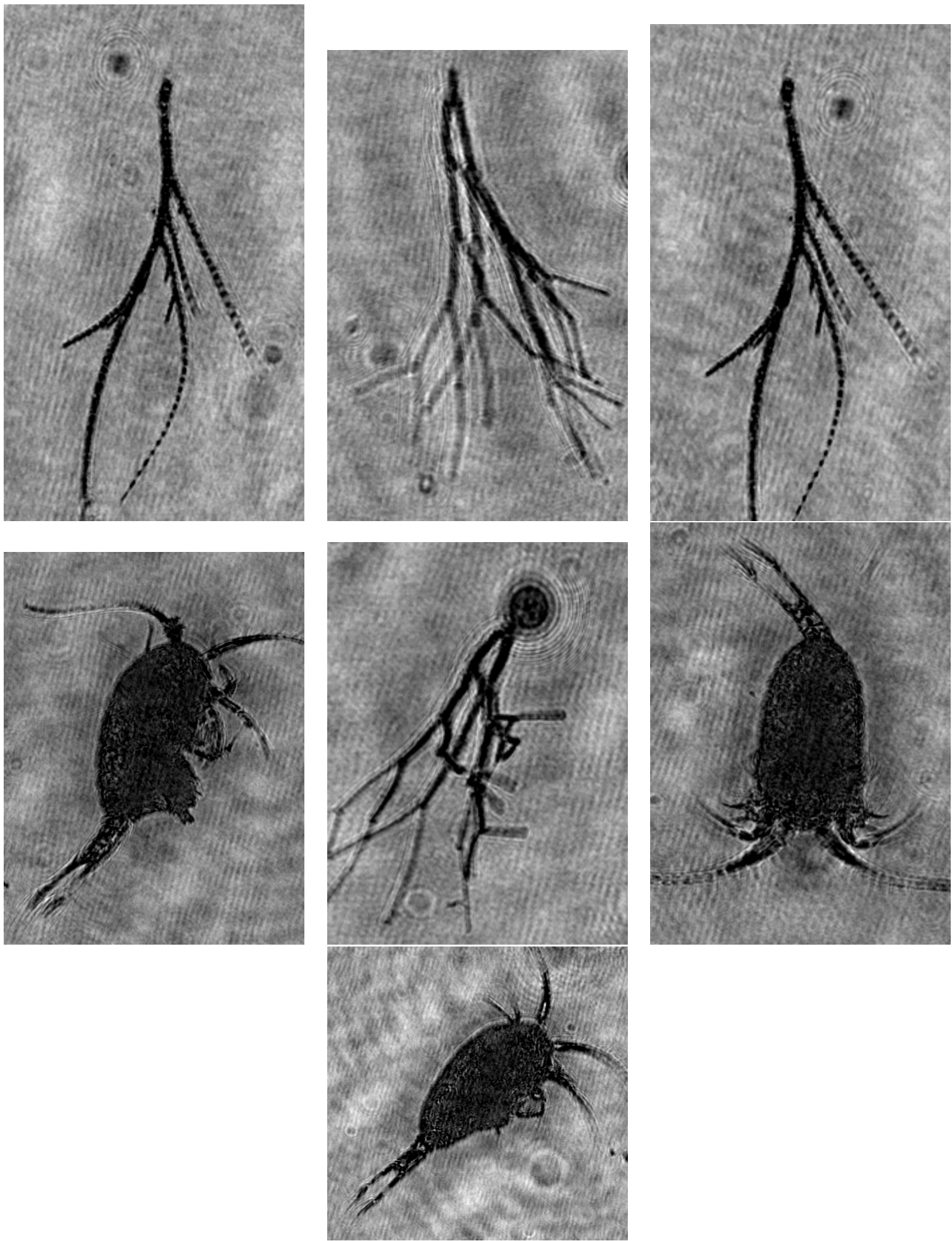

Figura B.1: Reconstruções do conjunto A utilizadas no experimento de focalização. 

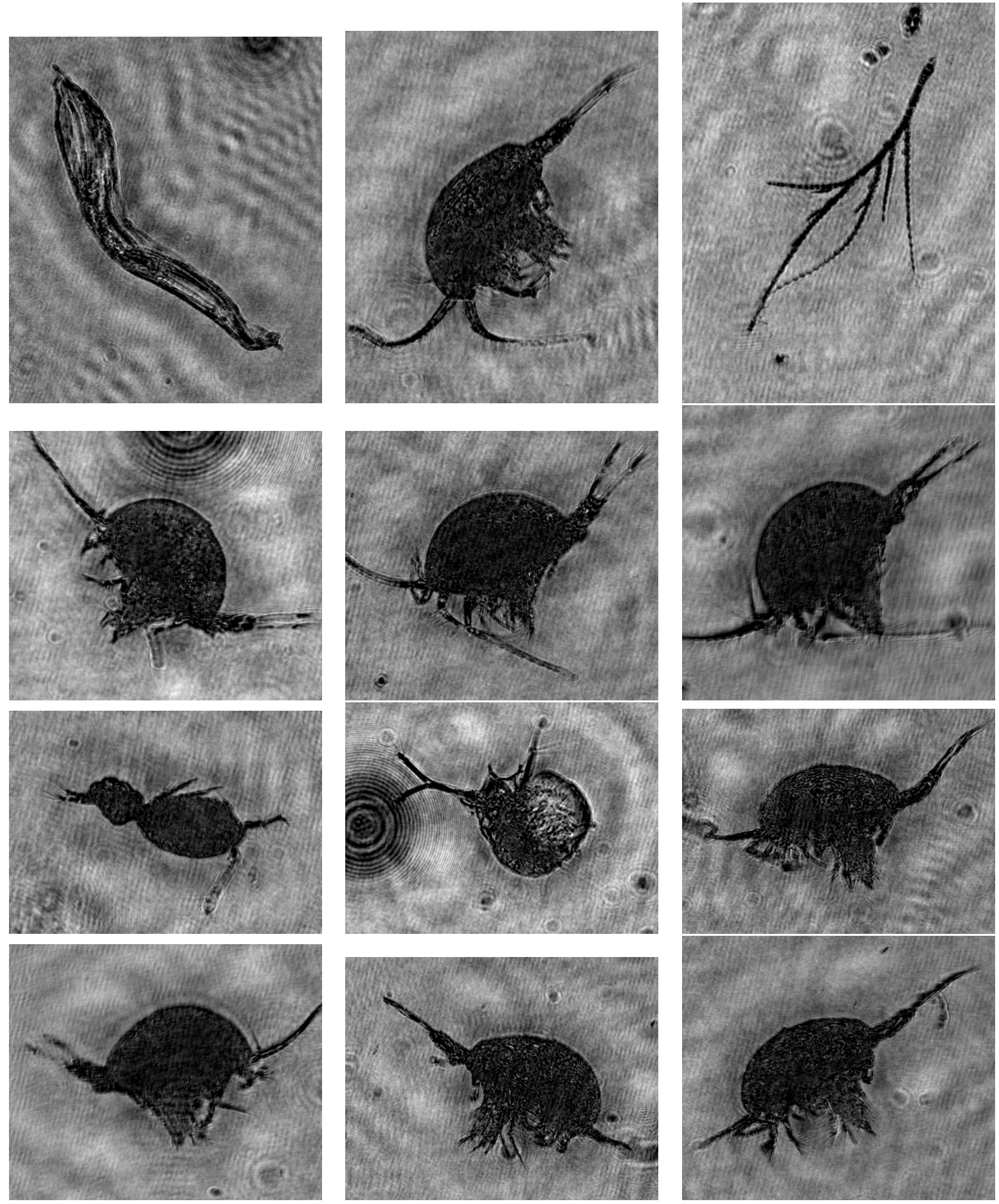

Figura B.2: Reconstruções do conjunto A utilizadas no experimento de focalização. 

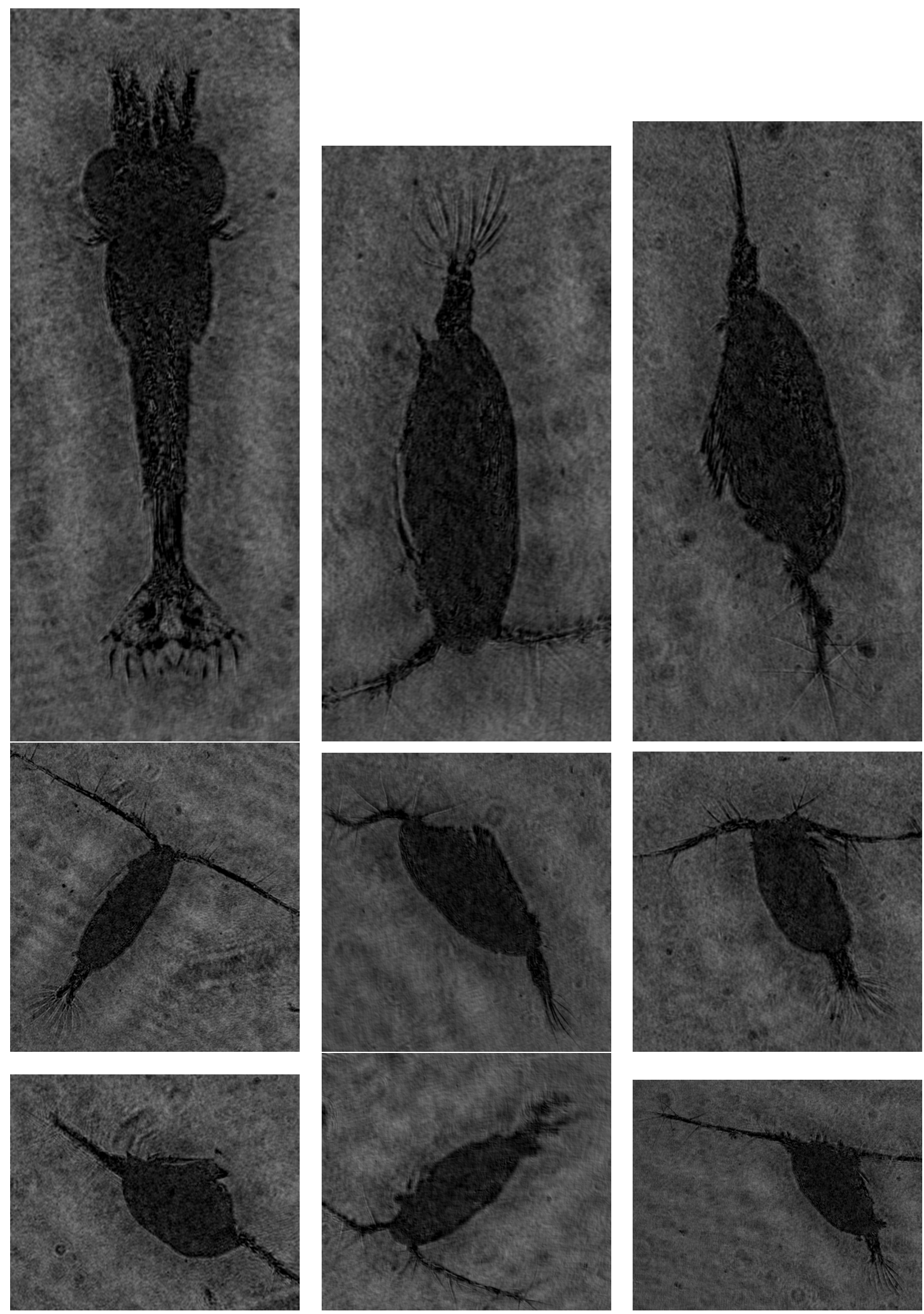

Figura B.3: Reconstruções do conjunto B utilizadas no experimento de focalização. 

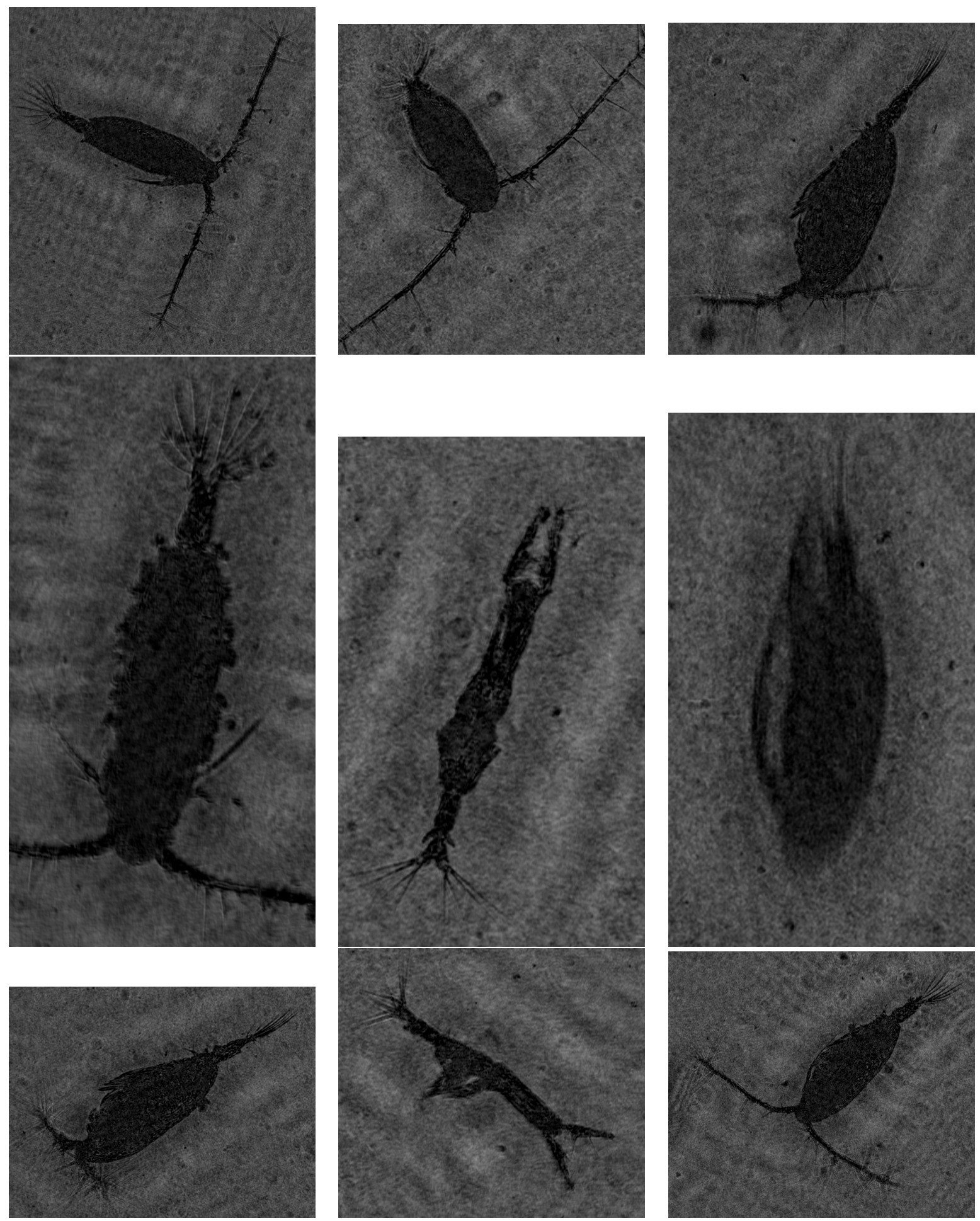

Figura B.4: Reconstruções do conjunto B utilizadas no experimento de focalização. 

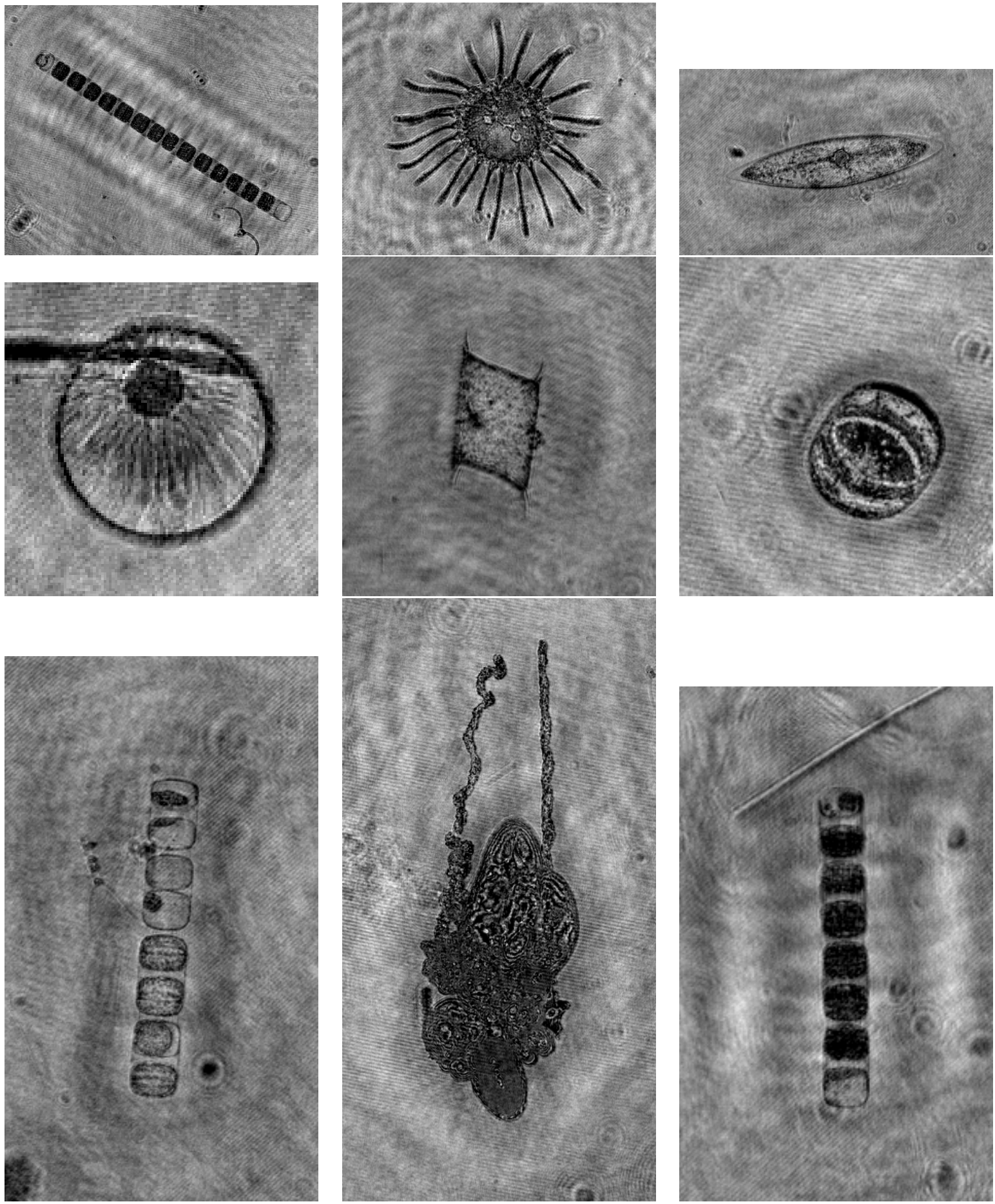

Figura B.5: Reconstruções do conjunto $C$ utilizadas no experimento de focalização. 

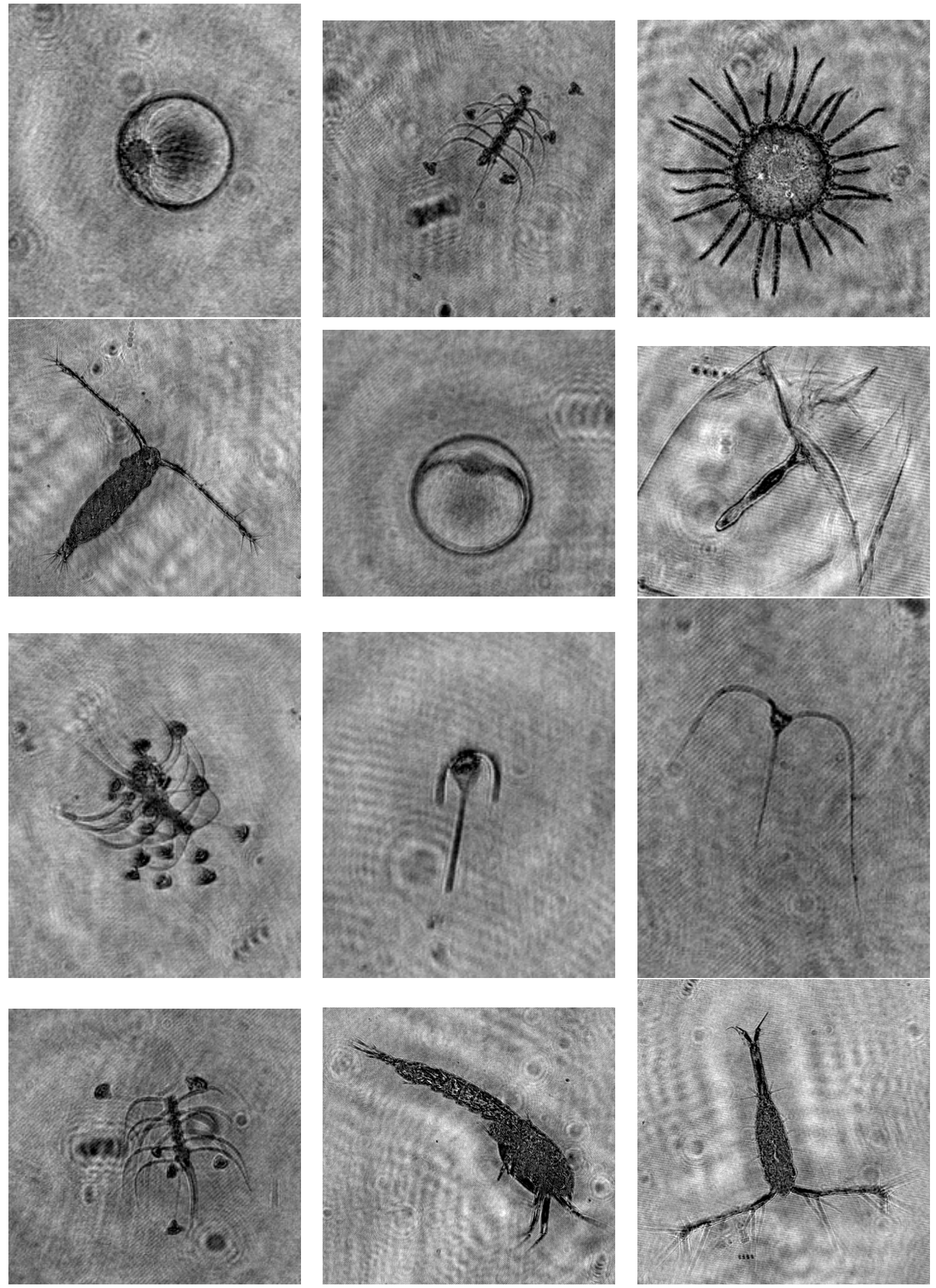

Figura B.6: Reconstruções do conjunto C utilizadas no experimento de focalização. 

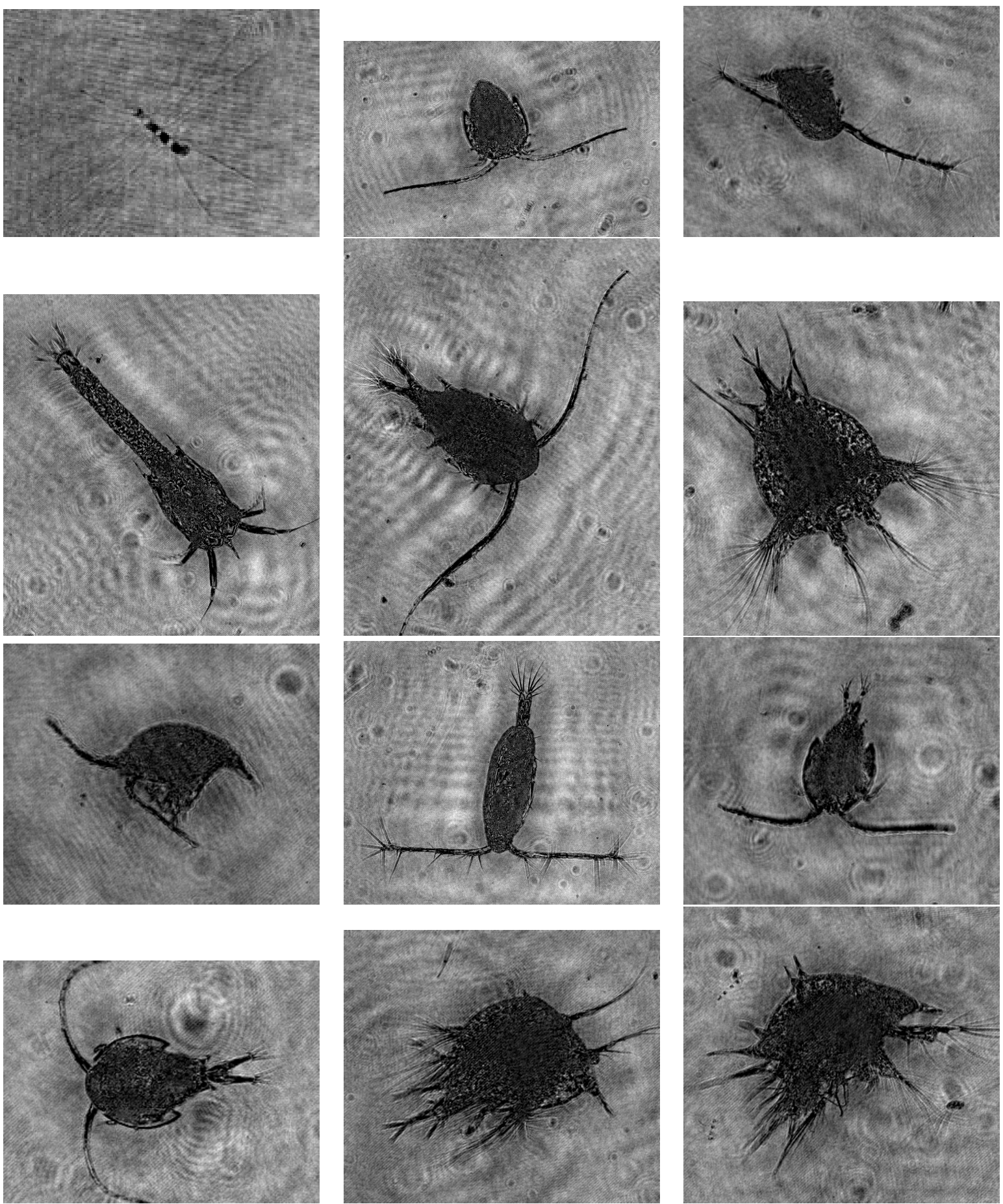

Figura B.7: Reconstruções do conjunto $C$ utilizadas no experimento de focalização. 

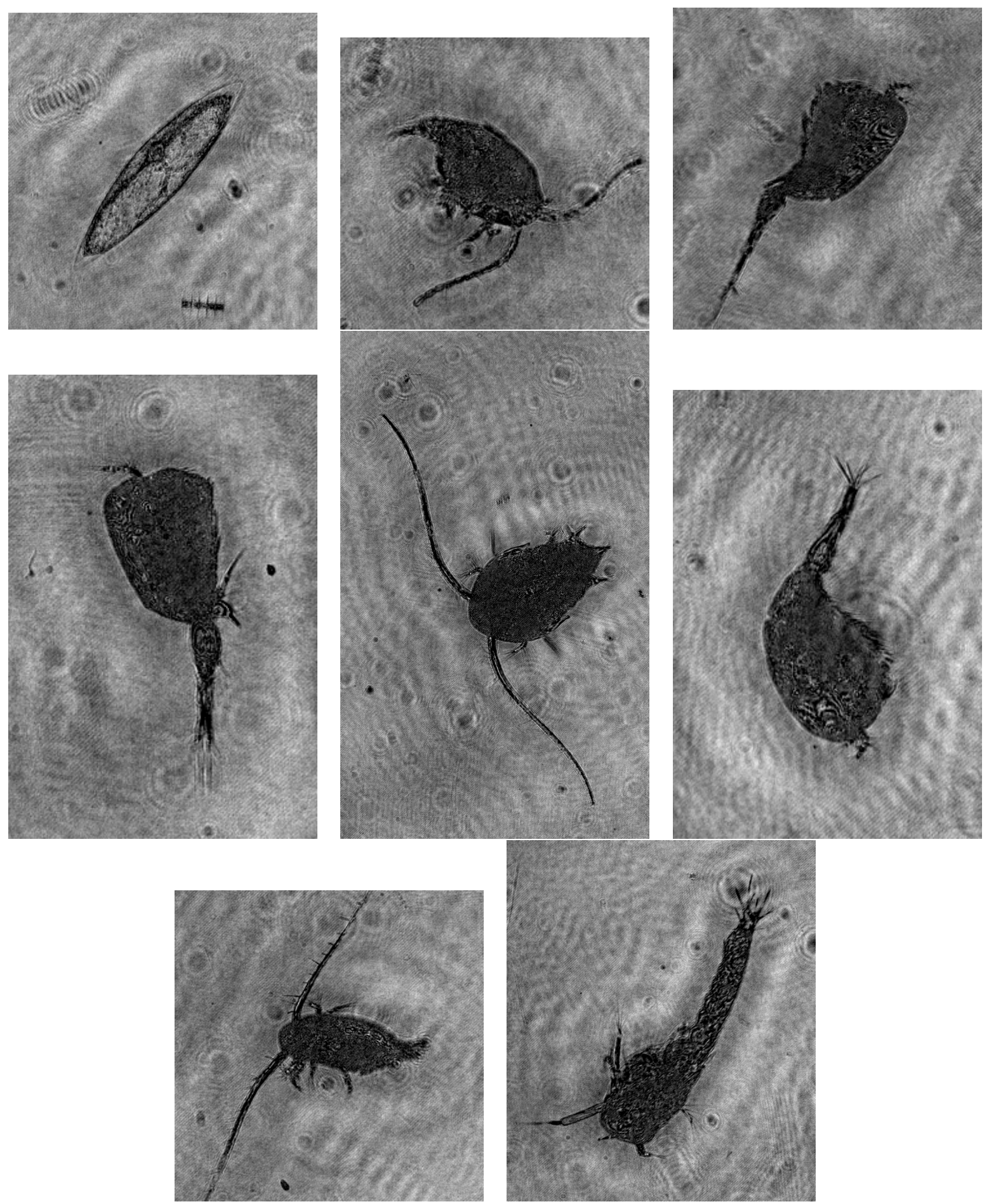

Figura B.8: Reconstruções do conjunto $C$ utilizadas no experimento de focalização. 

APÊNDICE B 


\section{Referências Bibliográficas}

[Abb73] E. Abbe. Beiträge zur theorie des mikroskops und der mikroskopischen wahrnehmung. Archiv für mikroskopische Anatomie, 9(1):413-418, 1873. 22

$\left[\mathrm{BCP}^{+} 09\right]$ Isabelle Bergoënd, Tristan Colomb, Nicolas Pavillon, Yves Emery e Christian Depeursinge. Depth-of-field extension and 3d reconstruction in digital holographic microscopy. Em SPIE Europe Optical Metrology, páginas 73901C-73901C. International Society for Optics and Photonics, 2009. 31, 57, 58, 61, 62, 86

$\left[\mathrm{BIA}^{+} 05\right]$ Mario A Bueno-Ibarra, Leonardo Acho et al. Fast autofocus algorithm for automated microscopes. Optical Engineering, 44(6):063601-063601, 2005. 61, 62, 63

[BW99] Max Born e Emil Wolf. Principles of optics: electromagnetic theory of propagation, interference and diffraction of light. CUP Archive, 1999. 6

[CMD00] Etienne Cuche, Pierre Marquet e Christian Depeursinge. Aperture apodization using cubic spline interpolation: application in digital holographic microscopy. $O p$ tics communications, 182(1):59-69, 2000. 33, 39

[CNAJ01] Nathaniel Ng Kuang Chern, Po Aun Neow e Marcelo H Ang Jr. Practical issues in pixel-based autofocusing for machine vision. Em Robotics and Automation, 2001. Proceedings 2001 ICRA. IEEE International Conference on, volume 3, páginas 2791-2796. IEEE, 2001. 58

$\left[\mathrm{CVM}^{+} 11\right]$ Giuseppe A. Cirino, Patrick Verdonck, Ronaldo D. Mansano, José C. Pizolato Jr., Daniel B. Mazulquim e Luiz G. Neto. Digital holography: Computer-generated holograms and diffractive optics in scalar diffraction domain. Em Dr. Freddy Monroy, editor, Holography - Different Fields of Application. InTech, 2011. 23

[CWR ${ }^{+}$03] Phil F Culverhouse, Robert Williams, Beatriz Reguera, Vincent Herry e Sonsoles González-Gil. Do experts make mistakes? a comparison of human and machine identification of dinoflagellates. Marine Ecology Progress Series, 247(17-25):5, 2003. 1

[DC06] José Antonio Domínguez-Caballero. Digital holographic imaging of aquatic species. Dissertação de Mestrado, Massachusetts Institute of Technology, 2006. 14, 27, 57

[DCG11] Lisa Dixon, Fook Chiong Cheong e David G Grier. Holographic deconvolution microscopy for high-resolution particle tracking. Optics express, 19(17):16410-16417, 2011. 31

[DFFD08] Loïc Denis, Corinne Fournier, Thierry Fournel e Christophe Ducottet. Numerical suppression of the twin image in in-line holography of a volume of micro-objects. Measurement Science and Technology, 19(7):074004, 2008. 31

[DJ07] Cuong Manh Do e Bahram Javidi. Multifocus holographic 3-d image fusion using independent component analysis. Display Technology, Journal of, 3(3):326-332, 2007. 86 
[DMYL02] Frank Dubois, Olivier Monnom, Catherine Yourassowsky e J-C Legros. Border processing in digital holography by extension of the digital hologram and reduction of the higher spatial frequencies. Applied optics, 41(14):2621-2626, 2002. 33, 35, 40,46

[DO08] Victor V Dyomin e Alexey S Olshukov. Digital holographic video of plankton. Em Optical Engineering + Applications, páginas 70732B-70732B. International Society for Optics and Photonics, 2008. 33

[DSCY06] Frank Dubois, Cédric Schockaert, Natcaha Callens e Catherine Yourassowsky. Focus plane detection criteria in digital holography microscopy by amplitude analysis. Optics Express, 14(13):5895-5908, 2006. 57

[FGA ${ }^{+}$05] Pietro Ferraro, Simonetta Grilli, Domenico Alfieri, Sergio De Nicola, Andrea Finizio, Giovanni Pierattini, Bahram Javidi, Giuseppe Coppola e Valerio Striano. Extended focused image in microscopy by digital holography. Optics express, 13(18):6738-6749, 2005. 86

[FJ98] Matteo Frigo e Steven G Johnson. Fftw: An adaptive software architecture for the fft. Em Acoustics, Speech and Signal Processing, 1998. Proceedings of the 1998 IEEE International Conference on, volume 3, páginas 1381-1384. IEEE, 1998. 46

[GK89] John Gillespie e RA King. The use of self-entropy as a focus measure in digital holography. Pattern recognition letters, 9(1):19-25, 1989. 57

[Goo96] J.W. Goodman. Introduction to Fourier optics. McGraw-Hill series in electrical and computer engineering. McGraw-Hill, 1996. 6, 8, 18, 27

$\left[\mathrm{GOP}^{+} 10\right]$ Gaby Gorsky, Mark D Ohman, Marc Picheral, Stéphane Gasparini, Lars Stemmann, Jean-Baptiste Romagnan, Alison Cawood, Stéphane Pesant, Carmen García-Comas e Franck Prejger. Digital zooplankton image analysis using the zooscan integrated system. Journal of Plankton Research, 32(3):285-303, 2010. 1

[GPWG04] Philippe Grosjean, Marc Picheral, Caroline Warembourg e Gabriel Gorsky. Enumeration, measurement, and identification of net zooplankton samples using the zooscan digital imaging system. ICES Journal of Marine Science: Journal du Conseil, 61(4):518-525, 2004. 1

[GYL85] Frans CA Groen, Ian T Young e Guido Ligthart. A comparison of different focus functions for use in autofocus algorithms. Cytometry, 6(2):81-91, 1985. 57, 58

[HJ07] Wei Huang e Zhongliang Jing. Evaluation of focus measures in multi-focus image fusion. Pattern Recognition Letters, 28(4):493-500, 2007. 57, 62

[HKPM09] Bryan M Hennelly, Damien P Kelly, Nitesh Pandey e David S Monaghan. Review of twin reduction and twin removal techniques in holography. 2009. 30, 86

[HS05] Bryan M Hennelly e John T Sheridan. Fast numerical algorithm for the linear canonical transform. JOSA A, 22(5):928-937, 2005. 18

[Jar76] Ray A Jarvis. Focus optimization criteria for computer image-processing. Microscope, 24(2):163-180, 1976. 58

$\left[\mathrm{JOP}^{+}\right]$Eric Jones, Travis Oliphant, Pearu Peterson et al. SciPy: Open source scientific tools for Python, 2001-. [Online; accessed 2014-08-16]. 46

[Kel14] Damien P Kelly. Numerical calculation of the fresnel transform. JOSA A, 31(4):755-764, 2014. 22, 24 
[KFK12] Tomasz Kozacki, Konstantinos Falaggis e Malgorzata Kujawinska. Computation of diffracted fields for the case of high numerical aperture using the angular spectrum method. Applied optics, 51(29):7080-7088, 2012. 24

[KHHS11] DP Kelly, JJ Healy, BM Hennelly e JT Sheridan. Quantifying the 2.5 d imaging performance of digital holographic systems. Journal of the European Optical Society-Rapid publications vol 6 11034, 6:1034, 2011. 22

[KHJ01] Volker Kebbel, Hans-Jürgen Hartmann e Werner PO Jüptner. Application of digital holographic microscopy for inspection of micro-optical components. Em Lasers in Metrology and Art Conservation, páginas 189-198. International Society for Optics and Photonics, 2001. 34

[KJYFF15] Jonathan Krause, Hailin Jin, Jianchao Yang e Li Fei-Fei. Fine-grained recognition without part annotations. Em Proceedings of the IEEE Conference on Computer Vision and Pattern Recognition, páginas 5546-5555, 2015. 2

[KNR ${ }^{+}$09] Damien P Kelly, Thomas J Naughton, William T Rhodes, Bryan M Hennelly e Nitesh Pandey. Resolution limits in practical digital holographic systems. Optical Engineering, 48(9):095801-095801, 2009. 22

[Kre02] Thomas M Kreis. Frequency analysis of digital holography with reconstruction by convolution. Optical Engineering, 41(8):1829-1839, 2002. 26

[KSDFF13] Jonathan Krause, Michael Stark, Jia Deng e Li Fei-Fei. 3d object representations for fine-grained categorization. Em Proceedings of the IEEE International Conference on Computer Vision Workshops, páginas 554-561, 2013. 2

[LGF10] Tatiana Latychevskaia, Fabian Gehri e Hans-Werner Fink. Depth-resolved holographic reconstructions by three-dimensional deconvolution. Optics express, 18(21):22527-22544, 2010. 31, 86

[LJ05] Feng Li e Hong Jin. A fast auto focusing method for digital still camera. Em Machine Learning and Cybernetics, 2005. Proceedings of 2005 International Conference on, volume 8, páginas 5001-5005. IEEE, 2005. 57, 58, 59

[LJ08] Renting Liu e Jiaya Jia. Reducing boundary artifacts in image deconvolution. Em Image Processing, 2008. ICIP 2008. 15th IEEE International Conference on, páginas 505-508. IEEE, 2008. 41

[LM15] Arthur Leclaire e Lionel Moisan. No-reference image quality assessment and blind deblurring with sharpness metrics exploiting fourier phase information. Journal of Mathematical Imaging and Vision, 52(1):145-172, 2015. 58, 59

[Loo11] Nicholas Charles Loomis. Computational imaging and automated identification for aqueous environments. Tese de Doutorado, Massachusetts Institute of Technology, 2011. $2,13,28,30,55,57,60$

[LSHW09] Jingbo Liu, Xiufa Song, Rui Han e Huaying Wang. Autofocus method in digital holographic microscopy. Em 4th International Symposium on Advanced Optical Manufacturing and testing technologies: Optical Test and Measurement Technology and Equipment, páginas 72833Q-72833Q. International Society for Optics and Photonics, 2009. 57, 60

[LY08] Shutao Li e Bin Yang. Multifocus image fusion using region segmentation and spatial frequency. Image and Vision Computing, 26(7):971-979, 2008. 62 
[MAK99] Edwin Malkiel, Omar Alquaddoomi e Joseph Katz. Measurements of plankton distribution in the ocean using submersible holography. Measurement Science and Technology, 10(12):1142, 1999. 1

$\left[\mathrm{MDP}^{+} 11\right]$ P Memmolo, C Distante, M Paturzo, A Finizio, P Ferraro e B Javidi. Automatic focusing in digital holography and its application to stretched holograms. Optics letters, 36(10):1945-1947, 2011. 58

[MDYL05] Olivier Monnom, Frank Dubois, Catherine Yourassowsky e Jean Claude Legros. Improvement in visibility of an in-focus reconstructed image in digital holography by reduction of the influence of out-of-focus objects. Applied optics, 44(18):38273832, 2005. 31

[MH03] Samir Mezouari e Andy Robert Harvey. Validity of fresnel and fraunhofer approximations in scalar diffraction. Journal of Optics A: Pure and Applied Optics, 5(4):S86, 2003. 17

[MHN08] Conor P McElhinney, Bryan M Hennelly e Thomas J Naughton. Extended focused imaging for digital holograms of macroscopic three-dimensional objects. Applied Optics, 47(19):D71-D79, 2008. 57, 86

[ML02] Jerome H Milgram e Weichang Li. Computational reconstruction of images from holograms. Applied optics, 41(5):853-864, 2002. 28

[MS09] Kyoji Matsushima e Tomoyoshi Shimobaba. Band-limited angular spectrum method for numerical simulation of free-space propagation in far and near fields. Optics express, 17(22):19662-19673, 2009. 26

[NN94] Shree K Nayar e Yasuo Nakagawa. Shape from focus. IEEE Transactions on Pattern analysis and machine intelligence, 16(8):824-831, 1994. 60

$\left[\right.$ NNŠ $\left.{ }^{+} 03\right]$ Markus Niederöst, Jana Niederöst, Jiří Ščučka, Markus Niederöst, Markus Niederöst, Jana Niederöst e Jana Niederöst. Automatic $3 D$ reconstruction and visualization of microscopic objects from a monoscopic multifocus image sequence. ETH, Swiss Federal Institute of Technology, Institute of Geodesy and Photogrammetry, 2003. 86

[OSB $\left.{ }^{+89}\right]$ Alan V Oppenheim, Ronald W Schafer, John R Buck et al. Discrete-time signal processing, volume 2. Prentice-hall Englewood Cliffs, 1989. 5

[PPCCMFV00] José Luis Pech-Pacheco, Gabriel Cristóbal, Jesús Chamorro-Martinez e Joaquín Fernández-Valdivia. Diatom autofocusing in brightfield microscopy: a comparative study. Em Pattern Recognition, 2000. Proceedings. 15th International Conference on, volume 3, páginas 314-317. IEEE, 2000. 57, 62, 63

[PTVF96] William H Press, Saul A Teukolsky, William T Vetterling e Brian P Flannery. Numerical recipes in C, volume 2. Cambridge university press Cambridge, 1996. 42

[PV08] Paolo Prandoni e Martin Vetterli. Signal processing for communications. CRC Press, 2008. 5

[RSR69] Lawrence R Rabiner, Ronald W Schafer e Charles M Rader. The chirp z-transform algorithm and its application. Bell System Technical Journal, 48(5):1249-1292, 1969. 16 
[SBB $\left.{ }^{+} 08\right]$ H Sun, PW Benzie, N Burns, DC Hendry, MA Player e J Watson. Underwater digital holography for studies of marine plankton. Philosophical Transactions of the Royal Society A: Mathematical, Physical and Engineering Sciences, 366(1871):1789-1806, 2008. 23

[SHPW07] Hongyue Sun, David C Hendry, Michael A Player e John Watson. In situ underwater electronic holographic camera for studies of plankton. Oceanic Engineering, IEEE Journal of, 32(2):373-382, 2007. 1

[SJ02] Ulf Schnars e Werner PO Jüptner. Digital recording and numerical reconstruction of holograms. Measurement science and technology, 13(9):R85, 2002. 16

[Sou81] WH Southwell. Validity of the fresnel approximation in the near field. JOSA, 71(1):7-14, 1981. 17

[SR89] AM Steane e HN Rutt. Diffraction calculations in the near field and the validity of the fresnel approximation. JOSA A, 6(12):1809-1814, 1989. 17

[SSY98] Christian K Sieracki, Michael E Sieracki e Charles S Yentsch. An imaging-in-flow system for automated analysis of marine microplankton. Marine Ecology Progress Series, 168:285-296, 1998. 1

[Syp95] Maciej Sypek. Light propagation in the fresnel region. new numerical approach. Optics communications, 116(1):43-48, 1995. 26

$\left[\mathrm{TBG}^{+} 05\right]$ Andrea Thelen, Jens Bongartz, Dominik Giel, Susanne Frey e Peter Hering. Iterative focus detection in hologram tomography. JOSA A, 22(6):1176-1180, 2005. 57

[TFHH09] Andrea Thelen, Susanne Frey, Sven Hirsch e Peter Hering. Improvements in shape-from-focus for holographic reconstructions with regard to focus operators, neighborhood-size, and height value interpolation. IEEE transactions on image processing: a publication of the IEEE Signal Processing Society, 18(1):151-157, 2009. $56,61,86,87$

$\left[\mathrm{THM}^{+}{ }^{13}\right]$ Siddharth Talapatra, Jiarong Hong, Malcolm McFarland, Aditya R Nayak, Cao Zhang, Joseph Katz, James Sullivan, Michael Twardowski, Jan Rines e Percy Donaghay. Characterization of biophysical interactions in the water column using in situ digital holography. Mar. Ecol. Prog. Ser, 473:29-51, 2013. 1

[TMY78] Hideyuki Tamura, Shunji Mori e Takashi Yamawaki. Texture features corresponding to visual perception. IEEE Transactions on System, Man and Cybernatic, 6, 1978. 58

$\left[\mathrm{TSV}^{+}\right.$98] Xiaoou Tang, W Kenneth Stewart, Luc Vincent, HE Huang, Marty Marra, Scott M Gallager e Cabell S Davis. Automatic plankton image recognition. Em Artificial Intelligence for Biology and Agriculture, páginas 177-199. Springer, 1998. 1

[VDWCV11] Stefan Van Der Walt, S Chris Colbert e Gael Varoquaux. The numpy array: a structure for efficient numerical computation. Computing in Science $\mathbb{E}$ Engineering, 13(2):22-30, 2011. 46

[VR09] David G Voelz e Michael C Roggemann. Digital simulation of scalar optical diffraction: revisiting chirp function sampling criteria and consequences. Applied optics, 48(32):6132-6142, 2009. 26, 27 
[YXH $\left.{ }^{+} 12\right]$ Xiao Yu, Tang Xiahui, Peng Hao, Wang Wei et al. Wide-window angular spectrum method for diffraction propagation in far and near field. Optics letters, 37(23):49434945, 2012. 26

[YXY ${ }^{+}$12] Xiao Yu, Tang Xiahui, Qin Yingxiong, Peng Hao e Wang Wei. Band-limited angular spectrum numerical propagation method with selective scaling of observation window size and sample number. JOSA A, 29(11):2415-2420, 2012. 26

$\left[\mathrm{ZFL}^{+}{ }^{+} 13\right]$ Yancao Zhang, Qi Fan, Xinchao Li, Jianjun Shi e Baiyu Yang. Optimization of the window function for digital hologram apodization in reconstructing the holographic image. Journal of Optics, 15(10):105406, 2013. 33

$\left[\mathrm{ZZF}^{+}\right.$09] Yancao Zhang, Jianlin Zhao, Qi Fan, Wei Zhang e Sheng Yang. Improving the reconstruction quality with extension and apodization of the digital hologram. Applied optics, 48(16):3070-3074, 2009. 35, 40 